\title{
Agricultural Bio-Fueled Generation of Electricity and Development of Durable and Efficient NOx Reduction
}

Project Title:

Agricultural Bio-Fueled Generation of Electricity and Development of Durable and Efficient NOx Reduction

\section{Covering Period:}

February 1, 2004 through May 1, 2007

\section{Date of Report:}

April 30, 2007

\section{Recipient:}

McMinnville Electric System

200 Morford Street

McMinnville, TN 37111-0608

\section{Award Number:}

DE-FG36-04G014250

\section{Subcontractors:}

EmeraChem

Steve DeCicco - Vice President of Operations - (865) 246-3000

Lisa Mitchell - Project Engineer - (865) 246-3000

Dr. Albin Chernichowski - GlidArc Technologies - +33-680-232-643

Stowers/Caterpillar

Tom Stanzione - Manager, Distributed Generation - (865) 675-2869

Dave Martin - Power Generation Project Manager - (865) 546-1414

Matt Kirkpatrick - Commercial Engine Sales - (865) 546-1414

Chris Kiczaja - Sales Manager Electric Power Generation - (615) 341-3215

Tennessee Valley Authority

Ralph Boroughs - Project Manager - (423) 751-4644

Chevales Ward - Environmental Engineer - (423) 751-7316

Duane Brigman - Environmental Scientist - (423) 876-4202 


\section{Other Partners:}

American Public Power Association - (202) 467-2900

National BioDiesel Board - (800) 841-5849

Tennessee Soybean Promotion Board - (931) 668-2772

Helen Hennon - Director of Governmental Services, Quantum Environmental \& Engineering Services, LLC - (865) 689-1395

Ryan Strickland - COO, Agri-Energy Management (931) 270-8129

Kelly Strebig - University of Minnesota Center for Diesel Research - (651) 330-0450

Will Ayers - V.P. Engineering, Cim-Tech Filtration - (217) 678-2511

Dr. Thomas Reed - Biomass Energy Foundation - (303) 279-3707

William Ayres - AgBioEnergy, LLC - (913) 341-7114

Dave Brown - Phillips Sales and Service - (931) 473-2450

\section{Project Contact(s):}

Technical:

MES Manager, Engineering and Operations - Ralph Dunn, (931) 473-3144, rdunn@mesystem.net

Business:

MES Manager, Finance and Accounting/Assistant General Manager - Neal Cox, (931)

473-3144, ncox@mesystem.net

\section{McMinnville Electric Project Team:}

MES General Manager - Rodney Boyd, (931) 473-3144,

rboyd@mesystem.net

MES Manager, Finance and Accounting/Assistant General Manager - Neal Cox, (931) 473-3144, ncox@mesystem.net

MES Manager, Engineering and Operations - Ralph Dunn, (931) 473-3144, rdunn@mesystem.net

MES Electrical Engineer - Huel Martin, (931) 473-3144.

hmartin@mesystem.net

\section{DOE Project Team:}

DOE-HQ contact - Valerie-Sarisky Reed, 202-586-1507

DOE Field Project Officer - Fred Gerdeman, 303 275-4928, fred.gerdeman@go.doe.gov 
DOE Contract Specialist - Pamela Brodie, 303-275-4741, pamela.brodie@go.doe.gov

DOE Project Monitor - Renae Binstock, 303-275-4772, renae.binstock@go.doe.gov 


\section{Summary Abstract}

\section{Project Title:}

Agricultural Bio-Fueled Generation of Electricity and Development of Durable and Efficient NOx Reduction

\section{Objectives:}

The objective of this project was to define the scope and cost of a technology research and development program that will demonstrate the feasibility of using an off-the-shelf, unmodified, large bore diesel powered generator in a grid-connected application, utilizing various blends of BioDiesel as fuel.

Furthermore, the objective of project was to develop an emissions control device that uses a catalytic process and BioDiesel (without the presence of Ammonia or Urea)to reduce NOx and other pollutants present in a reciprocating engine exhaust stream with the goal of redefining the highest emission reduction efficiencies possible for a diesel reciprocating generator.

\section{Process:}

Caterpillar Power Generation adapted an off-the-shelf Diesel Generator to run on BioDiesel and various Petroleum Diesel/BioDiesel blends. EmeraChem developed and installed an exhaust gas cleanup system to reduce NOx, SOx, volatile organics, and particulates. The system design and function was optimized for emissions reduction with results in the $90-95 \%$ range; especially for NOx. TVA measured the emissions and reviewed the environmental effects.

\section{Outcome to Date:}

Objective \#1 - using a 3516B Caterpillar generator, McMinnville Electric System has successfully generated 1,629,024 kWh's of renewable electric power (1008 hours of operation) using soybean based, American made BioDiesel as fuel. In the process McMinnville Electric System has used 126,126 gallons of BioDiesel which equates to 84,080 bushels of soybeans. After examining the internal rotating engine parts and combustion chamber, Caterpillar engineers report the "Test was very Successful". (See attached report BioDiesel Demonstration with SCONOx NOx Removal, Attachment "C")

Objective \#2 - we were able to achieve a 96.6\% reduction in NOx without the use of Ammonia or Urea as reductants utilizing EmeraChem's exhaust gas cleanup system and BioDiesel as a reductant. The NOx emission reduction results were independently measured and verified by the Tennessee Valley Authority. (See attached report BioDiesel Demonstration with SCONOx NOx Removal, Attachment "G") 


\section{Diagram of the Project:}

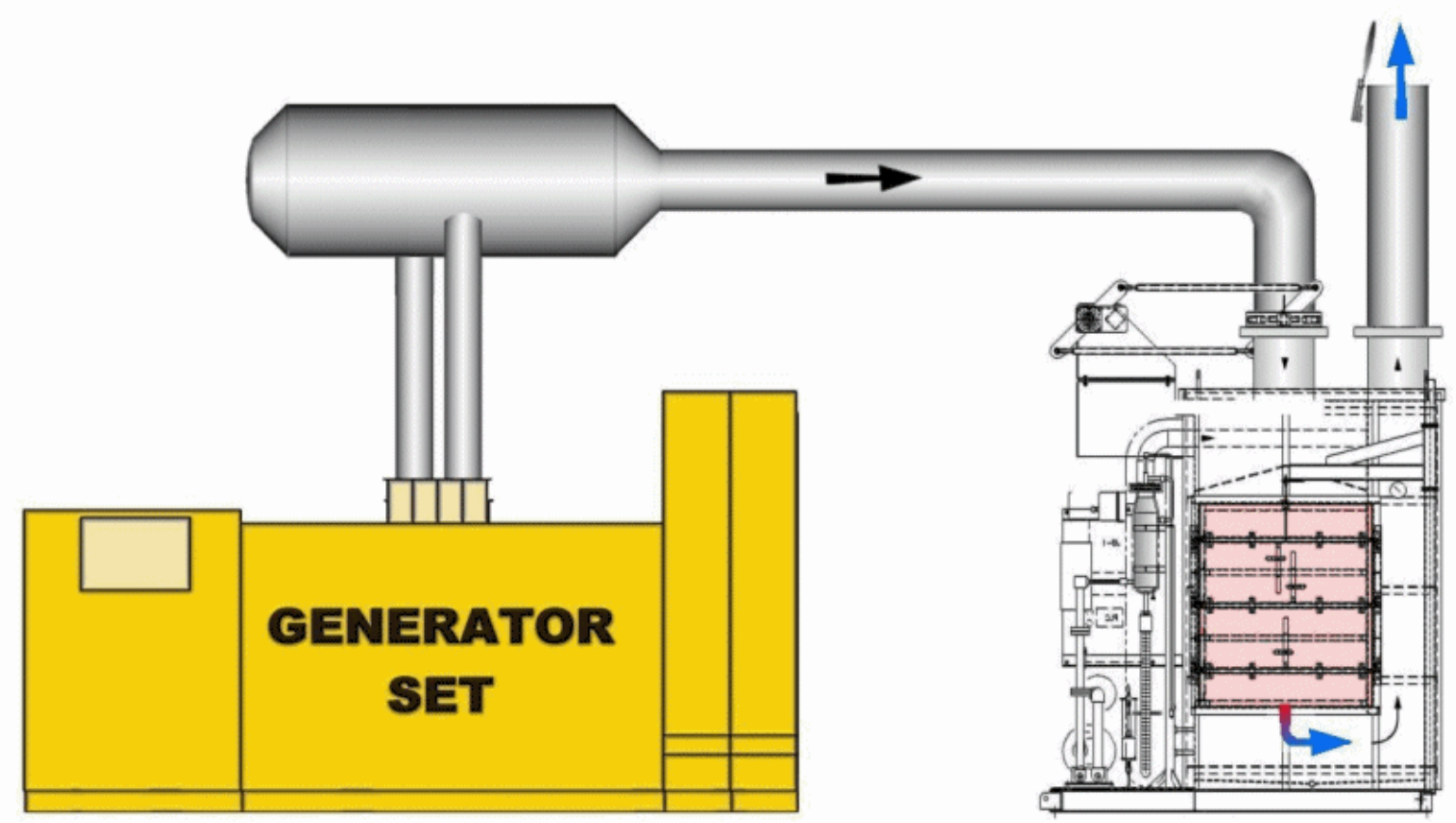

\section{Equipment:}

3516BDITA Caterpillar Generator, EmeraChem EMx Prototype Emissions System, 30,000 gallon fuel tank, 2000 kVA power transformer, EMCP II+ Control Panel, NexGear Series 1 Advanced Paralleling Switchgear, PointGuard on-site remote-monitoring hardware.

\section{What we have learned:}

We have success proven that a large-bore stationary diesel generator can utilize $99.9 \%$ Biodiesel as fuel for a prolonged period of time, that the BioDiesel has no effect on engine durability and performance and that BioDiesel can be successfully substituted for petroleum diesel in warmer climates. We have successfully proven that NOx emissions can be reduced by $>96.6 \%$ in a large bore stationary diesel engine without the use of ammonia or urea as reductants by reforming BioDiesel into hydrogen. We have learned that you can produce $>21 \% \mathrm{Hydrogen}$ by reforming BioDiesel. We also have learned that underground mining operations and generators in nonattainment areas could benefit from the experience gained from this report.

We have not been successful in operating the BioDiesel to hydrogen reformer for extended periods of time (beyond 30 hours) without operational issues. For this type of project to be successful, the reformer would need to operate for at least 200-400 hours without maintenance, breakdown or failure. Much research is being done in this area and it is our intent 
to continue our research until we have successfully overcome this obstacle. Much more detail and additional research findings can be found in the attached report entitled BioDiesel Demonstration with SCONOx NOx Removal.

\section{History:}

This project has been funded by the Department of Energy as a Congressionally Directed Project. Additional funds were provided by the American Public Power Association, National BioDiesel Board and the Tennessee Soybean Promotion Board. In-kind help was provided by EmeraChem, Stowers Caterpillar and the Tennessee Valley Authority.

Our original planned start date was February 02, 2004 with an original planned completion date of August 1, 2005. Circumstances beyond our expectations, including cold weather and total destruction of the original BioDiesel hydrogen reformer necessitated MES requesting and DOE graciously granting two (2) no-cost extensions which resulted in an actual completion date of April 30, 2007.

\section{Disclaimer:}

"This report was prepared as an account of work sponsored by an agency of the United States Government. Neither the United States Government nor any agency thereof, nor any of their employees, makes any warranty, express or implied, or assumes any legal liability or responsibility for the accuracy, completeness, or usefulness of any information, apparatus, product, or process disclosed, or represents that its use would not infringe privately owned rights. Reference herein to any specific commercial product, process, or service by trade name, trademark, manufacturer, or otherwise does not necessarily constitute or imply its endorsement, recommendation, or favoring by the United States Government or any agency thereof. The views and opinions of authors expressed herein do not necessarily state or reflect these of the United States Government or any agency thereof."

\begin{tabular}{|l|}
\hline FOR A MORE COMPLETE \\
EXPLINATION OF THE FINDINGS \\
CONTAINED IN THIS EXECUTIVE \\
SUMMARY AND ADDITIONAL \\
INFORMATION ABOUT THE PROJECT, \\
SEE THE ATTACHED REPORT \\
BioDiesel Demonstration with \\
SCONOX NOX Removal. \\
\end{tabular}




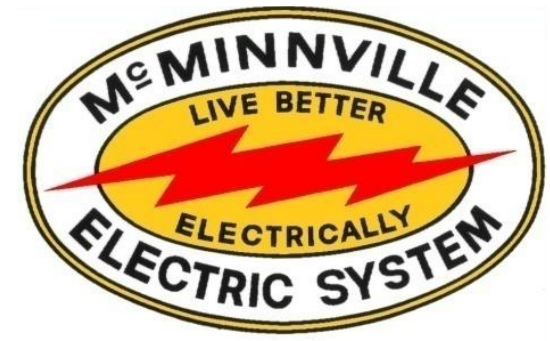

\section{BioDiesel Demonstration with SCONOx NOx Removal}

Award No. DE-FG36-04G014250

Prepared for:

U.S. Department of Energy

Golden Field Office

1617 Cole Boulevard

Golden, Colorado 80401-3393

Prepared by:

McMinnville Electric System

200 Morford Street

McMinnville, Tennessee 37110

April 30, 2007 


\section{Contents}

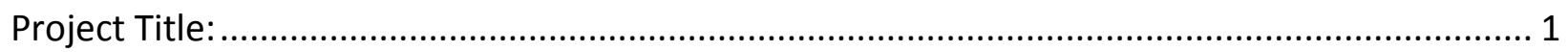

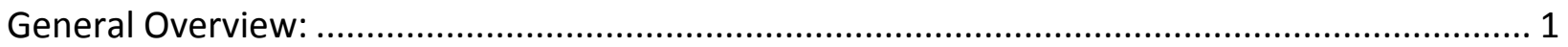

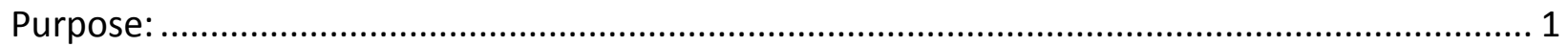

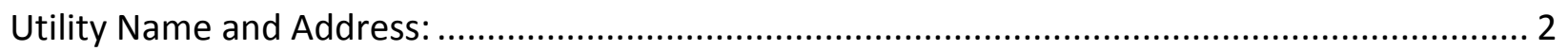

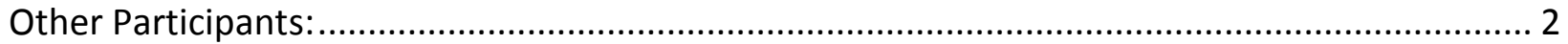

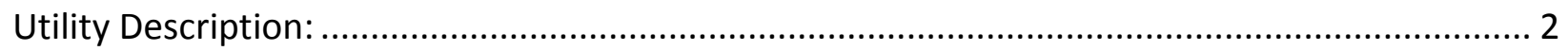

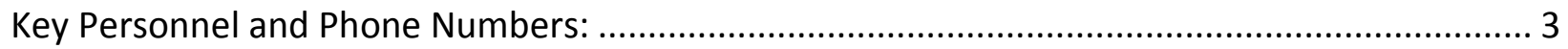

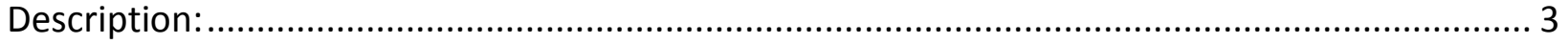

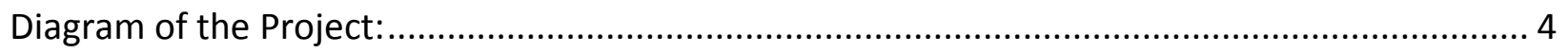

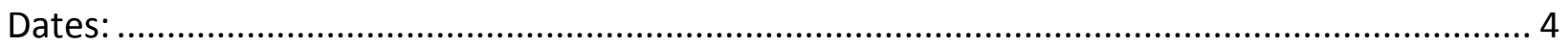

Alternatives:

Results to Date:

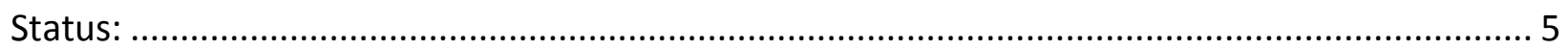

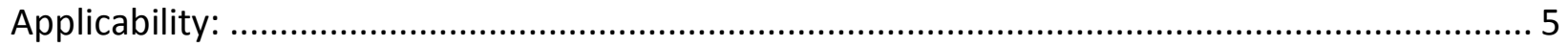

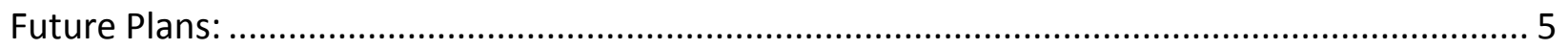

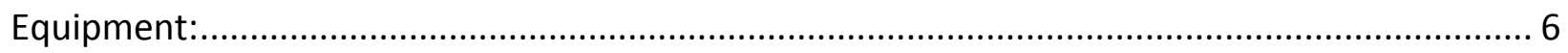

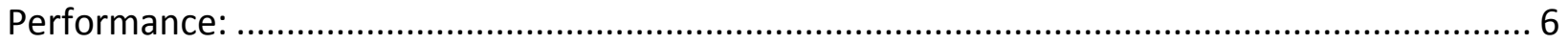

Injector Analysis after 500 Hours............................................................................. 11

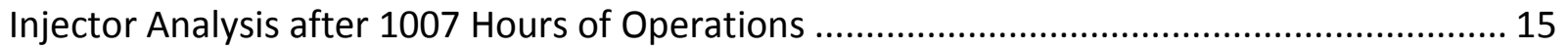

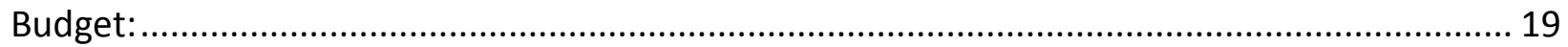

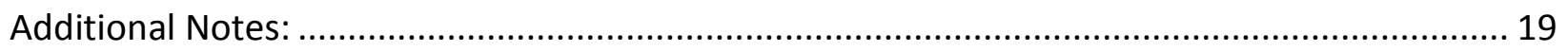

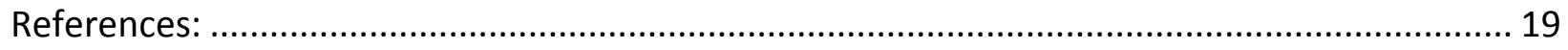

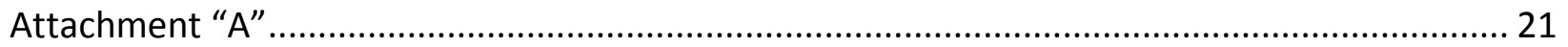

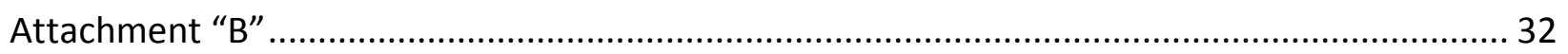

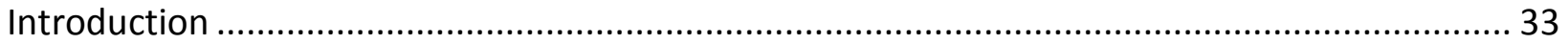

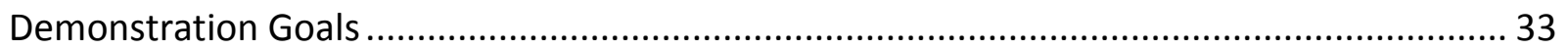

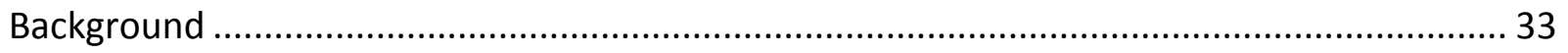

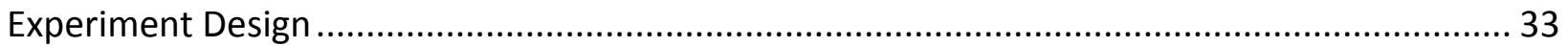

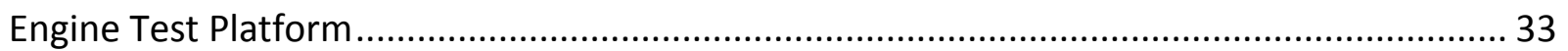

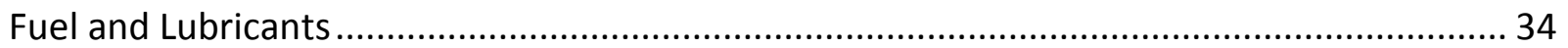

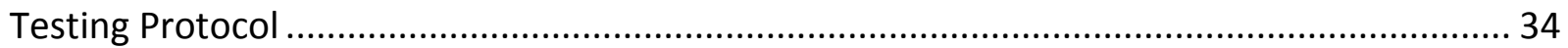

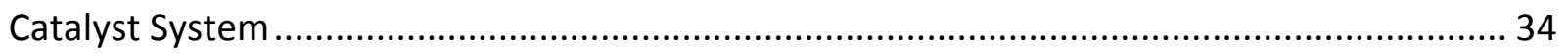

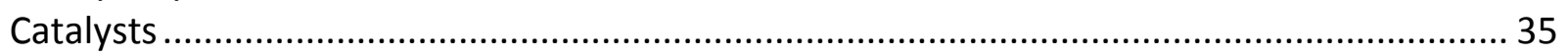

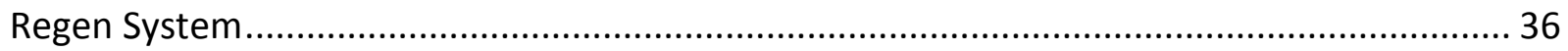

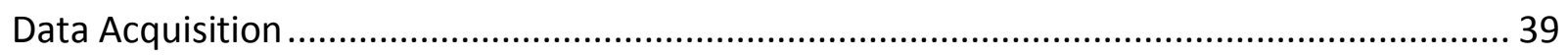

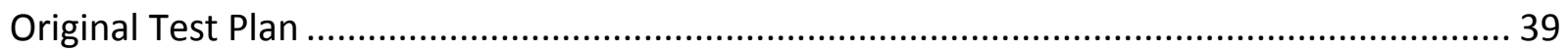

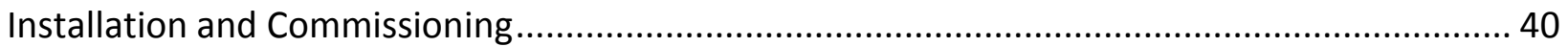

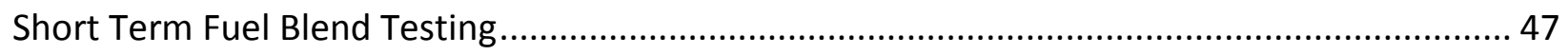

McMinnville Electric System 


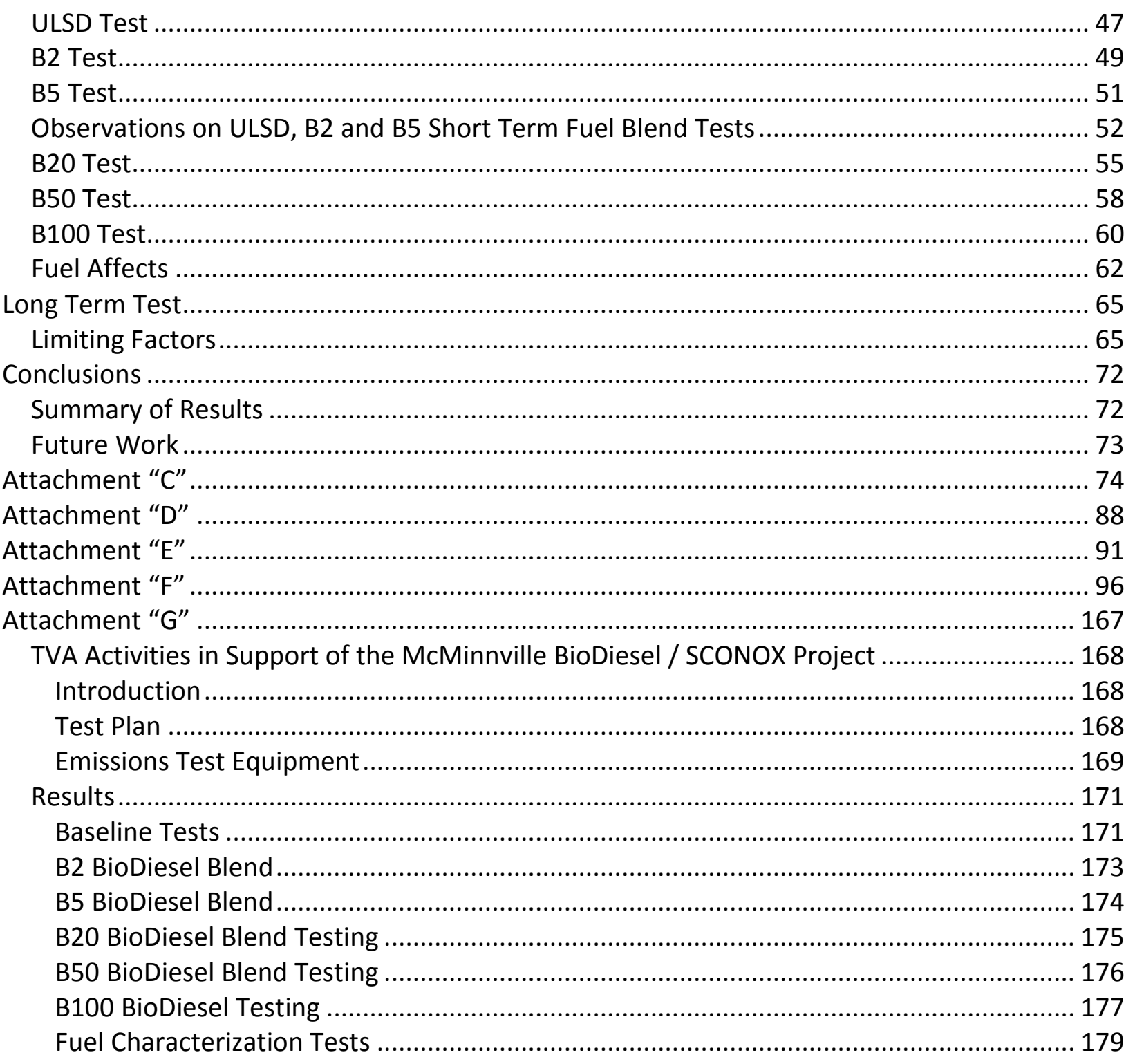




\section{Disclaimer}

The purpose of this Report is to share information about the use of BioDiesel, and a prototype NOx emissions reduction system, with all interested parties. It is furnished with the understanding that McMinnville Electric System, the City of McMinnville, Tennessee, and McMinnville Electric System's provider of power, and their respective directors, officers, agents, representatives, assigns, subcontractors, suppliers, and employees, and the McMinnville Electric System Board of Public Utilities, shall not be held liable for any claims, demands, causes of action, costs, or losses for personal injuries, property damage, or loss of life or property, arising out of or in any way connected with the testing or operation of a similar or similar Project(s), including claims based upon Breach of Contract, Breach of Agreement, Breach of Warranty, strict liability or negligence, or any other loss, damage, or injury caused by or relating to the design, manufacture, selection, delivery, condition, operation, use, maintenance or repair of a similar or similar Project(s). UNDER NO CONDITION OR CAUSE OF ACTION SHALL MCMINNVILLE ELECTRIC SYSTEM BE LIABLE FOR ANY LOSS OF ACTUAL OR ANTICIPATED BUSINESS OR PROFITS OR ANY SPECIAL, INDIRECT OR CONSEQUENTIAL DAMAGES.

Neither MES, the City of McMinnville, Tennessee, MES'S provider of power, nor their respective directors, officers, agents, representatives, assigns, employees, subcontractors, nor suppliers, nor McMinnville Electric System Board of Public Utilities, shall be liable for any direct, indirect, general, special, incidental, exemplary, or consequential loss or damage of any nature, including loss of life or injury, arising out of their performance or non-performance of the information provided hereunder. The provisions of this Section shall apply whether such liability rises in contract, agreement, tort (including negligence), strict liability or otherwise.

\footnotetext{
"This report was prepared as an account of work sponsored by an agency of the United States Government. Neither the United States Government nor any agency thereof, nor any of their employees, makes any warranty, express or implied, or assumes any legal liability or responsibility for the accuracy, completeness, or usefulness of any information, apparatus, product, or process disclosed, or represents that its use would not infringe privately owned rights. Reference herein to any specific commercial product, process, or service by trade name, trademark, manufacturer, or otherwise does not necessarily constitute or imply its endorsement, recommendation, or favoring by the United States Government or any agency thereof. The views and opinions of authors expressed herein do not necessarily state or reflect these of the United States Government or any agency thereof."
} 


\section{Acknowledgements}

A project of this magnitude cannot be undertaken without the help of many individuals to whom I would like to express my sincere thanks. The McMinnville Electric System Board of Public Utilities is the best utility board that a utility manager could ask for. They are among the rare leaders of an organization that will allow for and encourage "out-of-the-box" thinking. They have held me accountable throughout this Project, not in a critical way, but as an encouragement. They believe that we must protect our environment for future generations and that reliance on foreign governments to supply our fuel needs is questionable judgment. They are the true leaders of this project. Jeff Golden (chairman), Sam Martin (vice-chairman and R\&D Committee member), Jeff McKinley (R\&D Committee chairman), Bobby Kirby (aldermanic representative and R\&D Committee member) and Sally Brock (board member) should be thanked by our community for the commitment they, individually and as a Board, have to this organization. Robert Newman (general counsel) has also been an invaluable resource when it came to negotiating Purchase Power Agreements and Parallel Operating Agreements with TVA.

Congressman Lincoln Davis cannot be thanked enough for his sponsorship of this Project and his interest during the entire process. He and his staff (Beecher Fraser, Brandi Lowell and Cicely Simpson) have been fantastic to work with, during the last two years. Congressman Davis has a commitment to American farmers that is second to none in Congress. To me, he is an American hero in our Nation's capitol. Tennessee owes him many, many thanks!

Steve DeCicco and Lisa Mitchell (EmeraChem) have been by my side through the good times and bad. We have both raised our hands in victory during this Project and suffered agonizing moments when it appeared the obstacle before us was insurmountable - many times in the same day - sometimes within the same hour. Had it not been for their spirit of adventure and thirst for inventiveness, this Project would not have achieved the success that we have enjoyed. To them, a place in my heart and life will always abide. I would also like to thank Tom Girdlestone (EmeraChem) for allowing Steve and Lisa to continue to work on this project and to see it through to success.

Ralph Dunn and Huel Martin (McMinnville Electric System) have been the hands and engineering minds of this Project since it was first conceived back in 2001. They have literally worked day and night to make it successful; and without them beside me helping, and behind me pushing, I could not have made this Project a reality. My substation maintenance crew (Jonathan Womack, Troy Sauls and Jeremy Womack) worked throughout the night on many occasions to wash the catalyst and have them ready to reinstall and operate the next morning. The McMinnville Electric System line crew (Billy Pitmon, Gene Rhea, Tony Foster, Frankie Rains, Phillip Rowland, Craig Foster, Dwight Jones, Neal Smith and Jonathan Jacobs) installed the generator, all of the switchgear and wiring. What a remarkable group of craftsmen. 
Neal Cox (McMinnville Electric System) has been the finance and accounting mind behind the Project. Neal has worked tirelessly behind the scenes to make sure all of the accounting "i's" are dotted and " $\mathrm{t}$ ' $\mathrm{s}$ " are crossed and has been responsible for compiling the mounds of paperwork that must be supported during the Project. Neal is also a diligent champion of alternative fuels and believes that helping American farmers is in our nation's best interest.

Dave Brown and Joey Wilcher (Phillips Sales and Service) were the brawn and brains for the fuel delivery and filtration system. You can have the best fuel and the best storage facility, but if you can't get the fuel from the tank to the engine, you don't have anything. They were available at a moment's notice, 24-hours a day. When we needed help - anytime - they were there quickly. Their help and guidance through all the fuel blend testing was immeasurable - I give them thanks.

Ralph Boroughs (TVA) was a skeptic at first and later one of my most wholehearted supporters. His first and foremost objective is environmental protection; and at that, he is great. The first time Ralph and I met, you could tell from his non-verbal communication that there was no way that he was going to support a project like this. After he found out our goal was $>90 \%$ NOx reduction, we had his attention and his arms-crossed demeanor changed as well The day we achieved the $96.6 \%$ NOx reduction target, he was the one with the biggest smile on his face. Ralph Boroughs is a great guy and a good friend. Chevales Ward and Duane Brigman (TVA) were also of utmost help to the Project. During one particular emissions test, it was raining strait down and no one would have faulted Chevales and Duane for stopping the test and coming in out of the rain; however, these two committed environmental champions worked throughout the rain storm because they knew how tight our testing schedule was and that stopping at that point would have meant a week's setback. Thank you Chavales and Duane for a moment that I will not soon forget.

Others I would like to thank include Parks Wells (Tennessee Soybean Promotion Board), Tom Stanzione (Stowers/Caterpillar), Dave Martin (Stowers Caterpillar), Kelly Strebig (University of Minnesota Center for Diesel Research), Helen Hennon (Quantum Environmental and Engineering), Jonathan Overly (East Tennessee Clean Fuels Coalition), Ryan Strickland (Agri-Energy), Bill Ayers (AgBioEnergy), Gary Ewing (SECOR International), Mike Kossey (USDA), the American Public Power Association and Dr. Albin Chernichowski (GlidArc Technologies) who flew here from France to be part of this Project.

Also, I would like to thank Ms. Jane Flatt (McMinnville Electric System) for all her hard work and help. Jane is a one-in-a-million help and confidant. Among those who possess great literary skills, she stands as a giant; and among other traits, has the ability to make my documents look and read much better than I can write.

Finally, I would like to thank my wife who has endured countless trips to the generation substation in the middle of the night to bring me items which I need; forgiven me for the numerous times when all I had time to do was run in the house, change clothes, and run back out the door again because I was needed at the Project jobsite; and for all the nights that she has been kind enough to leave a light shining so I could see to get in the door after a long day of emissions testing. 


\section{Award Project Final Report}

\section{Project Title:}

BioDiesel Demonstration with SCONOx NOx Removal

\section{General Overview:}

The purpose of the study was to demonstrate the ability of an EMx catalyst to clean the emissions from a large stationary diesel reciprocating engine. EMx had been previously demonstrated on a $50 \mathrm{~kW}$ diesel reciprocating engine using regeneration via direct fuel injection into the catalyst. EMx has been in commercial practice on gas turbines. This demonstration project involved scaling up the reciprocating engine experience and scaling down the gas turbine experience. It also involved a new, emerging regeneration technology capable of utilizing liquid fuels (LSD, ULSD, BioDiesel, etc.) and a plasma reformer.

The catalyst used for the test was standard $\mathrm{EMx}$, utilizing $\mathrm{K}_{2} \mathrm{CO}_{3}$ sorber on a barium-alumina washcoat. The catalysts were on $200 \mathrm{cpsi}$ cordierite substrates. Four rows of EMx catalyst were installed in each chamber, with two $18^{\prime \prime} \times 42$ " $\times 6$ " modules per row. The total catalyst volume for each catalyst chamber was $21 \mathrm{ft}^{3}$. Sulfur management was handled by frequent washing of the catalyst; no ESx (sulfur) catalyst was installed. The catalyst regeneration gas was supplied by a plasma reformer fueled by the parent (native) fuel.

The engine utilized in the Project was an off-the-shelf 3516B EPG Caterpillar engine (build date 8/20/2004) with 2293 bhp coupled to a Caterpillar SR4B generator and capable of producing 1640 kW @ $60 \mathrm{~Hz}$ continuous. The engine has a $4.46 \mathrm{~g} / \mathrm{bhp}-\mathrm{hr}$ NOx emission rating. This particular engine was selected by Caterpillar because it is their most popular large-bore engine for stationary applications. This engine can be found around the country in back-up and standby power generation applications. Engine performance was remotely monitored by Caterpillar and emissions performance was monitored by the Tennessee Valley Authority across a wide spectrum of fuels including: $100 \%$ ULSD (ultra-low sulfur diesel), a blend of $2 \%$ soybean biodiesel and $98 \%$ ULSD, a blend of $5 \%$ biodiesel and $95 \%$ ULSD, a blend of $20 \%$ biodiesel and $80 \%$ ULSD, a blend of $50 \%$ biodiesel and $50 \%$ ULSD, and $100 \%$ biodiesel.

\section{Purpose:}

To demonstrate the feasibility of using an off-the-shelf, unmodified, large bore diesel powered generator in a grid-connected application, utilizing various blends of BioDiesel as fuel. In addition, a first-of-its-kind emissions control device that uses a catalytic process and BioDiesel (without the presence of Ammonia or Urea) was developed to reduce NOx and other pollutants present in a reciprocating engine exhaust stream. 
This Project was initiated with the belief that America must become less reliant on foreign sources of fuel (i.e., petrol diesel) and become more aware of the effect that engine exhaust gasses have on our health and our environment.

Soybeans represent a large segment of the world's agriculture, and in terms of gross production, soybeans are the dominant oilseed crop ${ }^{1}$. They absorb light from the sun (solar energy), water from the earth (hydro energy) and $\mathrm{CO}_{2}$ from the air (wind energy) and convert that stored energy into natures own battery (stored energy). Soybeans therefore become the greatest fuel treasure that we produce and harbor on American soil and should also be recognized as one of our greatest sources of renewable energy.

This Project is intended to provide information that fuel can be domestically produced, refined and utilized to provide clean, renewable power for American homes and businesses. All this, while providing economic incentives for farmers to make the most of fallow farmland, to provide a return on their investment and to invest that money back into our Nation's economy.

\section{Utility Name and Address:}

McMinnville Electric System

200 Morford St.

P.O. Box 608

McMinnville, TN 37110

\section{Other Participants:}

EmeraChem

Stowers/Caterpillar

Tennessee Valley Authority

American Public Power Association

National BioDiesel Board

Tennessee Soybean Promotion Board

Agri-Energy, LLC

\section{Utility Description:}

Size: 7860 Electric Customers

Annual Load: 243,682,957 kW

Services Offered: Surge Protection

Generation Resources: $22 \mathrm{MW}$ peaking plant

Other: 217 miles of line, 36 Customers/mile, 2 delivery points

${ }^{1}$ Bajjalieh, N., 2002, Proteins from Oilseeds, Integrative Nutrition, Inc. (Research note) 


\section{Key Personnel and Phone Numbers:}

McMinnville Electric System

Rodney Boyd - General Manager/CEO - (931) 473-3144

Ralph Dunn - Manager, Engineering and Operations - (931) 473-3144

Neal Cox - Manager, Finance and Accounting - (931) 473-3144

Huel Martin - Electrical Engineer - (931) 473-3144

EmeraChem

Steve DeCicco - Vice President of Operations - (865) 246-3000

Lisa Mitchell - Project Engineer - (865) 246-3000

Dr. Albin Chernichowski - GlidArc Technologies - +33-680-232-643

Stowers/Caterpillar

Tom Stanzione - Manager, Distributed Generation - (865) 675-2869

Dave Martin - Power Generation Project Manager - (865) 546-1414

Matt Kirkpatrick - Commercial Engine Sales - (865) 546-1414

Chris Kiczaja - Sales Manager Electric Power Generation - (615) 341-3215

Tennessee Valley Authority

Ralph Boroughs - Project Manager - (423) 751-4644

Chevales Ward - Environmental Engineer - (423) 751-7316

Duane Brigman - Environmental Scientist - (423) 876-4202

Other

Helen Hennon - Director of Governmental Services, Quantum Environmental \&

Engineering Services, LLC - (865) 689-1395

Ryan Strickland - COO, Agri-Energy Management (931) 270-8129

Kelly Strebig - University of Minnesota Center for Diesel Research - (651) 330-0450

Will Ayers - V.P. Engineering, Cim-Tech Filtration - (217) 678-2511

Dr. Thomas Reed - Biomass Energy Foundation - (303) 279-3707

William Ayres - AgBioEnergy, LLC - (913) 341-7114

Dave Brown - Phillips Sales and Service - (931) 473-2450

\section{Description:}

The objective of this project was to define the scope and cost of a technology research and development program that will result in ammonia free, pollution reduction system with the highest emission reduction efficiencies possible for the electric industry.

Caterpillar Power Generation adapted an off-the-shelf 3616 BDITA Diesel Generator to run on BioDiesel and various Petroleum Diesel/BioDiesel blends. EmeraChem developed and installed an exhaust gas cleanup system to reduce NOx, SOx, volatile organics, and particulates. The system design and function was optimized for emissions reduction with results in the $90-95 \%$ 
range; especially for NOx. TVA measured the emissions and reviewed the environmental effects.

See Attachment " $B$ " for a thorough discussion on the EMx Prototype test, Attachment " $C$ " for Caterpillar's engine analysis results and comments and Attachment " $D$ " and " $E$ " for information on GlidArc Technology.

\section{Diagram of the Project:}

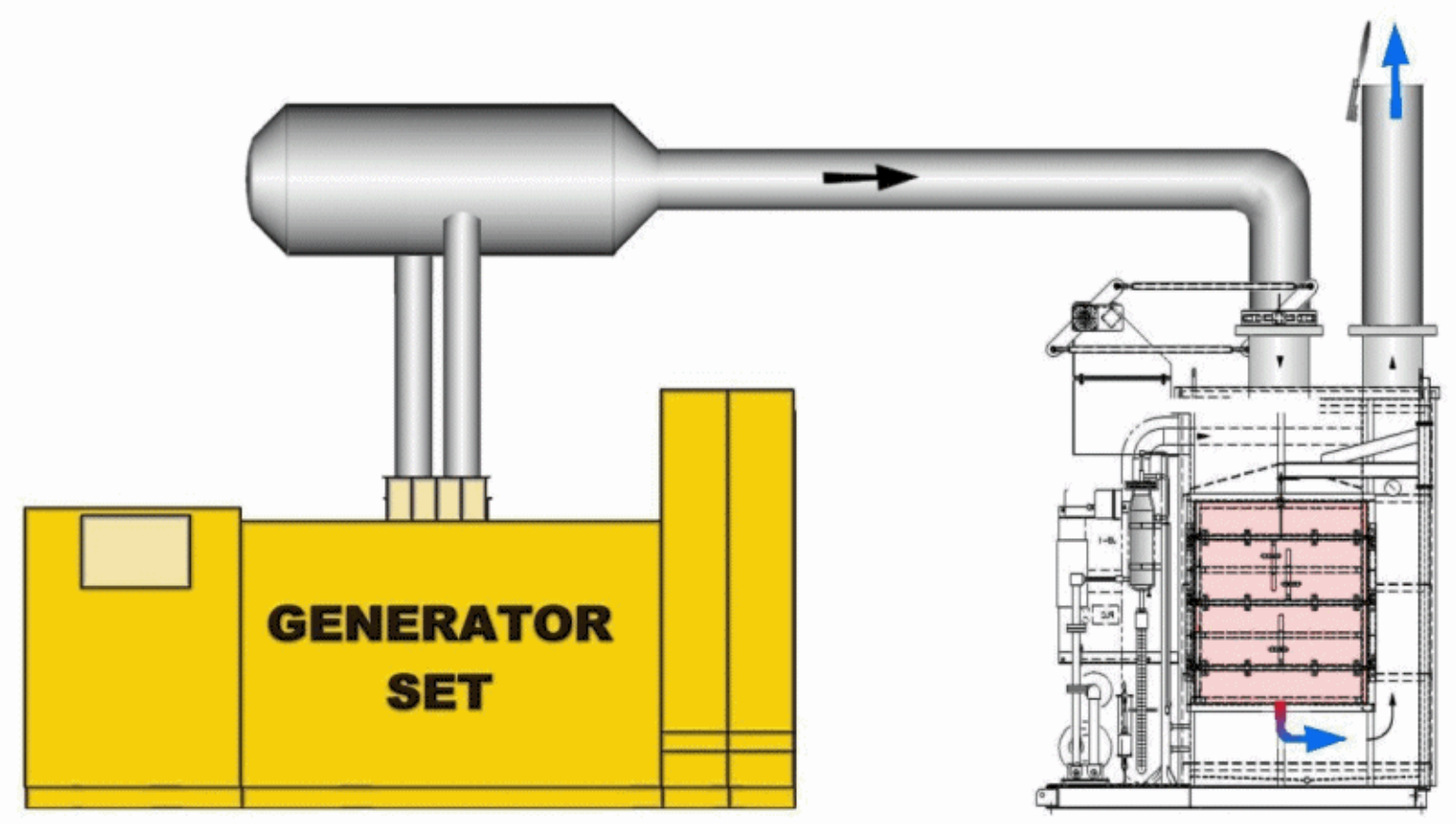

\section{Dates:}

The DEED Grant Agreement between McMinnville Electric System and the American Public Power Association was signed in February of 2005 and the project was completed in April 2007.

\section{Alternatives:}

Alternatives to the Project include: operating the generator engine without the use of external pollution controls; the use of a conventional Selective Catalytic Reduction (SCR, ammonia or urea injection system); the use of other NOx emission control technologies (lean NOx catalyst, three-way catalyst, etc.); the use of lesser blends of BioDiesel (B-2, B-5, B-10, B-20, etc.). 


\section{Results to Date:}

Using a 3516B Caterpillar generator, McMinnville Electric System has successfully generated $1,629,024 \mathrm{kWh}$ 's of renewable electric power using soybean based, American made BioDiesel as fuel. In the process McMinnville Electric System has used 126,126 gallons of BioDiesel which equates to 84,080 bushels of soybeans.

In addition, we were able to achieve a $96.6 \%$ reduction in NOx without the use of Ammonia or Urea as reductants.

Status:

Complete

\section{Applicability:}

Other utilities, especially those in non-attainment areas and environmentally sensitive areas, could use the results of this Project to site diesel powered generations in their area without the adverse environmental impact of untreated diesel exhaust emissions or the environmental impact of ammonia slip in the exhaust stream.

The underground mining industry would also benefit from the environmental findings of this Project; both on the use of BioDiesel in underground stationary generation and from the use of a catalytic NOx trap.

Utilities outside of the United States could use the results of this Project to site generation in areas that are remote; and thus, hard to deliver fuel to the site, by producing BioDiesel from palm oil, rape seed oil, canola oil, etc. local to the generation facility. One example is an inquiry that I have had from a location deep in the heart of Africa that has an abundance of palm oil. Transportation of petrol diesel to this area is difficult and expensive but the ability to site a BioDiesel refinery and install diesel generation is within the ability of the area.

\section{Future Plans:}

Future studies should include long-term studies of the effects of BioDiesel on the catalyst. All future studies hinge on the availability of reliable regeneration technologies, TVA's acceptance of BioDiesel fueled generation and their willingness to purchase the energy output of a BioDiesel fueled generation facility. If TVA is willing to purchase electric energy produced by the combustion of BioDiesel from this Project, McMinnville Electric System will work with EmeraChem and other partners toward development and automation of a durable plasma regeneration technology that will result in a robust, efficient and clean NOx removal technology.

Future plans should also include the development and construction of a more efficient and stable plasma regeneration technology possibly utilizing GlidArc-III technology. (see Attachment 
"E") and a long term durability test (>10,000 hours) on the Caterpillar motor/generator, in a grid-connected application, using B-99.9 as fuel.

\section{Equipment:}

Generator:

\begin{tabular}{|c|c|c|}
\hline Engine: Caterpillar 3616B & Duty: CONTINUOUS & Connection: SER STAR \\
\hline Generator Frame: 826 & Type: SR4B & No. of Bearings: 2 \\
\hline Generator Arr: 1441826 & Housing: 00 & Winding Type: FORM WOUND \\
\hline \multicolumn{2}{|c|}{ Genset Rating (kW): 1640 (kVA): 2050.0} & Sync Speed: 1800 \\
\hline Voltage: $277 / 4803$ phase & Frequency: $60 \mathrm{~Hz}$ & Pwf. Factor: 0.8 \\
\hline Rated Current: 2465.8 & Gen. Pitch: 0.7143 & No. of Leads: 6 \\
\hline
\end{tabular}

EmeraChem EMx Prototype Emissions System, 30,000 gallon fuel tank, 2000 kVA power transformer, EMCP II+ Control Panel, NexGear Series 1 Advanced Paralleling Switchgear, PointGuard on-site remote-monitoring hardware.

\section{Performance:}

Caterpillar Generator: No downtime due to engine, internal moving components in excellent condition, hose/seal material acceptable for <B-30 but needs to be modified for operating on B100 , engine test was very successful.

EmeraChem EMx Prototype: The EMx catalyst system performs at greater than $90 \%$ NOx removal, even with very high inlet NOx concentrations and operating temperatures of $750^{\circ} \mathrm{F}$. The EMx system eliminates the visible plume and significantly silences the engine exhaust.

One significant discovery was that as the fuel blend progressed from ULSD to B-100 the ability of the Caterpillar generator to export power to the grid went down accordingly. Upon Caterpillar's review it was noted that BioDiesel had approximately 10,000 less Btu's per gallon than ULSD and that the engine was in essence starving for fuel. When we attempted to adjust kW output beyond the load kW noted below, the engine would shut-down and bring testing to a halt. Caterpillar dispatched a technician to the job site and made a change to the throttle position sensor that allowed the engine to operate beyond the throttle limit and we were able to generate at a full $1640 \mathrm{~kW}$. On several occasions we operated at $1650 \mathrm{~kW}$ to see how the engine would respond.

Also of interest was the fuel consumption as we progressed from ULSD to B-100. As you can tell from the chart below, fuel consumption increased as the fuel blend decreased. Later, fuel consumption was checked on many other occasions at $1640 \mathrm{~kW}$ with B-99.9 and was found to be $+/-2 \%$ of $123 \mathrm{gph}$. Fuel consumption was calculated using a stopwatch and the change in fuel level in the generator day-tank. 


\begin{tabular}{rlrrr}
\multicolumn{1}{c}{ Date } & \multicolumn{1}{c}{ Fuel } & $\begin{array}{c}\text { Load } \\
\text { kW }\end{array}$ & $\begin{array}{r}\text { GPH Fuel } \\
\text { Consumption }\end{array}$ & kW/Gallon \\
7-Jul-05 & ULSD & 1625 & 120.00 & 13.54 \\
8-Jul-05 & B-2 & 1625 & 118.79 & 13.68 \\
8-Jul-05 & B-5 & 1625 & 120.60 & 13.47 \\
9-Jul-05 & B-20 & 1560 & 122.61 & 12.72 \\
9-Jul-05 & B-50 & 1545 & 123.33 & 12.53 \\
10-Jul-05 & B-100 & 1495 & 126.00 & 11.87
\end{tabular}

Fuel blending for all tests from B-2 through B-50 was conducted by an engineer and carefully calibrated using a certified Seraphin Model FS282 Field Standard Test Measure.
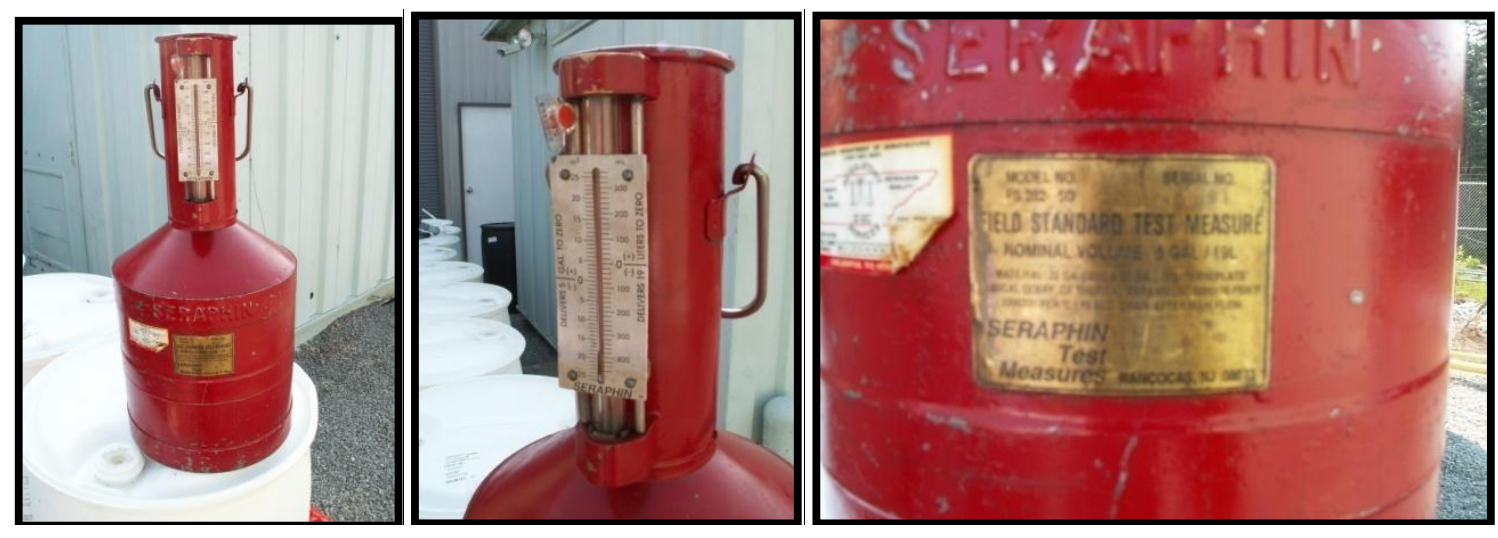

Fuel quality issues plagued us throughout the testing process and resulted in McMinnville Electric System using fuel from three different BioDiesel refineries. Test results from samples taken during the test showed anywhere from high levels of methanol (see Attachment " $A$ ") to high levels of glycerin. Pictures depicting some of our fuel quality struggles are shown below.
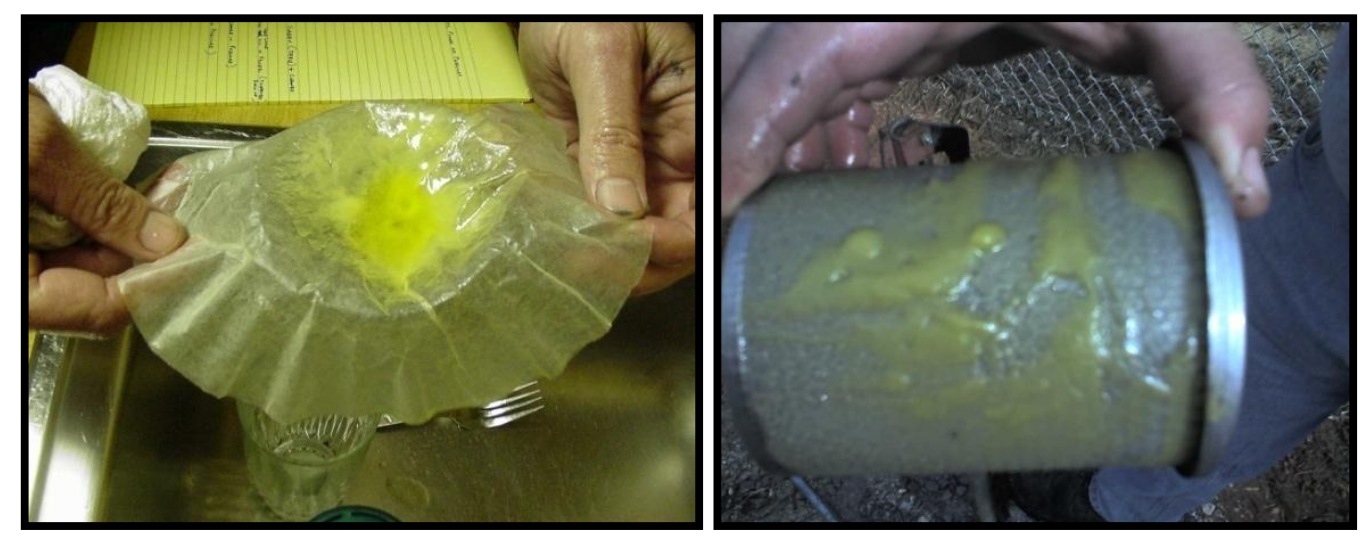
Fuel batch testing results are listed below:

\begin{tabular}{|c|c|c|c|c|c|c|c|c|c|c|c|c|}
\hline $\begin{array}{l}\text { ASTM } \\
\#\end{array}$ & test name & $\begin{array}{l}\text { Unit } \\
\%\end{array}$ & $\operatorname{Max}$ & Min & batch1 & batch2 & batch3 & batch4 & batch5 & batch6 & batch7 & batch8 \\
\hline D6584 & Free Glycerin & mass & 0.02 & & $0.000 \%$ & $0.000 \%$ & $0.000 \%$ & $0.000 \%$ & $0.000 \%$ & $0.000 \%$ & $0.000 \%$ & $0.000 \%$ \\
\hline D6584 & monoglycerides & & & & $0.814 \%$ & $0.792 \%$ & $0.793 \%$ & $0.671 \%$ & $0.554 \%$ & $0.633 \%$ & $0.814 \%$ & $0.693 \%$ \\
\hline D6584 & diglycerides & & & & $1.872 \%$ & $1.563 \%$ & $1.450 \%$ & $0.851 \%$ & $0.816 \%$ & $0.633 \%$ & $1.076 \%$ & $0.952 \%$ \\
\hline D6584 & triglycerides & $\%$ & & & $9.530 \%$ & $8.422 \%$ & $6.781 \%$ & $2.566 \%$ & $2.546 \%$ & $2.031 \%$ & $4.227 \%$ & $3.568 \%$ \\
\hline D6584 & Total Glycerin & mass & 0.24 & & $1.484 \%$ & $1.317 \%$ & $1.129 \%$ & $0.568 \%$ & $0.531 \%$ & $0.478 \%$ & $0.812 \%$ & $0.694 \%$ \\
\hline D93 & $\begin{array}{l}\text { Flash Point } \\
\text { Water \& }\end{array}$ & ${ }^{\circ} \mathrm{C}$ & & 130 & 172 & 174 & 174 & 166 & 167 & 172 & 171 & 177 \\
\hline D2709 & Sediment & $\begin{array}{l}\text { vol\% } \\
\%\end{array}$ & 0.05 & & $0.050 \%$ & $0.050 \%$ & $0.040 \%$ & $0.040 \%$ & $0.050 \%$ & $0.040 \%$ & $0.120 \%$ & \\
\hline D874 & Ash, Sulfated & $\begin{array}{l}\text { mass } \\
\%\end{array}$ & 0.02 & & & & & & & & & \\
\hline D5453 & Total Sulfur & mass & 0.05 & & $0.0001 \%$ & $0.0000 \%$ & $0.0000 \%$ & $0.0001 \%$ & $0.0001 \%$ & $0.0001 \%$ & $0.0000 \%$ & \\
\hline & & $\mathrm{mg}$ & & & & & & & & & & \\
\hline $\begin{array}{l}\text { D664 } \\
\text { Cc17- }\end{array}$ & Acid Number & $\mathrm{KOH} / \mathrm{g}$ & 0.8 & & 0.390 & 0.250 & 0.250 & 0.220 & 0.280 & 0.170 & 0.250 & 0.280 \\
\hline 95 & $\begin{array}{l}\text { Soap } \\
\text { Copper }\end{array}$ & $\mathrm{ppm}$ & & & 19 & & & 15 & & & & \\
\hline D130 & $\begin{array}{l}\text { Corrosion } \\
\text { Kinematic }\end{array}$ & & \#3 & & & & & & & & & $1 a$ \\
\hline D445 & $\begin{array}{l}\text { Viscosity } \\
\text { Carbon }\end{array}$ & $\mathrm{mm} / \mathrm{s}$ & 6 & 1.9 & 5.643 & 5.426 & 5.164 & 4.677 & 4.412 & 4.320 & 4.463 & 4.583 \\
\hline D524 & $\begin{array}{l}\text { Residue, } \\
\text { Ramsbottom }\end{array}$ & $\begin{array}{l}\% \\
\text { mass }\end{array}$ & 0.05 & & $0.060 \%$ & $0.200 \%$ & $0.040 \%$ & $0.030 \%$ & $0.042 \%$ & $0.040 \%$ & $0.044 \%$ & $0.010 \%$ \\
\hline
\end{tabular}

As the above table illustrates, fuel quality is a major concern going forward with the Project.

Of significant note was engine oil consumption. All large-bore stationary diesel engines are expected to consume a certain amount of oil during the engine duty cycle. Because a diesel powered generator in a grid-connected application operates under high load conditions and near the top of its horsepower range, some oil will naturally make its way past the piston rings and be ignited in the combustion process. This is natural and expected.

Our experience with the other 11 large-bore stationary diesel generators that McMinnville Electric System owns and operates has shown that a diesel generator will consume approximately one (1) gallon of oil for every six (6) hours of operation under normal load (generation) conditions. It was noted early in the operation of the Project that the generator engine was not using the same amount of oil as would have been expected. After 1008 hours of operation, the Caterpillar 3516B engine consumed 25 gallons of oil which is 0.025 gph as compared to our experience consumption of $0.167 \mathrm{gph}$. This represents an $85 \%$ reduction in oil consumption comparing expected with actual.

The test 3516B was equipped with a self-oiler from the Caterpillar factory and there was some concerned that the oiler was not operating properly or that some other issue was happening that we were unaware of. After review by a Caterpillar technician, there was no operational reason found why the engine was not consuming oil at the same rate as would be expected. It was theorized that the difference in lubricity between diesel fuel and BioDiesel might be a determining factor to the difference or that oil was bypassing the piston rings and making its 
way down into the crankcase resulting in lube-oil dilution. Without quantifiable data (operation of the engine for $>10,000$ hours) it will remain a theory and a mystery.

Caterpillar took oil samples and had analysis performed at 1, 235, 500, 800 and 1007 hours of operations. Results are shown below:

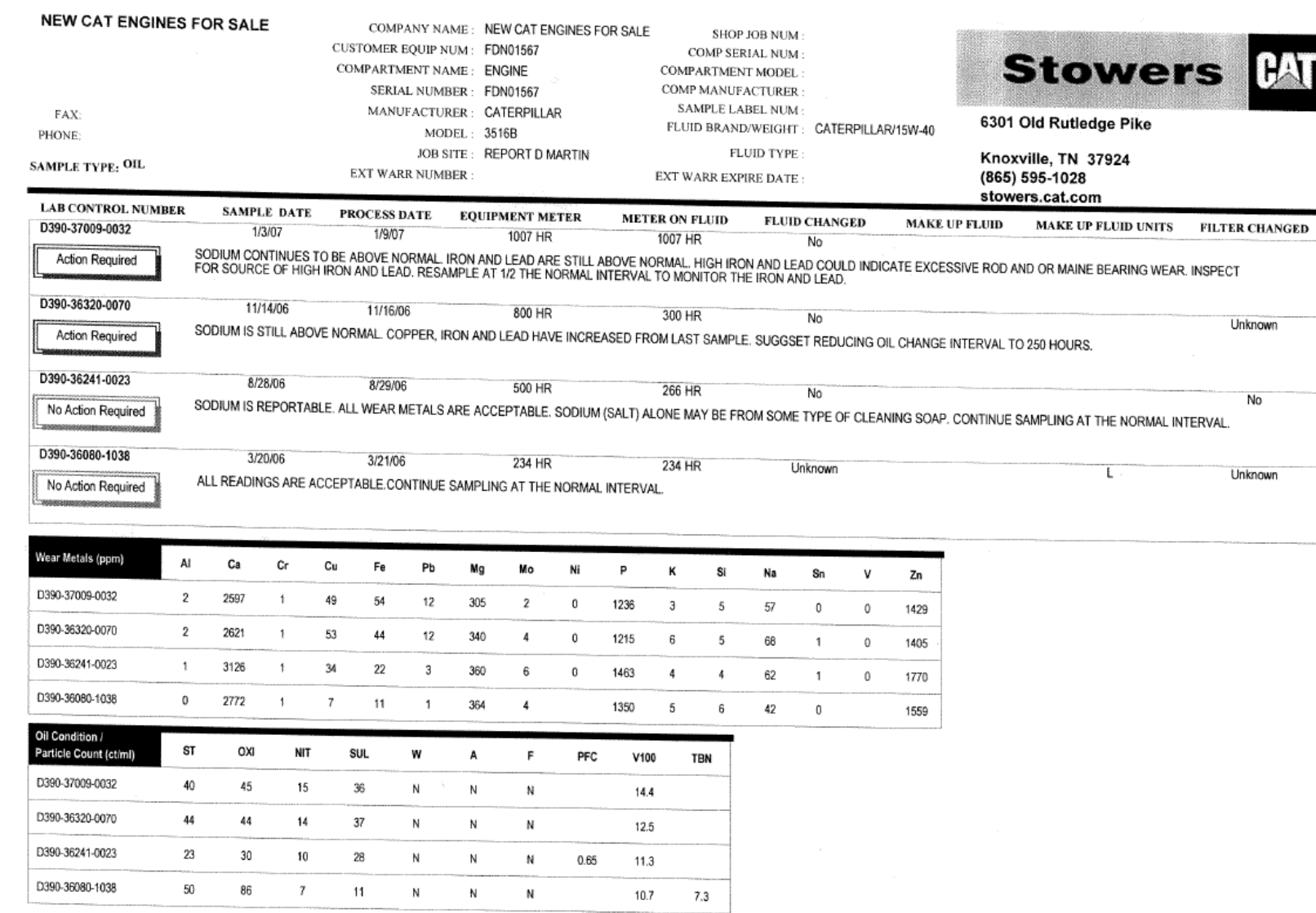

\section{Stowers BQ⿴囗十⺝} 6301 Old Rutledge Pike

Knoxville, TN 37924 (865) $595-1028$ stowers.cat.com

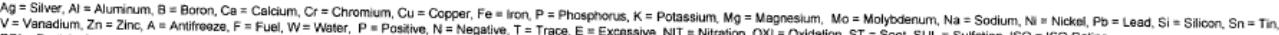

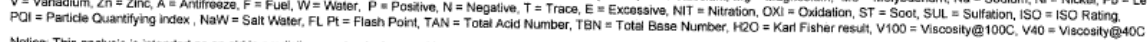

Nolice. This enalysis is imended as an aid in predicting mecharical wear. No guarantee, expressed or implied, is made against tallure of this piece of equipment of a component thereot. 


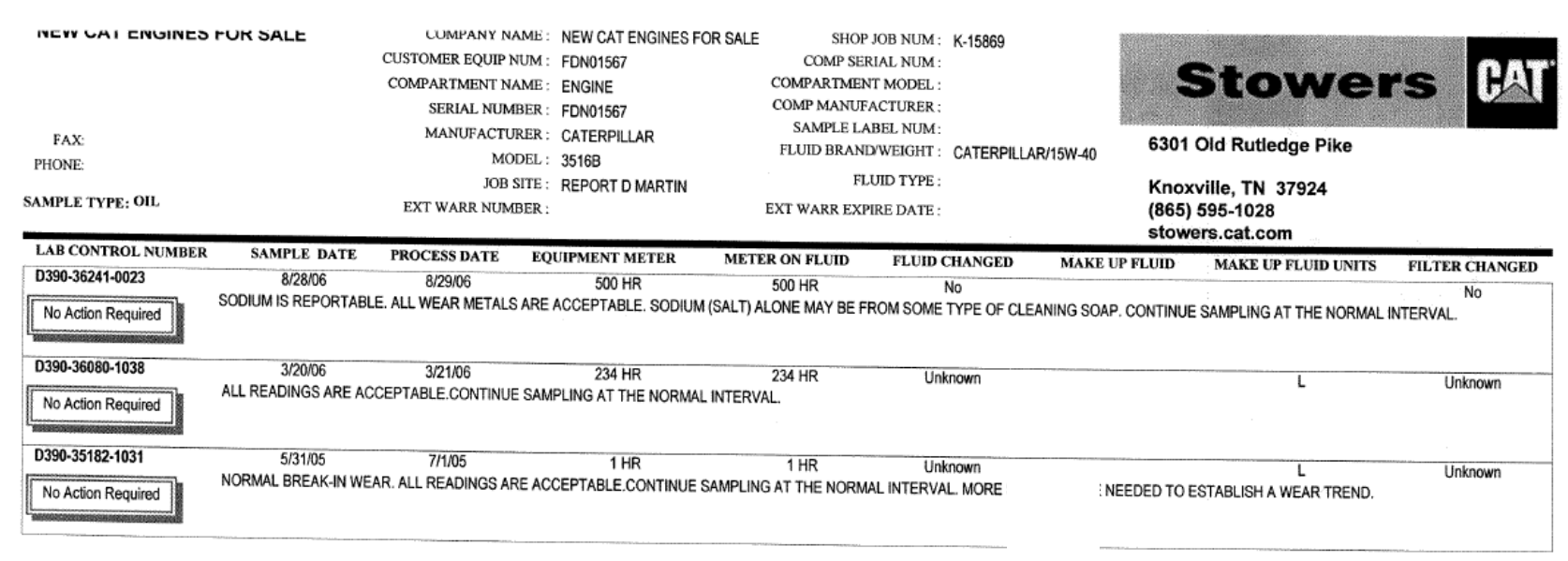

\begin{tabular}{|lcccccccccccccc}
\hline Wear Metals (ppm) & Al & Ca & Cr & Cu & Fe & Pb & Mg & Mo & Ni & P & K & Si & Na & Sn \\
\hline D390-36241-0023 & 1 & 3126 & 1 & 34 & 22 & 3 & 360 & 6 & 0 & 1463 & 4 & 4 & 62 & 1 \\
\hline $0390-36000-1038$ & 0 & 2772 & 1 & 7 & 11 & 1 & 364 & 4 & & 1350 & 5 & 6 & 42 & 0 \\
\hline $0390-35182-1031$ & 1 & 2323 & 0 & 2 & 5 & 1 & 293 & 3 & & 1184 & 2 & 4 & 0 & 0 \\
\hline
\end{tabular}

\begin{tabular}{|l|cccccccccc|}
\hline $\begin{array}{l}\text { OII Condition I } \\
\text { Particie Count (ctiml) }\end{array}$ & ST & OXI & NIT & SUL & W & A & F & PFC & V100 & TBN \\
\hline D390-36241-0023 & 23 & 30 & 10 & 28 & N & N & N & 0.65 & 11.3 & \\
\hline D390-36080-1038 & 50 & 86 & 7 & 11 & N & N & N & & 10.7 & 7.3 \\
\hline D390-35182-1031 & 15 & 1 & 0 & 0 & N & N & N & & 11.2 & \\
\hline
\end{tabular}

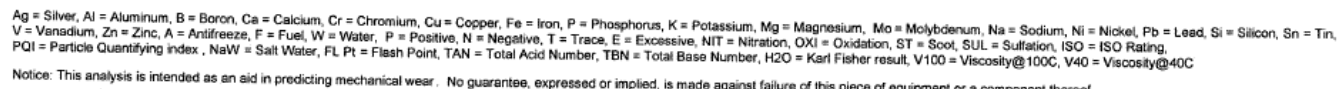

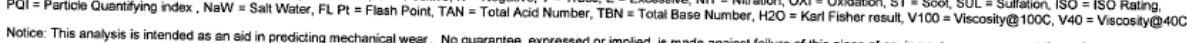

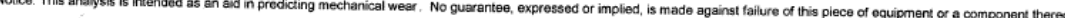

In the early planning stage of the project, one major concern regarding the use of B-100 was injector coking. According to the National BioDiesel Board, fuel injector coking can occur as a result of fuel that is of a higher viscosity that is allowed under ASTM D975 or ASTM D6752 resulting in poor fuel atomization and fuel degradation ${ }^{2}$. Because of such concern, Caterpillar removed several of the injectors at 500-hours runtime and other injectors at 1007-hours runtime and performed an injector analysis on their performance.

${ }^{2}$ Biodiesel Handling and Use Guidelines, 2006 (U.S. Department of Energy, Energy Efficiency and Renewable Energy). (Publication with no author given) 


\section{Fuel Systems Test}

\begin{tabular}{|c|c|c|c|}
\hline Failure Date: & N/A & Date Received: & $09 / 11 / 2006$ \\
\hline Product: & El800B & Engine Model: & 3516 \\
\hline Part\# & 2501314 & Eng. SN: & \\
\hline Miles/Hrs: & & Completion Date: & $01 / 08 / 07$ \\
\hline RMA\#: & 2 & & \\
\hline Quantity: & 642048 & 642049 & \\
\hline Injector SN(s): & & & \\
\hline Customer Complaint: & General inspection of injectors after 500 hrs engine testing with 100\% biodiesel \\
\hline
\end{tabular}

\section{Return Type:}

\begin{tabular}{|l|l}
\hline & Warranty \\
\cline { 1 - 1 } Special
\end{tabular}

\section{Performance Results:}

2501314 D2 Vs T2

8/17/2004 9:48:49 AM to 9/11/2006 2:13:47 PM

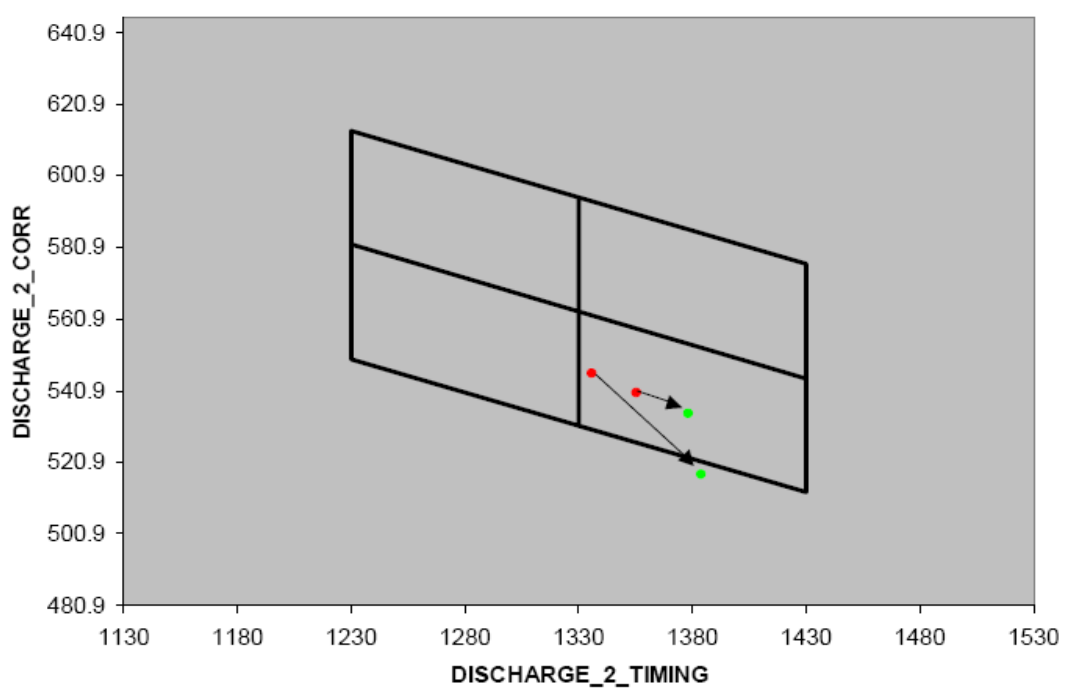

- M1736_original - M1736_retest

Figure 1. Performance plot for rated test point 


\section{Fuel Systems Test}

2501314 D3 Vs T3

8/17/2004 9:48:49 AM to 9/11/2006 2:13:47 PM

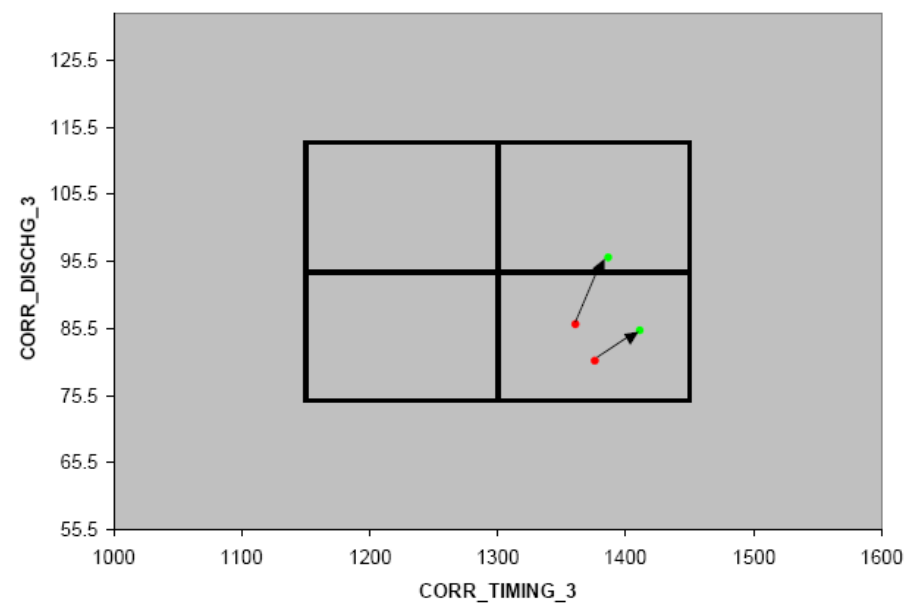

Figure 2. Performance plot for idle test point

Two injectors were sent to Pontiac for verifying their performance after $500 \mathrm{hrs}$ with bio-diesel. As shown above in the performance plots, Injectors performance is not significantly different from its original performance. Both the injectors were found to be low on delivery and timing. This small variation might be due to some debris clogged in the valve or the nozzle assembly. One of the injectors ( $\mathrm{S} / \mathrm{n} 642048$ ) passed the performance test on retesting and another ( $\mathrm{S} / \mathrm{n}$ 642049) failed marginally for lower rated delivery only (D2 Vs T2 relationship).

Table 1. Percentage decrease in the Rated delivery

\begin{tabular}{|c|c|}
\hline SN & $\begin{array}{c}\% \text { dec in rated } \\
\text { delivery }\end{array}$ \\
\hline 642048 & 1.0 \\
\hline 642049 & 5.2 \\
\hline
\end{tabular}

As shown in Table 1 there was only $1 \%$ decrease in the rated delivery for injector with $S / n$ 642048, which passed the test and there was 5.2\% decrease in the rated delivery for injector with $S / n$ 642049, which failed the test marginally but this is not a significant change. 


\section{Fuel Systems Test}

\section{BAT'Fuel}

Report No: 075-01080

Inspection:

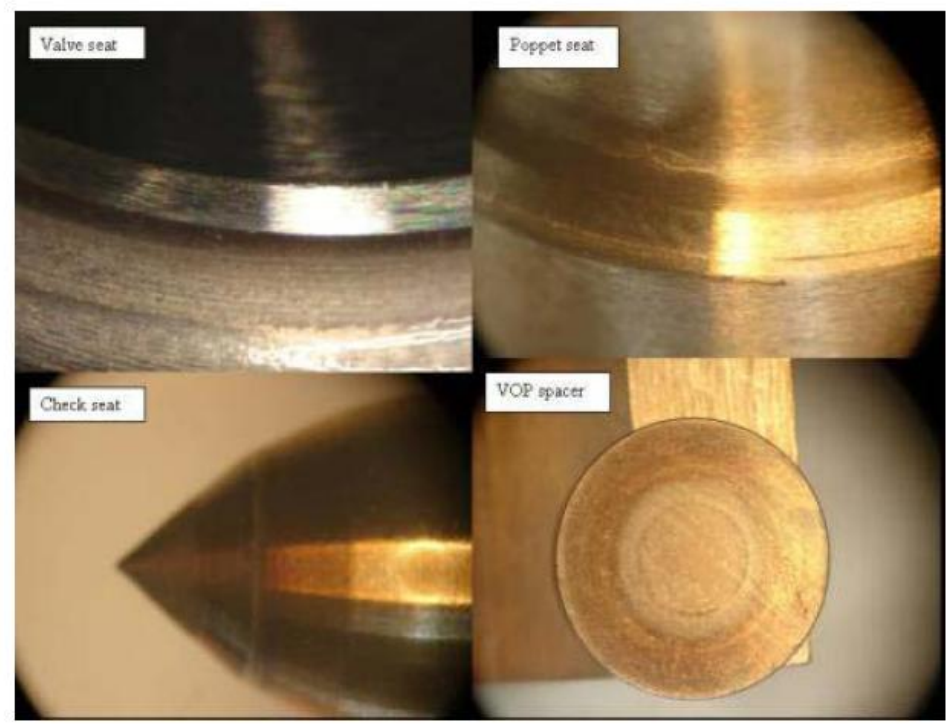

Figure 3. Parts torn down and inspected for S/n 642048

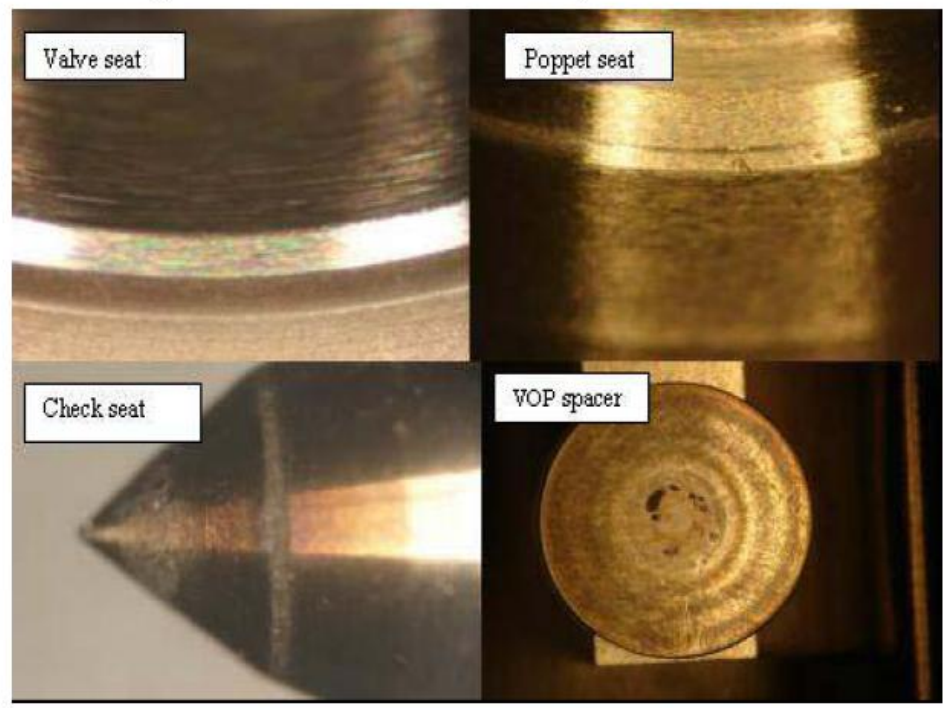

Figure 4. Parts torn down and inspected for S/n 642049

All the injector parts were inspected under magnification and as shown in the figure above none of the parts had any signs of cavitation or unusual wear. 


\section{Fuel Systems Test}

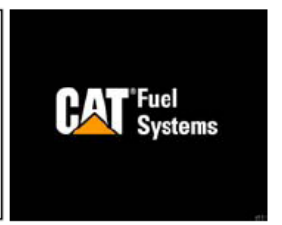

Report No: 075-010807

\section{Summary}

Two injectors were submitted for general inspection after $500 \mathrm{hrs}$ on engine with $100 \%$ biodiesel. Retest data is not significantly different from the original test data. One injector passed the performance test and one failed marginally for lower rated delivery as shown in the Figure 1 (D2 Vs T2 relationship). Rated as well as idle deliveries were on the lower side, which might be due to the flow restriction in the tips or bench movement.

\section{Analyzed By: Jaspal Rawat/Steve Wehri}

Ext.: 7-244-5852/5446

All components will be cored two weeks after the completion date unless otherwise noted! 
Fuel Systems Test

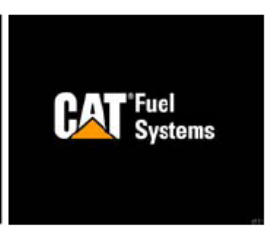

Report No: 076-011107

\begin{tabular}{|c|c|c|c|}
\hline Failure Date: & N/A & Date Received: & $01 / 10 / 2007$ \\
\hline Product: & El800B & Engine Model: & 3516 \\
\hline Part\# & 2501314 & Eng. SN: & $01 / 08 / 07$ \\
\hline Miles/Hrs: & & Complétion Date: & \\
\hline RMA\#: & 2 & & \\
\hline Quantity: & 642053 & & \\
\hline Injector SN(s): & & 642058 & \\
\hline Customer Complaint: & General inspection of injectors after 1000 hrs engine testing with 100\% biodiesel \\
\hline
\end{tabular}

\section{Return Type:}

X Warranty

Performance Results:

2501314 D2 Vs T2

$8 / 17 / 2004$ 10:05:57 AM to $1 / 11 / 2007$ 1:29:09 PM

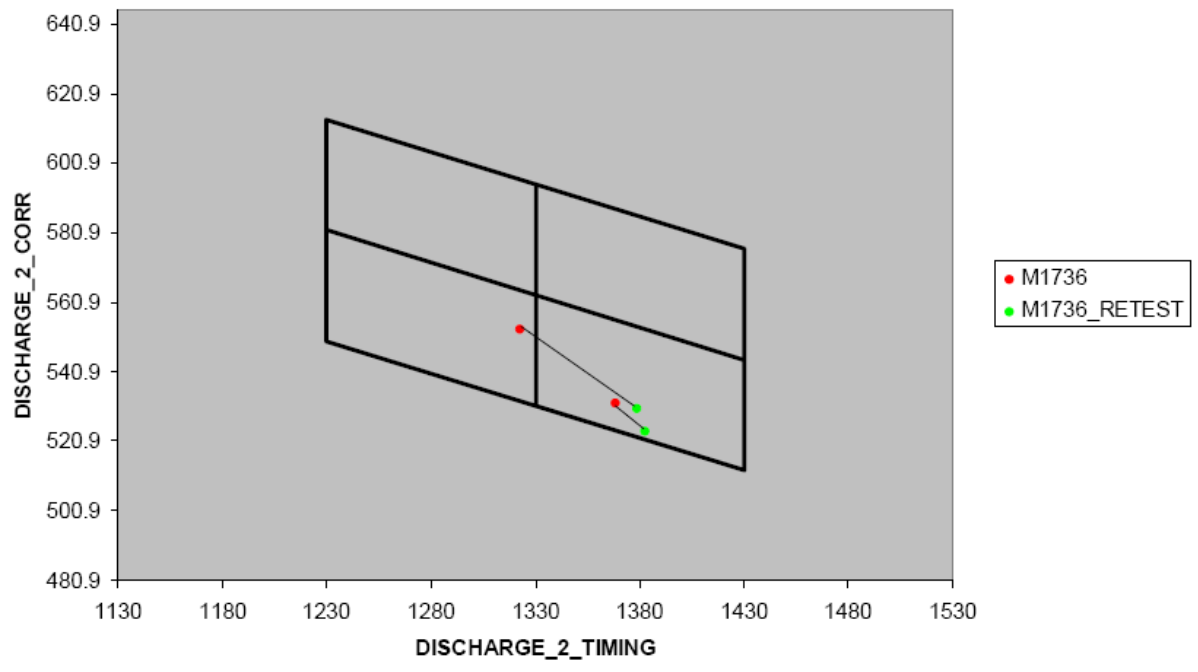

Figure 1. Performance plot for rated test point 


\section{Fuel Systems Test}

\section{BAN' Fyul}

2501314 D3 Vs T3

8/17/2004 10:05:57 AM to 1/11/2007 1:29:09 PM

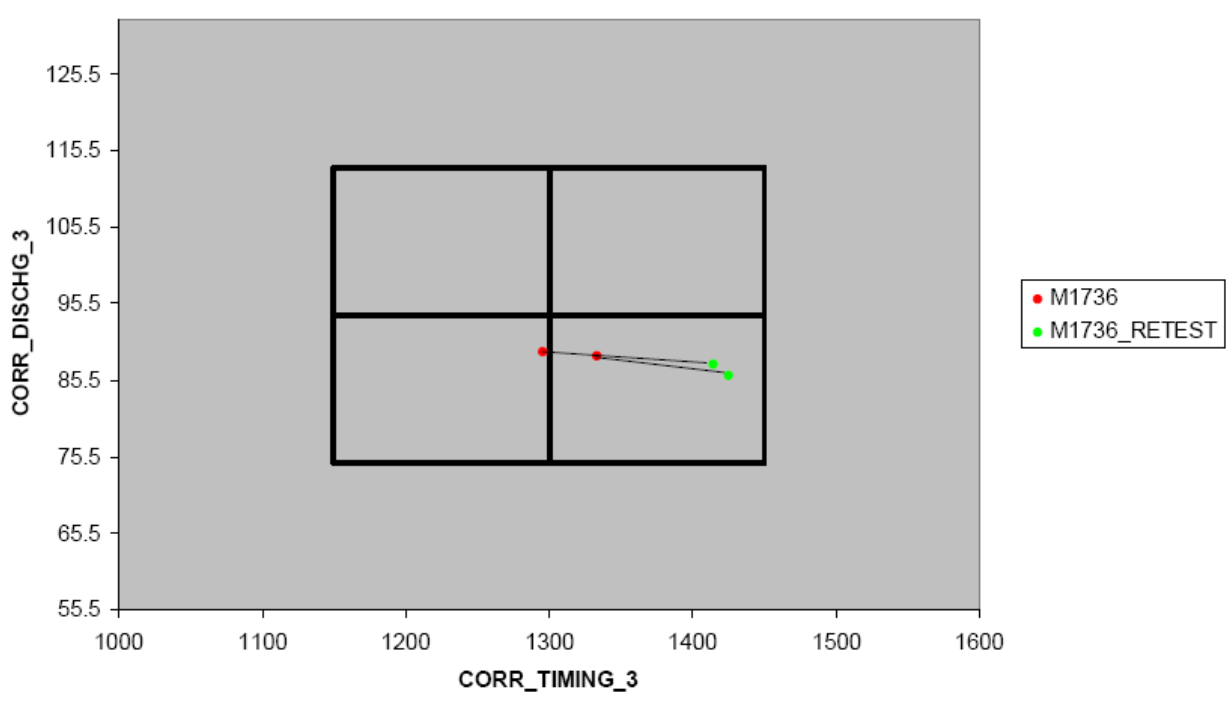

Figure 2. Performance plot for idle test point

Table1. Percentage decrease in the rated delivery

\begin{tabular}{|c|c|r|}
\hline SN & $\begin{array}{c}\text { \% dec in rated } \\
\text { delivery }\end{array}$ & $\begin{array}{c}\text { Leakage } \\
\text { (150MPa max) }\end{array}$ \\
\hline 642053 & 4.1 & 179.03 \\
\hline 642058 & 1.5 & 122.12 \\
\hline
\end{tabular}

Two injectors were sent to Pontiac for verifying their performance after $1000 \mathrm{hrs}$ with bio-diesel. As shown above in the performance plots, Injectors performance is not significantly different from its original performance. Both the injectors were found to be low on delivery and timing. This small variation might be due to some debris clogged in the valve or the nozzle assembly. As shown in Table 1, one of the injectors ( $S / n$ 642053) passed the performance test on retesting and another ( $S / n$ 642058) failed for leak, which is marginally out of the limit and which could be a bench error.

\section{Inspection:}

All the injector parts were inspected thoroughly under magnification and as show in the figure below, there is no sign of cavitation or unusual wear on the critical injector components. 


\section{Fuel Systems Test}

Report No: 076-01110"

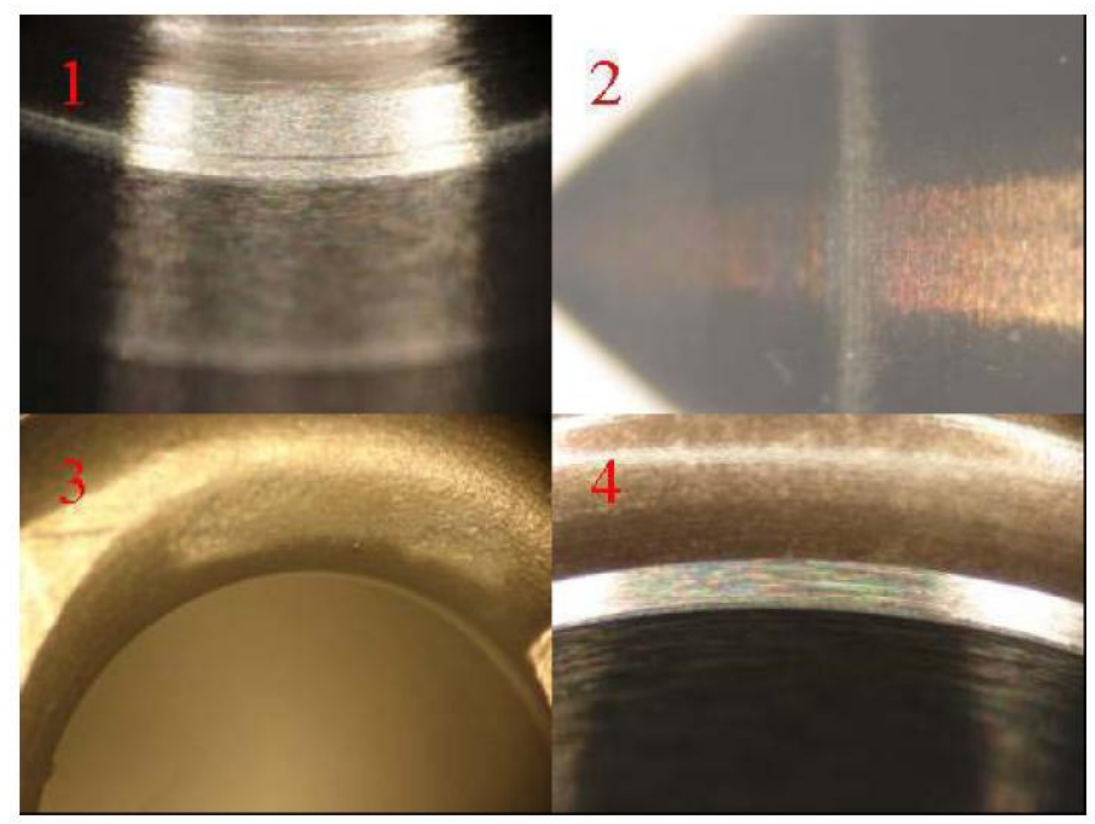

Figure 3. 1) Poppet seat 2) Check seat 3) Nozzle spring 4) Valve seat in 642058

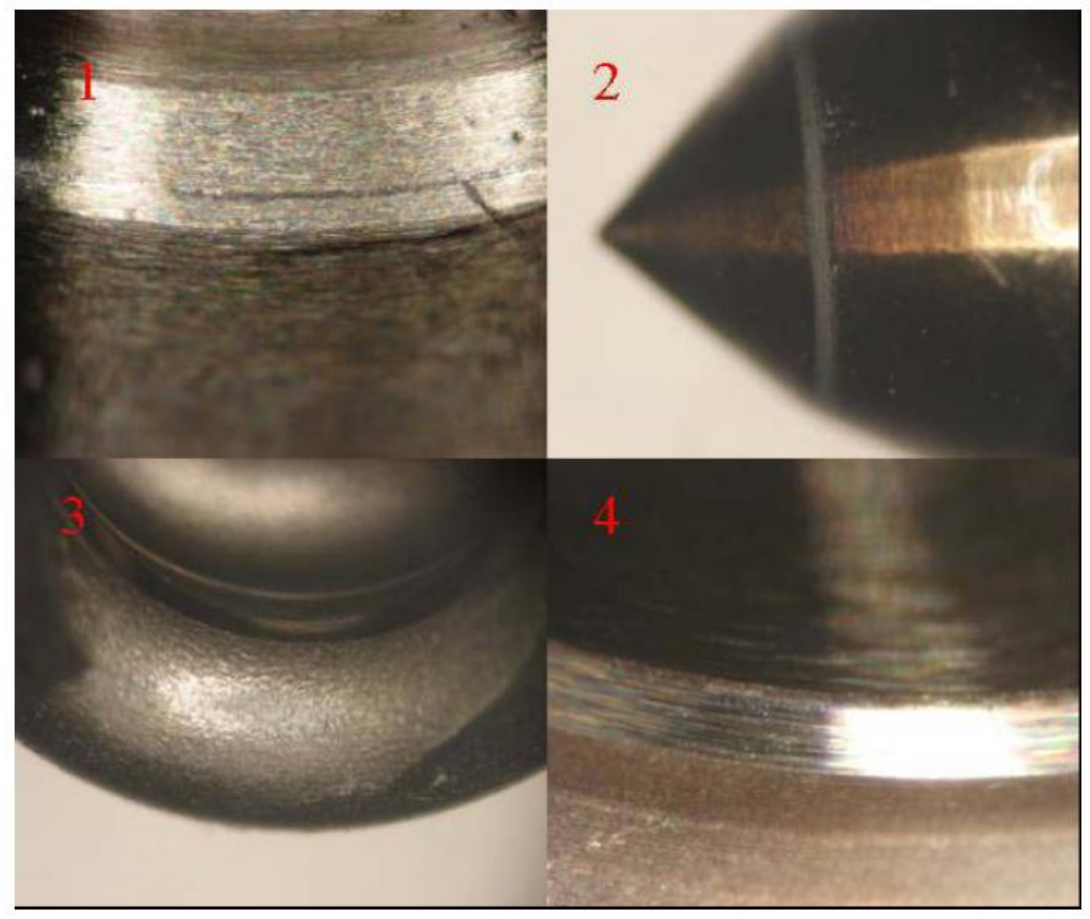

Figure 4. 1) Poppet seat 2) Check seat 3) Nozzle spring 4) Valve seat in 642053 


\section{Fuel Systems Test}

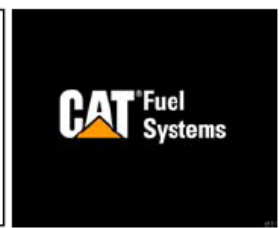

Report No: 076-011107

\section{Summary}

Two injectors were submitted for general inspection after $1000 \mathrm{hrs}$ of operation with $100 \%$ biodiesel in the engine. One injector passed the performance test on retesting and one failed marginally for leakage.

Performance results are not significantly different from the original test data. Rated as well as idle deliveries and timing are on the lower side, which might be because of the flow restriction in tips due to debris. This was also seen in the $500 \mathrm{hr}$ test returned injectors for inspection with $100 \%$ biodiesel (See report 075-010807).

\section{Analyzed By: Jaspal Rawat/Steve Wehri}

Ext.: 7-244-5852/5446

All components will be cored two weeks after the completion date unless otherwise noted! 


\section{Budget:}

Description Preliminary

Budget

$\begin{array}{lrr}\text { Generator - Caterpillar } & \$ & 505,850 \\ \text { Motor Testing } & \$ & 110,900 \\ \text { Fuel Tank } & \$ & 35,000 \\ \text { Fuel - Biodiesel } & \$ & 187,500 \\ \text { Transportation Cost } & \$ & 10,704 \\ \text { Catalyst } & \$ & 324,209 \\ \text { Payroll } & \$ & 100,921 \\ \text { Fringe Benefits } & \$ & 44,110 \\ \text { Attorney } & \$ & 16,000 \\ \text { Electrical Engineering } & \$ & 10,000 \\ \text { Energy Consultant \& Misc. } & \$ & 10,000 \\ \text { Transformer /equip } & \$ & 21,000 \\ \text { Environmental Consultant } & \$ & 4,300 \\ \text { Crane Work } & \$ & 2,000 \\ \text { Testing of Emissions } & \$ & 45,000 \\ \text { Travel } & \$ & 3,000 \\ & & \\ \text { TOTALS } & \$ & 1,430,494\end{array}$

\section{Additional Notes:}

On November 28, 2006, SECOR International Inc. prepared an Emissions measurements Report for McMinnville Electric System as detailed in Construction Permit No. 957279F, issued by the Tennessee Department of Environment and Conservation (TDEC), Division of Air Pollution Control (APC). The Permit specified, in Condition 15 of the construction permit, that McMinnville Electric System must conduct an emissions performance test to demonstrate compliance with the NOx emissions limit. Testing was performed in accordance with test methods and procedures detailed in 40 CFR 60, Appendix A. The report from SECOR in its entirety is hereby incorporated into this Report as Attachment " $F$ ".

\section{References:}

Mitchell, L. and DeCicco, S., 2007, EMx Prototype Testing on a Caterpillar 3616 TA Stationary Internal Combustion Engine Running on Various Blends of Petroleum Diesel and Soybean-Based BioDiesel. Working paper, EmeraChem, LLC., Research Notes (Working paper) 
McMinnville BioDiesel Test, 2007 (Publication with no author given)

Czernichowski, A., Czernichowski, M., Wesolowska, K., 2006, Generation of 1 kg/h of Hydrogen from Soybean BioDiesel (White paper prepared for the American Chemical Society $232^{\text {nd }}$ National Meeting and Exposition)

Czernichowski, A., Czernichowski, M., 2006, Further development of Plasma sources: the GlidArc-III. (White paper prepared by ECP - GlidArc Technologies, La Ferté St Aubin, France)

Czernichowski, A., Czernichowski, M., Czernichowski, P. Wesolowska, K., 2006, Hydrogen or Syngas Generation using Plasma Technology. (White paper from the Topsoe Catalysis Forum 2006, Future Hydrogen Generation and Application)

Rawat, J., Wehri, S., Report No: 075-010807, Fuel System Test (Caterpillar Fuel System). (Internal Report)

Rawat, J., Wehri, S., Report No: 075-011107, Fuel System Test (Caterpillar Fuel System). (Internal Report)

Ewing, G., 2006, Emissions Measurement Report for McMinnville Electric System. (Compliance Report prepared by SECOR International Inc.) 


\section{Attachment "A"}

(The following report, which pertains solely to BioDiesel fuel test results, was commissioned by the Tennessee Valley Authority for McMinnville Electric System and is therefore incorporated and is made part of this Final Report as submitted. The author is Jim Hedman with the Minnesota Department of Commerce, Weights and Measures Division, Petroleum Laboratory Services) 


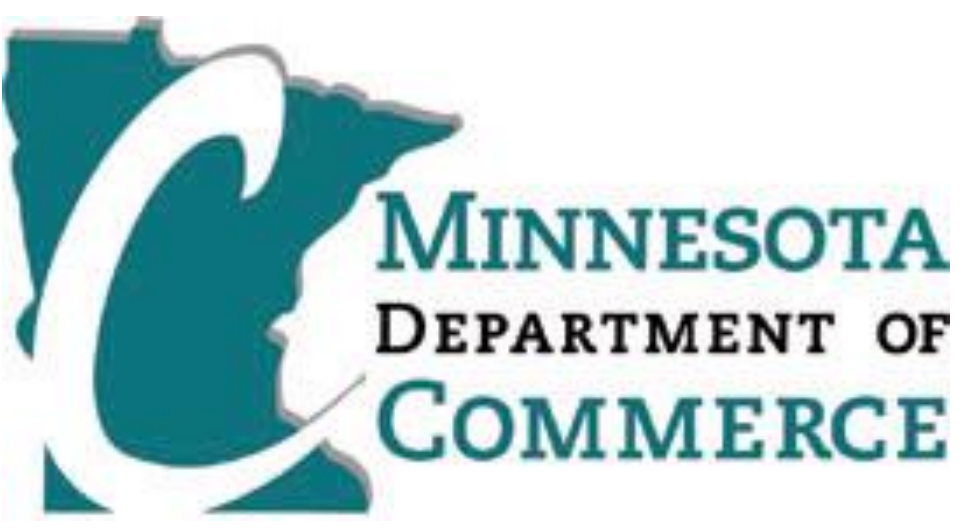

Weights and Measures Division

Petroleum Laboratory Services

2277 Highway 36

Roseville, MN 55113-3800

Jim Hedman, Metrologist

Direct: $651-296-2990$

Cell: 651-269-6808

Lab: 651-215-5842

Fax: 651-639-4014

E-Mail: Jim.Hedman@state.mn.us 
Results for TVA samples shipped 11/17/05

\begin{tabular}{|c|c|c|c|c|c|c|c|c|}
\hline Trace File Name & $\begin{array}{c}\text { Sample } \\
\text { I.D. }\end{array}$ & $\begin{array}{c}\text { Client } \\
\text { I.D. }\end{array}$ & $\begin{array}{c}\text { Peak } \\
\text { Absorb. }\end{array}$ & $\begin{array}{c}\text { Wave } \\
\text { Number }\end{array}$ & $\begin{array}{l}\% \text { Blend } \\
\text { Predict } \\
\end{array}$ & $\begin{array}{l}\text { Baseline } \\
\text { Absorb. }\end{array}$ & $\begin{array}{l}\text { Adjusted } \\
\text { Absorb. }\end{array}$ & $\begin{array}{c}\% \\
\text { Blend } \\
\text { Predict }\end{array}$ \\
\hline tva-unk aa_pm_1.spc & tva-unk a & A & 0.355465 & 1745.0 & 36.37 & 0.005998 & 0.349467 & 36.82 \\
\hline tva-unk aa_pm_2.spc & tva-unk a & A & 0.356975 & 1745.0 & 36.56 & 0.006157 & 0.350817 & 37.00 \\
\hline tva-unk aa_pm_3.spc & tva-unk a & A & 0.356563 & 1745.0 & 36.50 & 0.005157 & 0.351406 & 37.07 \\
\hline \multirow{3}{*}{\multicolumn{3}{|c|}{ Sample "A" }} & \multicolumn{3}{|c|}{ Average } & \multicolumn{2}{|r|}{ Average } & 36.96 \\
\hline & & & \multicolumn{2}{|r|}{ Std. Dev. } & 0.10 & \multicolumn{2}{|r|}{ Std. Dev. } & 0.13 \\
\hline & & & \multicolumn{2}{|c|}{ Uncertainty } & 0.27 & \multicolumn{2}{|c|}{ Uncertainty } & 0.35 \\
\hline tva-unk ba_pm_1.spc & tva-unk b & B & 0.027395 & 1747.4 & 1.95 & 0.005124 & 0.022272 & 1.81 \\
\hline tva-unk ba_pm_2.spc & tva-unk b & B & 0.027862 & 1747.2 & 1.99 & 0.004331 & 0.023531 & 1.92 \\
\hline tva-unk ba_pm_3.spc & tva-unk b & B & 0.027143 & 1747.3 & 1.93 & 0.003951 & 0.023191 & 1.89 \\
\hline \multirow{3}{*}{\multicolumn{3}{|c|}{ Sample "B" }} & \multicolumn{2}{|r|}{ Average } & 1.96 & \multicolumn{2}{|r|}{ Average } & 1.87 \\
\hline & & & \multicolumn{2}{|r|}{ Std. Dev. } & 0.03 & \multicolumn{2}{|r|}{ Std. Dev. } & 0.06 \\
\hline & & & \multicolumn{2}{|c|}{ Uncertainty } & 0.09 & \multicolumn{2}{|c|}{ Uncertainty } & 0.16 \\
\hline tva-unk ca_pm_1.spc & tva-unk c & $\mathrm{C}$ & 0.216798 & 1746.1 & 20.17 & 0.004015 & 0.212783 & 20.68 \\
\hline tva-unk ca_pm_2.spc & tva-unk c & $\mathrm{C}$ & 0.218639 & 1746.1 & 20.37 & 0.004519 & 0.214120 & 20.83 \\
\hline tva-unk ca_pm_3.spc & tva-unk c & $\mathrm{C}$ & 0.218284 & 1746.1 & 20.33 & 0.004780 & 0.213504 & 20.76 \\
\hline \multirow{3}{*}{\multicolumn{3}{|c|}{ Sample "C" }} & \multicolumn{2}{|r|}{ Average } & 20.29 & \multicolumn{2}{|r|}{ Average } & 20.76 \\
\hline & & & \multicolumn{2}{|r|}{ Std. Dev. } & 0.11 & \multicolumn{2}{|r|}{ Std. Dev. } & 0.07 \\
\hline & & & \multicolumn{2}{|c|}{ Uncertainty } & 0.29 & \multicolumn{2}{|c|}{ Uncertainty } & 0.14 \\
\hline tva-unk da_pm_1.spc & tva-unk d & D & 0.058266 & 1746.9 & 4.61 & 0.001905 & 0.056362 & 4.87 \\
\hline tva-unk da_pm_2.spc & tva-unk d & $\mathrm{D}$ & 0.058221 & 1746.9 & 4.61 & 0.002322 & 0.055899 & 4.83 \\
\hline tva-unk da_pm_3.spc & tva-unk d & $\mathrm{D}$ & 0.059020 & 1746.9 & 4.68 & 0.002947 & 0.056073 & 4.85 \\
\hline \multirow{3}{*}{\multicolumn{3}{|c|}{ Sample "D" }} & \multicolumn{2}{|r|}{ Average } & 4.64 & \multicolumn{2}{|r|}{ Average } & 4.85 \\
\hline & & & \multicolumn{2}{|r|}{ Std. Dev. } & 0.04 & \multicolumn{2}{|r|}{ Std. Dev. } & 0.02 \\
\hline & & & \multicolumn{2}{|c|}{ Uncertainty } & 0.11 & \multicolumn{2}{|c|}{ Uncertainty } & 0.06 \\
\hline tva-unk ea_pm_1.spc & tva-unk e & $\mathrm{E}$ & 0.754085 & 1741.8 & 96.35 & 0.007425 & 0.746660 & 96.10 \\
\hline tva-unk ea_pm_2.spc & tva-unk e & E & 0.760908 & 1741.8 & 97.55 & 0.007996 & 0.752911 & 97.18 \\
\hline tva-unk ea_pm_3.spc & tva-unk e & $E$ & 0.763620 & 1741.8 & 98.03 & 0.008349 & 0.755271 & 97.59 \\
\hline \multirow{3}{*}{\multicolumn{3}{|c|}{ Sample "E" }} & & Average & 97.31 & & Average & 96.95 \\
\hline & & & & Std. Dev. & 0.87 & & Std. Dev. & 0.77 \\
\hline & & & & ccertainty & 2.40 & & Incertainty & 2.13 \\
\hline
\end{tabular}




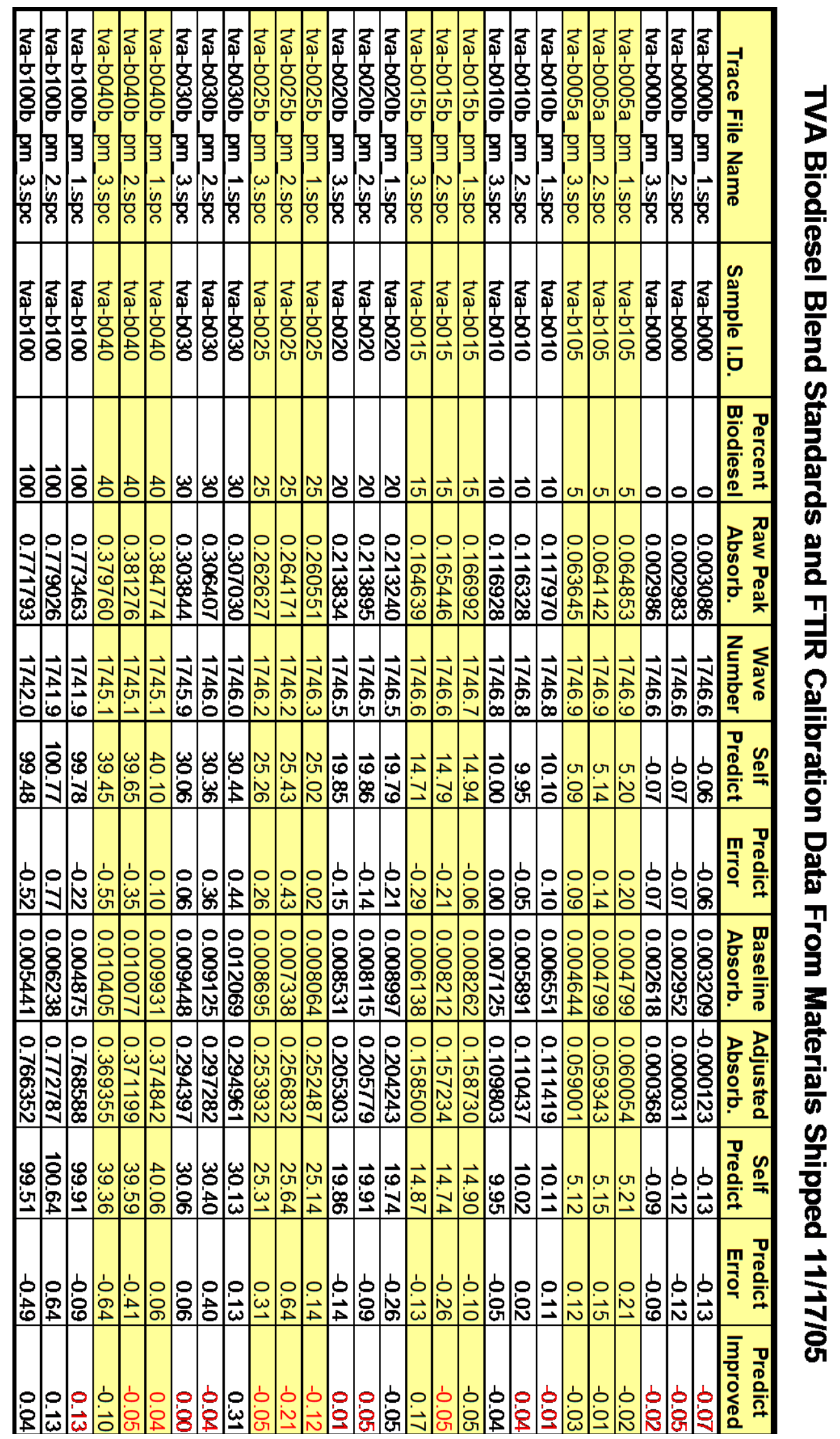




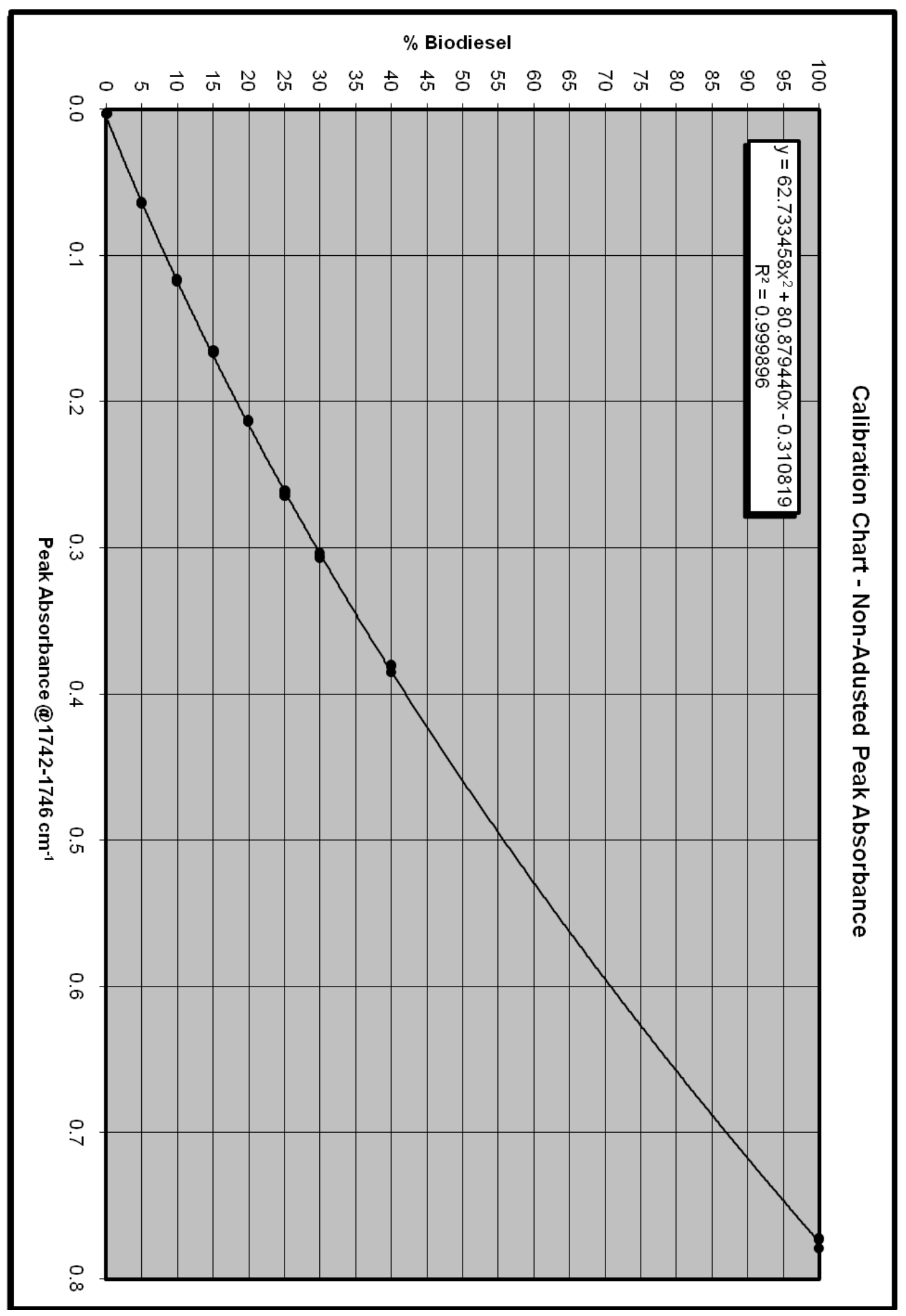




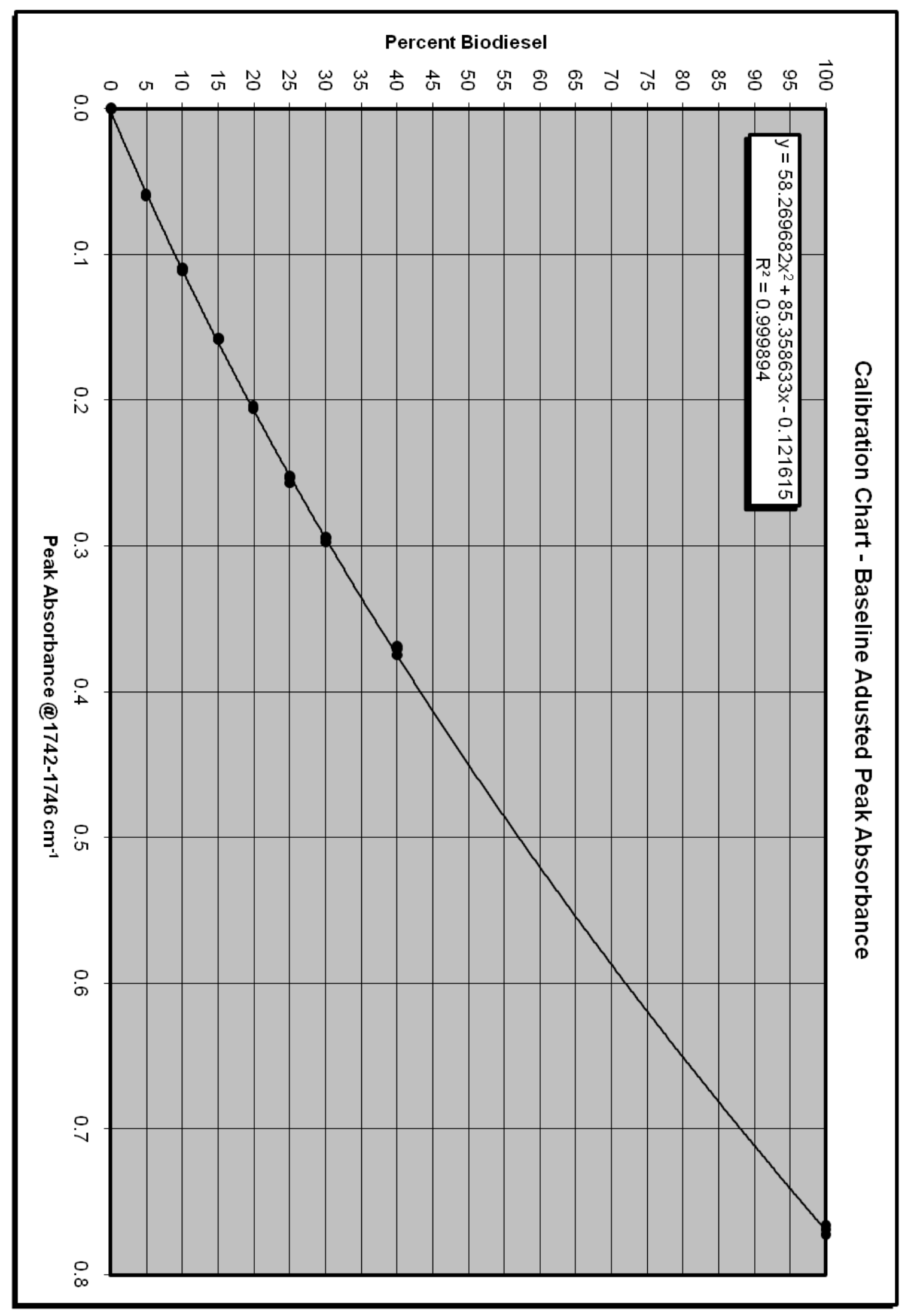



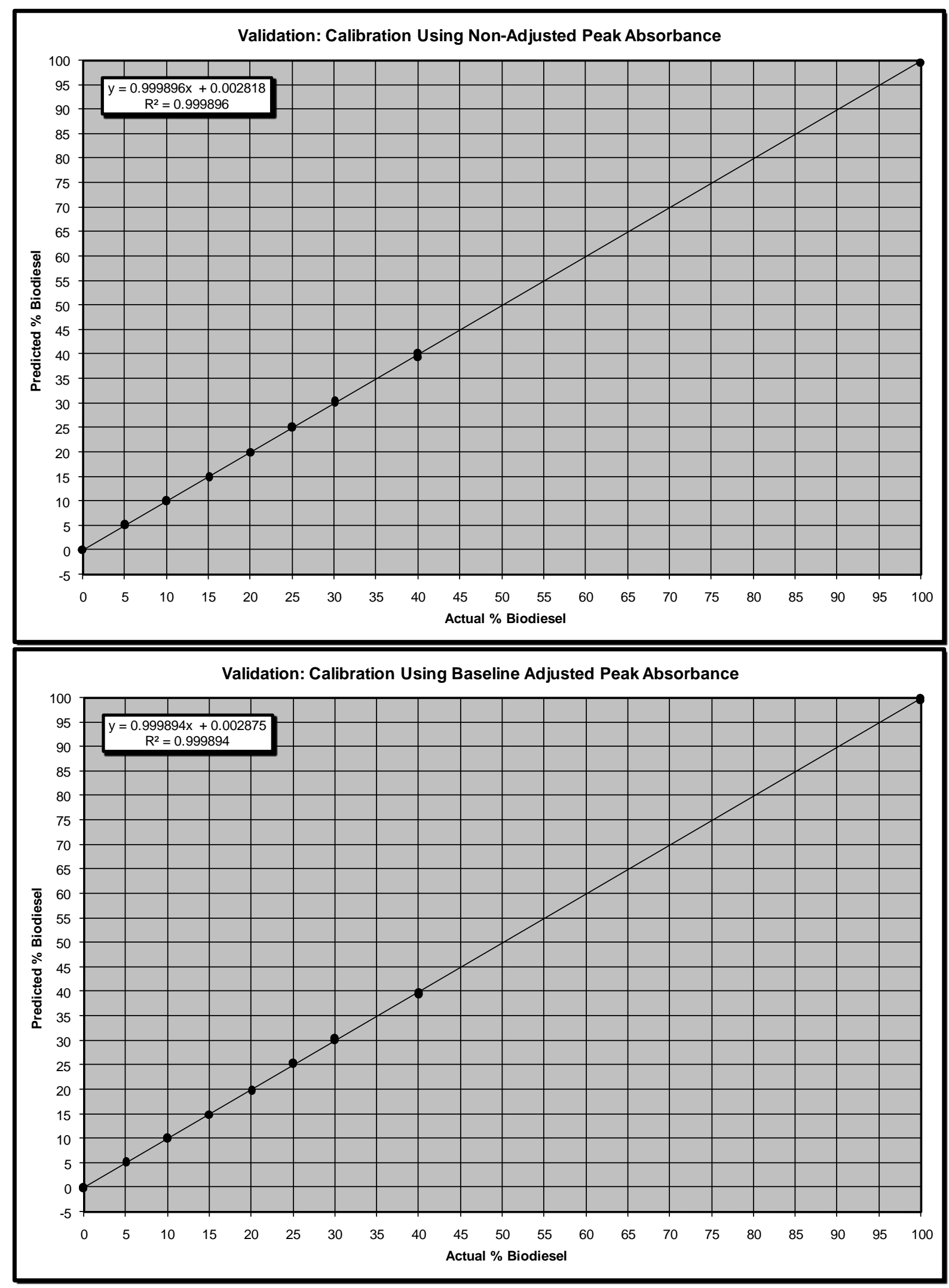
December 20, 2005

Tennessee Valley Authority

Attn: Ralph Boroughs

1110 Market Street, SP-5D

Chattanooga, TN 37402

Mr. Boroughs:

My apologies for the delay in getting results back to you on the samples you shipped November $17^{\text {th }}$ for biodiesel blend determinations. However, from late fall through this early winter we have be swamped with priority investigative and oversight work on a number of pressing issues such as water in gasoline, gasoline octane misrepresentation, methanol in biodiesel, and a number of varied filter clogging issues involving biodiesel blended diesel fuel. As luck would have it, the delay was somewhat fortuitous because of a contamination problem I found with the B100 biodiesel sample you submitted, that probably would not have been recognized had I not had to deal with a biodiesel flashpoint issue that materialized some weeks ago. I will deal with the contamination problem shortly, but for now I turn to the biodiesel blend determinations you requested.

Results were as follows:

- Sample A: $\quad 36.96$ Volume \% Full validation of the quadratic regression calibration

- Sample B:

- Sample C:

- Sample D:

- Sample E:

protocol employed has yet to be accomplished, but 1.87 Volume $\%$ past work indicates uncertainties should range from 20.76 Volume \% about 0.2 vol.\% up to B5, under 0.8 vol. \% through B20, under 1.5 vol\% through B40 and under 3 vol. \%

4.85 Volume $\%$ at B100. Details of the calibration procedure can be 96.95 Volume \% reviewed by viewing the companion Excel workbook file: TVA Biodiesel Blend Calibration.xls. Please note that data for a B50 standard was discarded from the calibration set as an "outlier".

\section{I now return to the unanticipated problem with the biodiesel blend-stock submitted for use as a standard:}

There appeared to be something a bit unusual about the B100 trace file so I compared it, using an overlay plot, with a pair of soy methyl ester sample retains from different plants. It became immediately obvious that there was unusually high absorbance in the spectral trace for your 
B100 at about $1030 \mathrm{~cm}^{-1}$. This would correlate with methanol contamination. I realized this because, as luck would have it, I have recently undertaken a methanol-in-biodiesel quantification project, based on FTIR spectroscopic analysis. Locally, some biodiesel flash point issues have materialized. As you are probably aware, the ASTM D6851 biodiesel specification sets a very high flash point criterion $\left(130^{\circ} \mathrm{C}\right)$, as the test is employed as a surrogate for a direct methanol test. However, there are reproducibility problems with flash point determination at such high temperatures and also there are issues with the appropriateness of the test as a methanol screen when sampling is undertaken down-stream from a production plant.

Therefore, I have recently initiated a project to develop a direct test for methanol contamination of biodiesel by FTIR. The project is still in the pilot phase, but I have acquired a few scans of methanol contamination standards for demonstration purposes. I compared your TVA submitted B100 sample, using an overlay plot, with B100 samples spiked with $5 \%$ and $1 \%$ methanol by volume. Also included was the stock sample used for the methanol spikes. This overlay is depicted in Figure 1.

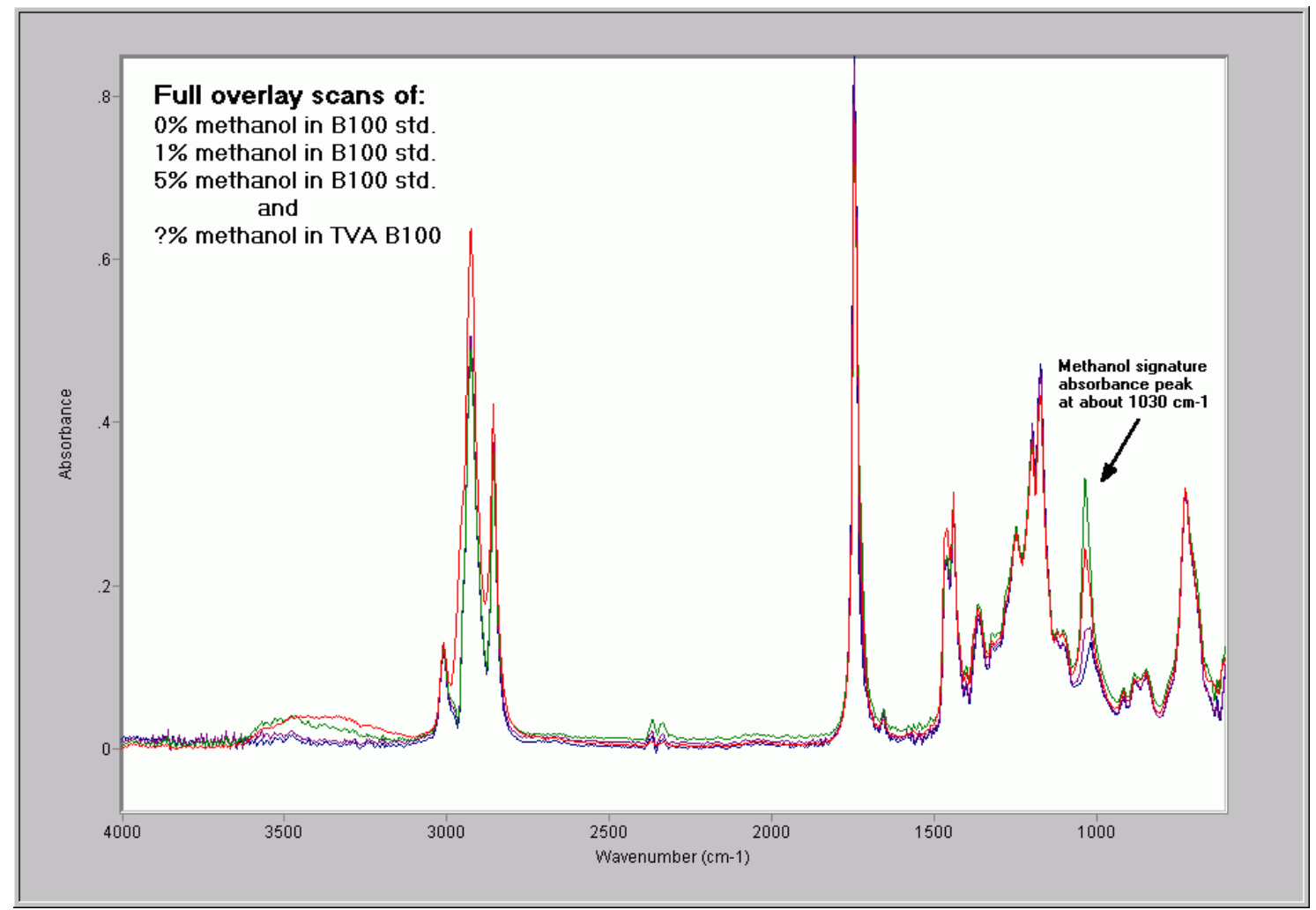

Figure 1. Overlay plot of spectral traces for TVA submitted sample compared with $0 \%, 1 \%$ and $5 \%$ methanol spiked B100 "standards". The "signature" peak for methanol appears at about $1030 \mathrm{~cm}^{-1}$ and is very evident. 
Next, in Figure 2, the region about wavenumber $1030 \mathrm{~cm}^{-1}$ is shown in a zoomed view to facilitate detailed comparison of the spectra.

Clearly, the peak absorbance for the TVA submitted sample lies about midway between the peak absorbencies for the $1 \%$ and $5 \%$ methanol spiked B100 standards. Therefore, it can be concluded that the TVA submitted sample contains roughly $3 \%$ methanol. A more precise estimate could be obtained by using additional interlaying standards, preferably employing them in a calibration protocol using regression or multivariate analysis. One potential problem in developing a low-level methanol in biodiesel calibration is the "native" biodiesel absorbance increase at about $1017 \mathrm{~cm}^{-1}$ wavenumber. The interference of the biodiesel peak is already evident in the $1 \%$ methanol trace. However, the methanol contamination in the TVA submitted B100 is far above the trace amounts anticipated in a method that will hopefully be sensitive to concentrations down to $0.2 \%$ or lower.

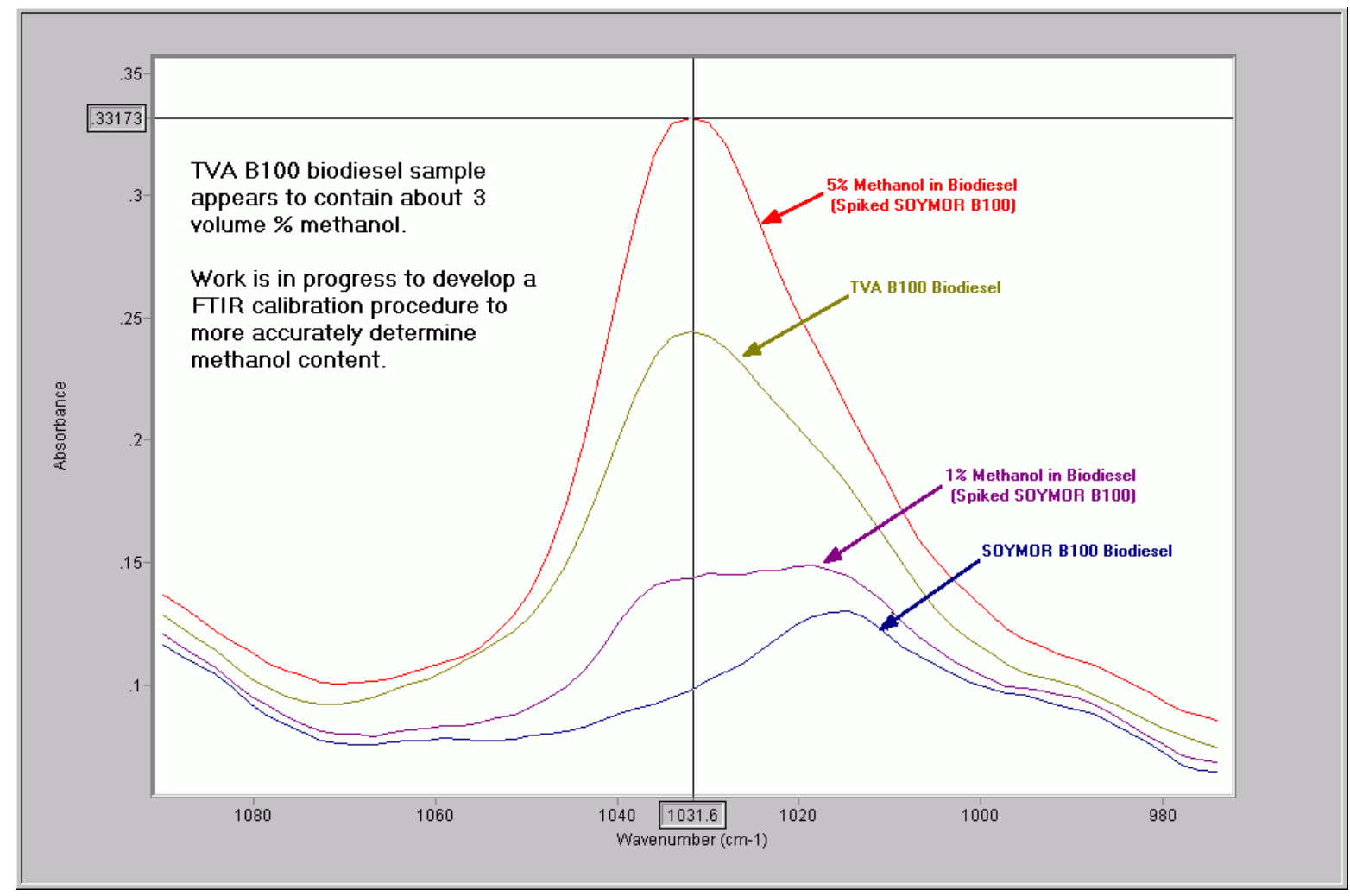

Figure 2. Zoomed "methanol signature region" overlay plot of spectral traces for TVA submitted sample compared with $0 \%, 1 \%$ and $5 \%$ methanol spiked B100 "standards". The contamination in the TVA sample appears to be about 3 vol. \%. 
I was rather surprised, if not shocked, to see such a high level of methanol contamination in the B100 you supplied. The anticipated methanol level associated with the ASTM D6851 flash point specification of $130^{\circ} \mathrm{C}$ is only $0.2 \%$ - with a view to harmonization with the European biodiesel specification.

It should also be noted that a "methanol signature" was clearly evident in the TVA samples identified as $A, C$ and $E$. These were the three highest determined biodiesel blend levels. Assuming that the B100 indeed contains 3\% methanol, at B5 the methanol concentration would be reduced to $3 \times .05=0.15$ vol.\%, which is probably near the limit of detection for this sort of analysis (time and effort will tell).

Again my apologies for the delay in submitting this report, but had I made the blend determinations in a very timely manner, the methanol contamination issue would most likely have been overlooked. See companion paper (in zipped file) Biodiesel - MeOH Detection (051129a).pdf for more information about the methanol detection method project that led to the discovery of the methanol issue with the samples you submitted.

Please feel free to write or call me at 651-296-2990 with any questions, concerns or commentary.

Sincerely,

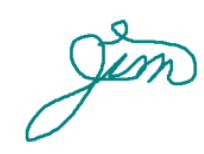

Jim Hedman, Metrologist 


\section{Attachment "B"}

(The following report, which pertains solely to the Prototype SCONOX NOx emissions reduction system which as designed and built for this Project by EmeraChem, LLC., was commissioned by McMinnville Electric System and is therefore incorporated and is made part of this Final Report as submitted. The authors are Steve DeCicco and Lisa Mitchell, EmeraChem, LLC) 


\section{Introduction}

\section{Demonstration Goals}

The ultimate goal of MES' demonstration program is to demonstrate the ability to generate electricity on $100 \%$ renewable fuel source, while maintaining emissions at or lower than nonrenewable sources. This would allow McMinnville Electric System to qualify for TVA's "Green Power Switch" program.

EmeraChem's goal is to demonstrate clean emissions on a large stationary IC engine across all liquid fuel blends. Furthermore, EmeraChem hopes to develop a commercial product for stationary diesel engine applications.

\section{Background}

EmeraChem's NOx adsorber catalysts have been demonstrated on bench scale reactors and on diesel engine exhaust. Long term data on $\mathrm{EMx}^{\mathrm{TM}}$ performance exists from commercial applications on 5-50 MW natural-gas and dual fuel fired turbines demonstrating NOx emissions less than $1 \mathrm{ppm}$ and virtually undetectable $\mathrm{CO}$ and $\mathrm{HC}$ levels. Long term data on $\mathrm{EMx}^{\mathrm{TM}}$ on diesel engines is limited to studies on small, $5-50 \mathrm{~kW}$, diesel engine generator-set test platforms, demonstrating more than $90 \%$ removal of NOx, CO, and $\mathrm{HC}$. This test represents the verification of the performance of the catalyst on the exhaust from a larger scale, 2 MW, stationary diesel engine.

\section{Experiment Design}

\section{Engine Test Platform}

The engine generator-set is Caterpillar 3516B TA diesel engine (see Figure II-1) coupled to a Caterpillar SR4B generator and has a 4.46 g/bhp-hr NOx emission rating. The exhaust flow is assumed to be 5,636 scfm (wet, at $32^{\circ} \mathrm{F}$ and $29.98^{\prime \prime} \mathrm{Hg}$ ) as predicted by Caterpillar. The gen-set is attached to the electric grid, and is at full load at all times. The engine was run for approximately 16 hours prior to the start of testing to break in the engine and ensure sealing of all exhaust system components.

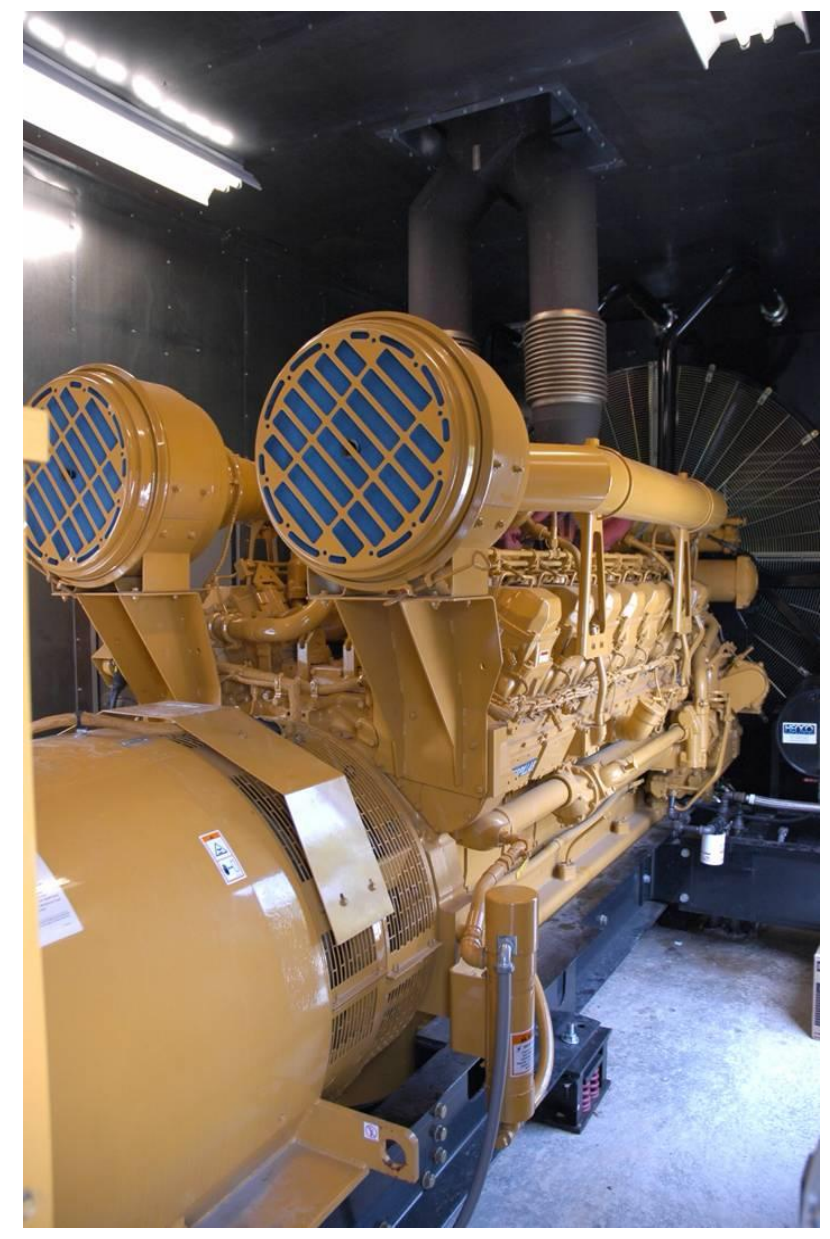

Figure II-1 


\section{Fuel and Lubricants}

Various blends of ultra-low sulfur diesel (ULSD) and $100 \%$ soybean based biodiesel (B100) fuels were used to fuel both the engine and the plasma reformer for regen gas generation. The fuels were mixed manually in the fuel day tank. The ratios of ULSD to B100 fuel were chosen to represent various fuel blends commercially available. The sulfur content of the ULSD was 15 ppm, and 0 ppm for the biodiesel.

\section{Testing Protocol}

Prior to the emissions testing, the plasma reformer operation was optimized to develop a startup procedure and confirm sufficient hydrogen production. The catalyst modules were not installed prior to the initial day of ULSD fuel testing.

The catalyst was operated with a cycle time of 4 minutes for early testing, and revised to 3.5 minutes before B20 testing began.

After the 4-hour tests on each of the various fuel blends, the engine was run on B100 for the remainder of the testing. The catalyst was washed after each day of testing to eliminate the effects of sulfur accumulation from test to test.

\section{Catalyst System}

The catalyst system is a dual chamber reactor with inlet exhaust isolation valves controlling the direction of exhaust flow (see Figure II-2). The exhaust isolation valves used a common actuator and were linked together to assure that the engine exhaust would always have an open flow path and never be restricted. Regeneration was accomplished by generating a regen gas from the parent fuel using a plasma reformer. The regen gas was injected in a "forward-flow" geometry (the regen gas flowed in the exhaust flow direction).

The catalyst system was mounted $20 \mathrm{ft}$ from the gen-set exhaust as shown in Figure II-3; thus, allowing enough thermal loss in the uninsulated exhaust pipe to bring the catalyst operating temperature down to an operating temperature of $750^{\circ} \mathrm{F}$. The gen-set was enclosed in a sound-reducing housing and catalyst system was installed outside with no

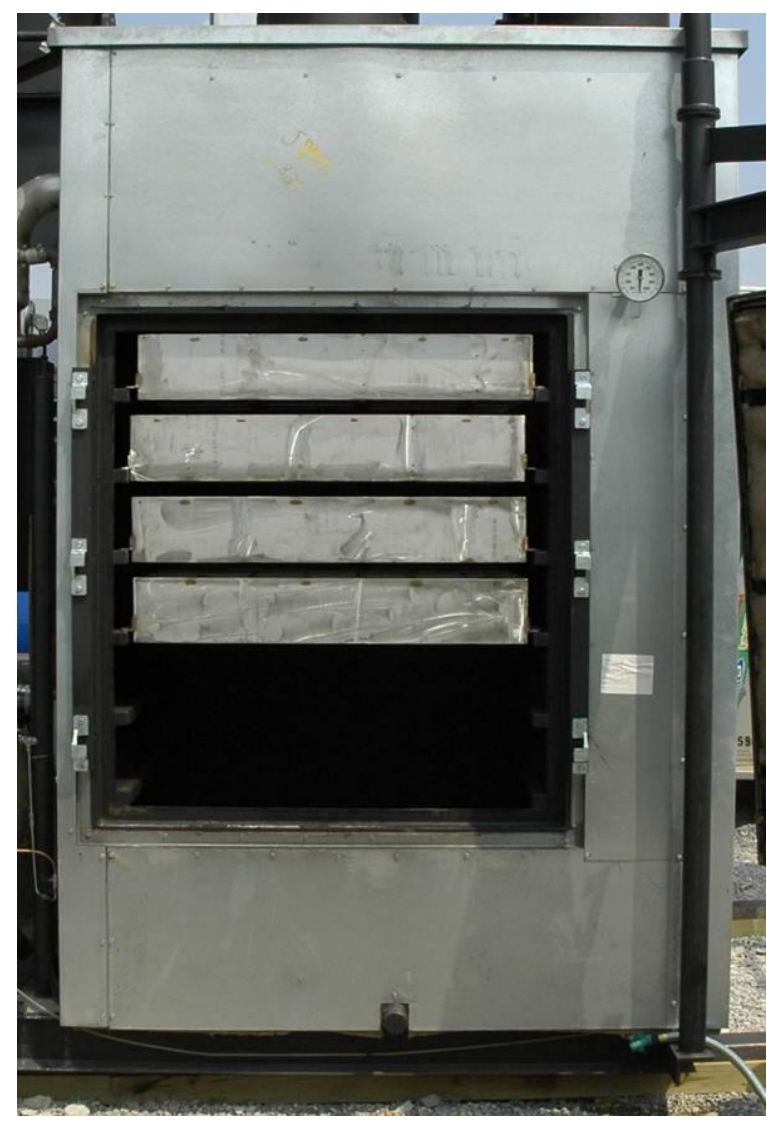

Figure II-2 
additional rain protection.

\section{Catalysts}

The catalyst (see Figure II-4) used for the test was standard EMx, utilizing $\mathrm{K}_{2} \mathrm{CO}_{3}$ sorber on a barium-alumina washcoat. The catalysts were on $200 \mathrm{cpsi}$ cordierite substrates. Four rows of EMx catalyst were installed in each chamber, with two $18^{\prime \prime} \times 42$ " $\times 6$ " modules per row. The total catalyst volume for each catalyst chamber was $21 \mathrm{ft}^{3}$. Sulfur management was handled by frequent washing of the catalyst, no ESx catalyst was installed.

The EMx catalyst works by simultaneously oxidizing $\mathrm{CO}$ to $\mathrm{CO}_{2}$, VOCs to $\mathrm{CO}_{2}$ and $\mathrm{H}_{2} \mathrm{O}$, NO to $\mathrm{NO}_{2}$, and then absorbing $\mathrm{NO}_{2}$ onto its surface through the use of an alkaline metal solution absorber coating such as potassium carbonate. These

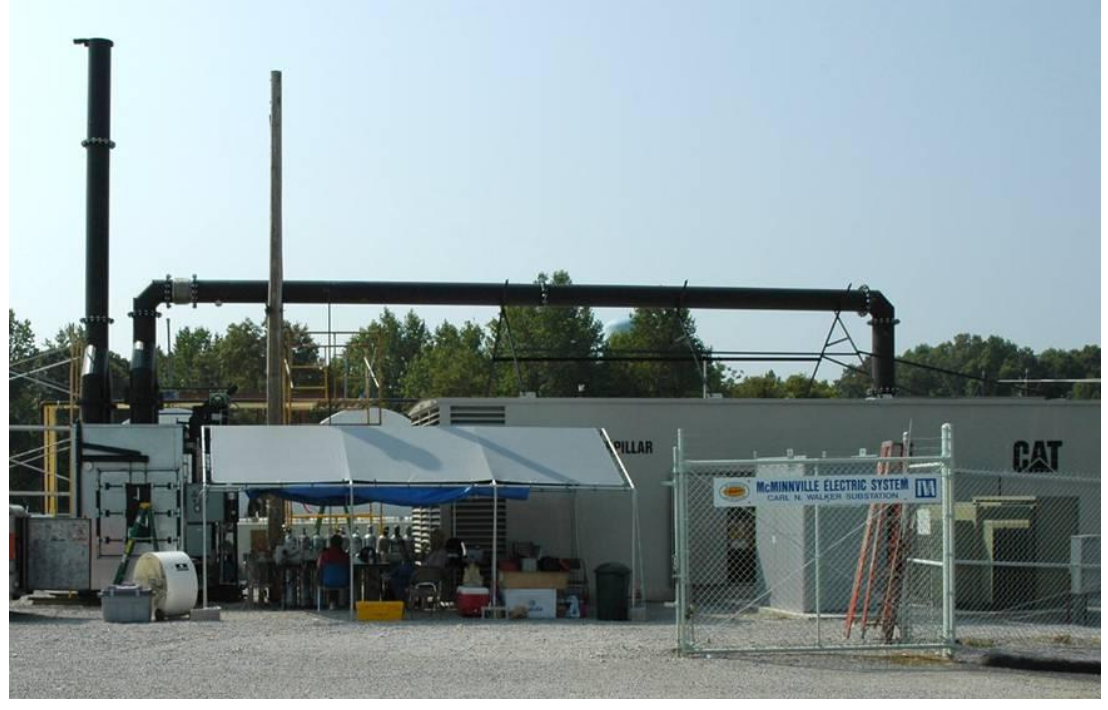

Figure II-3

reactions are shown below, and are referred to as the "Oxidation/Absorption Cycle".

$$
\begin{gathered}
\mathrm{CO}+1 / 2 \mathrm{O}_{2} \rightarrow \mathrm{CO}_{2} \\
\mathrm{CH}_{2} \mathrm{O}+\mathrm{O}_{2} \rightarrow \mathrm{CO}_{2}+\mathrm{H}_{2} \mathrm{O} \\
\mathrm{NO}+1 / 2 \mathrm{O}_{2} \rightarrow \mathrm{NO}_{2} \\
2 \mathrm{NO}_{2}+\mathrm{K}_{2} \mathrm{CO}_{3} \rightarrow \mathrm{CO}_{2}+\mathrm{KNO}_{2}+\mathrm{KNO}_{3} \\
2 \mathrm{NO}_{2}+\mathrm{Ba}_{2} \mathrm{CO}_{3} \rightarrow \mathrm{CO}_{2}+\mathrm{BaNO}_{2}+\mathrm{BaNO}_{3}
\end{gathered}
$$

The small quantity of $\mathrm{CO}_{2}$ in the above reactions exhausts up the stack. Note that during this cycle, the potassium carbonate coating quantitatively and chemically bonds and traps the nitrogen oxides to form potassium nitrites and nitrates, which are then present on the surface of the catalyst. Before the potassium

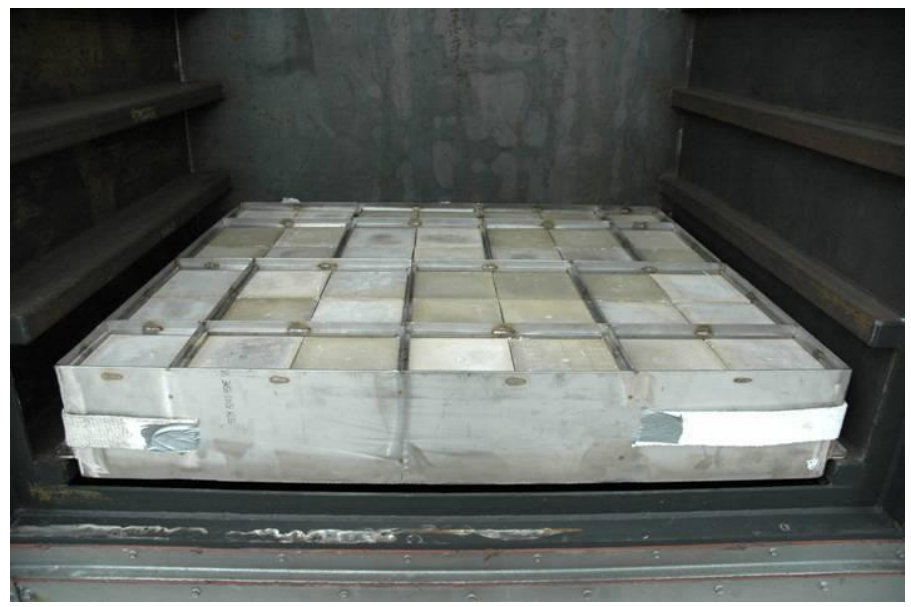


carbonate on the surface of the catalyst becomes saturated with nitrogen oxides, the catalyst enters the regeneration cycle.

The regeneration of the EMx catalyst, one of the features that makes the system so unique, is accomplished by passing a reducing gas across the surface of the catalyst in the absence of oxygen. The reductants in the regeneration gas (hydrogen and carbon monoxide) react with nitrites and nitrates to form water, elemental nitrogen, and potassium hydroxide. Carbon dioxide in the engine exhaust reacts with potassium hydroxide to form potassium carbonate, which is the absorber coating that was on the surface of the catalyst before the oxidation/absorption cycle began. This cycle is referred to as the "Regeneration Cycle", and the relevant reaction is shown below.

$$
\mathrm{KNO}_{2}+\mathrm{KNO}_{3}+4 \mathrm{H}_{2}+\mathrm{CO}_{2} \rightarrow \mathrm{K}_{2} \mathrm{CO}_{3}+4 \mathrm{H}_{2} \mathrm{O}+\mathrm{N}_{2}
$$

Water (as steam) and elemental nitrogen are exhausted up the stack instead of NOx, and potassium carbonate is once again present on the surface of the catalyst, allowing the oxidation/absorption cycle to begin again. There is not a net gain or net loss of potassium carbonate after the oxidation/absorption and regeneration cycle.

\section{Regen System}

To qualify for the "Green Power Switch", all energy sources utilized must be $100 \%$ renewable. To satisfy this requirement, a GlidArc plasma reformer fabricated by ECP of France was chosen. This unit had been demonstrated on many fuels including diesel, gasoline, natural gas, propane, canola, glycerol, and sugar water. The reformer was sized to mix approximately $3.5 \mathrm{gal} / \mathrm{hr}$ of biodiesel with $25 \mathrm{scfm}$ of air and spray the mixture into an electric arc. The fuel penalty was $2.7 \%$. When properly adjusted, the resulting regen gas is $18 \% \mathrm{H}_{2}, 18 \% \mathrm{CO}, \mathrm{N}_{2}, \mathrm{H}_{2} \mathrm{O}$, and $\mathrm{CO}_{2}$. (For more information on GlidArc technology, see Attachment " $C$ " and " $D$ ", specifically the sections referring to McMinnville Electric System)

The GlidArc reformer (see Figure II-5 and Figure II-6) is a cold plasmaassisted reformer that produces hydrogen and carbon monoxide through partial oxidation of liquid or gaseous fuels. A rich mixture of fuel, air, and water are sprayed through a low current, high-voltage gliding arc. The fuel is ignited by the arc and hot internals of the reformer. Excess fuel is converted to hydrogen and carbon monoxide in the in the activated refractory of the post-plasma zone. The entire reformer is surrounded by an annular pre-heat zone to pre-heat the air supply. The outside of the reformer is wrapped in ceramic wool insulation for safety.

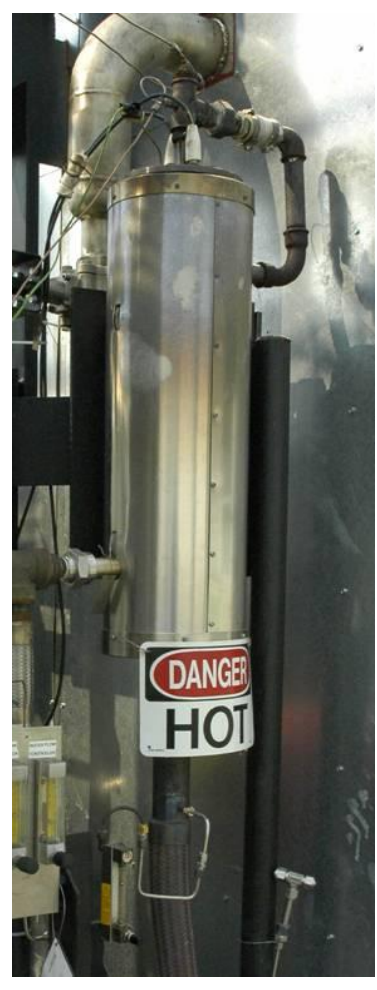

Figure II-5 

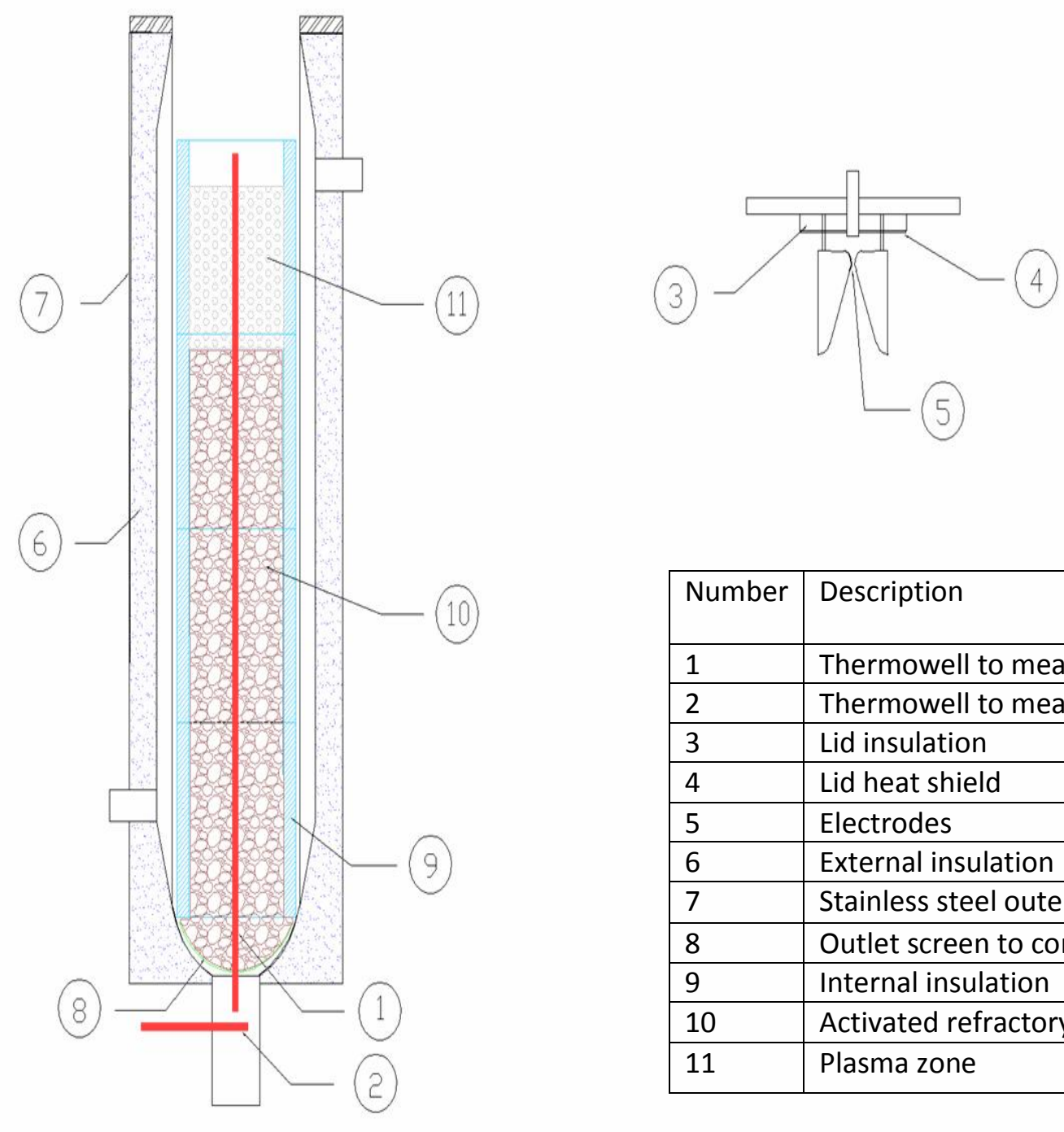

\begin{tabular}{|l|l|}
\hline Number & Description \\
\hline 1 & Thermowell to measure internal temps \\
\hline 2 & Thermowell to measure outlet temp \\
\hline 3 & Lid insulation \\
\hline 4 & Lid heat shield \\
\hline 5 & Electrodes \\
\hline 6 & External insulation \\
\hline 7 & Stainless steel outer wrap \\
\hline 8 & Outlet screen to contain refractory \\
\hline 9 & Internal insulation \\
\hline 10 & Activated refractory-post-plasma zone \\
\hline 11 & Plasma zone \\
\hline
\end{tabular}

Figure II-6 
For partial oxidation, the reforming temperature must be maintained between $800{ }^{\circ} \mathrm{C}$ and 1000 ㅇ $\mathrm{C}$ as shown in Figure II-7. This temperature is maintained through the addition of air and/or steam. Adding air alone increases the temperature of the reaction, and can lead to damaging the reformer internals. Adding steam alone decreases the temperature and can lead to soot formation. By adding the appropriate mixture of air and steam, a stable reformation temperature can be achieved, leading to the formation of maximum hydrogen.

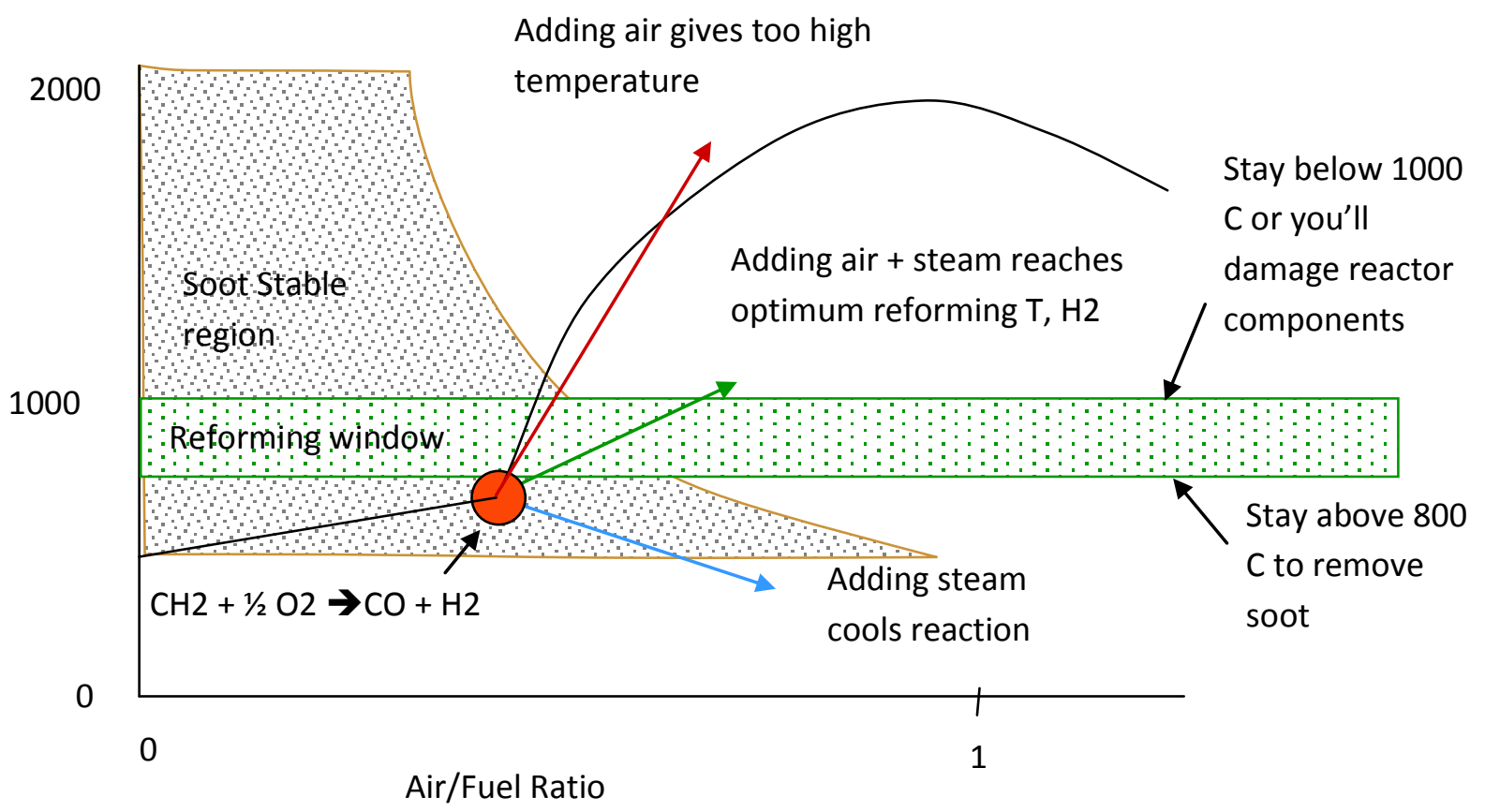

Figure II-7 


\section{Data Acquisition}

The data acquisition system for the test included a gas chromatograph, a portable combustion analyzer, and a portable hydrogen analyzer as shown in Figure II-8. Exhaust was sampled from four positions:

\section{1. "engine out" - upstream of the catalyst system}

2. "catalyst out" -

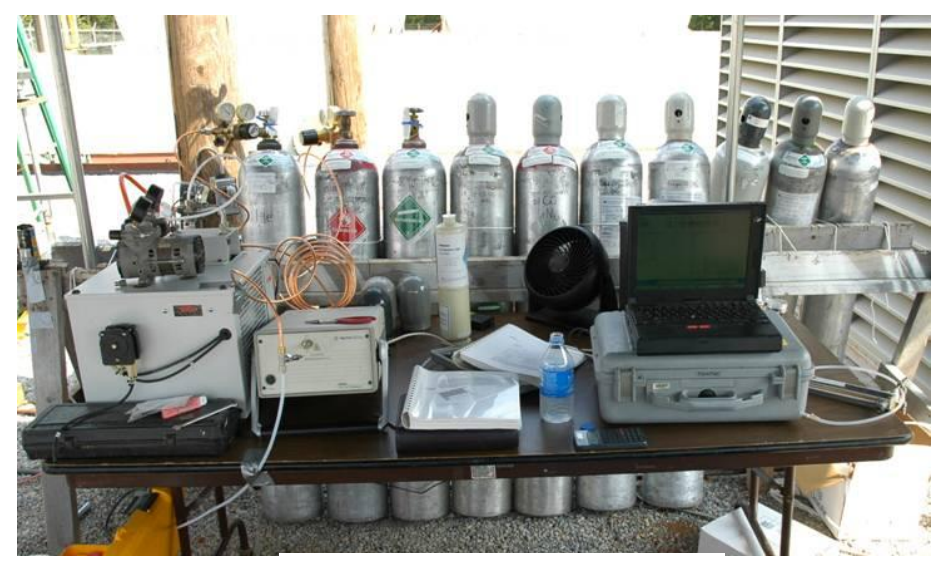

Figure II-8 downstream of the catalyst system (inside the catalyst chamber, below the last module)

3. "system out) - downstream of the union joining the exhaust from both reactor chambers, as in Figure II-9

4. "regen inlet" - in the regen gas supply pipe

Dry gas from the chiller was analyzed with a gas chromatograph and a $\mathrm{H}_{2}$ analyzer. The portable combustion analyzer was used to analyze the exhaust gas directly at the sample ports.

Temperature measurements were made upstream of the catalyst system. In addition, the catalyst temperature in each chamber was measured at one location downstream of the catalyst in each chamber. A manometer was used to sample the exhaust pressure upstream and downstream of the catalyst system.

\section{Original Test Plan}

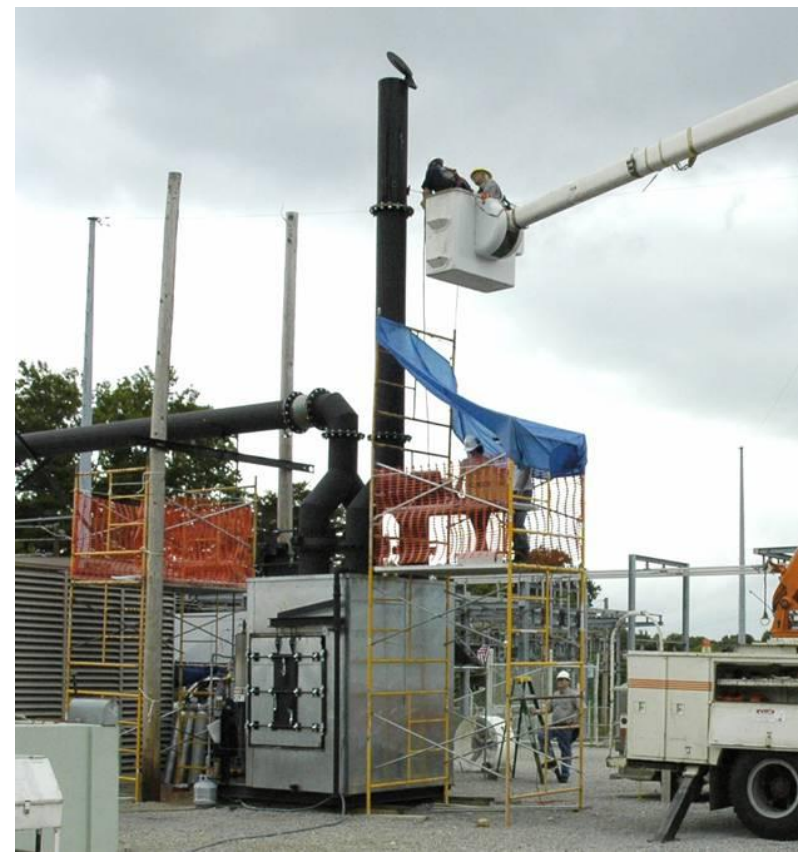

Figure II-9

The installation and commissioning of the components and the system was planned for $6 / 28 / 05$ through $7 / 3 / 05$. During this time, the following steps were planned:

1. Install plasma reformer and connect engine exhaust to the EMx emission control system 
2. Start the plasma reformer and optimize operation

3. Run the plasma reformer for 24 hour to verify long-term stability

4. Install the EMx catalyst

5. Start the engine and optimize the function of complete system

6. Verify oxygen depletion in the chamber during regen, as an indication that regen gas was reaching all of the modules

7. Verify sufficient mass flow rate of hydrogen content in the regen gas for complete regeneration of the modules

After commissioning the system, we would begin a series of short term tests. Each test would last 4 hours, with sampling beginning 2 hours into the test. After each test, the catalyst would be washed to re-establish the baseline. The fuels tested would be ULSD, $2 \%$ biodiesel, $5 \%$ biodiesel, $20 \%$ biodiesel, $50 \%$ biodiesel, and $100 \%$ biodiesel.

Long-term test would follow, using only $100 \%$ biodiesel. The test would last 1500 hours, with stops at 500,1000, and 1500 hours for Caterpillar to inspect the engine for wear and inspect the fuel filters and injectors for blockage.

\section{Installation and Commissioning}

Table III-1 summarizes the plasma reformer runs during installation and commissioning. The engine was not operating and the EMx catalyst was not installed until just before run 9. Start-up issues such as overheating, soot built-up and insufficient supplies of ULSD prevented a 24 hour run of the plasma reformer prior to EMx system start-up.

\begin{tabular}{|c|c|c|c|c|c|}
\hline Run & Date & Fuel & Duration & Reason Stopped & Comments \\
\hline 1 & $6 / 29 / 05$ & ULSD & $0: 24$ & End of day & \\
\hline 2 & $6 / 30 / 05$ & ULSD & $1: 29$ & $\begin{array}{l}\text { Flare impinging on } \\
\text { isolation valve actuator }\end{array}$ & \\
\hline 3 & $6 / 30 / 05$ & ULSD & $1: 33$ & End of day & $\begin{array}{l}13 \% \mathrm{H} 2 \text {, no soot, full air and fuel flow } \\
\text { for } 30 \text { minutes }\end{array}$ \\
\hline 4 & $7 / 1 / 05$ & ULSD & 1:09 & Storm/lightening & $\begin{array}{l}18 \% \mathrm{H} 2 \text {, no soot, invisible flame } \mathrm{H} 2 \\
\text { flow }-0.924 \mathrm{~kg} / \mathrm{hr} \text {, Total regen gas } \\
\text { flow }-35.1 \mathrm{scfm}\end{array}$ \\
\hline 5 & $7 / 1 / 05$ & ULSD & $0: 25$ & $\begin{array}{l}\text { Reformer thermowell } \\
\text { breached }\end{array}$ & $\begin{array}{l}\text { Fuel valve closed, mixture went lean, } \\
\text { max temp } \sim 1271^{\circ} \mathrm{C}\end{array}$ \\
\hline 6 & $7 / 2 / 05$ & ULSD & $1: 51$ & End of day & $\begin{array}{l}\text { New thermowell, } \mathrm{H} 2-15.2 \%-18.5 \% \text {, } \\
\text { CO 18\% }\end{array}$ \\
\hline 7 & $7 / 3 / 05$ & B100 & $0: 55$ & Storm/lightening & \\
\hline
\end{tabular}




\begin{tabular}{|l|l|l|l|l|l|}
\hline 8 & $7 / 3 / 05$ & B100 & $2: 25$ & Test complete & $\begin{array}{l}\text { Changed to larger fuel and water } \\
\text { lines, } \mathrm{H} 2-21 \%-23.5 \%, \mathrm{CO} \sim 21 \%\end{array}$ \\
\hline 9 & $7 / 3 / 05$ & USLFO & $1: 00$ & End of day & $\begin{array}{l}\text { Initial loading of catalyst. Closed vent } \\
\text { - Cycling regen gas through EMx } \\
\text { (engine off) }\end{array}$ \\
\hline 10 & $7 / 4 / 05$ & ULSD & $4: 33$ & Decreasing air flow & $\begin{array}{l}\text { Electrodes, Ni balls \& thermowell in } \\
\text { good condition }\end{array}$ \\
\hline 11 & $7 / 5 / 05$ & ULSD & $7: 17$ & $\begin{array}{l}\text { Decreasing air flow, } \\
\text { concerned about soot } \\
\text { formation }\end{array}$ & $\begin{array}{l}\text { Post-run inspection revealed heavy } \\
\text { carbon buildup, some fusing of } \\
\text { catalyst media, some Ni balls fused }\end{array}$ \\
\hline
\end{tabular}

Table III-1

Figure III-1 shows the increase in the chamber temperature (with catalyst installed) during startup as well as the untreated engine $\mathrm{CO}$ and NOx emissions during start-up. Both the temperature and emissions are stabilized in less than 1 hour.

\section{System Temperatures During Startup}

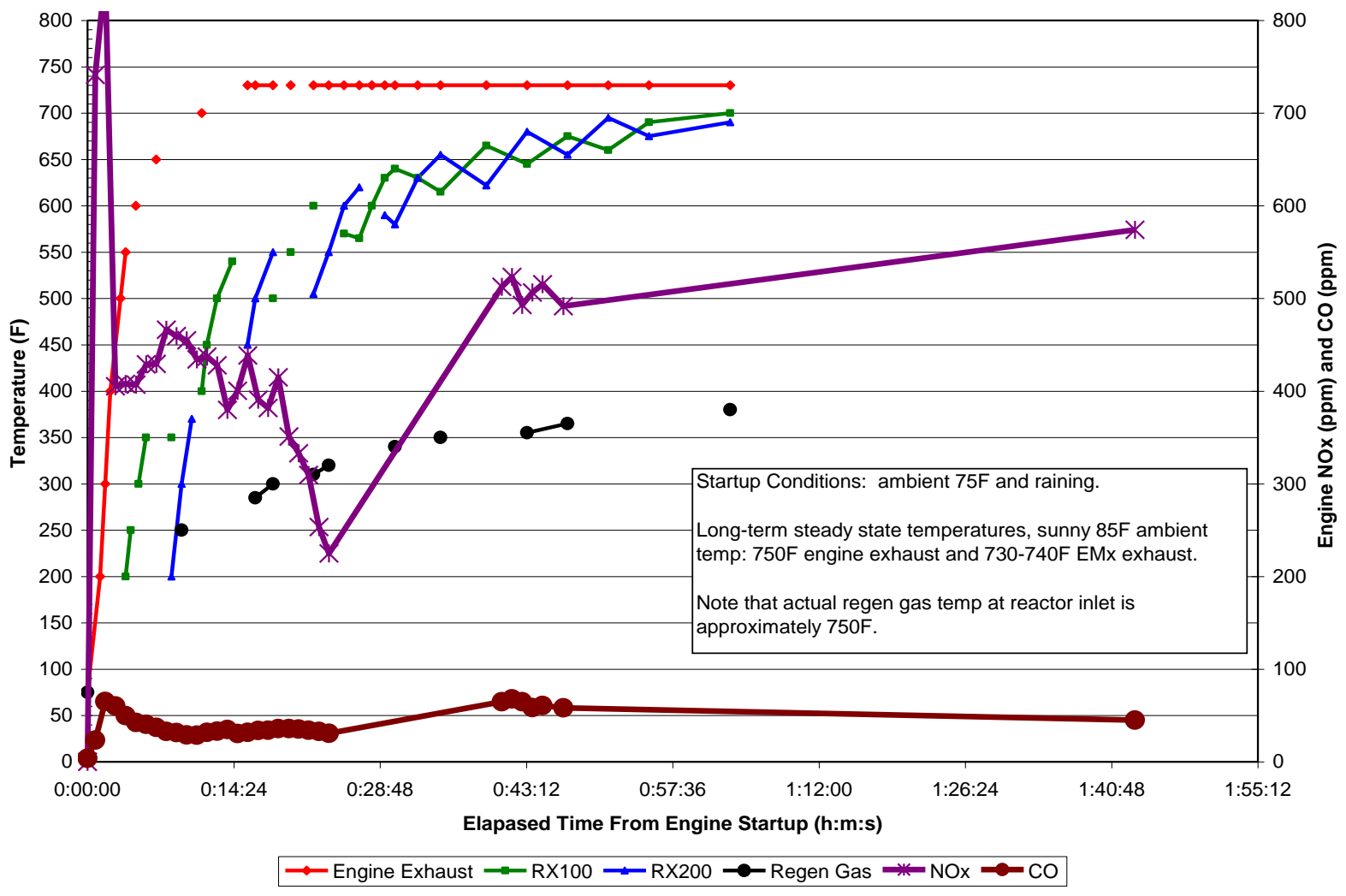

Figure III-1 
Figure III-2 shows the oxygen depletion in both chambers measured approximately 1 foot below (downstream) of the last catalyst module. Chamber RX100 is slower to respond and is not reaching as low of a level of oxygen concentration as chamber RX200. This could indicate a small leak in the isolation valve (allowing engine exhaust to leak into the chamber during regen) or a leak in the regen gas supply line (lowering the flow rate of regen gas into the chamber).

EMx Outlet - Oxygen Depletion ULSD - 7/5/05

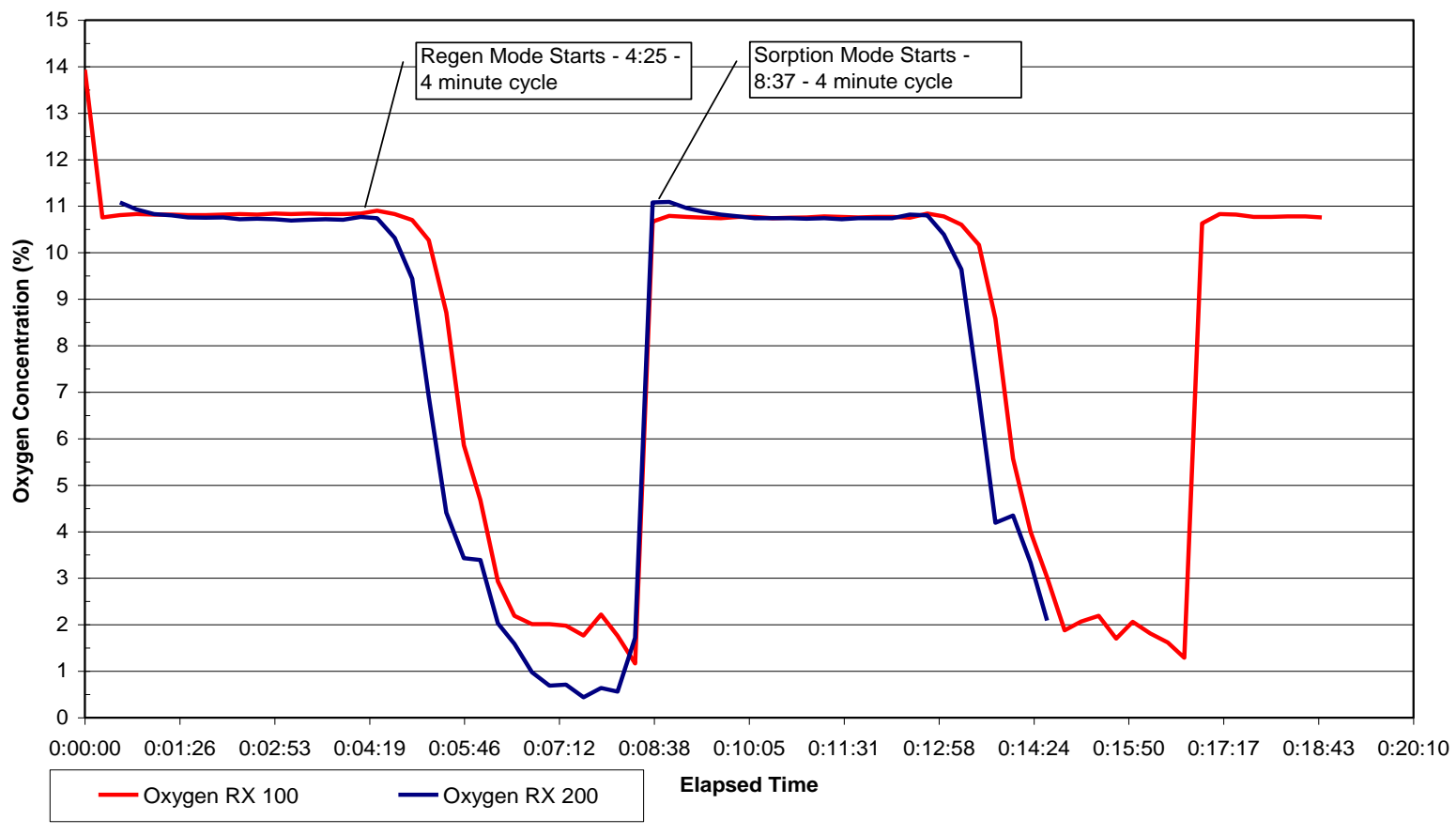

Figure III-2 
Figure III-3 shows the NOx concentration in each chamber below the last EMx module throughout the cycle on one of the commissioning runs using ULSD. These measurements were not simultaneous, but were overlaid to represent the same point in the sorption/regen cycle. These values indicate the concentration in ppm of NOx in the reactor chamber downstream of the catalyst and have not been normalized for flow rates. (During regen, the concentration of NOx was high, but the flow rate was very low - approximately $0.7 \%$ of engine flow, so the effect that it had at the stack was very low.) Chamber RX200 is capturing more NOx than Chamber RX 100. This could be caused by lower NOx sorption capacity due to insufficient regeneration or by untreated exhaust leakage past the catalyst modules in this chamber.

\section{EMx Outlet - NOx Levels \\ ULSD - 7/5/05}

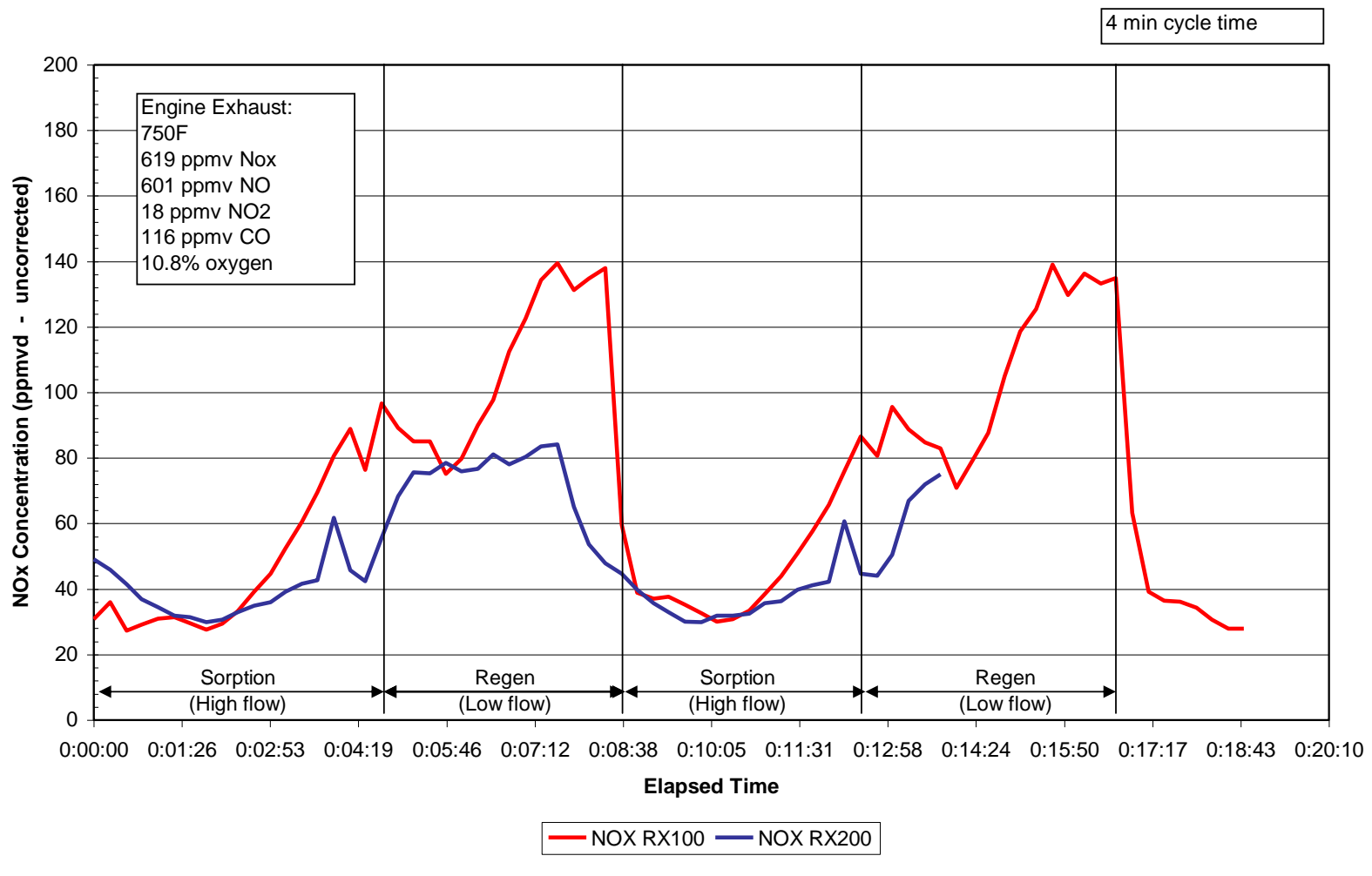

Figure III-3 
Figure III-4 shows the $\mathrm{CO}$ concentration in each chamber below (downstream of) the last EMx module throughout the cycle. These measurements were not simultaneous, but were overlaid to represent the same point in the sorption/regen cycle. These values indicate the concentration in ppm of $\mathrm{CO}$ in the reactor chamber downstream of the catalyst and have not been normalized for flow rates. (During regen, the concentration of $\mathrm{CO}$ was high, but the flow rate was very low - approximately $0.7 \%$ of engine flow, so the effect that it had at the stack was very low.) The slow drop in $\mathrm{CO}$ concentration during later sorption cycles represents the slow recovery of the analyzer after exposure to very high concentrations of $\mathrm{CO}$, and does not represent actual $\mathrm{CO}$ outlet concentrations during sorption. The first sorption cycle is indicative of actual CO outlet concentrations.

Chamber RX100 is releasing much less CO than chamber RX200 during regeneration. This seems to indicate the chamber RX100 is not getting sufficient regeneration, therefore more of the $\mathrm{CO}$ is getting used as the reducing agent to regenerate the catalyst.

\section{EMx Outlet - CO Levels \\ ULSD - 7/5/05}

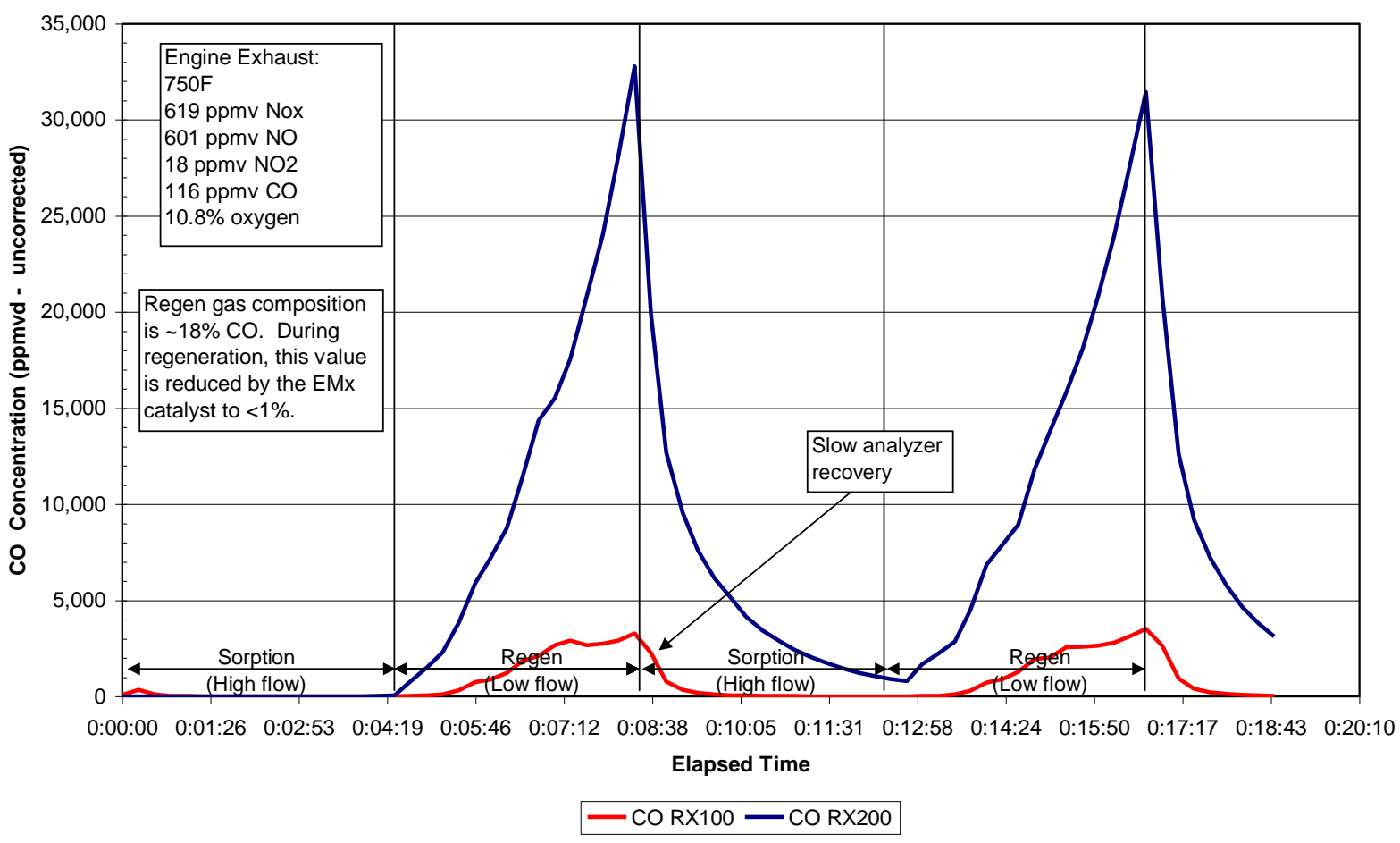

Figure III-4 
Figure III-5 shows the results of the NOx capacity test run on chamber RX100. Earlier, observations were made that indicate that chamber RX100 is not achieving full regeneration:

1. Figure III-2 shows that the concentration of oxygen in chamber RX100 is getting reduced slower than in chamber RX200

2. Figure III-2 also shows that the minimum concentration of oxygen achieved in chamber RX100 is $1-2 \%$, which is higher than chamber RX200.

3. Figure III-3 shows that chamber RX100 has a higher NOx outlet concentration during sorption than chamber RX200.

4. Figure III-4 shows that chamber RX100 has a lower $\mathrm{CO}$ outlet concentration during regeneration than chamber RX200.

5. We later learned that a significant amount of untreated engine exhaust was leaking around the catalyst and influencing the outlet NOx values.

All of these observations indicate that the catalyst in chamber RX100 is not performing as well as it could be. The regen gas is displacing the exhaust gas at a slower rate and does not appear to be fully displacing the exhaust gas during the regen cycle. This chamber is relying on the CO in the regen gas to regenerate the catalyst. The catalyst in chamber RX100 is not performing as well as the catalyst in RX200. The actual sorption capacity of EMx catalyst under these conditions is therefore higher than this graph would indicate. This data SHOULD NOT be used as a representation of the maximum capacity of EMx catalyst at this temperature and space velocity.

\section{EMx NOx Capacity Test \\ RX100 Outlet \\ 7hr ULSD - 7/5/05}

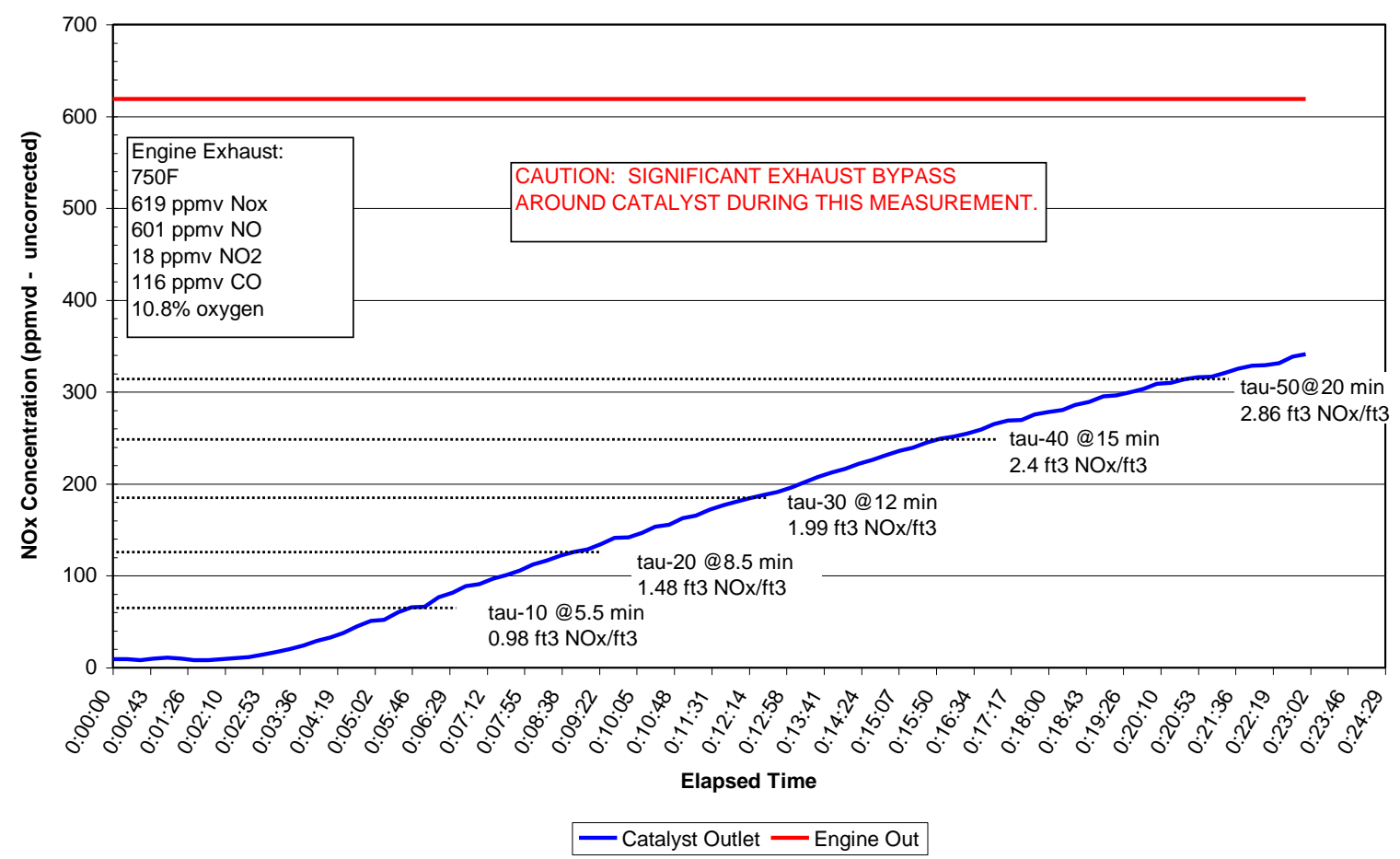

Figure III-5 
Figure III-6 shows the long term CO emissions during the NOx capacity test. The CO outlet slightly increases over the duration of the test. This confirms that the oxidation performance of the catalyst is virtually unaffected by the level of saturation of the NOx sorbent.

\section{CO Performance Test \\ RX100 Outlet \\ 7hr ULSD - 7/5/05}

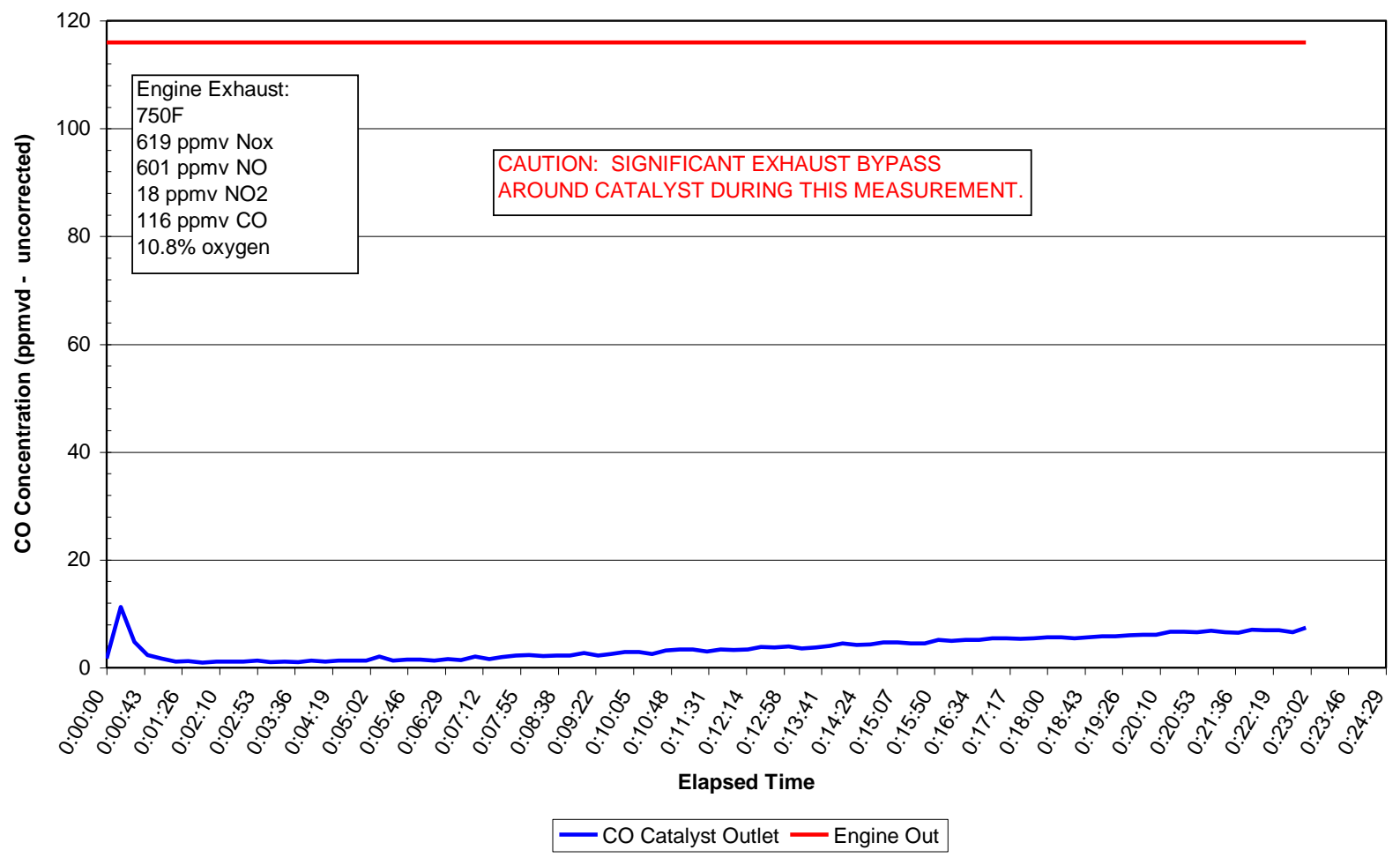

Figure III-6 


\section{Short Term Fuel Blend Testing}

\section{ULSD Test}

Figure IV-1 shows the engine emissions of NOx and CO when the engine is running ultra-low sulfur diesel as fuel. Figure IV-2 shows the catalyst outlet emissions measured in the common exhaust stack for both reactor chambers. The measurements combine the treated engine exhaust from the chamber in absorption mode with the spent regen gas leaving the chamber in regeneration mode. The NOx removal for both chambers averages $80 \%$. We later learned that a significant amount of untreated engine exhaust was leaking around the catalyst and influencing the outlet NOx values. The NOx emissions for RX 100 are higher than those for RX 200 as observed during installation and commissioning. The CO spikes are due to the high CO concentration regeneration gas being swept in a plug flow from the chamber that was in regeneration. The higher CO spike is from regeneration on chamber RX 200, as observed during installation and commissioning.

Figure IV-3 shows the CO removal if we remove the effects of the $\mathrm{CO}$ in the regen gas. This would indicate that a CO removal efficiency of $95.5 \%$ would have been measured if a shift reactor were added to remove the $\mathrm{CO}$ from the regen gas. This $\mathrm{CO}$ removal efficiency is low for an oxidation catalyst with this level of precious metal loading when operated at $750^{\circ} \mathrm{F}$ at this gas hourly space velocity. This low oxidation performance indicates exhaust gas bypass around the catalyst.

The pressure drop from the engine exhaust pipe ahead of the reactor to just below the catalyst (during sorption) was measured to be $16.2^{\prime \prime} \mathrm{H}_{2} \mathrm{O}$. This includes pressure drop through the elbows, the open isolation valve, the perforated diffuser plate, the catalyst, the $180^{\circ}$ turn in the reactor, and the union joining the two reactor exhaust stacks.

For this test, the plasma reformer was run for a total of 10 hours, 20 minutes. The air flow remained steady for the run, ranging from $20.7 \mathrm{scfm}$ at 13:20 to 19.8 at 19:50. The regen gas was composed of $19.6 \%$ hydrogen, $18.7 \%$ carbon monoxide, $54.5 \%$ nitrogen, $1.6 \%$ methane, and unmeasured concentrations of carbon dioxide and water vapor.

After the ULSD fuel blend test, the catalyst was chemically washed to remove any sulfur and any other masking agents that may have accumulated on the catalyst. The modules were still slightly damp when they were re-installed into the chamber. 
Engine Exhaust Characteristics

ULSD - 7/6/05

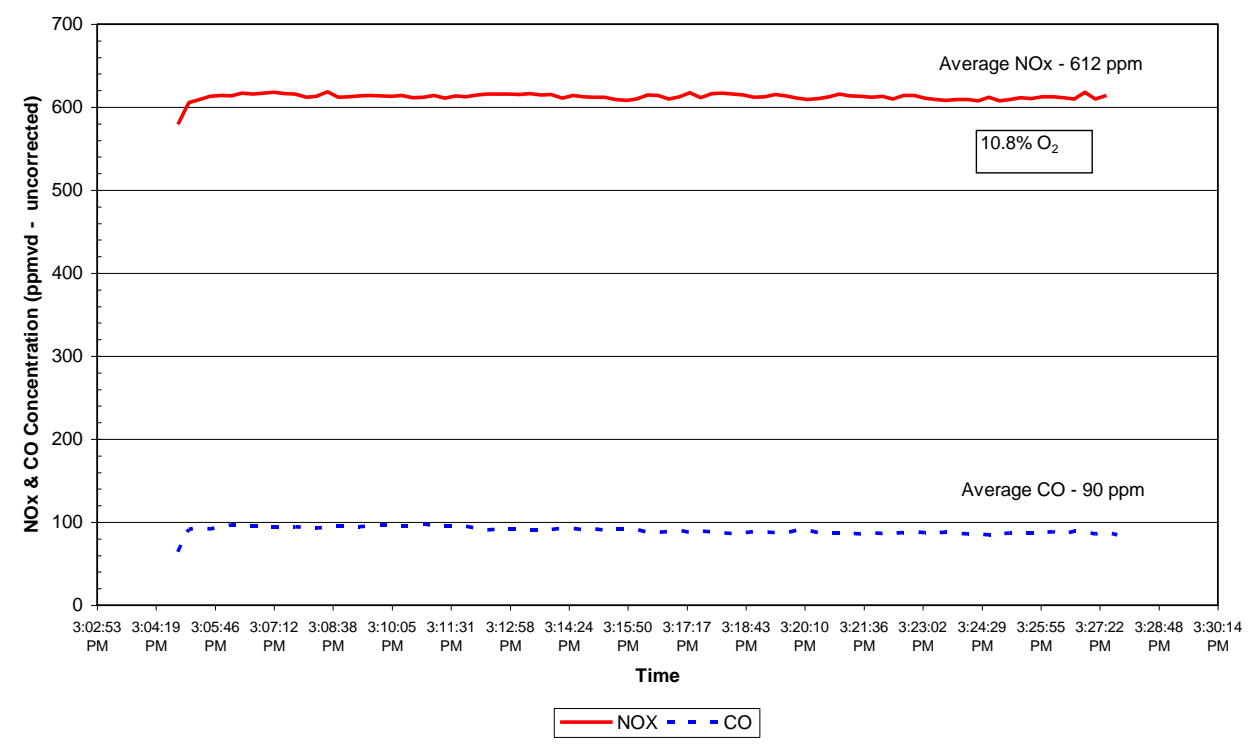

Figure IV-1

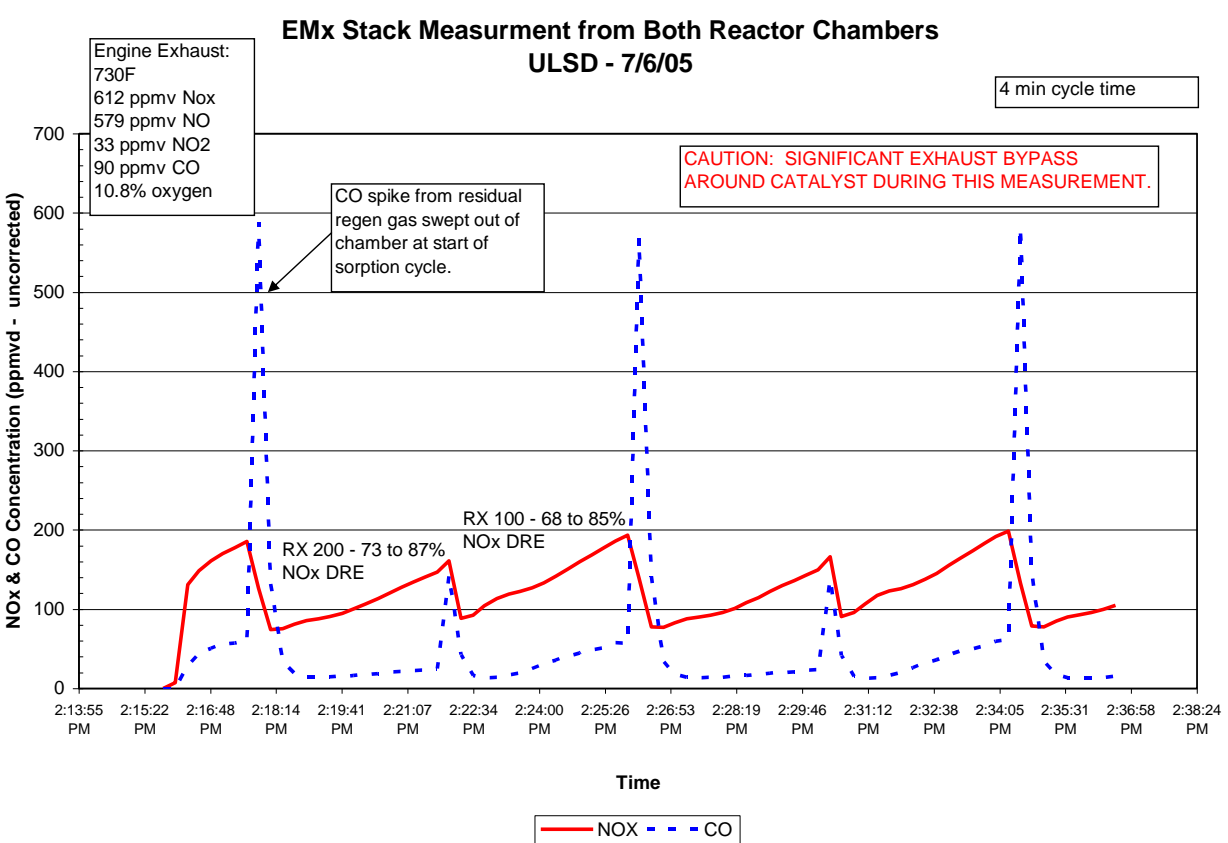

Figure IV-2 


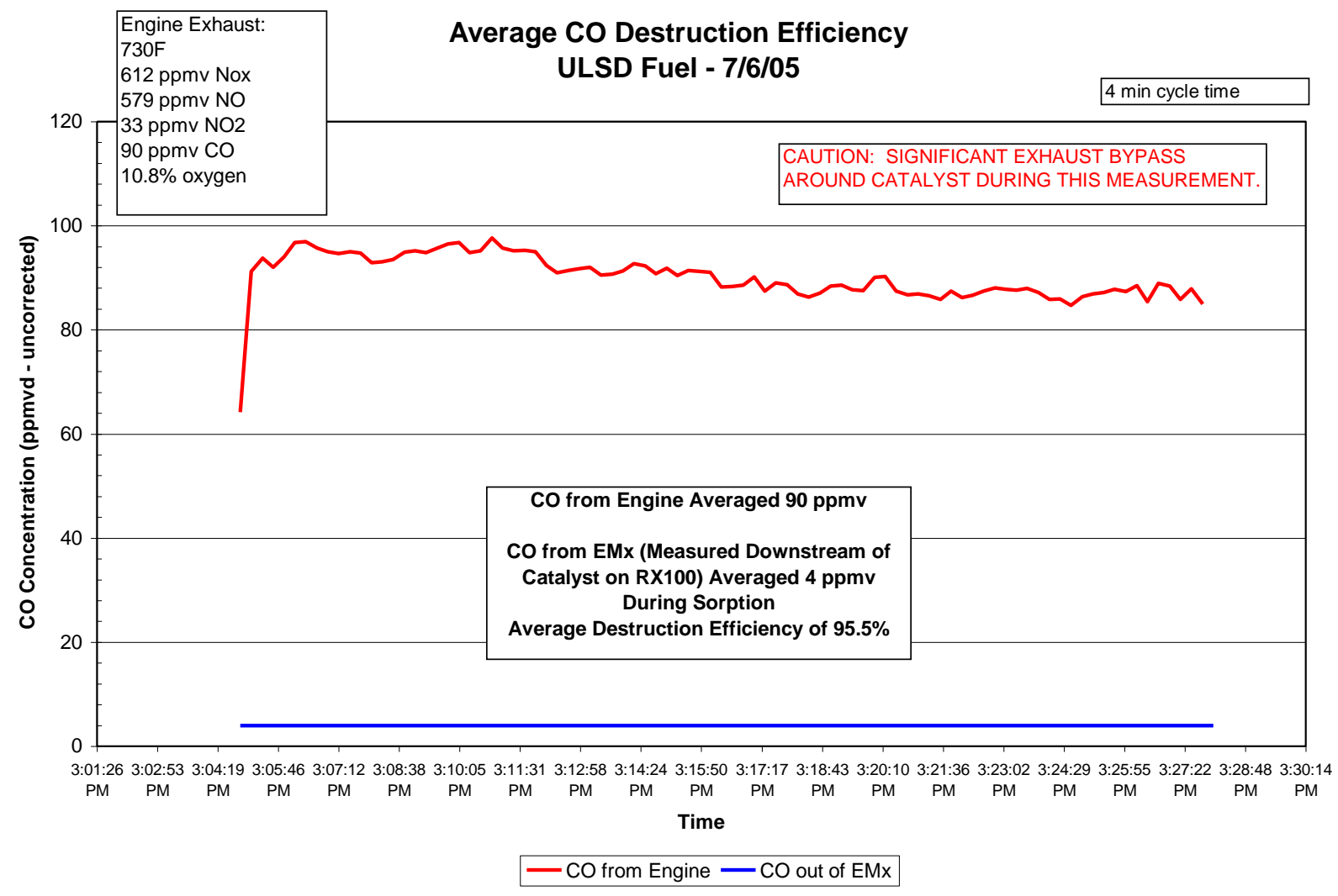

Figure IV-3

\section{B2 Test}

Figure IV-4 shows the engine emissions of NOx and CO when the engine is running $98 \%$ ultralow sulfur diesel mixed with $2 \%$ biodiesel as fuel. Figure IV-5 shows the catalyst outlet emissions. The NOx removal for both chambers averages $88 \%$. The NOx emissions for both chambers are lower than in the previous test, but the discrepancy between the two is greater. The CO spikes are much lower than in the previous test. It was later discovered that exhaust bypass around the catalyst was occurring.

The pressure drop from the engine exhaust pipe ahead of the reactor to just below the catalyst (during sorption) was measured to be 15.1 " $\mathrm{H}_{2} \mathrm{O}$ on the RX100 chamber and 16.7" $\mathrm{H}_{2} \mathrm{O}$ on the RX200 chamber side.

For this test, the plasma reformer was run for a total of 8 hours, 5 minutes. The regen gas was composed of $17.2 \%$ hydrogen, $17.1 \%$ carbon monoxide, $54.9 \%$ nitrogen, and $1.6 \%$ methane, and unmeasured concentrations of carbon dioxide and water vapor. The regen gas flow rate was calculated to be $31.5 \mathrm{scfm}$ (76 acfm) versus design specification of $35 \mathrm{scfm}$. The hydrogen flow rate was calculated to be $0.76 \mathrm{~kg} / \mathrm{hr}$ versus design specification of $1 \mathrm{~kg} / \mathrm{hr}$. The plasma 
reformer's flow rate and hydrogen concentration were below the design specification, which adversely affected the EMx catalyst performance.

\section{Engine Exhaust Characteristics}

B2 - 7/7/05

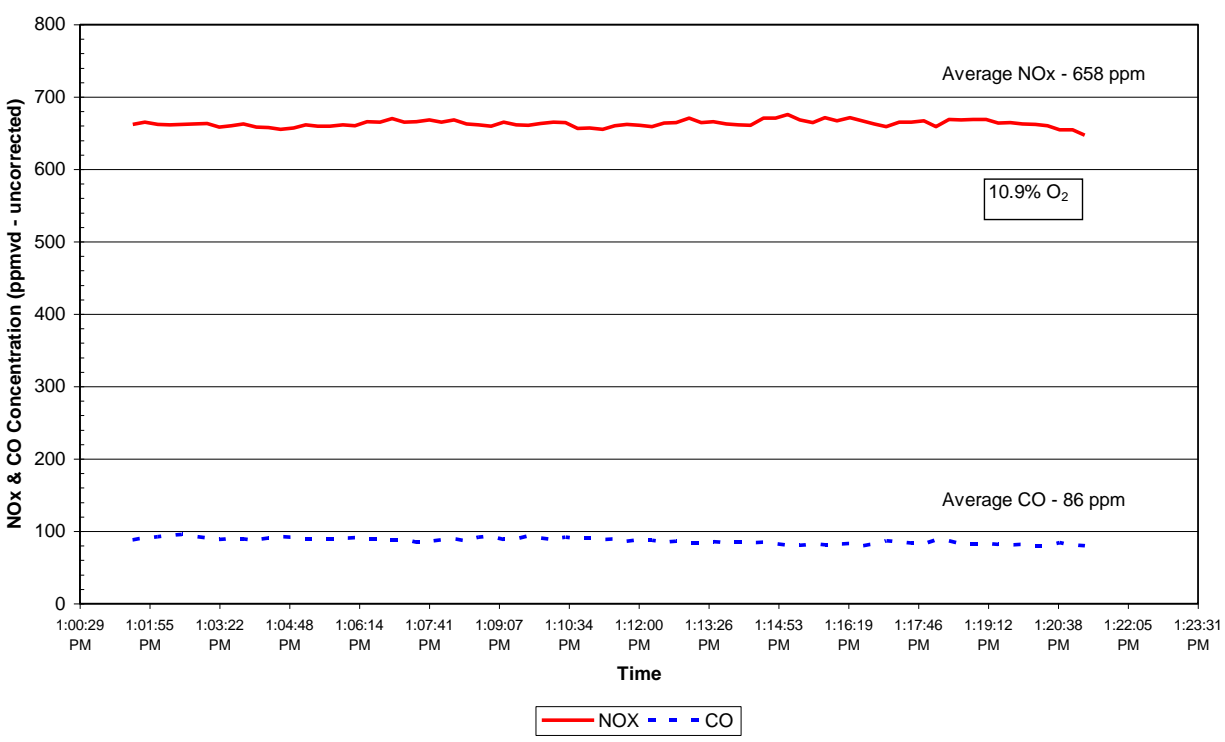

Figure IV-4

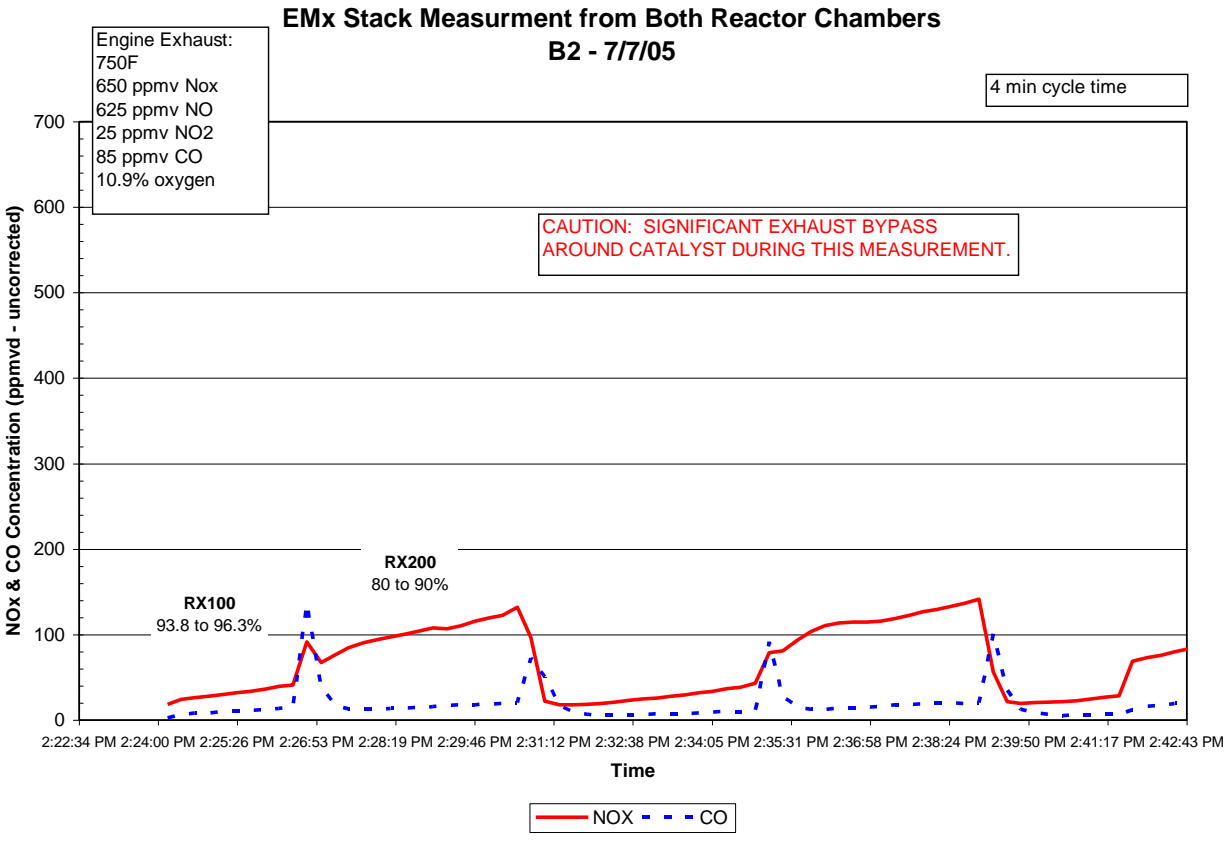

Figure IV-5 


\section{B5 Test}

Figure IV-6 shows the engine emissions of NOx and CO when the engine is running $95 \%$ ultralow sulfur diesel mixed with $5 \%$ biodiesel as fuel. Figure IV-7 shows the catalyst outlet emissions. The NOx removal for both chambers averages $72 \%$. The discrepancy in NOx emissions for the two chambers continues to grow. The $\mathrm{CO}$ spikes are higher than the previous test, but lower than the ULSD test. It was later discovered that exhaust bypass around the catalyst was occurring.

For this test, the plasma reformer was changed from B2 to B5 while running and continued to run for another 2 hours, 13 minutes. The regen gas was composed of $17.2 \%$ hydrogen, $17.0 \%$ carbon monoxide, $52.6 \%$ nitrogen, and $1.5 \%$ methane, and unmeasured concentrations of carbon dioxide and water vapor.

\section{Engine Exhaust Characteristics \\ B5 - 7/7/05}

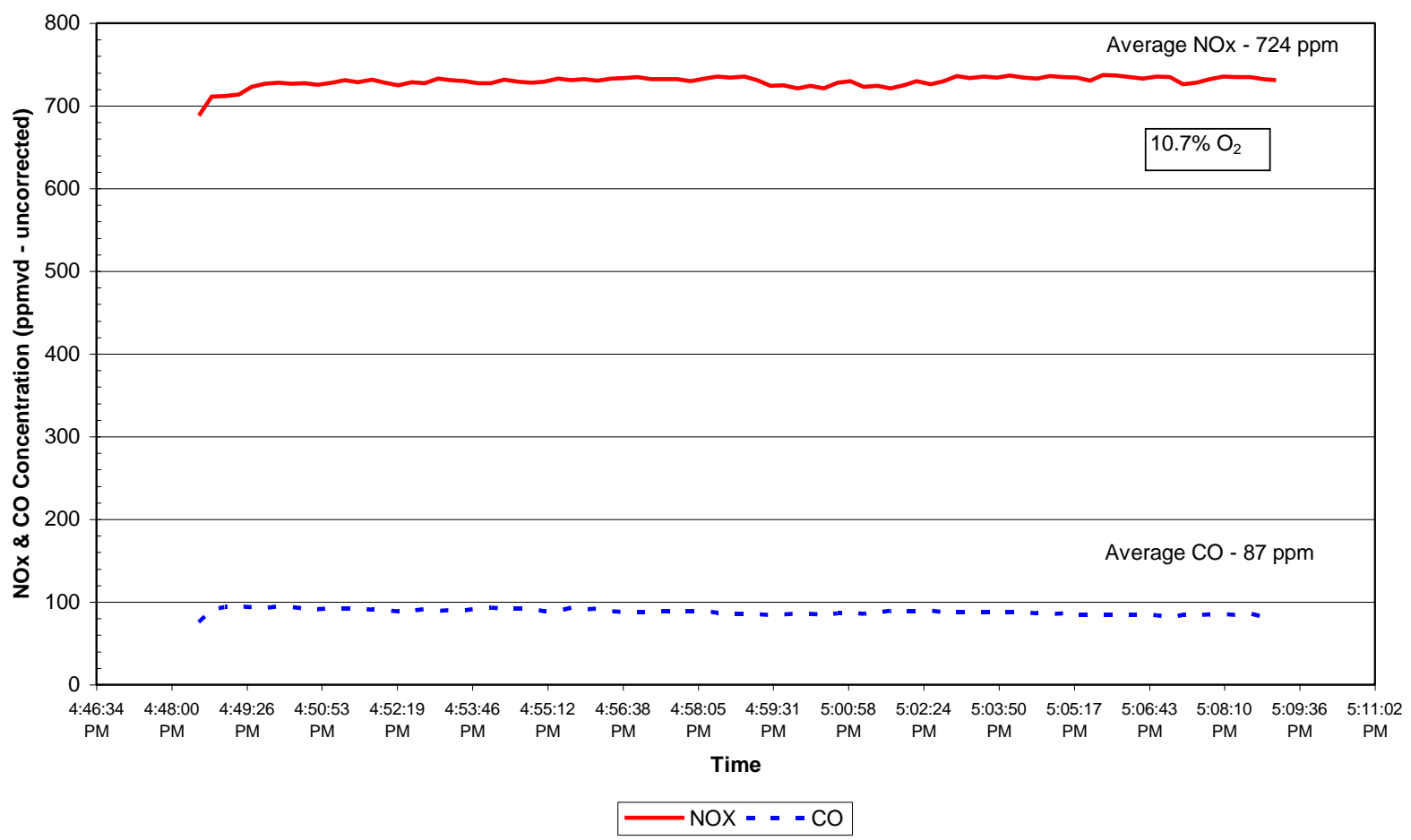

Figure IV-6 


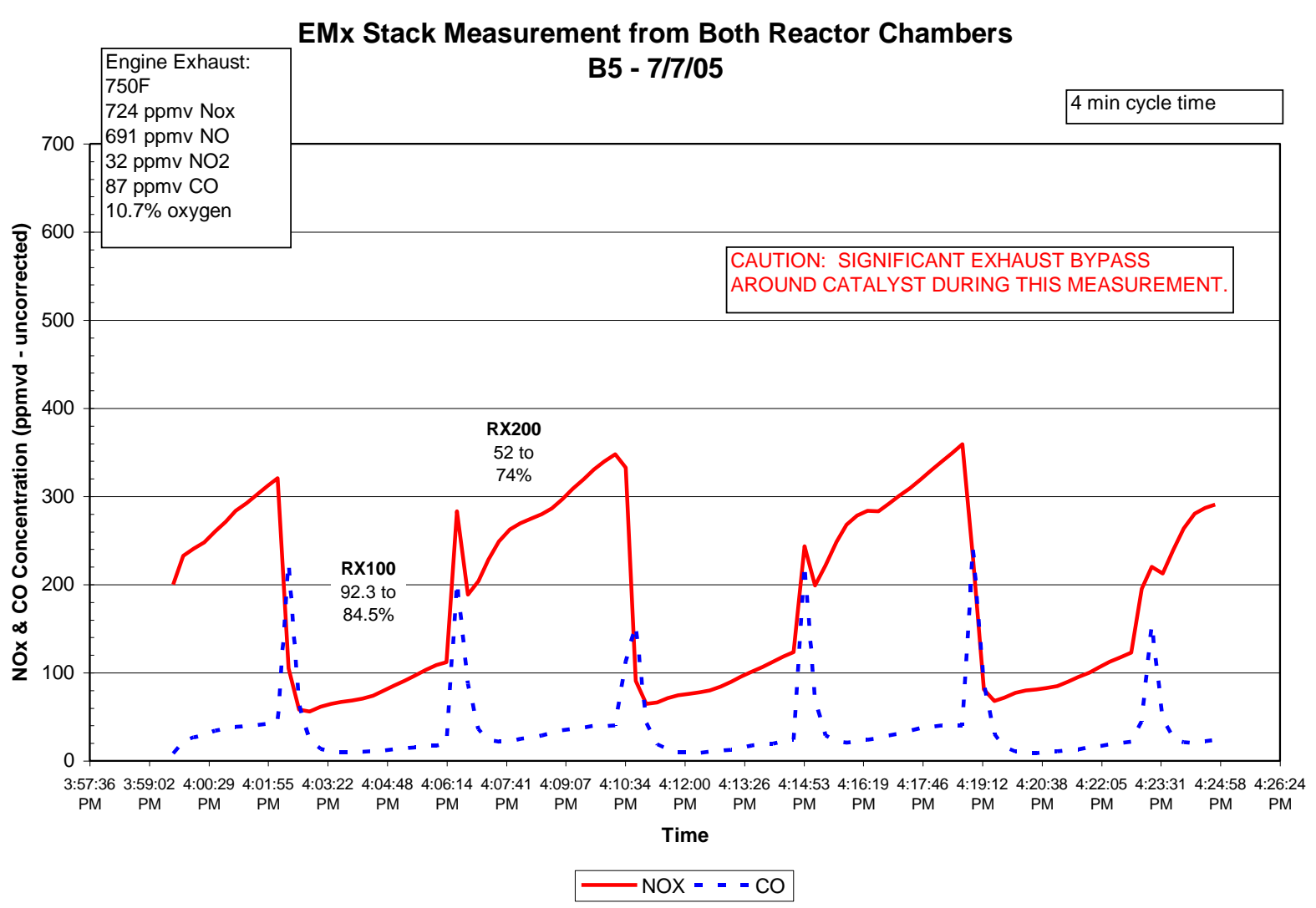

Figure IV-7

\section{Observations on ULSD, B2 and B5 Short Term Fuel Blend Tests}

The incoming NOx levels were much higher than were expected. At an inlet concentration of nearly 700ppm, the flow rate of NOx is approximately $4.2 \mathrm{scfm}$ or $16.8 \mathrm{ft} 3$ in a 4 minute cycle. This consumes $84 \%$ of the measured Tau 10 capacity. This minimizes the safety factor to compensate leakage or inefficient regeneration. Reducing the cycle time to 3 minutes would reduce the loading to $63 \%$ of the Tau 10 capacity.

More hydrogen is needed for regeneration to compensate for the higher incoming NOx loading. The primary reaction taking place is:

$$
\mathrm{KNO}_{3}+3 \mathrm{H}_{2}=3 \mathrm{H}_{2} \mathrm{O}+1 / 2 \mathrm{~N}_{2}
$$

$\frac{16.8 \mathrm{ft}^{3} \mathrm{NOx}}{4 \mathrm{~min}} * \frac{1 \text { moleNO}}{379 \mathrm{ft}^{3}} * \frac{3 \text { moles } \mathrm{H}_{2}}{\text { moleNO}_{2}} * \frac{2 \mathrm{lbH}}{\mathrm{moleH}_{2}}=.26 \mathrm{H}^{\mathrm{lb} \mathrm{H}_{2}} / \mathrm{cycle}$

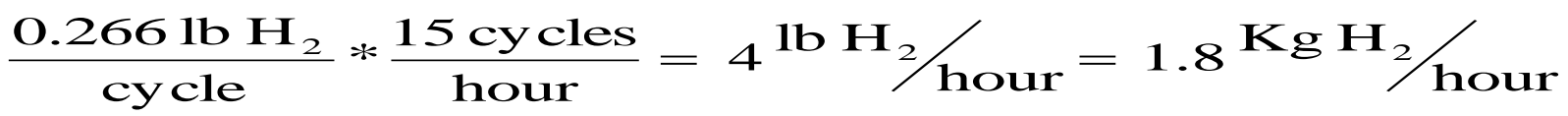


As noted during the $\mathrm{B} 2$ fuel blend test, the actual hydrogen production was measured at 0.76 $\mathrm{kg} / \mathrm{hr}$. This is $42 \%$ of the minimum theoretical requirement.

Fortunately, $\mathrm{CO}$ is contributing to regen. Regen gas containing approximately $18 \% \mathrm{CO}$ is reduced to approximately $2 \%$ after catalyst during regen. This suggests that the $\mathrm{CO}$ is a strong reductant, contributing to the regeneration of the catalyst.

It should be noted that the actual time available for regeneration was less than 4 minutes. During the oxygen depletion study, it was shown that it took approximately $1 \frac{1 / 2}{2}$ minutes for the oxygen to be depleted. Depending on the mixing in the chamber, some of the hydrogen is reacting with the oxygen present. As the chamber fills with regen gas, it begins to move in a plug flow through the catalyst modules and displaces the oxygen. Regeneration will not begin until regen gas containing hydrogen and carbon monoxide reaches the first row of catalyst, most likely after plug flow is established. At the end of the cycle, regen gas that is introduced in approximately the last 30 seconds does not reach the last row of catalyst before the sorption cycle begins and the regen gas is swept out of the chamber by the engine exhaust.

The performance of chamber RX 200 has degraded significantly throughout the course of the tests. The performance of chamber RX 100 has fluctuated, but remained close to $90 \%$ at its peak value. It appears that chamber RX 200 is not getting sufficient regeneration, and the working capacity is steadily decreasing as a result. Bypass could also be worsening as the wall separating the two chambers warps.

Furthermore, leaks have been witnessed around the doors of the chambers, which is not only dangerous for the on-site observers, but can reduce the affectivity of the regeneration. When the catalyst chamber was opened for inspection and to wash the catalyst, black leak paths were observed at the corners of the catalyst as shown in Figure IV-8 indicating that exhaust and regen gas were leaking out of the doors and around the catalyst modules. A leak path was also identified behind the catalyst. The chambers had a common wall on the back that was a flat plate of carbon steel. During the initial heat-up of the system, the wall was subjected to uneven heating as first one side of the wall was heated and then the other. As a result, the wall warped, leaving a leak path behind the modules as shown in Figure IV-9.

When the catalyst modules were chemically washed after the B2 and B5 fuel blend runs, the wash solution was unusually dirty. There was a high amount of floating, black, oily matter that would rise out of the blocks. The surface of the dry blocks, even the $4^{\text {th }}$ downstream row, had oil that could be wiped off with a finger. After 5 modules had been washed, tank 1 looked like dense brown, turbid muddy water. Sludge had already begun to accumulate on the bottom of the tank. Tank 1 needed original charge plus 2 additional changes to wash 16 modules. We concluded that some of the washes were not effective, and may have re-contaminated the catalyst with oil. 


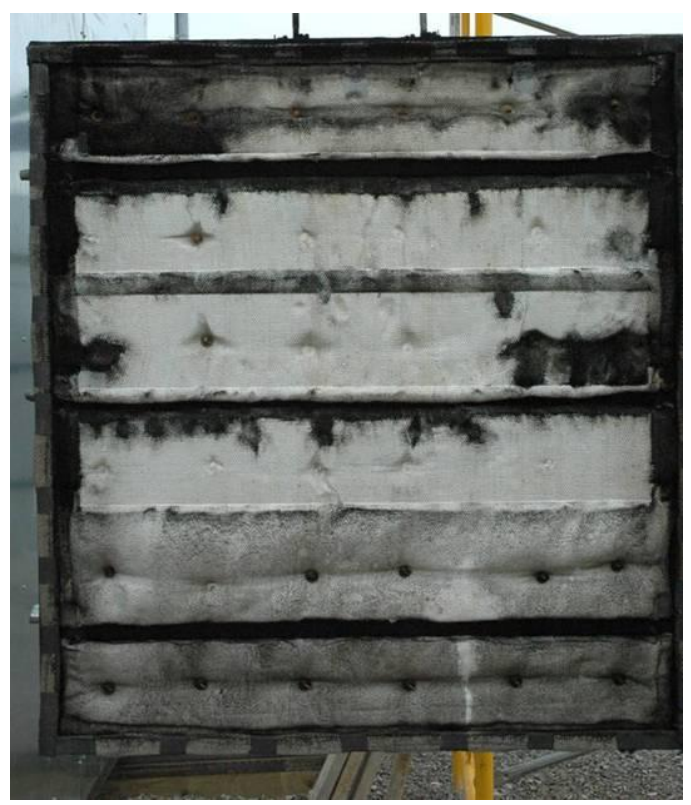

Figure IV-8

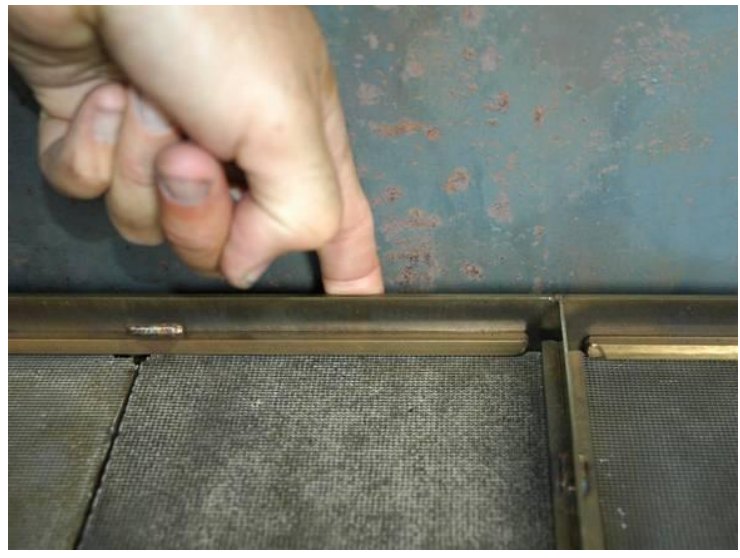

Figure IV-9

Before the start of the B20 testing, some modifications were made to improve the results. The sorption/regen cycle time was reduced to 3.5 minutes. Gaskets were added to the door to improve sealing on the front side of the catalyst as seen in Figure IV-10. Bars were added to the back wall of the catalyst chamber to straighten the wall and to act as a labyrinth seal as seen in Figure IV-11. On the plasma reformer, the catalyst media was re-activated using Ni salts, a short section of small diameter pipe at the reformer inlet was removed to increase the regen gas flow and hydrogen flow rate, and a small supply of water was added downstream of the reformer to add steam to the regen gas and increase the regen gas flow rate.

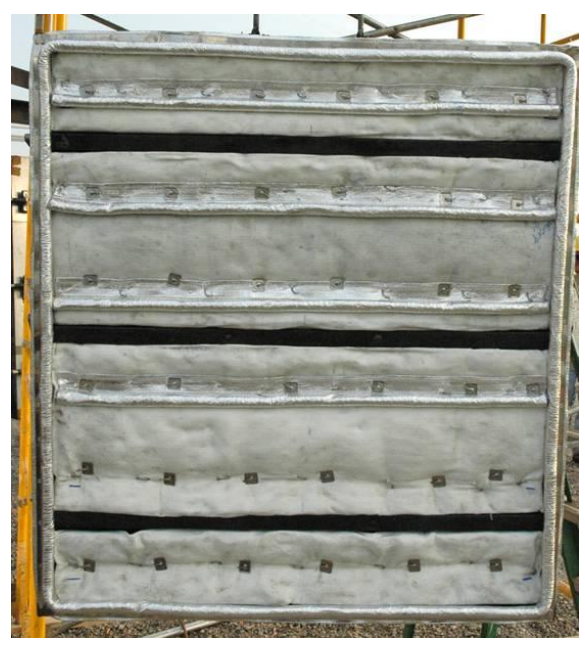

Figure IV-10

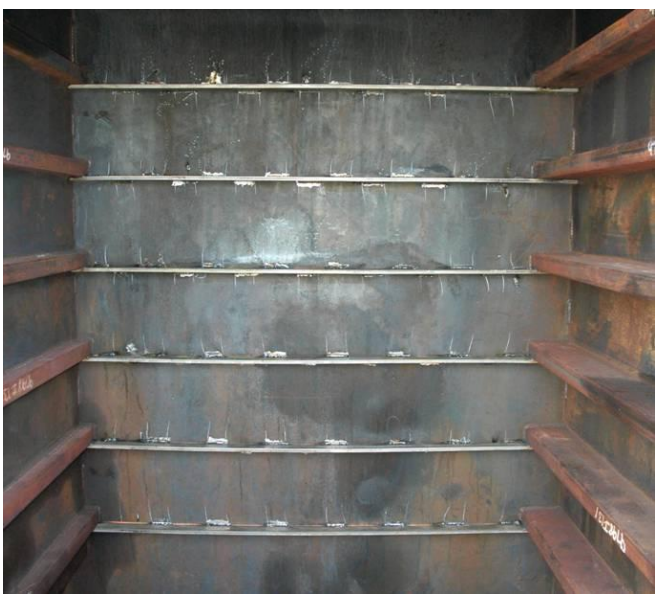

Figure IV-11 


\section{B20 Test}

Figure IV-12 shows the engine emissions of NOx and CO when the engine is running $80 \%$ ultralow sulfur diesel mixed with $20 \%$ biodiesel as fuel. Compared to Figure IV-6, note that NOx emissions decreased from an average of $724 \mathrm{ppm}$ to an average of $619 \mathrm{ppm}$. Figure IV-13 and Figure IV-14 show the catalyst outlet emissions. The NOx removal for both chambers averages $97 \%$. The revisions made to the system seem to have removed the discrepancy in NOx removal between the two chambers observed during installation and commissioning and earlier testing. The CO spike from regeneration is still higher for one chamber than the other, as observed during earlier testing, indicating that there is still a discrepancy in regen efficiency between the two chambers. The $\mathrm{CO}$ spike is significantly higher for this test than in previous testing. This may indicate that the catalyst is fully regenerated by the hydrogen in the regen gas and therefore consuming less $\mathrm{CO}$ or that there is less oxygen present in the chamber, which would allow the $\mathrm{CO}$ to oxidize to $\mathrm{CO}_{2}$.

Figure IV-15 shows the oxygen depletion study as repeated on chamber RX100. The increased flow rate of regen gas has decreased the amount of time required for the chamber to be purged. In supplementary testing, the oxygen concentration in chamber RX100 was down to $0.5 \%$ in $1: 50$ minutes, and down to $0.0 \%$ in $2: 20$ minutes. For chamber RX200, the oxygen concentration was down to $0.5 \%$ in $3: 02$ minutes and down to $0.0 \%$ in $3: 40$ minutes. The minimum oxygen concentration achieved was $0 \%$, which was not achieved in the earlier oxygen depletion testing. The oxygen concentration in chamber RX100 was below $2 \%$ by 54 seconds into the regeneration cycle.

For this test, the plasma reformer was run for a total of 7 hours, 38 minutes total, with a switch to B50 about 5 hours into the test. Approximately 23 liters per hour of water was added as a secondary supply of steam to the regen gas. This rate of water injection far exceeded the amount of heat available to vaporize it (even if it had been finely atomized). As a result, water accumulated in the bottom of the regen outlet piping, increased the resistance of the system and eventually reduced the air flow rate. Small droplets of grey/black water were showering from the vent stack. During the B20 portion of the test, the regen gas was composed of $19.2 \%$ hydrogen, $19.8 \%$ carbon monoxide, $52 \%$ nitrogen, and $0.86 \%$ methane, and unmeasured concentrations of carbon dioxide and water vapor. 
Engine Exhaust Characteristics

B20 - 7/9/05

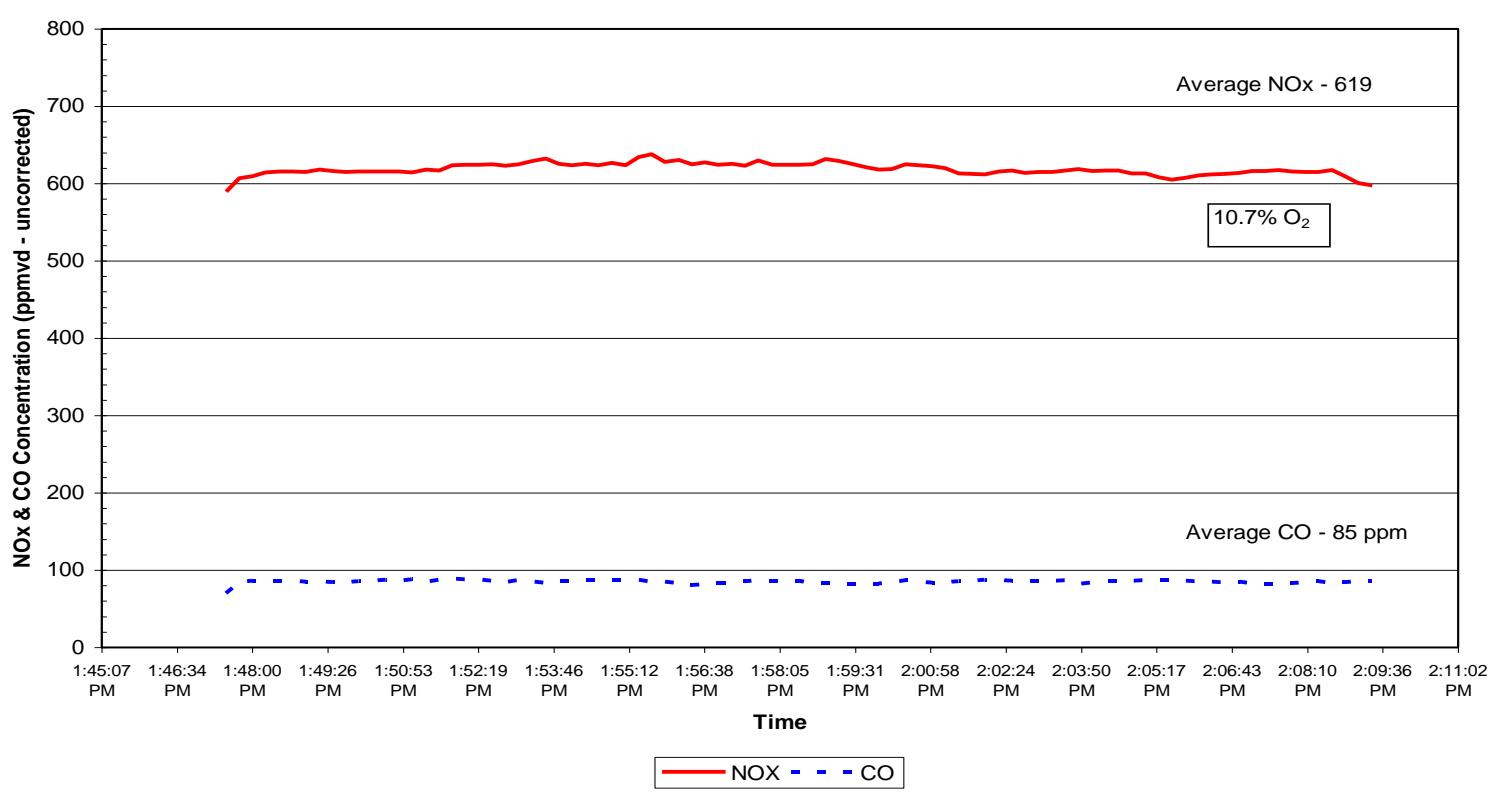

Figure IV-12

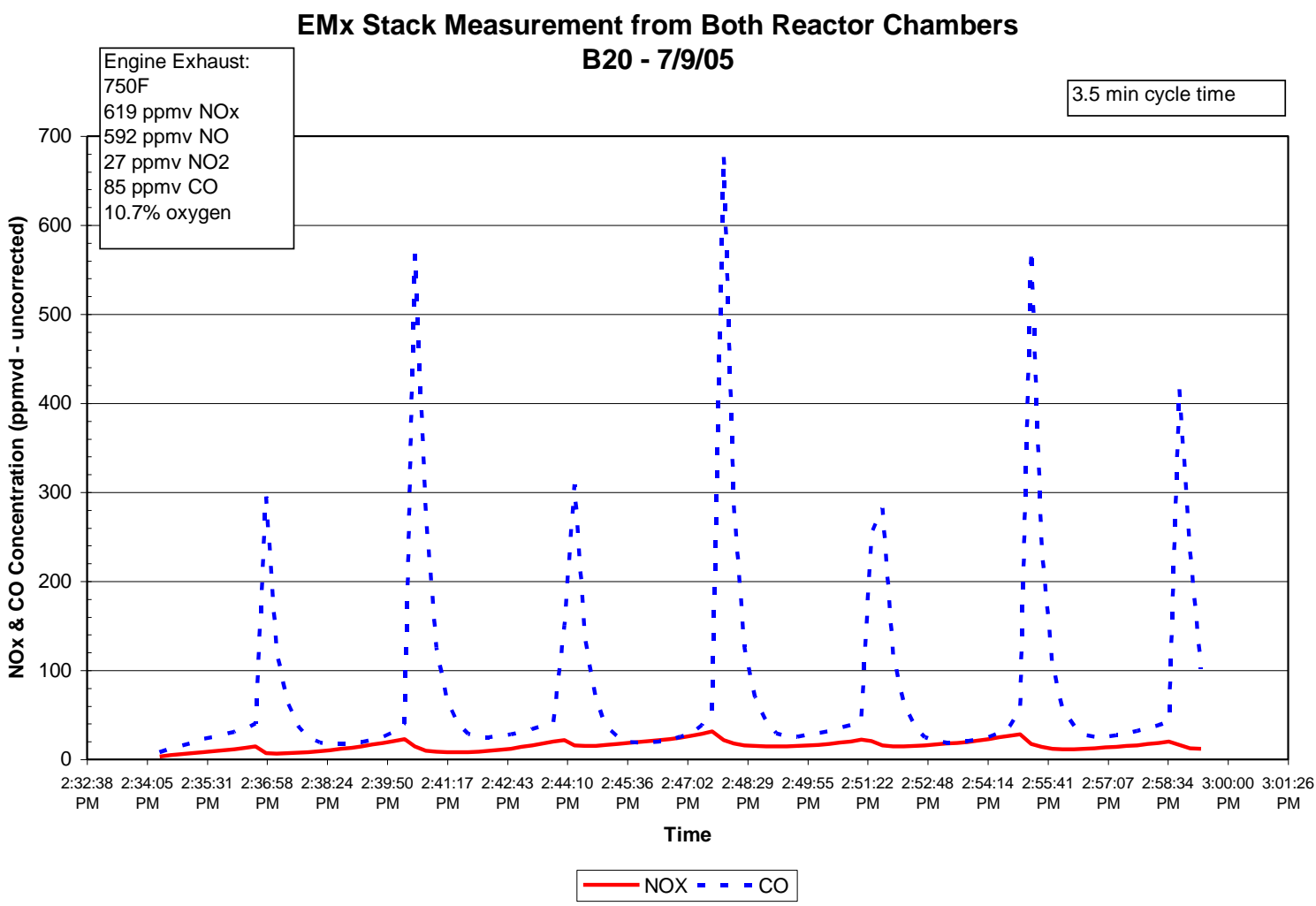

Figure IV-13 


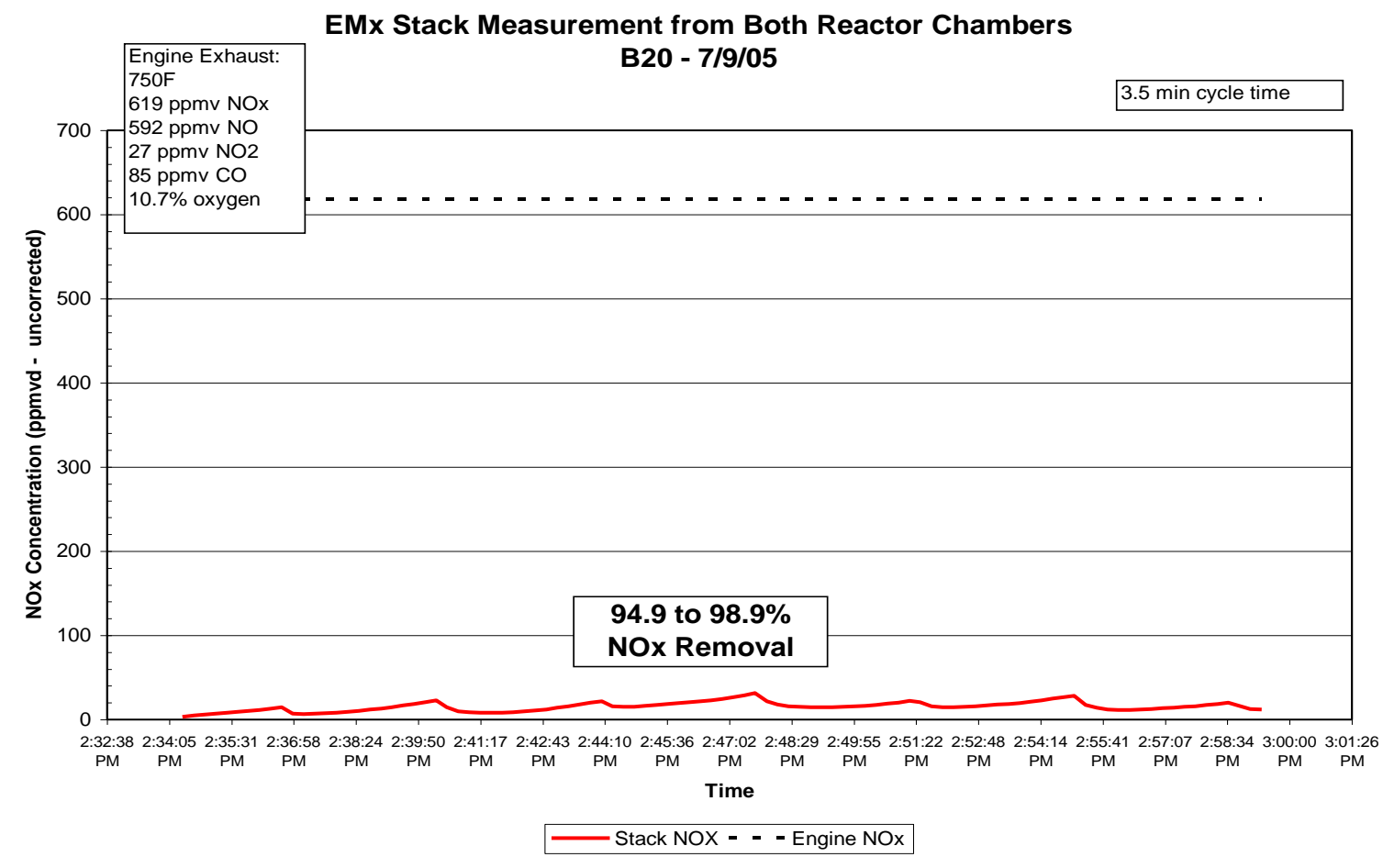

Figure IV-14

\section{Oxygen Depletion RX100}

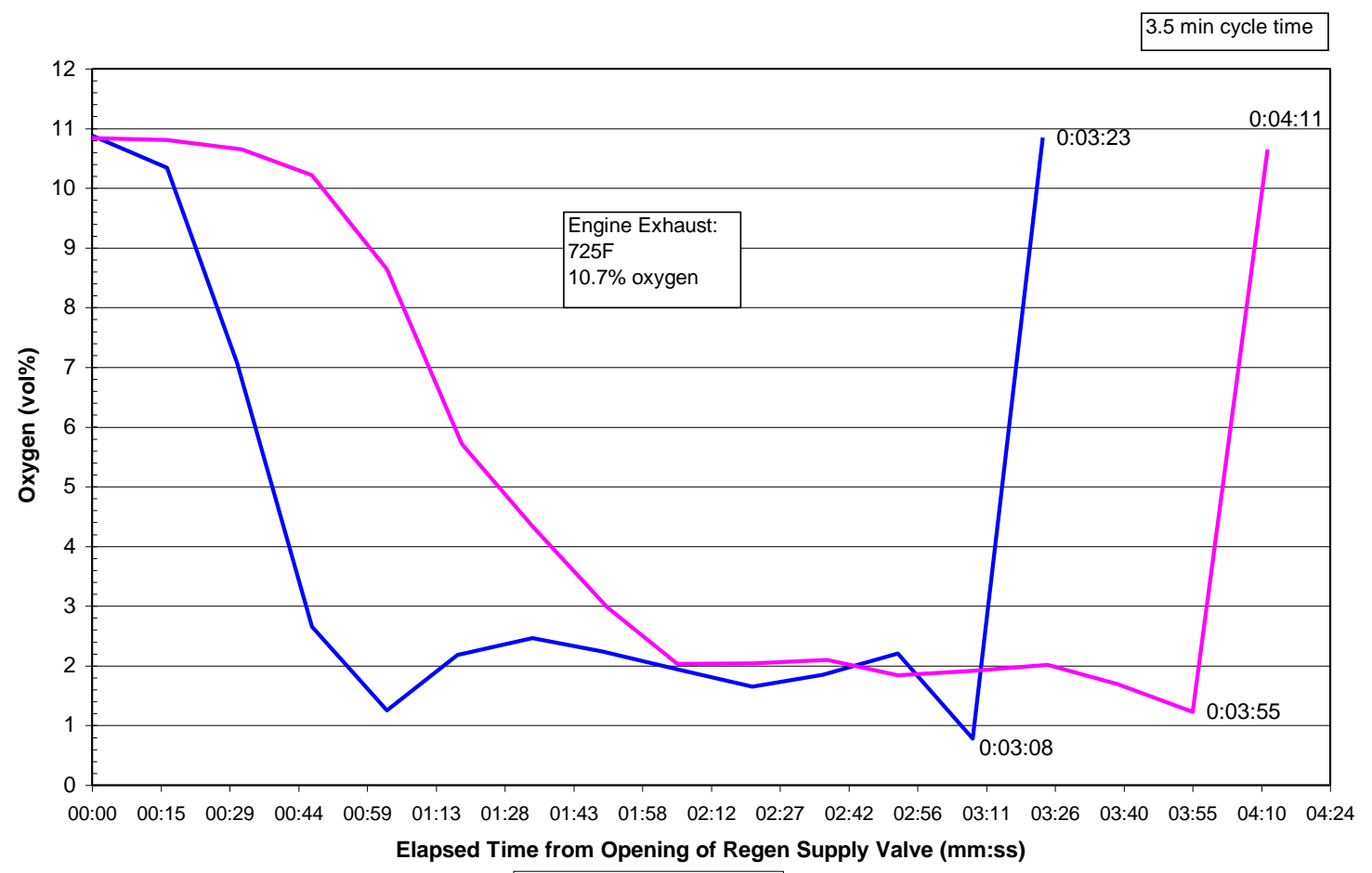

$-7 / 9 / 2005-7 / 5 / 2005$

Figure IV-15 


\section{B50 Test}

Figure IV-16 shows the engine emissions of NOx and CO when the engine is running $50 \%$ ultralow sulfur diesel mixed with $\mathbf{5 0 \%}$ biodiesel as fuel. Figure IV-17 and Figure IV-18 show the catalyst outlet emissions. The NOx removal for both chambers averages $98 \%$. The NOx removal is nearly identical between the two.

The pressure drop from the engine exhaust pipe ahead of the reactor to just below the catalyst (during sorption) was measured to be $13.5^{\prime \prime} \mathrm{H}_{2} \mathrm{O}$ on the RX100 chamber and $14.9^{\prime \prime} \mathrm{H}_{2} \mathrm{O}$ on the RX200 chamber side.

For this test, the plasma reformer was run for a total of 7 hours, 38 minutes total, with a switch to B50 about 5 hours into the test. During the B50 portion of the test, the regen gas was composed of $19.3 \%$ hydrogen, $18.2 \%$ carbon monoxide, $50.8 \%$ nitrogen, and $1.5 \%$ methane, and unmeasured concentrations of carbon dioxide and water vapor. The regen gas flow rate was calculated to be $39.9 \mathrm{scfm}(91.3 \mathrm{acfm})$. The hydrogen flow rate was calculated to be $1.24 \mathrm{~kg} / \mathrm{hr}$. This flow rate and hydrogen production rate exceed the design specification.

\section{Engine Exhaust Characteristics \\ B50 - 7/9/05}

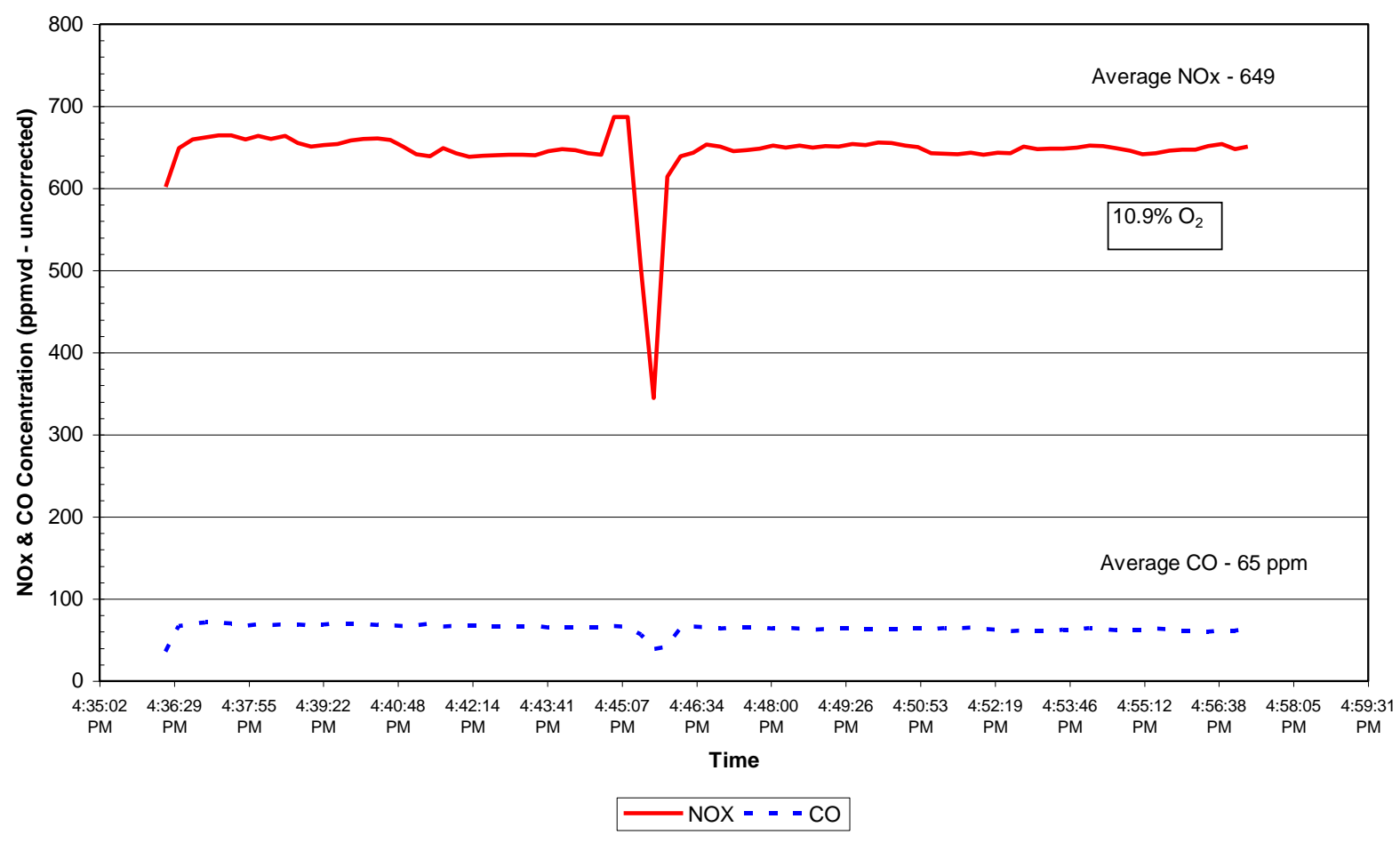

Figure IV-16 


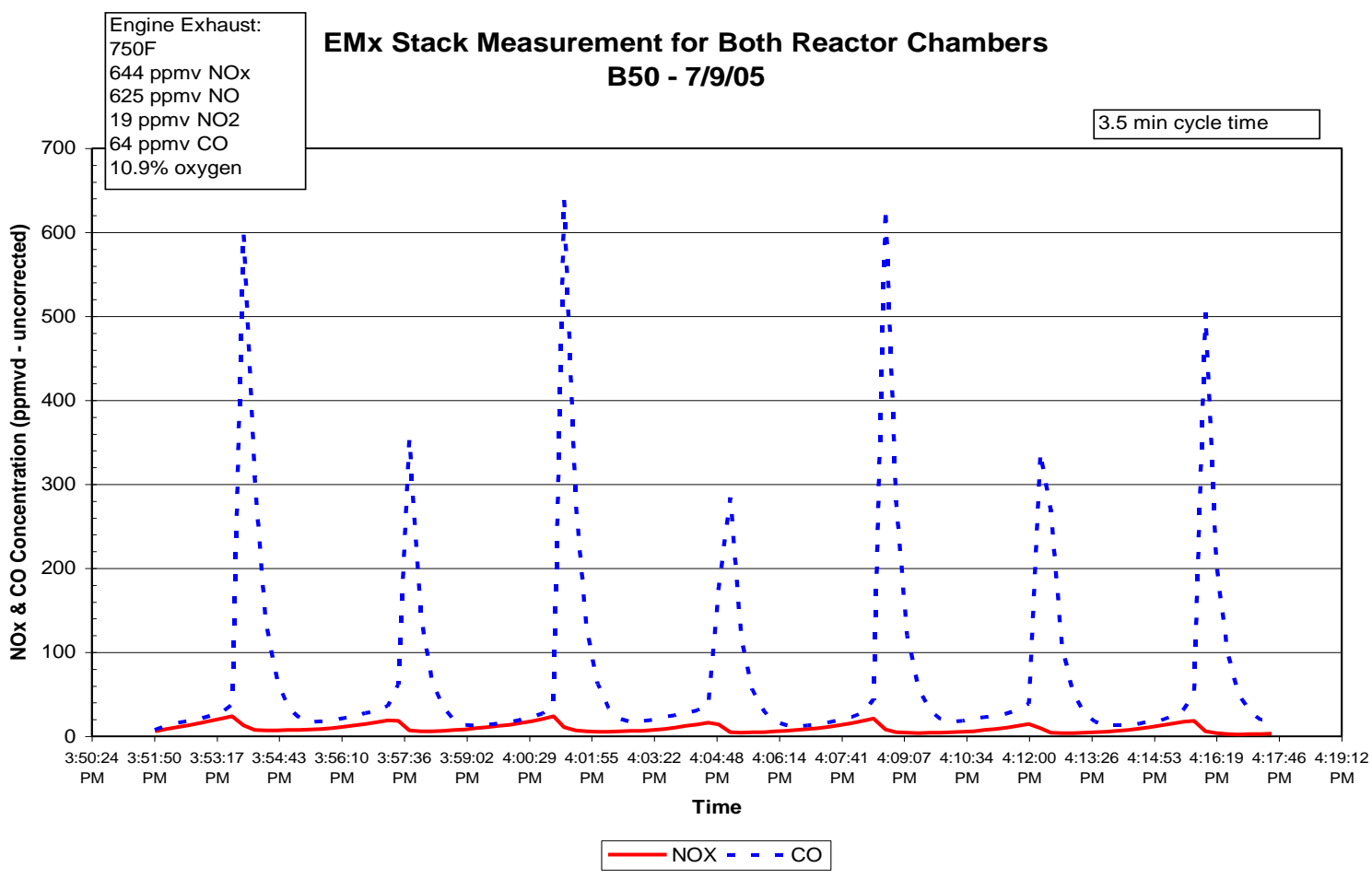

Figure IV-17

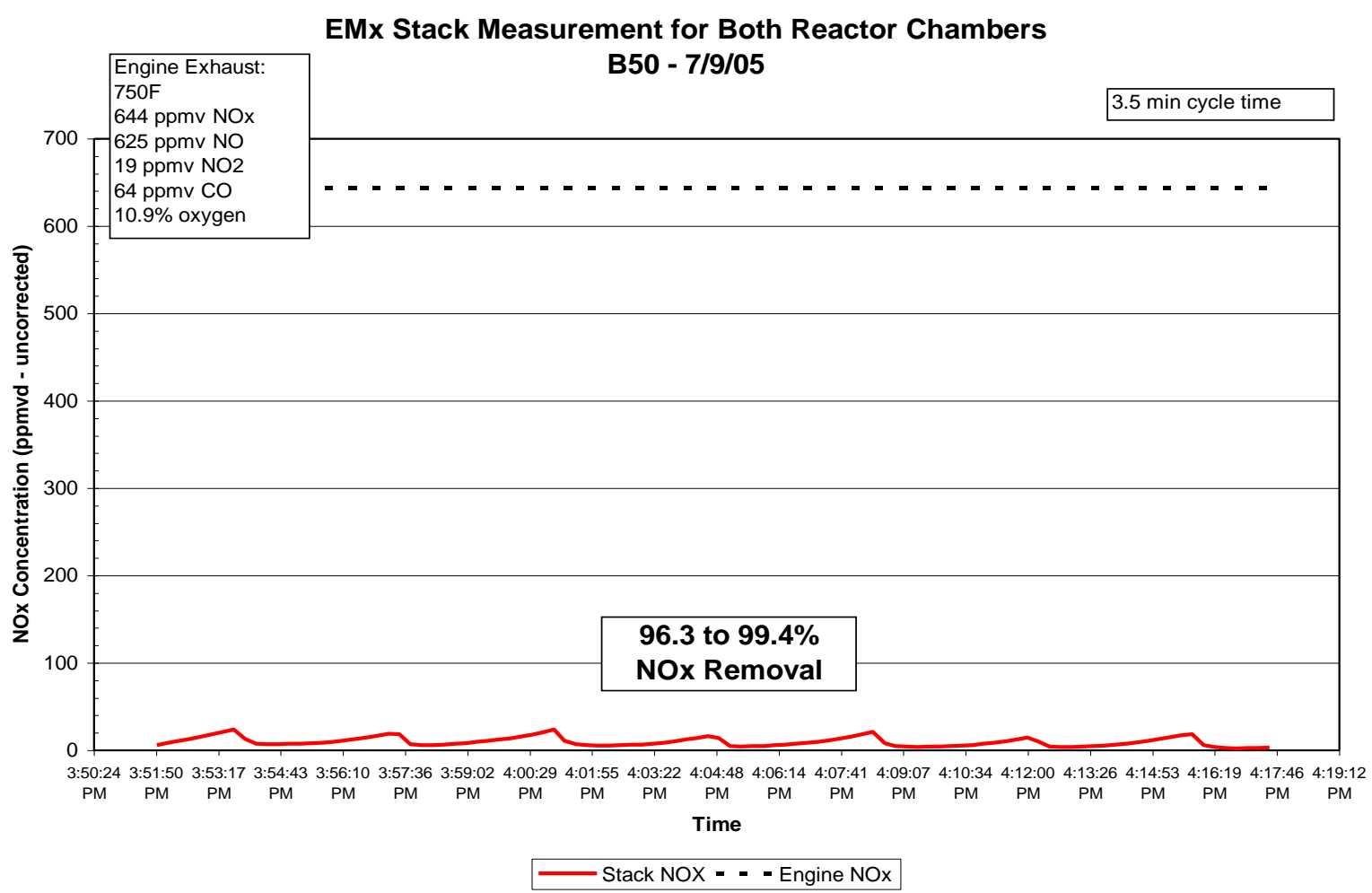

Figure IV-18 


\section{B100 Test}

Figure IV-19 shows the engine emissions of NOx and CO when the engine is running $100 \%$ biodiesel as fuel. The NOx concentration of $786 \mathrm{ppm}$ is an $18 \%$ increase over the B50 NOx emissions of $649 \mathrm{ppm}$ and a $25 \%$ increase over the ULSD emissions of $612 \mathrm{ppm}$. Figure IV-20 and Figure IV-21 show the catalyst outlet emissions. The NOx removal for both chambers averages $96.6 \%$. The NOx emissions for one chamber are slightly higher than those for the other chamber. The $\mathrm{CO}$ spikes slightly higher than the previous test, and displays a less consistent pattern.

For this test, the plasma reformer was run for a total of 5 hours, 4 minutes. The regen gas was composed of $19 \%$ hydrogen, $18.4 \%$ carbon monoxide, $54 \%$ nitrogen, and $0.83 \%$ methane, and unmeasured concentrations of carbon dioxide and water vapor. The hydrogen concentration remained steady throughout the test, varying from $17.5 \%$ to $20 \%$.

TVA had defined a target NOx emission level of $0.5 \mathrm{~g} / \mathrm{bhp}$-hr for the system, when running on B100. For this test, we calculated a NOx emission level of $0121 \mathrm{~g} / \mathrm{BHP}-\mathrm{hr}$, far exceeding the required reduction in NOx emissions.

\section{Engine Exhaust Characteristics B100 - 7/10/05}

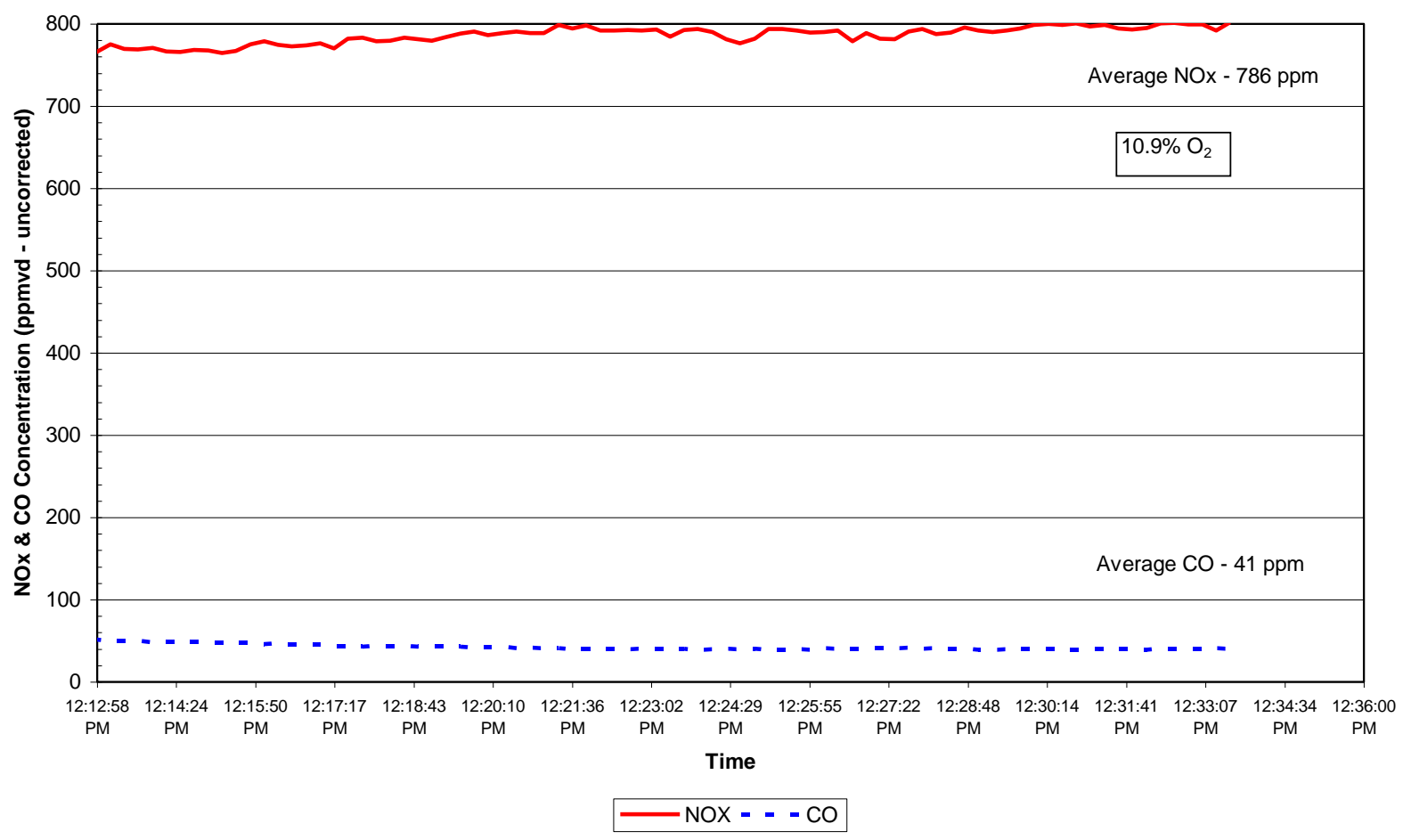

Figure IV-19 


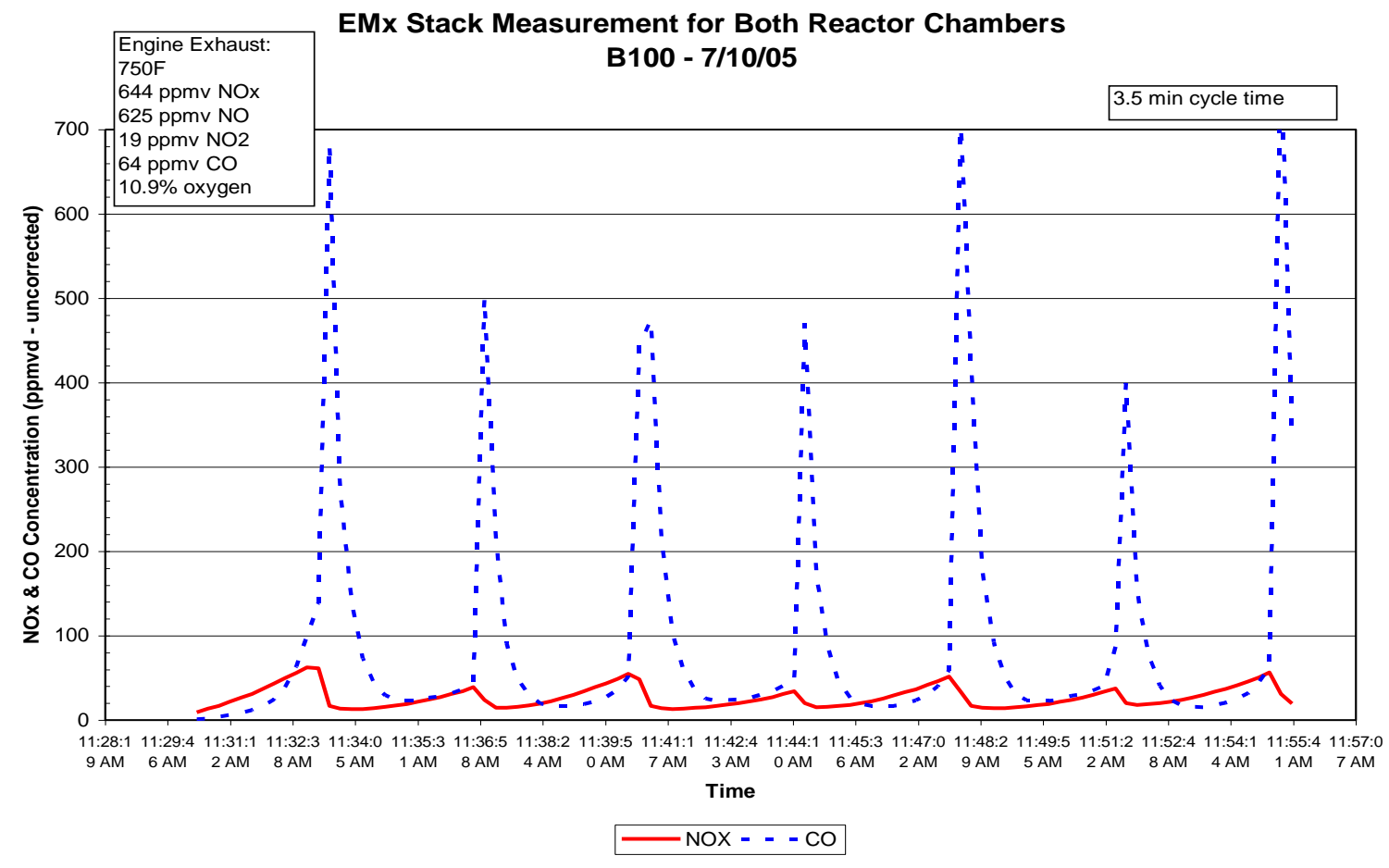

Figure IV-20

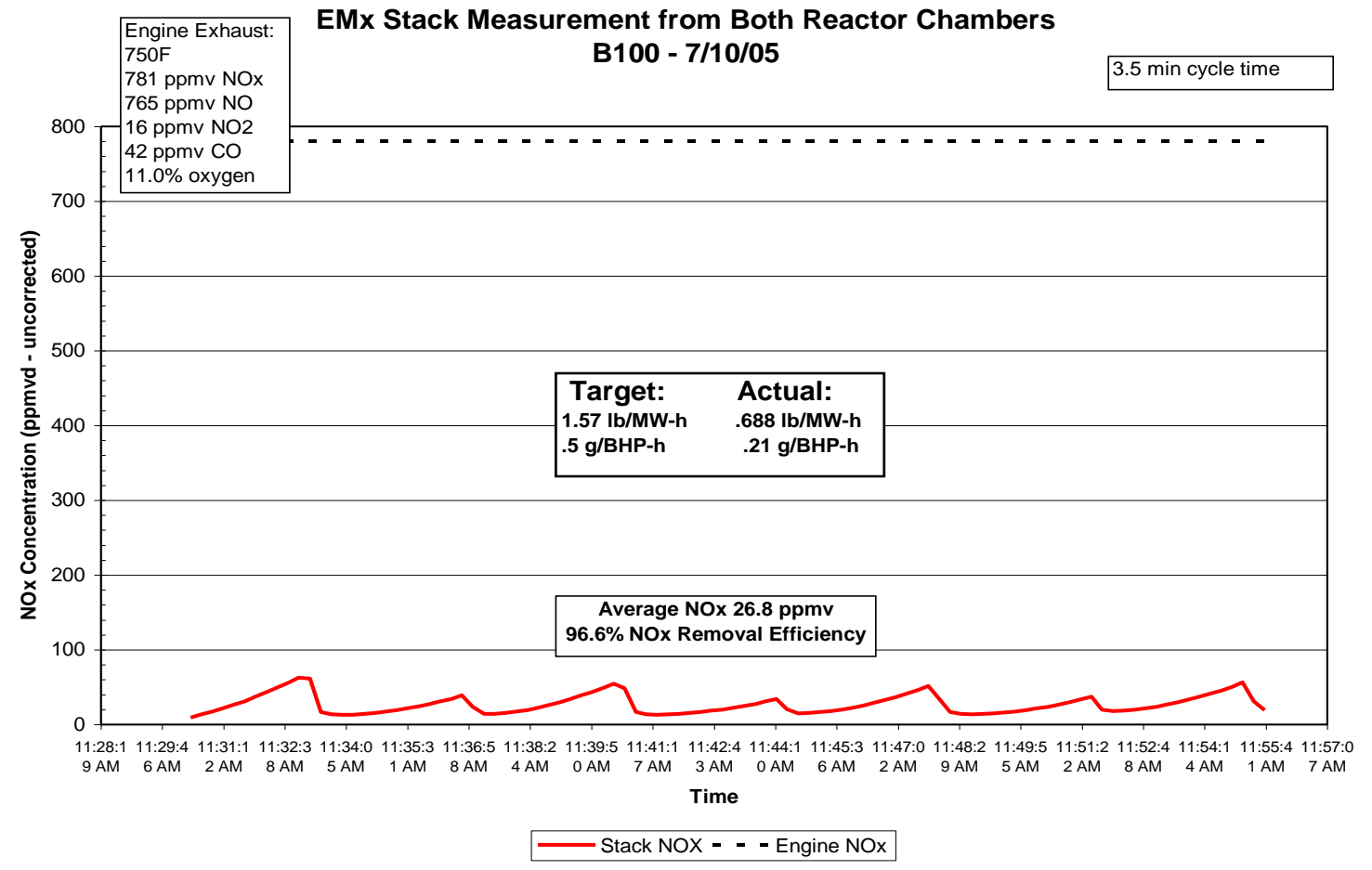

Figure IV-21 


\section{Fuel Affects}

Figure IV-22 and Figure IV-23 show the affect on engine emissions of NOx and CO when the engine is running various blends of ULSD and Biodiesel. In Figure IV-22, the effect is shown as a $\%$ change from pure ULSD fuel. In Figure IV-23, the NOx emissions (in ppmvd) are shown as measured before and after the catalyst. Figure IV-24 shows the affect on regen gas composition when the plasma reformer is fueled by various blends of ULSD and Biodiesel.

\section{Effect of BioDiesel on Emissions Untreated Engine Exhaust}

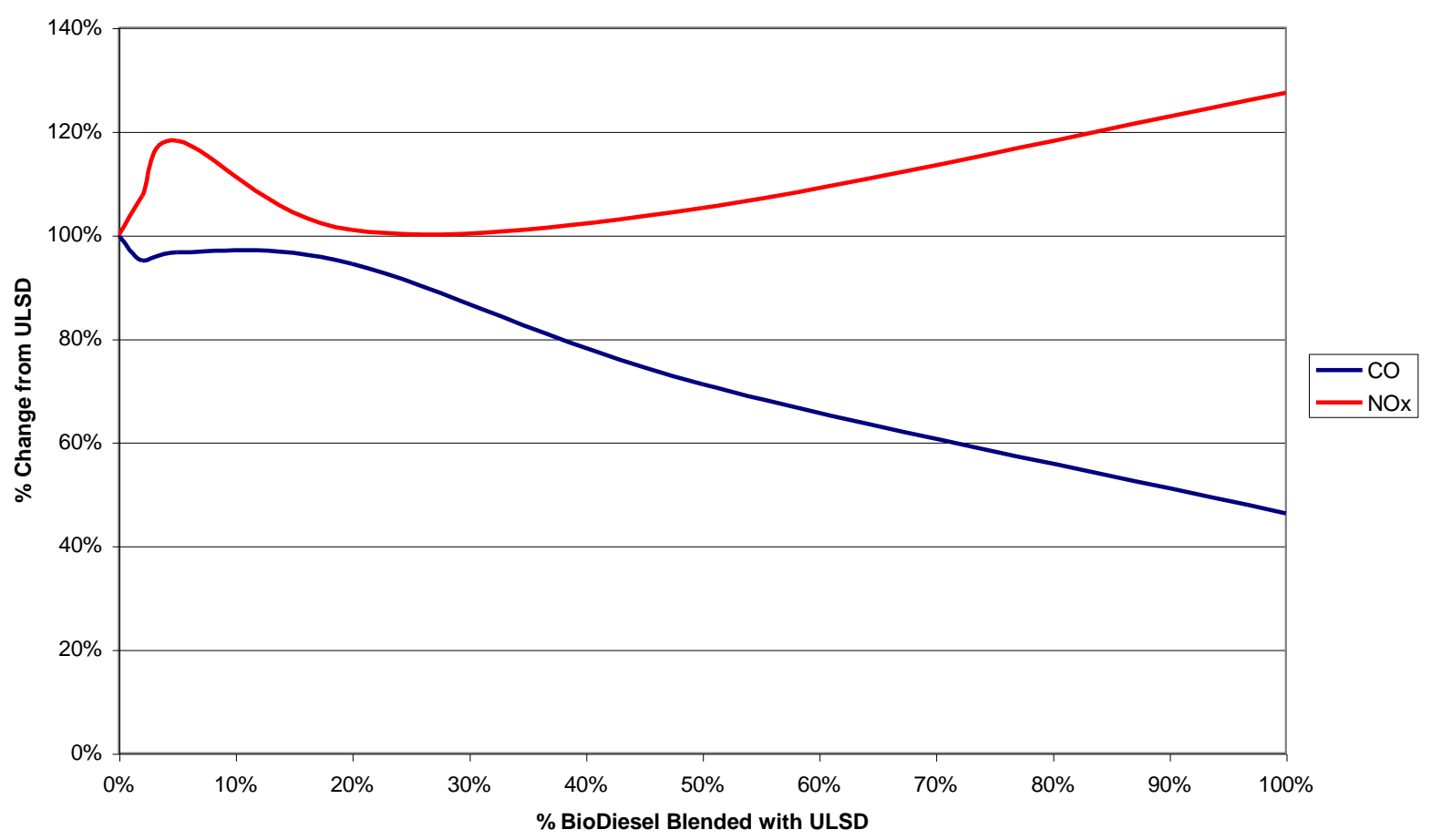

Figure IV-22 


\section{Effect of BioDiesel on Engine NOx Emissions}

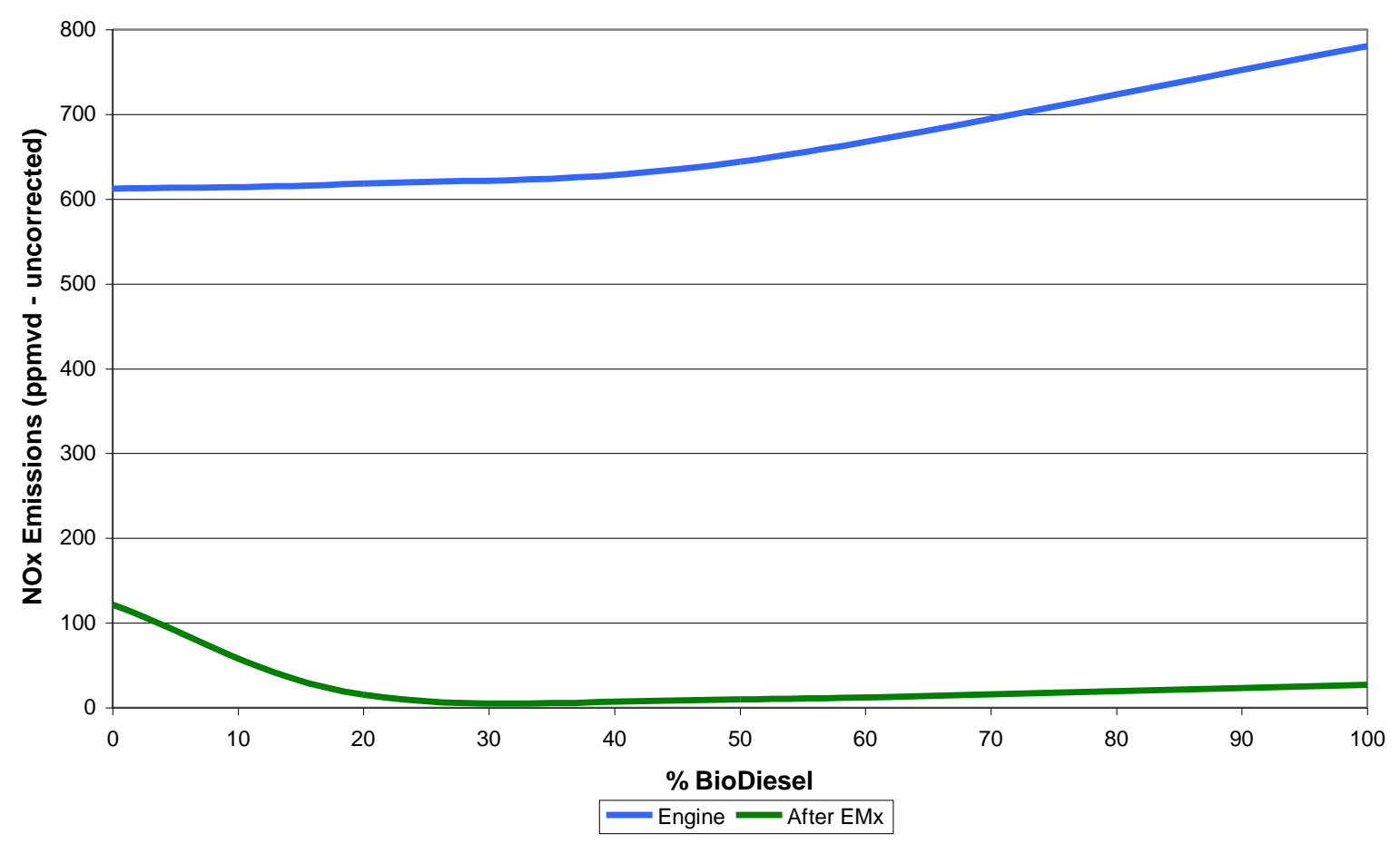

NOTE: Other variables were changed in addition to fuel type such as sorption cycle time, regen gas flow rate, etc.

Figure IV-23 


\section{Effect of Biodiesel on Regen Gas}

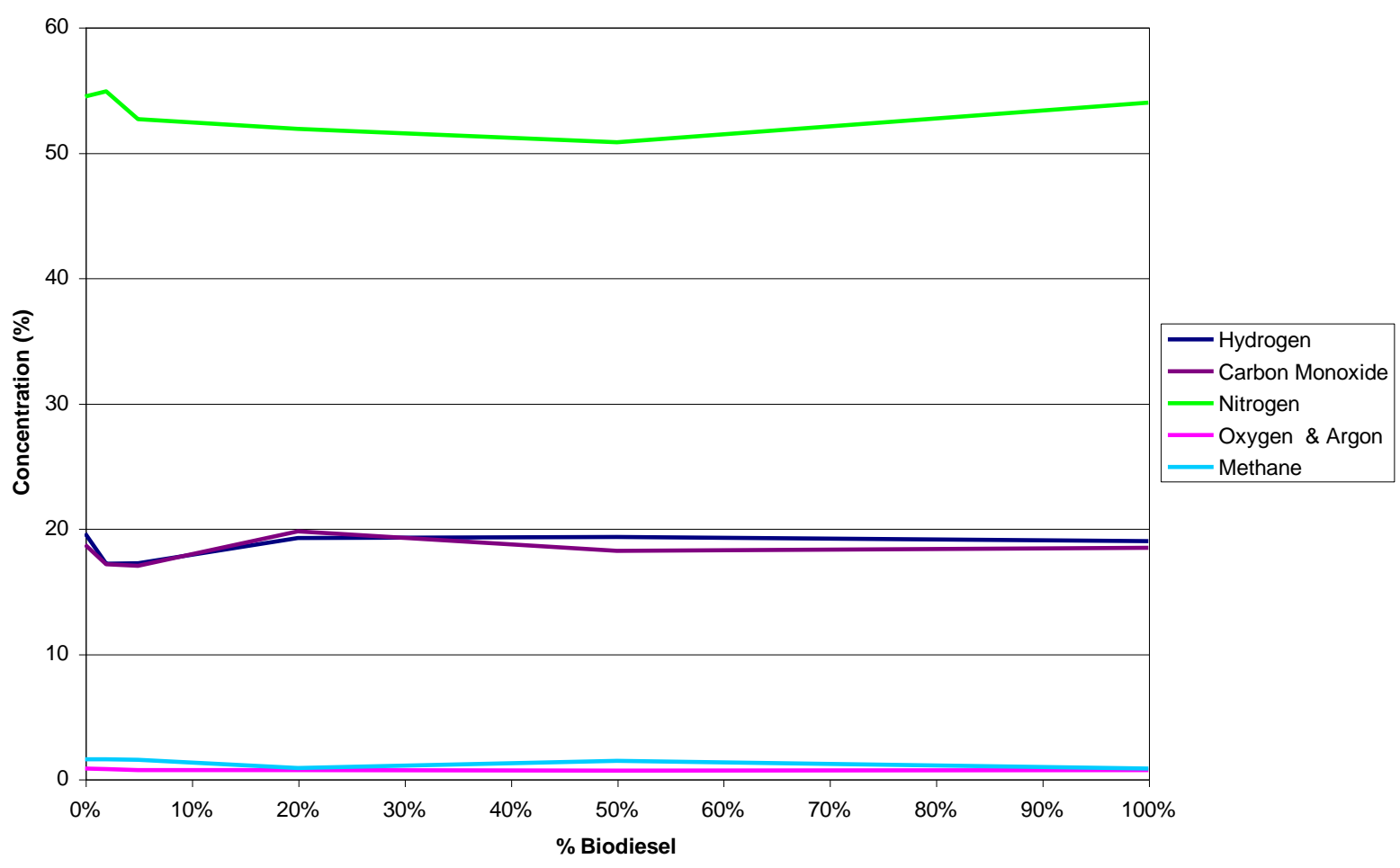

NOTE: Other variables were changed in addition to fuel type such as operating temperature, water addition, air to fuel ratio, etc.

Figure IV-24 


\section{Long Term Test}

\section{Limiting Factors}

Throughout the short term testing, the plasma reformer was not run for a full 24 hours. To achieve a 1500 hour run, this hurdle must first be crossed. After run 28, the EMx catalyst was removed from the system and never tested again. The entire demo program shifted to developing the plasma reformer. Table $\mathbf{V} \mathbf{- 1}$ and Table $\mathbf{V}-\mathbf{2}$ summarize the plasma reformer runs completed in an attempt to accomplish this goal. Reliable, stable operation of the plasma reformer was not accomplished for periods longer than 30 hours.

\begin{tabular}{|c|c|c|c|c|c|}
\hline Run & Date & Fuel & $\begin{array}{l}\text { Duration } \\
\text { (H:MM) }\end{array}$ & $\begin{array}{l}\text { Reason } \\
\text { Stopped }\end{array}$ & Comments \\
\hline 17 & $7 / 21 / 05$ & B100 & $0: 58$ & $\begin{array}{l}\text { Head } \\
\text { leaking, } \\
\text { replace } \\
\text { gasket \& } \\
\text { re-tap } \\
\text { bolts }\end{array}$ & $\begin{array}{l}\text { Air in water line - short excursion to } \\
1200^{\circ} \mathrm{C} \text {. Post-run inspection revealed no } \\
\text { damage to Ni balls, electrodes, or } \\
\text { thermowell. Applied high temp caulk, new } \\
\text { grade } 5 \text { zinc coated steel bolts, trimmed } \\
\text { damaged wires, re-connected ceramic } \\
\text { connectors, trimmed damaged section of air } \\
\text { line flex connection and re-attached, re- } \\
\text { routed wires to avoid hot surfaces, bled air } \\
\text { out of fuel and water lines. }\end{array}$ \\
\hline 18 & $7 / 22 / 05$ & B100 & $0: 43$ & $\begin{array}{l}\text { Air line } \\
\text { leaking }\end{array}$ & Pre-heat flex hose leaking \\
\hline 19a & $7 / 25 / 05$ & B100 & $2: 49$ & $\begin{array}{l}\text { Engine } \\
\text { tripped }\end{array}$ & Engine fuel supply empty \\
\hline $19 \mathrm{~b}$ & $7 / 25 / 05$ & B100 & $5: 17$ & $\begin{array}{l}\text { Engine } \\
\text { tripped }\end{array}$ & \\
\hline 21 & $7 / 26 / 05$ & B100 & $14: 54$ & $\begin{array}{l}\text { Low air } \\
\text { flow }\end{array}$ & $\begin{array}{l}\text { Air flow decreased from } 21.6 \mathrm{scfm} \text { at } 51 \mathrm{~Hz} \\
\text { at 7:04 to } 18 \mathrm{scfm} \text { at } 60 \mathrm{~Hz} \text { at } 21: 21 \text {. Post } \\
\text { run inspection revealed reformer full of } \\
\text { carbon. Cleaned Ni balls, replaced granules }\end{array}$ \\
\hline 22 & $7 / 30 / 05$ & B100 & $0: 33$ & $\begin{array}{l}\text { Air line } \\
\text { leaking }\end{array}$ & Pre-heat flex line leaking \\
\hline 23 & $8 / 4 / 05$ & B100 & $1: 30$ & $\begin{array}{l}\text { Temps too } \\
\text { high }\end{array}$ & $\begin{array}{l}\text { Temps too high for entire run. Water } \\
\text { dripping at air inlet on lower side of } \\
\text { reformer. }\end{array}$ \\
\hline 24 & $8 / 8 / 05$ & B100 & $3: 58$ & $\begin{array}{l}\text { Engine } \\
\text { tripped }\end{array}$ & $\begin{array}{l}\text { Installed new thermowell } 2 \text { " deep in Ni balls. } \\
\text { Right electrode wire burned through, arcing } \\
\text { to center pipe. }\end{array}$ \\
\hline 25 & $8 / 9 / 05$ & B100 & 7:43 & $\begin{array}{l}\text { Low air } \\
\text { flow }\end{array}$ & $\begin{array}{l}\text { Air flow rates dropped from } 21.6 \mathrm{scfm} \text { at } 50 \\
\mathrm{~Hz} \text { at } 10: 45 \text { to } 18.2 \mathrm{scfm} \text { at } 60 \mathrm{~Hz} \text { at } 5: 40 \text {. }\end{array}$ \\
\hline
\end{tabular}




\begin{tabular}{|c|c|c|c|c|c|}
\hline Run & Date & Fuel & $\begin{array}{l}\text { Duration } \\
\text { (H:MM) }\end{array}$ & $\begin{array}{l}\text { Reason } \\
\text { Stopped }\end{array}$ & Comments \\
\hline 26 & $9 / 21 / 05$ & B100 & $0: 18$ & $\begin{array}{l}\text { Liquids } \\
\text { leaking } \\
\text { around } \\
\text { spark } \\
\text { plugs }\end{array}$ & $\begin{array}{l}\text { Tightened plugs but couldn't restart - both } \\
\text { porcelain insulators cracked inside reformer, } \\
\text { arcing to lid instead of electrodes. Replaced } \\
\text { plugs, connectors, and sealed plugs with } \\
\text { ceramic caulk. }\end{array}$ \\
\hline 27 & $9 / 22 / 05$ & B100 & $\begin{array}{l}\text { 19:54 } \\
\text { Longest run } \\
\text { to date. }\end{array}$ & $\begin{array}{l}\text { Low air } \\
\text { flow }\end{array}$ & $\begin{array}{l}\text { Targeting } 4.9 \text { air/fuel ratio and } 900^{\circ}-1000^{\circ} \\
\text { C per Dr. Tom Reed. Air flow rates dropped } \\
\text { from } 21.6 \mathrm{scfm} \text { at } 50 \mathrm{~Hz} \text { at } 13: 17 \text { to } 18.5 \\
\text { scfm at } 60 \mathrm{~Hz} \text { at 8:24. Engine shut down and } \\
\text { went to flare at 9:50 to reduce backpressure. } \\
\text { During this run, we used the temperature } 1^{\prime \prime} \\
\text { above the reformer outlet as the control } \\
\text { point, maintaining temperatures above } 800^{\circ} \\
\text { C minimum temperature to avoid the soot } \\
\text { formation region described by Dr. Reed. This } \\
\text { was the longest run to date, confirming the } \\
\text { proper air/fuel/water ratios for soot-free } \\
\text { operation. White/grey powder on Ni balls } \\
\text { analyzed and determined to be due to } \\
\text { minerals in water used for reformer. } \\
\text { Demineralizer was installed before next run. }\end{array}$ \\
\hline 28 & $\begin{array}{l}11 / 6 / 05 \\
- \\
11 / 7 / 05\end{array}$ & B100 & $\begin{array}{l}30 \mathrm{hr} \\
\text { Longest run } \\
\text { to date. }\end{array}$ & $\begin{array}{l}\text { Fuel filter } \\
\text { plugged }\end{array}$ & $\begin{array}{l}\text { As with run } 27, \text { we used the temperature } 1 \text { " } \\
\text { above the reformer outlet as control point. } \\
\text { This was our most successful run, with } \\
\text { extremely stable temperature and } \mathrm{H}_{2} \\
\text { production. Air flow very slowly decreasing } \\
\text { from } 22.5 \mathrm{scfm} \text { at } 50 \mathrm{~Hz} \text { at } 16: 28 \text { on } 11 / 6 \text { to } \\
21.6 \mathrm{scfm} \text { at } 52 \mathrm{~Hz} \text { at } 19: 17 \mathrm{on} 11 / 7 \text {. Fuel } \\
\text { flow decreasing from } 2.81 \mathrm{ml} / \mathrm{s} \text { at } 58 \% \text { full } \\
\text { stroke at } 17: 01 \text { on } 11 / 6 \text { to } 2.47 \mathrm{ml} / \mathrm{s} \text { at } 75 \% \\
\text { full stroke at } 22: 40 \text { on } 11 / 7 \text {. System left } \\
\text { unattended after above adjustment. } \\
\text { Overnight, fuel filter plugged, mixture went } \\
\text { lean and overheated. By } 6: 30 \text { am, system } \\
\text { was cool, air and water were still on at full } \\
\text { flow. }\end{array}$ \\
\hline
\end{tabular}

Table V-1

At this point, the plasma reformer had suffered high temperature thermal damage. The reformer was completely redesigned and rebuilt with heavier gauge metals, more readily available components (e.g. spark plugs), larger internal capacities, and better fuel, air, and water mixing and atomization. 
During run 28, measurements were taken to determine if the EMx system is still performing as it did in the early days of testing. Figure $\mathbf{V - 1}$ shows the temperature profile inside the plasma reformer during runs number 27 and 28 , the two most stable runs that were achieved.

Plasma Reformer Temperature Profile

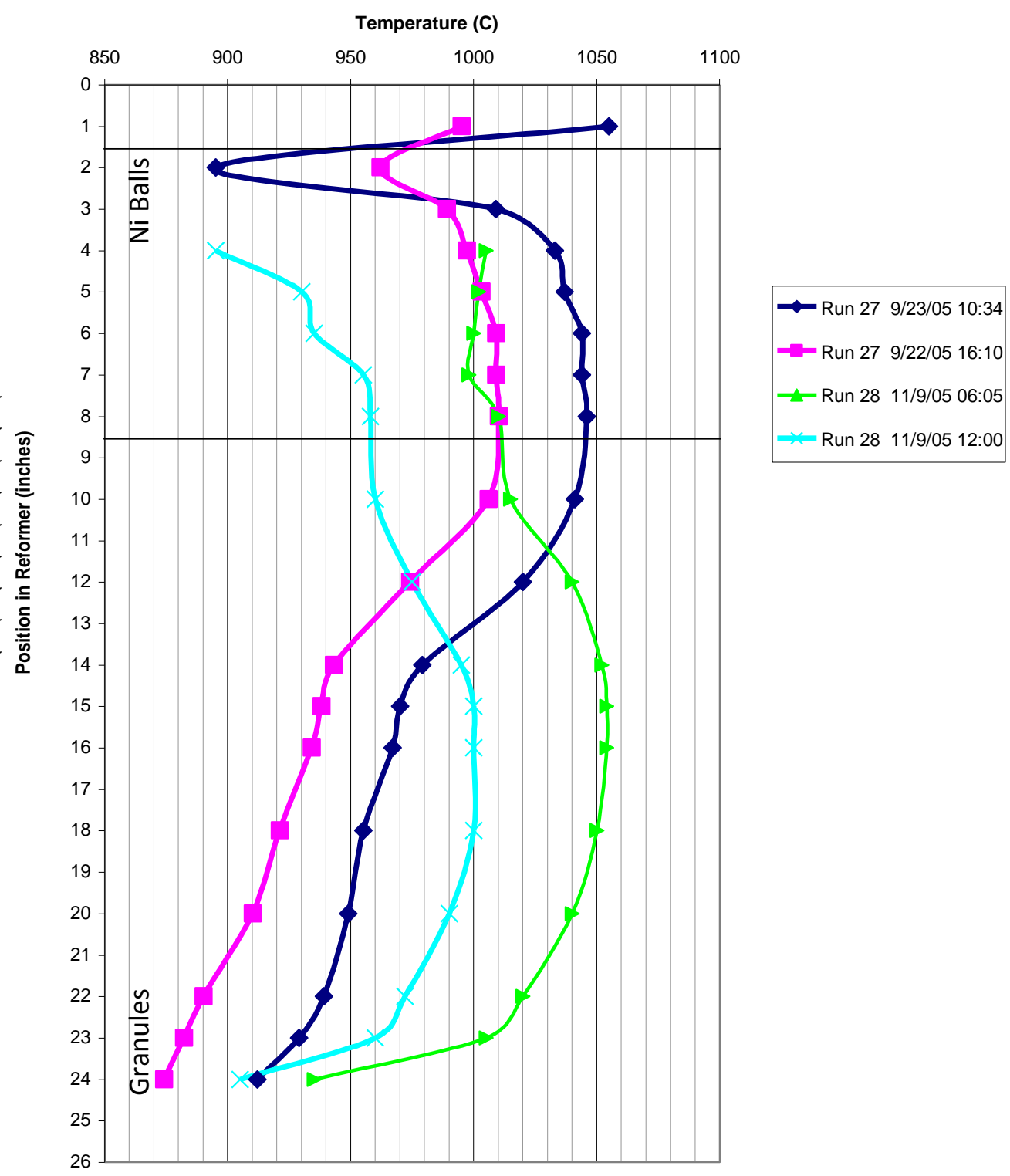

Figure $V-1$ 
Figure $\mathbf{V - 2}$ shows the oxygen depletion during run 28 . The low minimum value indicates that there is little or no bypass around the catalyst modules. The amount of time that elapses before the minimum oxygen concentration is achieved is longer than in the tests run just after the catalyst and door seals were repaired. It is possible that the total regen gas flow rate is lower than during the earlier test.

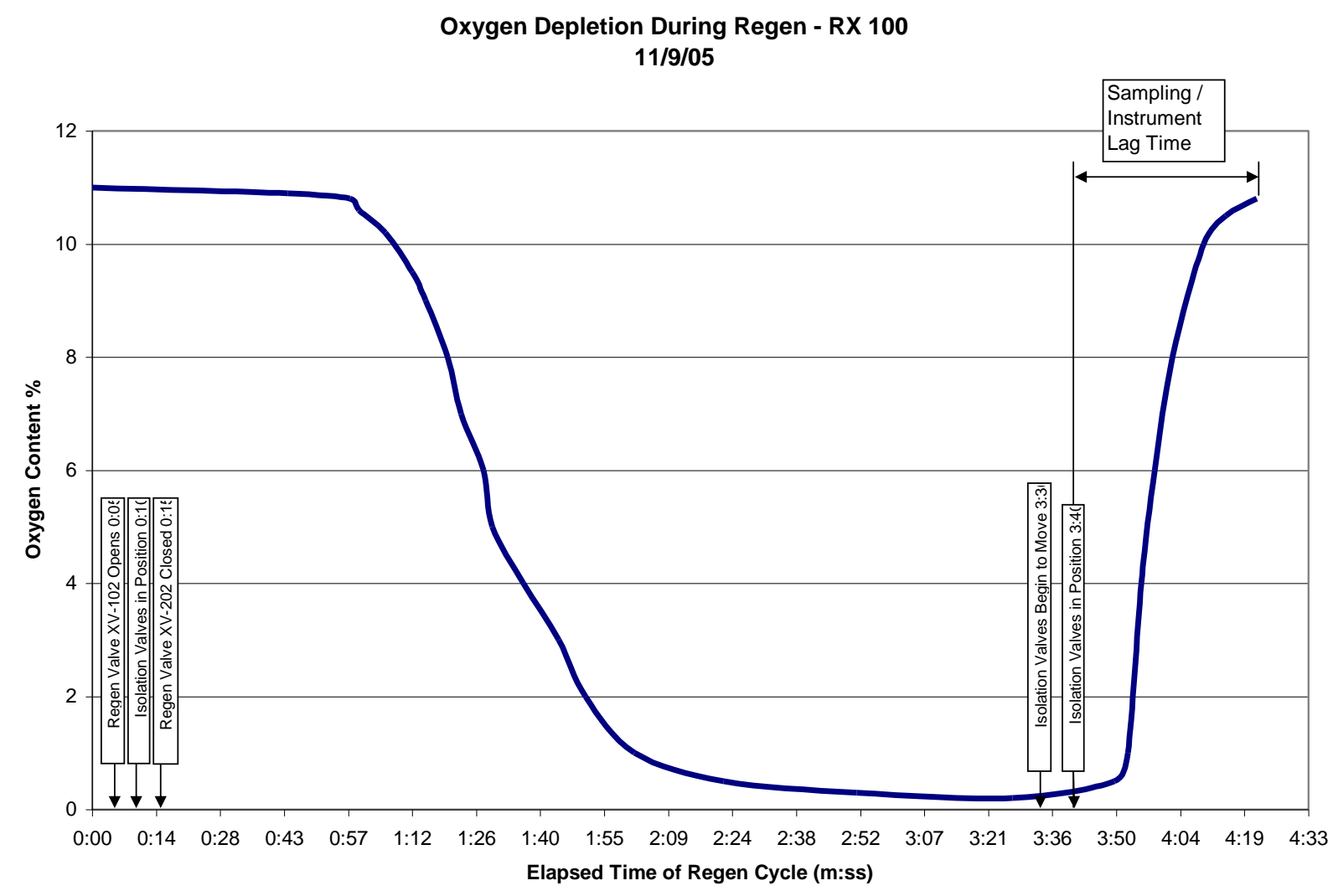

Figure $\mathrm{V}-2$

After the catastrophic failure of the catalyst at the end of run 28 , a new plasma reformer was designed as shown in Figure V-3 and Figure V-4. The design included a thicker walled vessel, with off-the-shelf components wherever possible. All components were specified to be available in the United States, in contrast with the original design, which contained electrode connectors only available in Europe. 


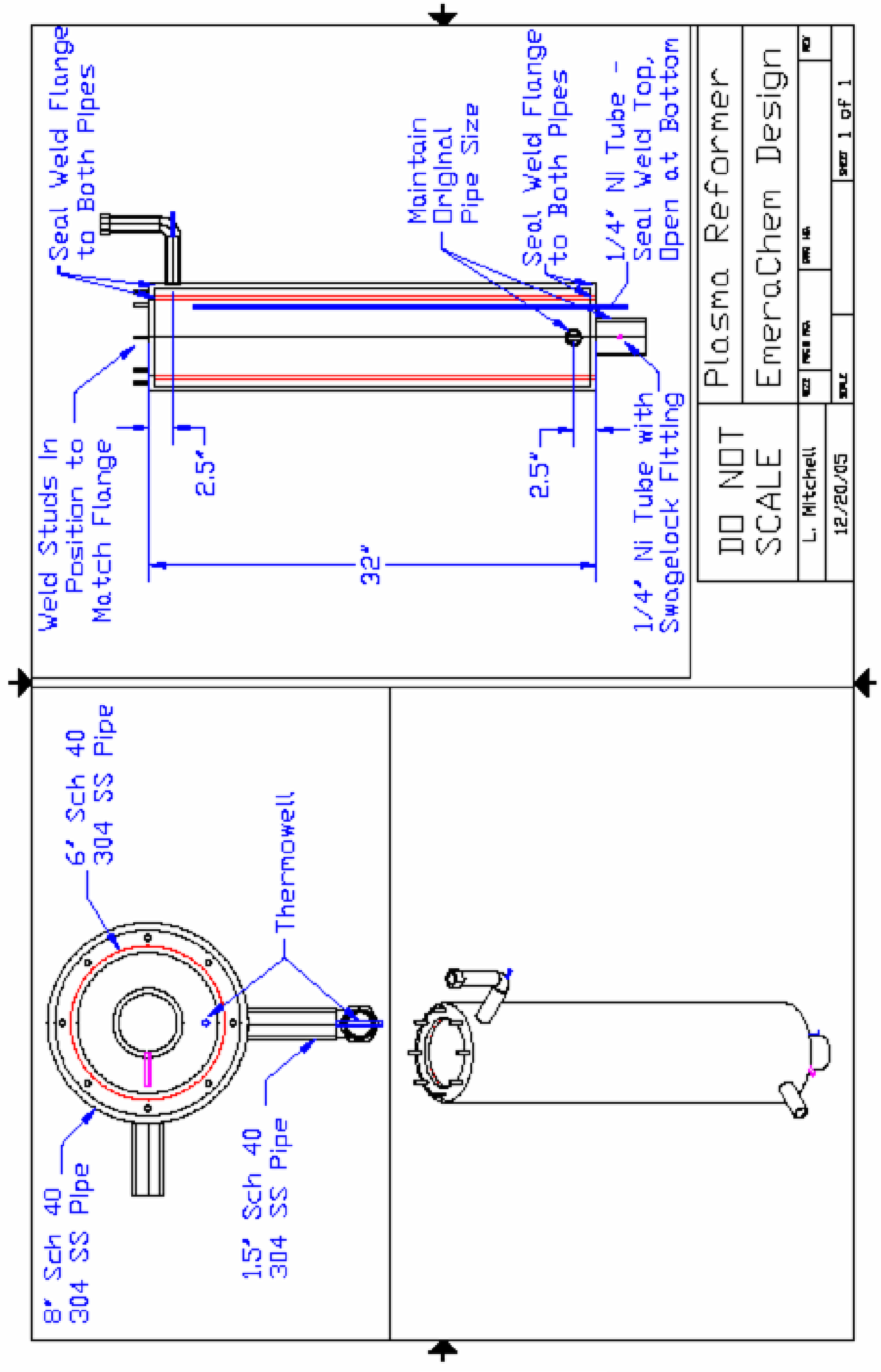

Figure V-3 


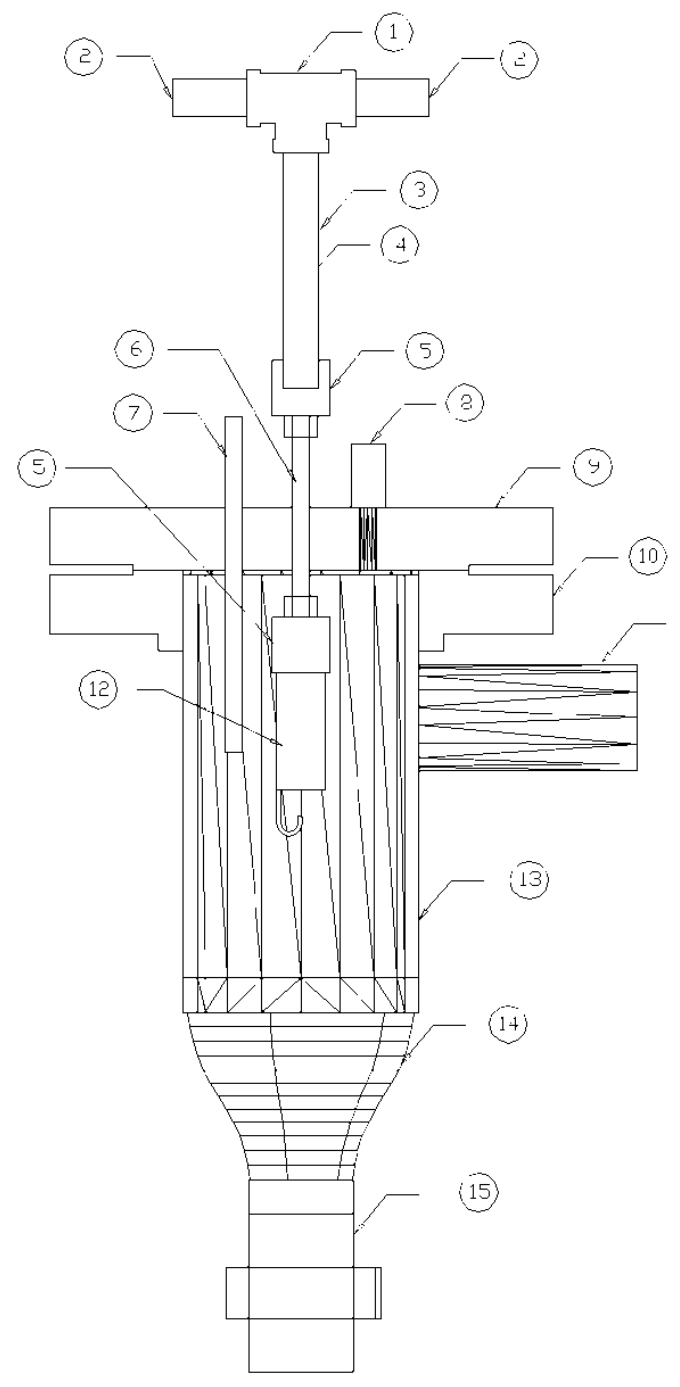

\begin{tabular}{|c|c|c|}
\hline Item & Qty & Description \\
\hline 1 & 1 & $\begin{array}{l}316 \text { SS Female Tee 1/4"NPT x 1/4"NPT } \\
\text { (McMaster 4464K48) }\end{array}$ \\
\hline 2 & 2 & $\begin{array}{l}316 \text { SS Adapter 1/4" NPT Male x 1/4” } \\
\text { YOR-LOK (McMaster 5182K111) }\end{array}$ \\
\hline 3 & 1 & $\begin{array}{l}316 \text { SS } 1 / 4 \text { ” Pipe Nipple, Threaded } 3 \text { 1/2 “ } \\
\text { Long (McMaster 4548K144) }\end{array}$ \\
\hline 4 & 1 & Static Mixer, 3 1/2" Long \\
\hline 5 & 2 & $\begin{array}{l}316 \text { SS Adapter 1/4" NPT Female x 1/4" } \\
\text { Tube Socket Weld (McMaster } \\
51255 \mathrm{~K} 302 \text { ) }\end{array}$ \\
\hline 6 & 1 & 316 SS 1/4" Tube, Thick Walled \\
\hline 7 & 1 & Thermowell \\
\hline 8 & 1 & $\begin{array}{l}316 \text { SS Adapter 1/8" NPT Male x 1/8" } \\
\text { YOR-LOK (McMaster 5182K804) }\end{array}$ \\
\hline 9 & 1 & $\begin{array}{l}\text { 316 SS Forged Type Blind Flange 3" } \\
\text { (McMaster 44695K118) }\end{array}$ \\
\hline 10 & 1 & $\begin{array}{l}\text { 316 SS Forged Type Slip-On Flange 3" } \\
(\text { McMaster 44695K38) }\end{array}$ \\
\hline 11 & 1 & 316 SS 1 1 1/2" SCH 40 Pipe \\
\hline 12 & 1 & Bete 1/4P28@5303 SS Fogging Nozzle \\
\hline 13 & 1 & $\begin{array}{l}\text { 316 SS 3" Pipe Nipple, Threaded } 1 \text { End, } \\
\text { 6" Long (McMaster 9110T79) }\end{array}$ \\
\hline 14 & 1 & $\begin{array}{l}316 \text { SS Reducing Coupling, 3" x 1" } \\
\text { Butt-Weld x Butt-Weld }\end{array}$ \\
\hline 15 & 1 & $\begin{array}{l}316 \text { SS 1" Pipe Union, Socket-Weld x } \\
\text { Socket-Weld }\end{array}$ \\
\hline
\end{tabular}




\begin{tabular}{|c|c|c|c|c|c|}
\hline Run & Date & Fuel & $\begin{array}{l}\text { Duration } \\
\text { (H:MM) }\end{array}$ & Reason Stopped & Comments \\
\hline 29 & $10 / 9 / 06$ & B100 & $2: 43$ & $\begin{array}{l}\text { Unstable, not } \\
\text { making hydrogen }\end{array}$ & $\begin{array}{l}\text { First restart after complete rebuild } \\
\text { of system. Larger vessel, larger } \\
\text { diameter fuel and water lines, } \\
\text { additional filter on fuel, additional } \\
\text { filter on water, larger pre-heat air } \\
\text { line, fuel/water mixing chamber } \\
\text { installed with atomizer, no Ni balls } \\
\text { - only untreated alumina balls }\end{array}$ \\
\hline 30 & 10/10/06 & B100 & Unknown & $\begin{array}{l}\text { Temp spiked - } \\
1343^{\circ} \mathrm{C}\end{array}$ & $\begin{array}{l}\text { Very unstable. Max fuel and water } \\
\text { reached, could not push one } \\
\text { without restricting other. Temp } \\
\text { spike was } 10^{\prime \prime} \text { into balls. Melted } \\
\text { thermowell. Lid wedged onto } \\
\text { studs, had to be pried off. }\end{array}$ \\
\hline 31 & $10 / 26 / 06$ & B100 & $0: 59$ & $\begin{array}{l}\text { Leaking fuel } \\
\text { caught on fire }\end{array}$ & $\begin{array}{l}\text { Oil leaking from mixing chamber } \\
\text { onto lid. Max } \mathrm{H} 2-14 \% \text {, flare } \\
\text { unstable. During cool down (very } \\
\text { low air flow) } \mathrm{H} 2 \text { reached } 22 \% \text {. } \\
\text { Temp higher in the middle of the } \\
\text { reformer. Suspect air/water } \\
\text { mixture was hitting walls and } \\
\text { running down, resulting in worse } \\
\text { atomization than original design }\end{array}$ \\
\hline 32 & $10 / 27 / 06$ & B100 & $1: 23$ & $\begin{array}{l}\text { Temperature } \\
\text { spike to } 1250^{\circ} \mathrm{C}\end{array}$ & $\begin{array}{l}\text { Added } 3 / 4 \text { " layer of Ni balls to top of } \\
\text { reformer and moved spray nozzle } \\
\text { to mixer throat. Reformer lid } \\
\text { gasket leaking, small leak between } \\
\text { mixing chamber and reformer. H2 } \\
\text { never above } 8 \% \text {, flare unstable, } \\
\text { pulsating sound noted. } \\
\text { Temperature climbed suddenly and } \\
\text { rapidly to } 1250^{\circ} \mathrm{C} \text { at } 3^{\prime \prime} \text { into the } \\
\text { balls. Thermowell melted at } 18^{\prime \prime} \\
\text { from bottom, Ni balls meted at top, } \\
\text { ceramic balls slumped } 1 " \text { below } \\
\text { bridge of Ni balls. Ceramic balls } \\
\text { free flowing. Nozzle black w/baked } \\
\text { on carbon and tar. }\end{array}$ \\
\hline
\end{tabular}




\begin{tabular}{|l|l|l|l|l|l|}
\hline Run & Date & Fuel & $\begin{array}{l}\text { Duration } \\
\text { (H:MM) }\end{array}$ & Reason Stopped & Comments \\
\hline 33 & $10 / 28 / 06$ & B100 & $\sim 1 \mathrm{hr}$ & $\begin{array}{l}\text { Too hot - 1264 }{ }^{\circ} \mathrm{C} \\
\text { at 18" from top of } \\
\text { reformer. }\end{array}$ & $\begin{array}{l}\text { Polished mating surface between } \\
\text { mixing chamber and reformer to } \\
\text { eliminate leaks. Replaced Ni } \\
\text { thermowell and cut new gasket for } \\
\text { reformer lid. Replaced spray nozzle } \\
\text { and coated alumina beads with Ni } \\
\text { salt prior to run. Very unstable } \\
\text { hydrogen concentration - 4\% to } \\
\text { 18\%. When more water is added, } \\
\text { the fuel pressure goes up, resulting } \\
\text { in lower fuel flow. Also, increasing } \\
\text { water flow rate reduced temps at } \\
\text { top of bed but greatly increased } \\
\text { them in the middle of the bed. } \\
\text { Suspect exothermic water/gas shift } \\
\text { reaction is occurring inside the } \\
\text { media. }\end{array}$ \\
\hline
\end{tabular}

Table V-2

After run 33, it was concluded that the plasma reformer instability had increased. Further progress will require extensive development efforts on the plasma reformer or an alternative source for regen gas. This may be due to the substitution of alumina balls for the fragile, but catalytically activated pumice stones, or the coating of the alumina balls with a nickel salt catalyst solution.

\section{Conclusions}

The EMx catalyst system performs at greater than $90 \%$ NOx removal, even with very high inlet NOx concentrations and operating temperatures of $750^{\circ} \mathrm{F}$. The EMx system eliminates the visible plume and significantly silences the engine exhaust.

\section{Summary of Results}

1. NOx performance was high across all blends of biodiesel.

2. Exhaust bypass around the catalyst was discovered midway through the testing. This compromised several of the measurements made during commissioning and on the shortterm fuel blend tests.

3. Unfortunately, most of the demo project focused on developing the plasma reformer, e.g., learning how to start up the system, how to operate it in a stable manner, how to avoid soot formation and high temperature extremes, how to retrofit it with safety interlocks, etc. Several design/rebuild retrofits were undertaken to improve the reliability of the reformer system and the durability of the hardware components. Ultimately, the plasma reformer proved to be unstable and unreliable and curtailed the studies of EMx performance. 


\section{Future Work}

1. Future studies should include long-term studies of the effects of biodiesel on the catalyst.

2. All future studies hinge on the availability of reliable technologies to produce regeneration gas. 


\section{Attachment "C"}

(The following report, which pertains solely to the Caterpillar 3516B genset, was commissioned by McMinnville Electric System as part of this Project and is therefore incorporated and made part of this Final Report as submitted. The author is unknown) 


\section{McMinnville Biodiesel Test}

- Caterpillar 3516B EPG

- Engine Built 8/20/04

-2293 BHP

- 1640 Gen. KW @ 60 Hz (continuous)

- Low Emission Strategy

\section{Test Plan}

- Blend B100 with Ultra Low Sulfur Diesel

$-4 \mathrm{hrs}$ on $98 \%$ ULSD and $2 \%$ B100

$-4 \mathrm{hrs}$ on $95 \%$ ULSD and 5\% B100

$-4 \mathrm{hrs}$ on $80 \%$ ULSD and $20 \%$ B100

- $4 \mathrm{hrs}$ on $50 \%$ ULSD and $50 \%$ B100

- Remainder of $1000 \mathrm{hr}$. test on $100 \%$ B100 


\section{(Continued)}

- Sample oil every 100hrs (Dealer)

- B100 Fuel Sample prior to start-up (OK)

- Lubricity (wear scar test @ 60C) tested at

$0.169 \mathrm{~mm}$ compared to a max. limit of $0.45 \mathrm{~mm}$

- $500 \mathrm{hr}$ inspection

- Return two injectors for analysis by Cat Fuel Systems

- $1000 \mathrm{hr}$ inspection

- Return two injectors for inspection (Cat Fuel Systems)

- Return two cylinder packs (Cat)

- Return two cylinder heads (Cat)

\section{Miscellaneous Engine Information}

- Fuel settings increased to compensate for B100. New settings allow engine to produce advertised horsepower

- Engine shutdown for winter with B100 in the fuel lines/injectors and started up w/o problems

- Totals

- Hours 1007

- Fuel Burned 108,966 gal.

- Load Factor $88 \%$ 


\section{Injector Inspection/Analysis 500 Hours}

- Two injectors removed at $\mathbf{5 0 0} \mathrm{hrs}$.

- Two injectors were sent to Pontiac for verifying their performance after $500 \mathrm{hrs}$ with bio-diesel. As shown above in the performance plots, Injectors performance is not significantly different from its original performance. Both the injectors were found to be low on delivery and timing. This small variation might be due to some debris clogged in the valve or the nozzle assembly. One of the injectors ( $/ \mathrm{n}$ 642048) passed the performance test on retesting and another ( $\mathrm{S} / \mathrm{n}$ 642049) failed marginally for lower rated delivery only (D2 Vs T2 relationship).

- As shown in Table 1 there was only $1 \%$ decrease in the rated delivery for injector with S/n 642048, which passed the test and there was $5.2 \%$ decrease in the rated delivery for injector with $S / n$ 642049, which failed the test marginally but this is not a significant change.

\section{Injector Inspection/Analysis 500 Hours (continued)}

- Summary

- Two injectors were submitted for general inspection after $500 \mathrm{hrs}$ on engine with $100 \%$ biodiesel. Retest data is not significantly different from the original test data. One injector passed the performance test and one failed marginally for lower rated delivery as shown in the Figure 1 (D2 Vs T2 relationship). Rated as well as idle deliveries were on the lower side, which might be due to the flow restriction in the tips or bench movement. 


\section{Injector Inspection/Analysis 1000 Hours}

- Two injectors removed at $\mathbf{1 0 0 0} \mathrm{hrs}$.

- Two injectors were sent to Pontiac for verifying their performance after $1000 \mathrm{hrs}$ with bio-diesel. As shown above in the performance plots, Injectors performance is not significantly different from its original performance. Both the injectors were found to be low on delivery and timing. This small variation might be due to some debris clogged in the valve or the nozzle assembly. As shown in Table 1, one of the injectors ( $S / n$ 642053) passed the performance test on retesting and another ( $\mathrm{h} / \mathrm{n}$ 642058) failed for leak, which is marginally out of the limit and which could be a bench error.

- Inspection:

- All the injector parts were inspected thoroughly under magnification and as show in the figure below, there is no sign of cavitation or unusual wear on the critical injector components.

\section{Injector Inspection/Analysis 1000 Hours (continued)}

- Summary

- Two injectors were submitted for general inspection after $1000 \mathrm{hrs}$ of operation with $100 \%$ biodiesel in the engine. One injector passed the performance test on retesting and one failed marginally for leakage. Performance results are not significantly different from the original test data. Rated as well as idle deliveries and timing are on the lower side, which might be because of the flow restriction in tips due to debris. This was also seen in the $500 \mathrm{hr}$ test returned injectors for inspection with $100 \%$ biodiesel (See report 075-010807). 


\section{Load Factor Histogram}

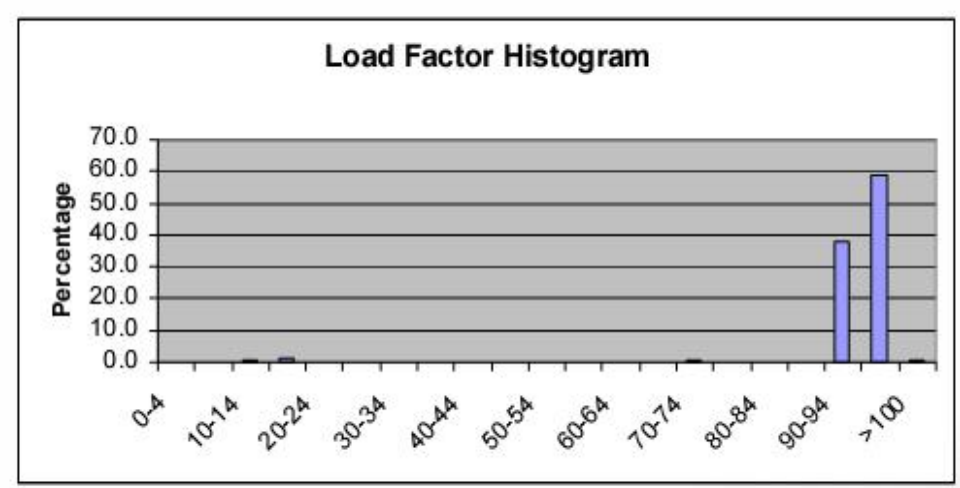

\section{Exhaust Temperature Histograms}

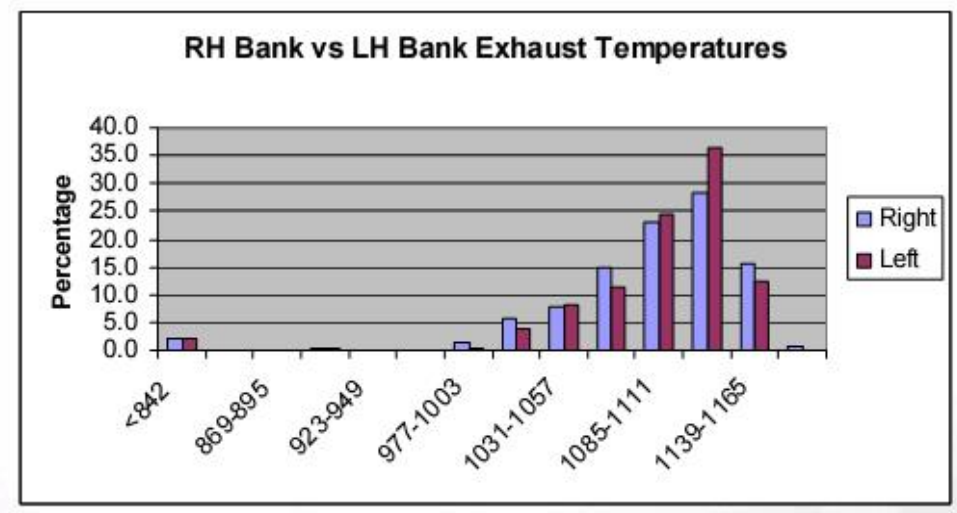




\section{Logged Diagnostic Codes}

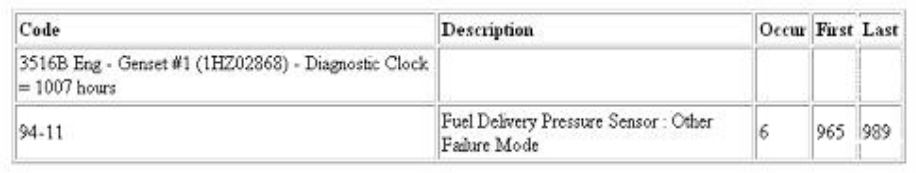

\section{Issues Identified at $1000 \mathrm{hr}$. Inspection}

- Items negatively affected by B100

- Lower cylinder liner seals

- ECM fuel cooling hoses

- Fuel cooler hoses

- Oil cooler outer tube seals

- Engine oil samples

- Issues not related to B100

- Right hand bank wet stacking 


\section{Summary}

- No downtime due to engine

- Internal moving components in excellent condition

- Hose/seal material acceptable for <B30, needs to be modified for operating on B100

- Test was very successful

\section{Floating \\ Bridges}

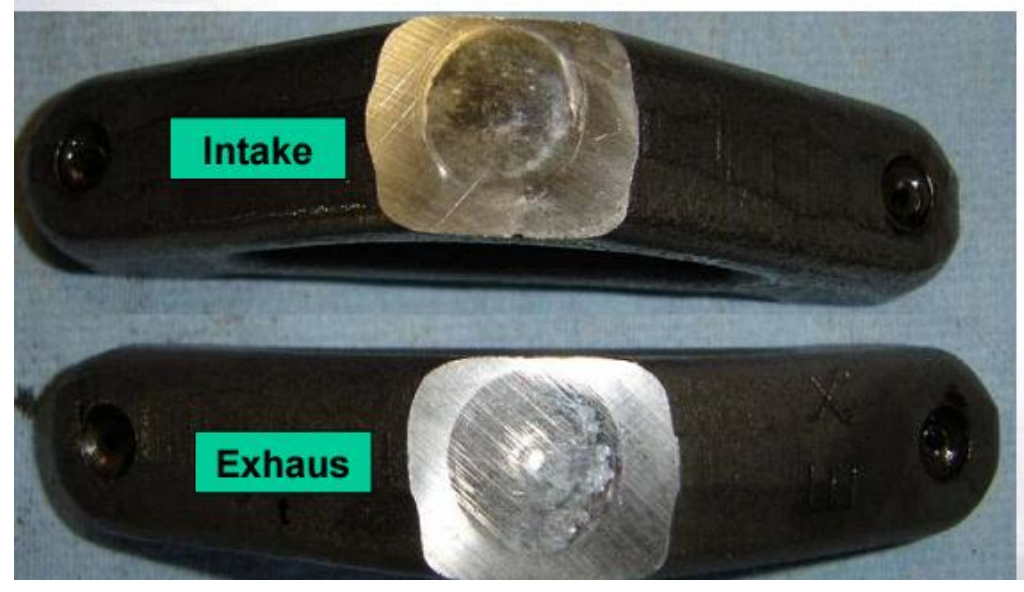

McMinnville Electric System

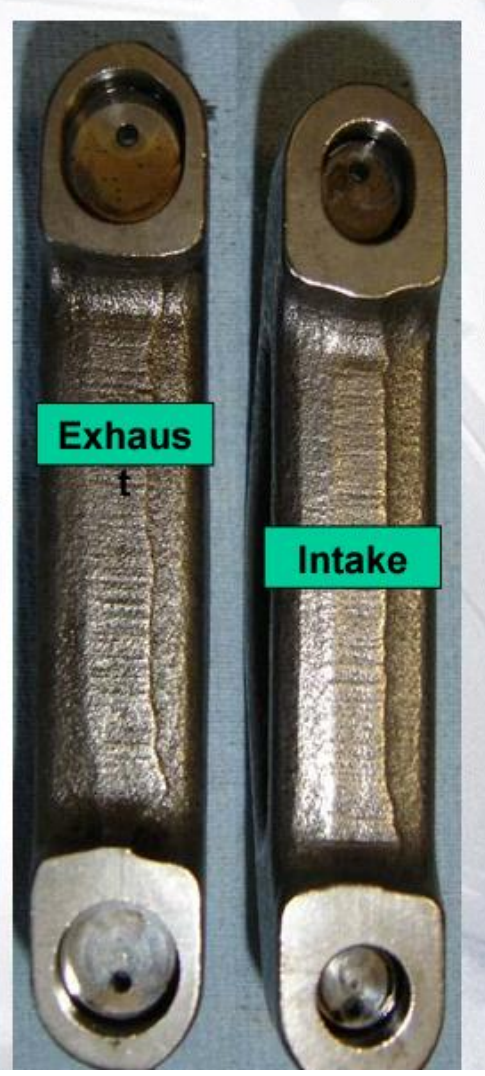

Page 81 of 182 


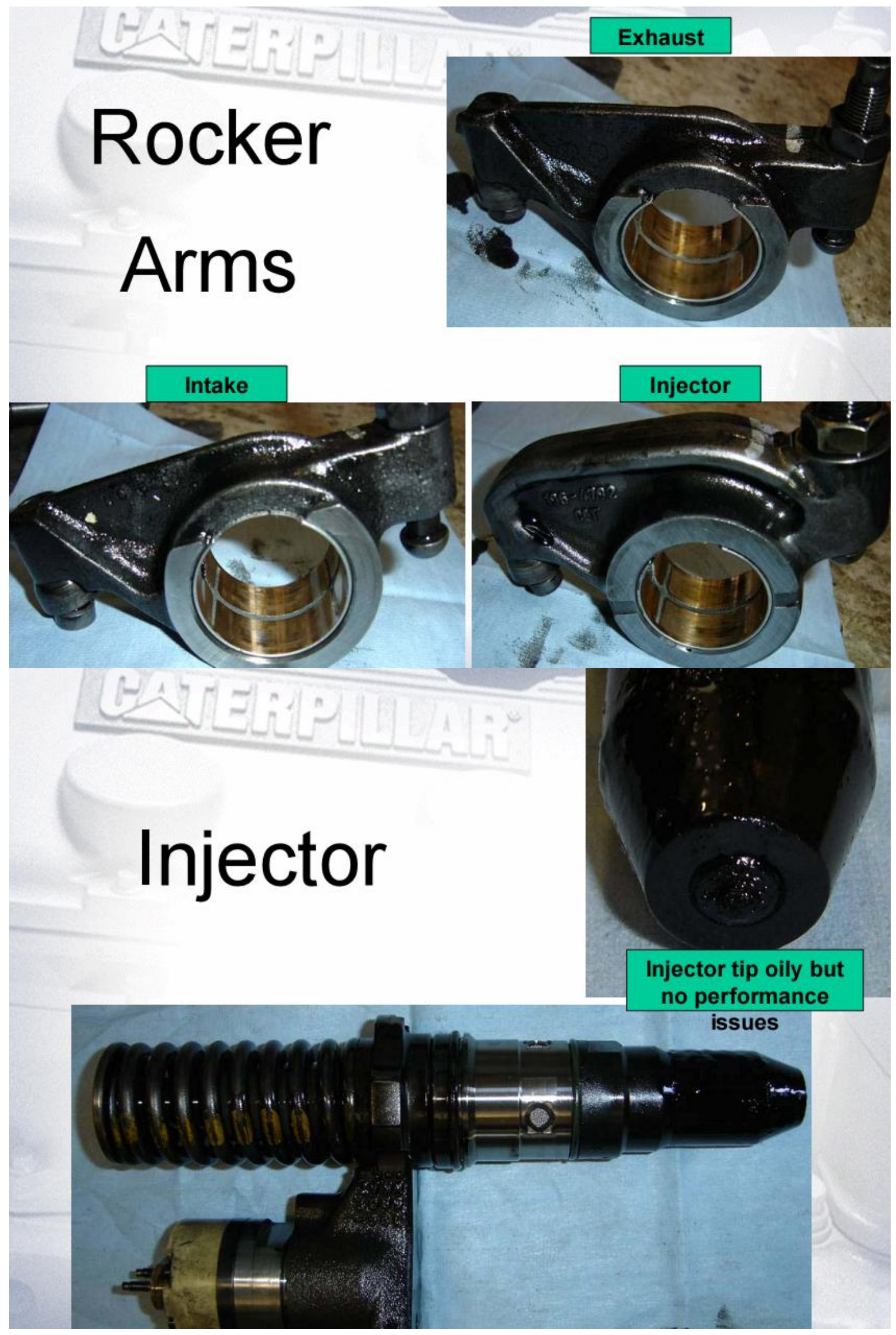



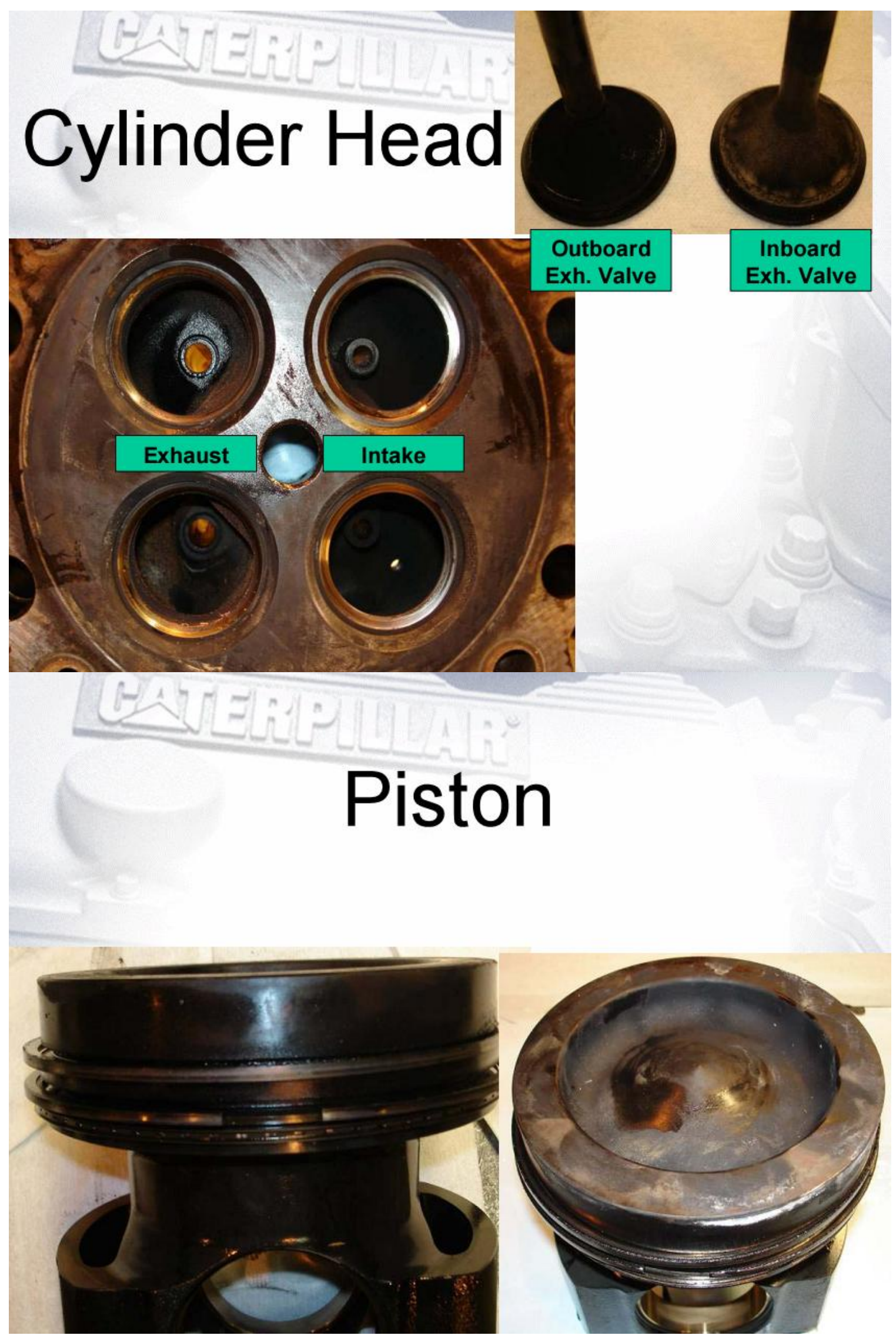

Page 83 of 182 


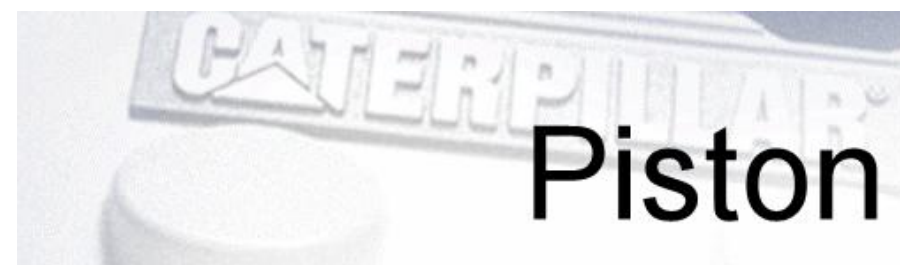

\section{(continued)}
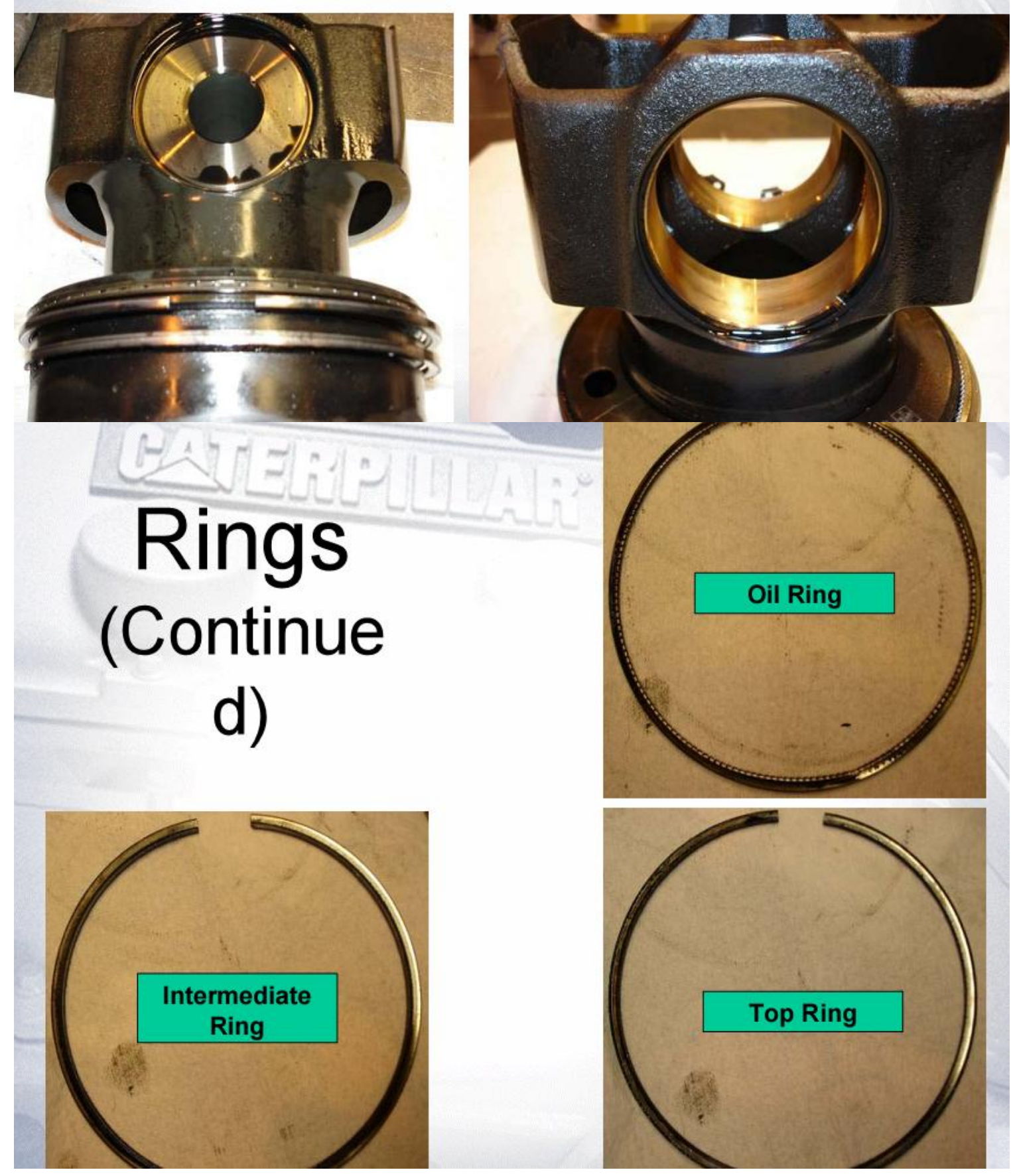


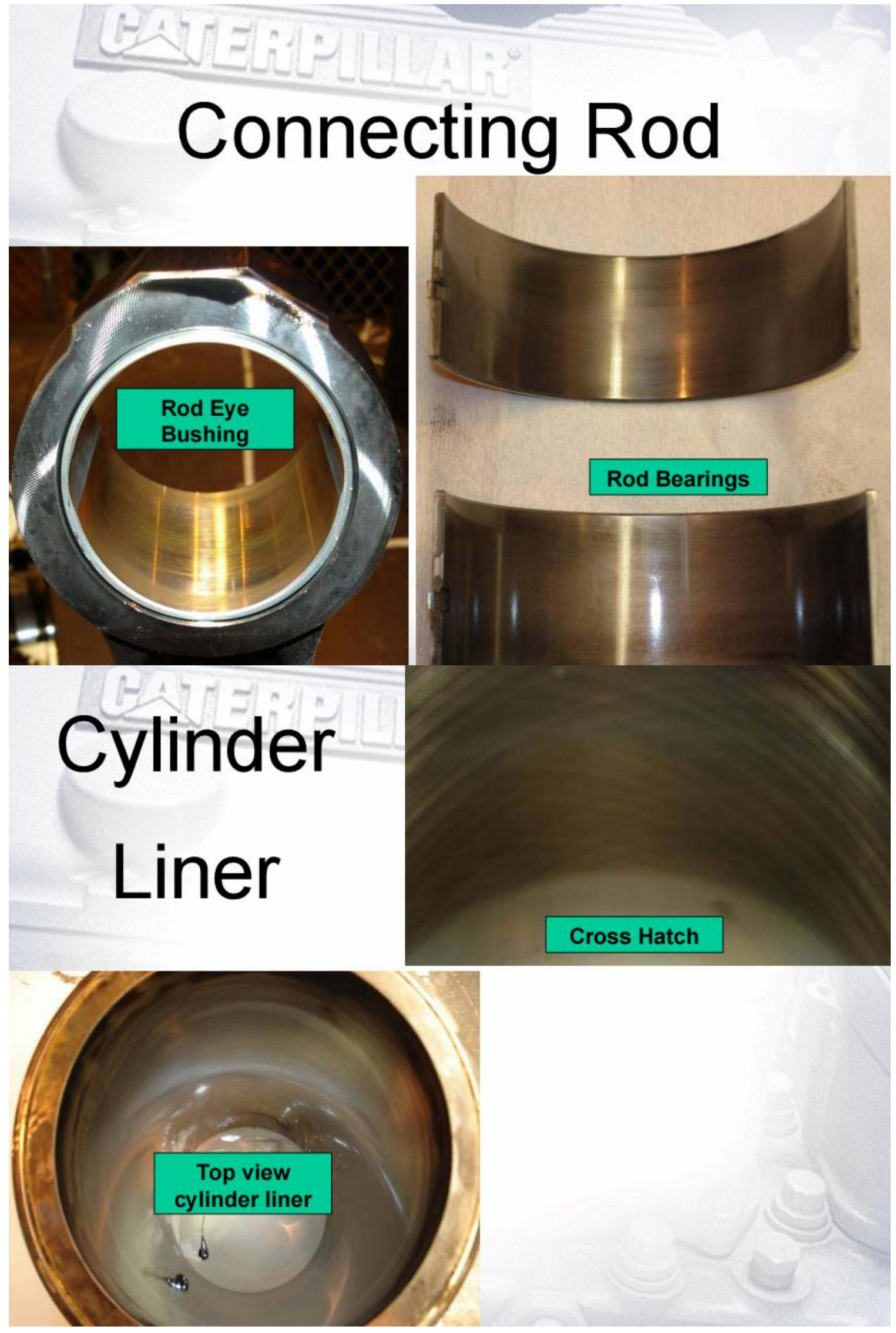




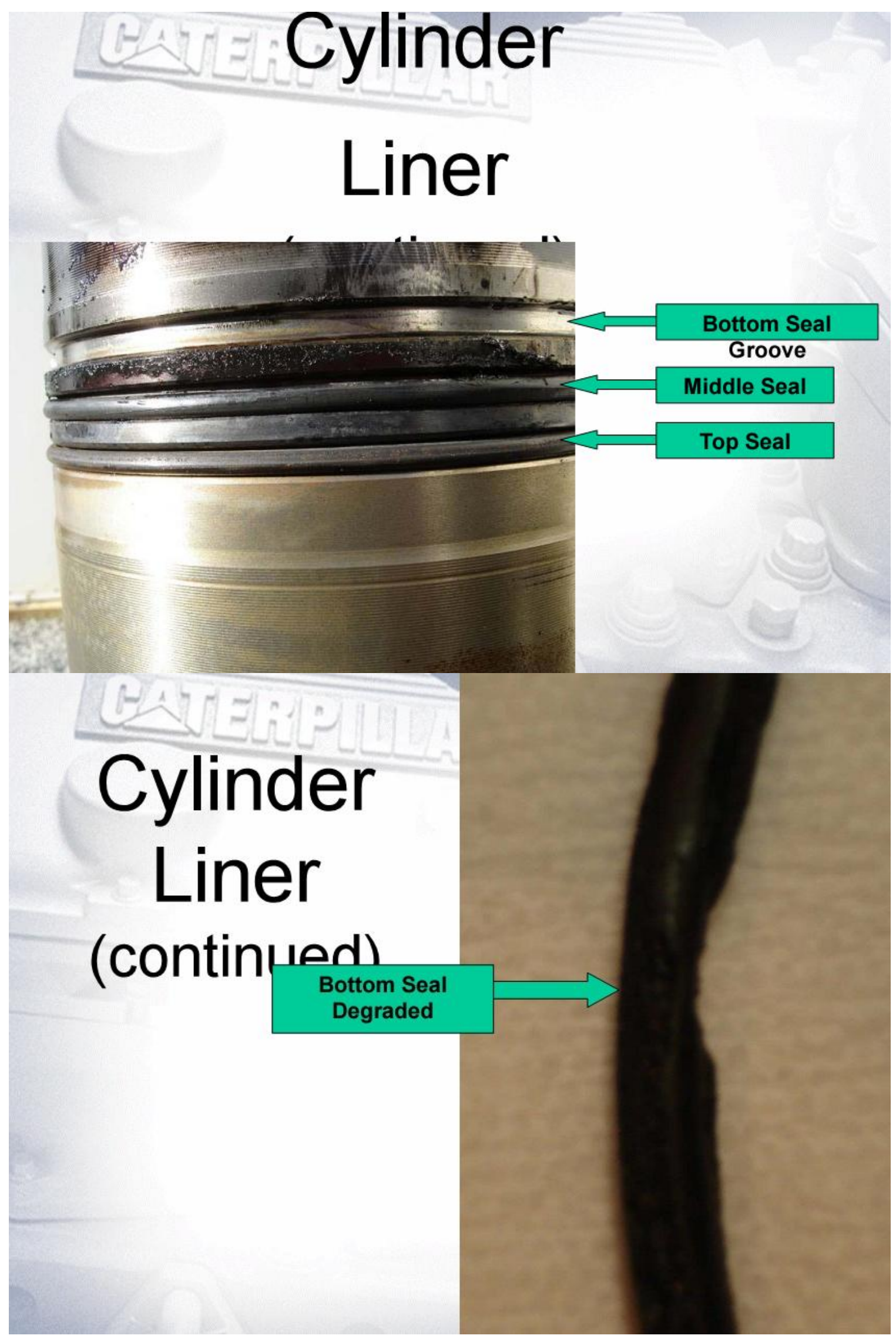




\section{Camshaft Lobes}

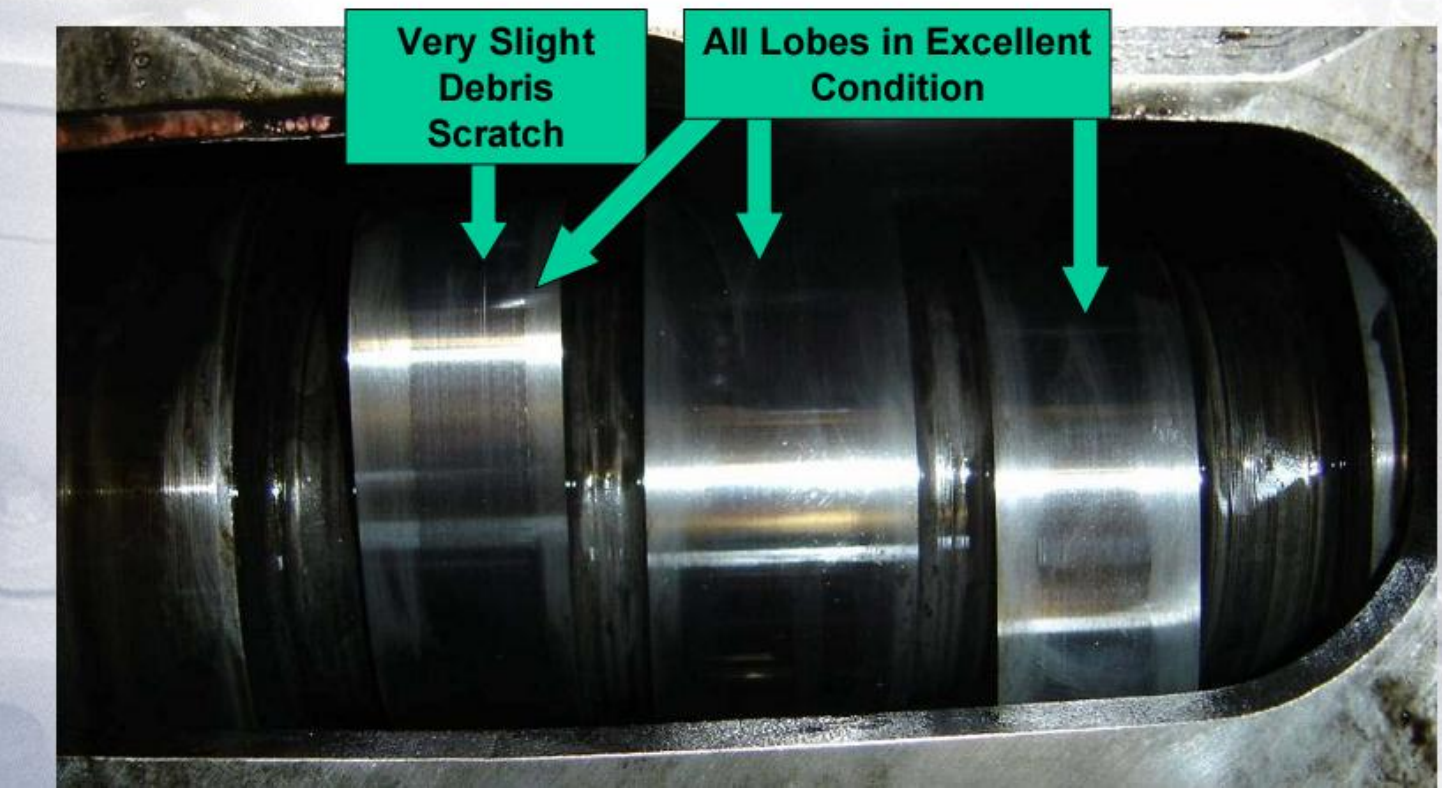


Attachment “D” 


\section{GENERATION OF $1 \mathrm{~kg} / \mathrm{h}$ OF HYDROGEN FROM SOYBEAN BIODIESEL}

\section{A. Czernichowski, M. Czernichowski and K. Wesolowska}

ECP - GlidArc Technologies, 45240 La Ferté Saint Aubin, France

\section{Introduction}

Efficient and non-sooting conversion of carbonaceous feeds into the SynGas (a mixture containing $\mathrm{H}_{2}$ and $\mathrm{CO}$ ) still remains at the R\&D stage. We believe that the Partial Oxidation (POX) process assisted by our GlidArc plasma is the best way of Syngas production. It uses an internal heat generation via low- or hightemperature combustion of a part of the feed in order to raise the temperature to a level where the POX can be done. At sufficiently high temperature it does not ask for complex, fragile and expensive catalysts.

Two US companies have been interested in our plasmaassisted technology to check if such biodiesel-into-SynGas converter, gas product flow rate, and gas quality can be used as a:

a) Part of de-NOx process in which frequent catalyst regeneration using Hydrogen is required,

b) Gaseous fuel to feed (or only boost) ordinary engines (ICEs) for decentralized power generation.

BCP has accepted both challenges and accordingly we built three prototypes of such reformers of $100 \%$ soybean biodiesel. Two prototypes installed in Tennessee and Colorado were successfully tested last summer and fall, respectively.

\section{GlidAre-assisted reformer}

The principle and a picture of our two-zone POX reformer are presented in two parallel papers on biomethane reforming ${ }^{1}$ and on bioethanol processing ${ }^{2}$. Our GlidArc discharge (see Fig. 1) is inserted in a plasma-assisted zone of the reformer.

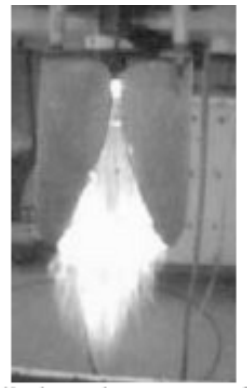

Figure 1. GlidArc discharge between two flat electrodes in air.

This zone communicates with the second zone filled with activated refractory granules where the fuel conversion is completed. A $10-\mathrm{kV}$ supply provides both an ionization of the oxidant/fuel mix and then a transfer of the electric energy into the plasma. The electric power measured at the mains is $0.5 \mathrm{~kW}$ as maximum for almost $80 \mathrm{~kW}$ output SynGas power (based on its Lower Heating Value, LHV). The reformer is thermally insulated to keep the post-plasma zone hot. It also contains a double wall in which air is preheated. Total inside volume of our reformers reaches presently $6 \mathrm{~L}$. Some thermocouples measure the post-plasma zone temperatures. Almost all SynGas is immediately flared during the laboratory trials or sent to an application like here presented de-

\footnotetext{
${ }^{1}$ Gernichowski, A.; Wesolowska, K. Prepr. Pap. - Am. Chem. Soc., Div. Fuel Chem., 2006, 5 I (2).

${ }^{2}$ Czernichowski, A.; Wesolowska, K. Prepr. Pap. - Am. Chem. Soc., Div. Fuel Chem, 2006, 51 (2).
}

NOx catalyst regeneration or an ICE feeding. A sample of SynGas crosses white wool for soot presence check. Other sample is analyzed using a two-channel $\mu$-GC dedicated to $\mathrm{H}_{2}, \mathrm{O}_{2}, \mathrm{~N}_{2}, \mathrm{CH}_{4}$, $\mathrm{CO}, \mathrm{CO}_{2}, \mathrm{C}_{2} \mathrm{H}_{4}, \mathrm{C}_{2} \mathrm{H}_{6}, \mathrm{C}_{2} \mathrm{H}_{2}, \mathrm{C}_{3} \mathrm{H}_{8}+\mathrm{C}_{3} \mathrm{H}_{6}$, and residual moisture.

Reforming

Feed. Soybean biodiesel used for our tests in France presents the LHV of $10.4 \mathrm{kWh} / \mathrm{kg}$ and a chemical formula $\left(\mathrm{CH}_{1.87} \mathrm{O}_{0.11}\right)_{n}$ Atmospheric air is used as oxidant. No air-drying is applied.

Chemistry. An ideal POX process of biodiesel conversion into SynGas using air can be written as:

$\mathrm{CH}_{1.87} \mathrm{O}_{0.11}+0.445 \mathrm{O}_{2}\left(+1.68 \mathrm{~N}_{2}\right)=\mathrm{CO}+0.935 \mathrm{H}_{2}\left(+1.68 \mathrm{~N}_{2}\right)$. (1)

It would ask for 3.05 Litres [at normal (n) conditions] per gram of biodiesel. Unfortunately, such reaction cannot be realized, as the Thermodynamic prefers to form rather methane $\mathrm{CH}_{4}$ and soot to find its deepest Gibbs energy level. To suppress these unwanted products one needs to add more Oxygen (from air in this case) that will highly rise the temperature of the process and produce other unwanted (but more acceptable) products: $\mathrm{CO}_{2}$ and $\mathrm{H}_{2} \mathrm{O}$. To simplify one can write a paral lel full combustion reaction: $\mathrm{CH}_{1.87} \mathrm{O}_{0.11}+1.41 \mathrm{O}_{2}\left(+5.32 \mathrm{~N}_{2}\right)=\mathrm{CO}_{2}+0.935 \mathrm{H}_{2} \mathrm{O}\left(+5.32 \mathrm{~N}_{2}\right)$ (2)

that asks for $9.65 \mathrm{~L}(\mathrm{n})$ of air per gram of biodiesel.

As result one can consider such non-sooting conversion of the biodiesel as a mix of the reactions (1) and (2) in a proportion of " $x$ " moles of biodiesel completely burnt according to the reaction (2) per one mole of biodiesel converted according to the reaction (1). Some steam is already produced by the reaction (2). Adding extra water we promote the water-shift reaction:

$$
\mathrm{CO}+\mathrm{H}_{2} \mathrm{O}=\mathrm{CO}_{2}+\mathrm{H}_{2} \mathrm{O}
$$

$$
\text { (3) }
$$

as well as other endothermic processes of soot gasification and methane Steam Reforming (SR) like:

$$
\mathrm{CH}_{4}+\mathrm{H}_{2} \mathrm{O}=\mathrm{CO}+3 \mathrm{H}_{2}
$$

so that the value " $x$ " can be diminished.

Our GlidArc-assisted process can therefore be considered as Compromise between an ideal POX, full combustion and SR processes in the presence of a contact surface. Our very simple cold plasma source ignites these processes and keeps them progressing through an injection of highly activated catalytic species.

Experiments in ECP's facility. An industrial blower at the input pressure up to 370 mbar provides air. The air flow at variable rates is set in a function of the variable fuel flow rates that define a wanted output SynGas flow. Air enters the double-wall of the reformer where it is preheated in order to integrate a waste process heat for better thermal efficiency of the reforming. A pump sucks biodiesel the from a recipient put on a scale. Water directly taken from the water-supplying pipe is injected to the reformer through the same injection pipe that we use for the fuel. The following ranges of parameters and conditions are explored:

$\begin{array}{lll}\begin{array}{l}\text { Air input flow-rate } \\ \quad \text { L(n)/min }\end{array} & 137-464 & \\ \text { Biodiesel oil flow-rate } & 29-150 & \mathrm{~g} / \mathrm{min} \\ \text { Water flow rate } & 21-75 & \mathrm{~g} / \mathrm{min} \\ \text { Input power (LHV) of fuel } & 18-94 & \mathrm{~kW} \\ \text { Air/fuel ratio } & 3.1-5.2 & \mathrm{~L}(\mathrm{n}) / \mathrm{g} \\ \text { Water/fuel ratio } & 0.47-1.1 & \mathrm{~g} / \mathrm{g}\end{array}$

As results we are generating the SynGas containing the following species (dry, in vol.\%):
$\mathrm{H}_{2}$
$\mathrm{H}_{2}+\mathrm{CO}$
$19-23$ (av. 22) $\mathrm{CO}$
$10-20$ (av. 15)
$\mathrm{CO}_{2}$
$6.7-11$ (av. 8.5) $\mathrm{CH}_{4}$
av. 53
$\mathrm{C}_{2} \mathrm{H}_{4} \quad 0.05-0.25 \quad \mathrm{C}_{2} \mathrm{H}_{6} \quad 0.02-0.05$

0.9)

Prepr. Pap.-Am. Chem. Soc., Div. Fuel Chem. 2006, 51 (2), xxxx 
$\mathrm{O}_{2}, \mathrm{C}_{2} \mathrm{H}_{2}$ absent $\quad \mathrm{C}_{3} \quad 0-0.003$

From the mass balance we calculate the following: Output of $\mathrm{H}_{2}+\mathrm{CO}$ (accounted as pure)

64 -

\section{$329 \quad$ L(n)/min}

Output Syngas Power (LHV)

$\mathrm{H}_{2}+\mathrm{CO}$ output efficiency

$\mathrm{H}_{2} / \mathrm{CO}$ ratio in SynGas $\mathrm{mol} / \mathrm{mol}$ )

Figures 2 and 3 present some results of the biodiesel reforming. No soot is observed.

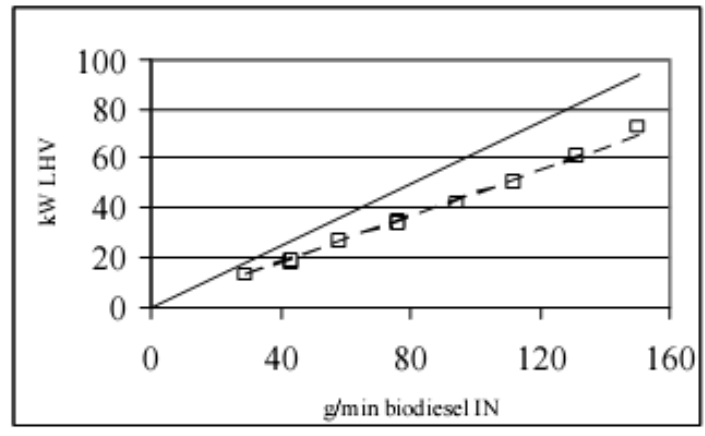

Figure 2 Output SynGas power (points) and input biodiesel power (solid line) as the function of the fuel input flow-rate. The ratio of two line slopes indicates a $74 \%$ averaged thermal efficiency of our reforming.

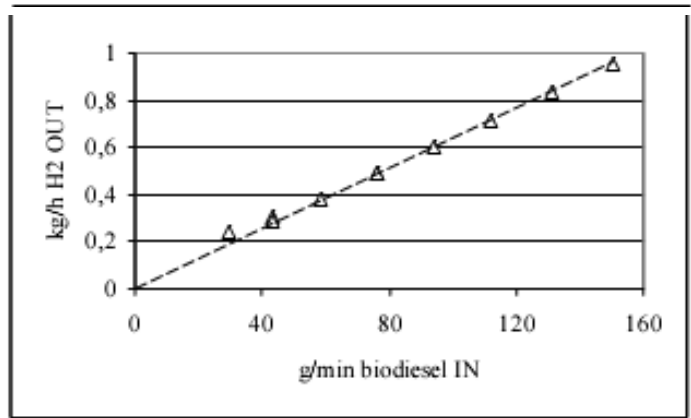

Figure 3. Generated Hydrogen output flow rate as the function of biodiesel input flow-rate.

Application: Large-scale de-NOx. After first concluding tests in our facility, one of the reformers was installed in McMinnville (TN) peak power station where the full-scale tests of NOx removal from an engine exhaust were performed in July 2005, see Fig. 4. Our partner installed there its prototype of the full-scale exhaust gas cleaning from a 4-MW Caterpillar Diesel engine. Specific de-NOx operation is based on a catalytic process requiring frequent catalyst regeneration by Hydrogen. As the Diesel engine was driven by $100 \%$ Soybean biodiesel derived, the evident choice of the primary feed to generate Hydrogen-containing gas for the catalyst regeneration was the same fuel. Under an independent control (TNA) our partner and ECP have successfully demonstrated the feasibility of the full industrial-scale cleaning of the whole exhaust of this engine. In fact the NOx concentration in the engine exhaust gas was reduced by more than $96 \%$ to a very acceptable level of about $30 \mathrm{ppm}$. Also all other characteristic of the exhaust have passed successfully the TNA regulation so that the local electric power station can apply to produce more electric power based on renewable biodiesel.

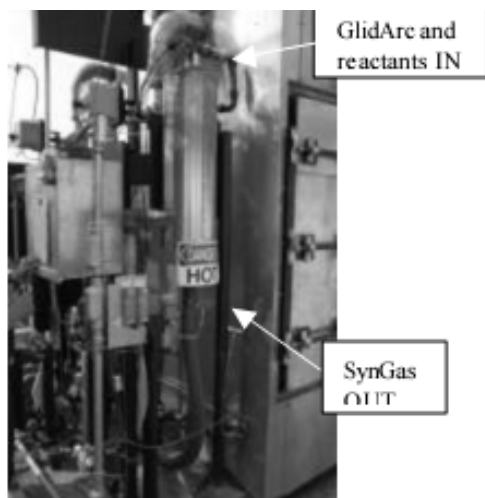

Figure 4. ECP's reformer hooked on the de-NOx pilot plant capable to remove $96 \%$ of NOx from $4 \mathrm{MW}$ engine fuelled by biodiesel. The reformer generates continuously $1 \mathrm{~kg} / \mathrm{h}$ of Hydrogen gas from the same biodiesel for cyclic de-NOx catalyst regeneration.

Application: Fueling of an ICE. Another copy of ECP's reformer is tested in the Renewable Hydrogen Foundation (RHF) in Golden, CO. The goal of this demonstration is to show the feasibility to supplement the grid of a rural electric cooperative using a classical spark-ignited ICE running on the SynGas produced from biodiesel. Such installation will help to supplement the grid by producing $5-30 \mathrm{~kW}$ at the peak periods. While this is a small project, it intends to demonstrate the ability of our united technologies to cover peak usage and to provide an economic benefit. Powering a spark engine with biodiesel would be a great step on the way to practical alternative fuels and their use within the USA current infrastructure.

In November 2005 we started testing the biodiesel reforming using ECP's reformer shown on Fig. 5. First, a 24-hours continuous nu was successfully performed while whole generated SynGas was flared outside. After this run we dismantled the reformer and did not find any trace of soot. Then a spark-ignited engine ran several times using the reformed biodiesel. The maximum RPM value for the engine during the test was 3500 . That was the maximum flow rate of biodiesel that current valve set up would allow.

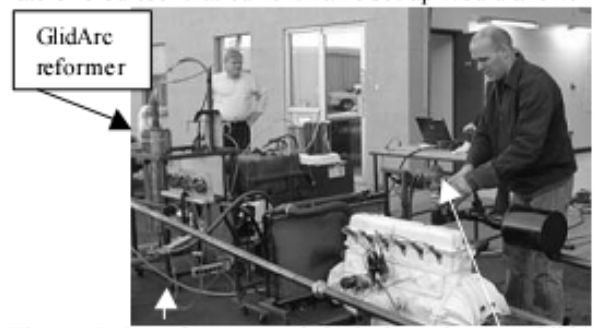

Figure 5. Running a spark-ignited engine on GlidArc-reformed biodiesel.

Second component of our project is research on reforming of raw vegetable oils. On November 28,2005 RHF has successfully ran an engine on reformed soy oil; to our knowledge this is the first time that has been done. Hopefully, we will have a minimally modified, typical car or hybrid car running on Hydrogen from such oils. The Rapeseed oil conversion to SynGas was already successfully tested ${ }^{3}$ as an example of various renewable oils processing.

\footnotetext{
${ }^{3}$ Czernichowski, A.; Czernichowski, M.; Wesolowska, K. Hydrogen and Fuel Cells Canf. Vancouver, Canada, 2003, CD proceedings, 8 pp.
}

Prepr. Pap.-Am. Chem. Soc., Div. Fuel Chem. 2006, 51 (2), xxxx 


\section{Attachment "E"}




\title{
Further development of plasma sources: the GlidArc-III \\ A. Czernichowski, M. Czernichowski \\ ECP - GlidArc Technologies, La Ferté St Aubin, France
}

\begin{abstract}
A 45 years story of construction and development of various plasma sources for various applications is presented. It starts with a stabilized low-voltage but high-current intensity DC free-burning arc, a typical example of so-called "thermal plasma". Nowadays, we rather prefer our completely unstable AC highvoltage and very low-current plasma sources called "GlidArc". Third generation of this low-cost (and lowtech) devices is under development.
\end{abstract}

Keywords: GlidArc, plasma sources

\section{Introduction}

Since 46 years the first author has been involved in construction and/or development of various plasma sources for chemistry, metallurgy, atomic and molecular spectroscopy, deposition, assisted partial or fulloxidation, and other. Under direction of Professor Wlodzimierz Trzebiatowski he started in 1959 with a DC free-buming low-voltage arc (up to 1500A in Argon) as a high-temperature source for some refractory minerals decomposition in Wroclaw's Technical University, Poland. Then he has successively built the first Polish DC plasma torch (1960) and started a study of the Argon plasma spectral emission. In 1962 he switched to an $800 \mathrm{~A}$ DC arc in water- or Nitrogen-swirl; these plasma reactors were used for the Iron Titanate and Zirconium Silicate processing (Ph.D. thesis in 1966). Successively came a new DC torch having a Tungsten cathode and a segmented Copper anode (each segment actively power supplied at various electric potentials) for $\mathrm{SiO}_{2}, \mathrm{TiO}_{2}$ and $\mathrm{ZrO}_{2}$ reduction in Hydrogen (1970). In turn a microwave torch for $\mathrm{NO}_{x}$ synthesis (3kW, 1973), an arc striking to the molten LiCl (1974), an induction-coupled torch (atmospheric pressure, 25kW, 1975), a metal-wall-stabilized arc for plasma spectroscopy (150A, 1975), a multipleelectrode and high intensity rotating/pulsating arc (1980), an unstable and very active transferred DC arc for Hydrocarbon or $\mathrm{H}_{2} \mathrm{~S}$ processing (1983), a high current circuit breaker (1983), an electro-burner for Methane flame over-heating (1985), and a semi-industrial $250 \mathrm{~kW}$ DC transferred arc furnace (1987) took his attention...

In early 1980 's the plasma-chemical community started to abandon the so-called "thermal plasma" devices for chemical applications, as it appeared that their high electric energy consumption cannot be accepted for most of industrial processes. Also the microwave and induction-coupled sources did not get a large approval because of their complex electric supplying, especially for higher power units. Other non-thermal ("cold" or "out-of-equilibrium") plasmas were demanded... Accordingly, the gliding arc device was proposed in 1988 [1]; it is now known under its short name "GlidArc".

\section{Gliding Discharges}

\subsection{GlidArc-I}

The GlidArc generates non-thermal plasma that enhances various processes through active catalytic species: electrons, ions, and excited atoms. This source has at least two diverging electrodes immersed in a fast gas or vapour flow. A high voltage and relatively low current discharge (up to $30 \mathrm{kV}, 0.05-5 \mathrm{~A}, 0$ $20 \mathrm{kHz}$ ) is generated across the flow between the electrodes as it is shown on the Fig. 1. The discharge forms at the closest point between the electrodes, glides along the electrode's edges, and disappears. Another discharge immediately reforms close to the initial spot. The discharge performs its own maintenance on the electrodes, preventing chemical corrosion and/or thermal erosion. The electrodes are not water-cooled so the electric power is directly and totally transferred to the processed feed. Any gas or vapour can be directly processed at $0.05-12$ bar range. Droplets, mists, and powders can be present. Feeds of any initial temperature are accepted.

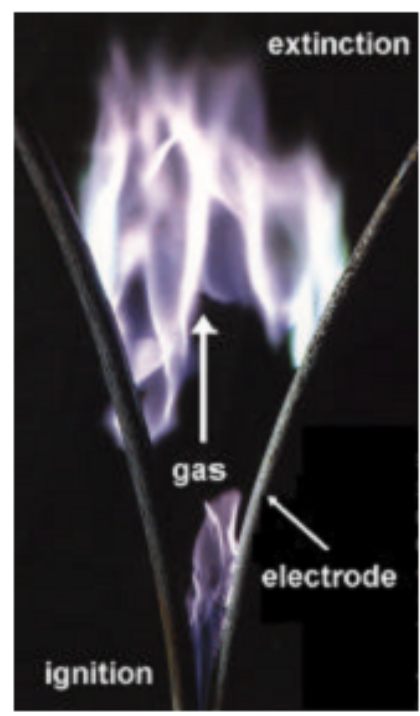

Fig. 1. The GlidArc-I 
Gliding discharges of GidArc-I type can be also installed between metallic electrodes and a conducting liquid [2]. Multiple electrode systems can be installed for large gas steams processing. Their electric powering is described in [3]. Structures of several dozens of electrodes can be organized a "clusters" forming some plasma heads for powerful AC plasma reactors supplied from unique 3-phase transformer [4].

\subsection{GlidAre-II}

In 1996 we started to develop an alternative way of gliding discharges generation using a rotating central electrode and "connecting" it, via high-voltage AC discharges, to several stationary electrodes located around the central electrode [5]. As result we have obtained a new GlidArc-II device. Figure 2 presents the principle of such cold-plasma source while the Fig. 3 shows a principle of multiple-stage reactor in which the processed fluid can cross several electric discharges to reach a suitable rate of conversion.

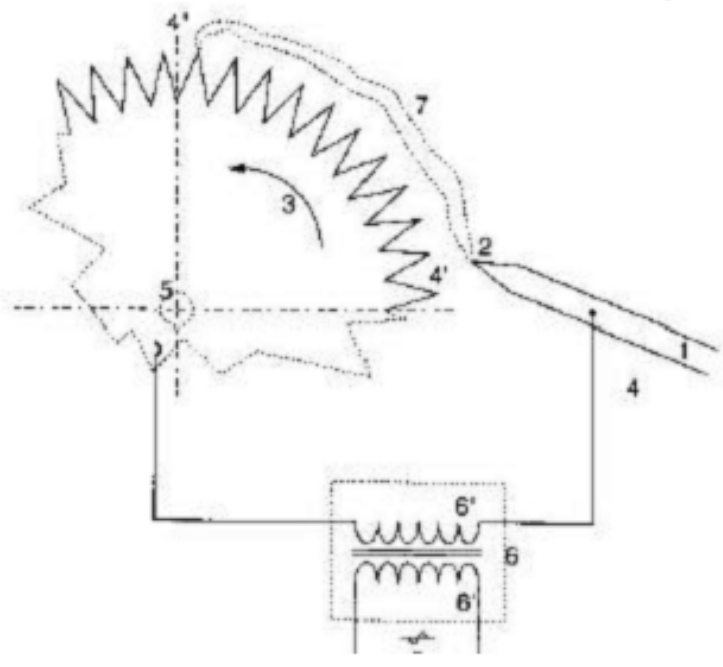

Fig. 2. Principle of the GlidArc-II device: 1 - stationary electrode, 3 - rotating electrode, 6 - power supply, 7 high-voltage discharge filaments.

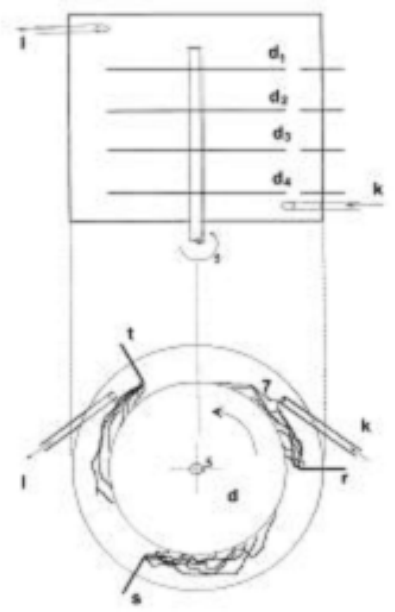

Fig. 3. Multiple-stages and multiple-electrodes GlidArc-II reactor: $\mathrm{r}, \mathrm{s}$, and $\mathrm{t}$ - three-p hasesupplied stationary electrodes, $\mathrm{k}$ and $\mathrm{l}-$ input and output of the processed gas, $\mathrm{d}$ - rotating electrodes.

There are multiple advantages of the new structure. The high voltage discharges generation and the processed gas flow rates are no more self-dependent so that even a very low gas flow can now be accepted at any power as there is no more need to accelerate the gas at the proximity of electrodes. The mobile electrodes rotate in the range of $50-1000 \mathrm{rad} / \mathrm{s}$, which are acceptable speeds. The discharges can "touch" several times the same gas flux without any obligation to push the gas between the stages. The reactor is quite compact for even large gas flows. For example one can realize three $5 \mathrm{~A}$ and $2 \mathrm{kV}$ discharges for one stage. When adding 4 stages it makes us a $120 \mathrm{~kW}$ reactor realized in a $0.3 \mathrm{~m}$ diameter cylinder of $0.5 \mathrm{~m}$ length ( $30 \mathrm{~L}$ of volume). Such reactor can process roughly up to $2400 \mathrm{~m}^{3} / \mathrm{h}$ of gas.

A 60-L stainless steel reactor was built by ECP for $\mathrm{H}_{2} \mathrm{~S}-$ related streams processing. This reactor presented on the Fig. 4 contains 9 stages, each of them being powered by 3 stationary electrodes so that 36 active electrodes are present (including central electrodes).

First successive tests of this reactor were performed with an active participation of Piotr Czernichowski. We have obtained better than $50 \%$ conversion of an $\mathrm{H}_{2} \mathrm{~S}$-rich acid gas into the SynGas.

Fig. 4, 60-L, 36-electrodes GlidArc-II pilot plant for Hydrogen Sulphide processing (SulfArc).

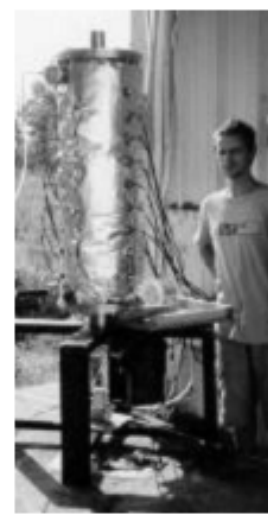

Page 93 of 182 
Several application tests and studies were performed in laboratory or pilot scale GlidArc-I and-II reactors for gases, vapours, liquids, and solids processing (decomposition, conversion, upgrading, activation) as well as for flames overheating or stabilization (flaring for example). More than twenty French and foreign patents protect some of GlidArc-I and -II principles, powering, and applications.

\subsection{GlidArc-III}

Since long time we have been also working on plasma assisted partial oxidation of various fuels into the synthesis gas [6]. During this process it appeared that soot or other solid particles could deposit on highvoltage insulators of the GlidArc-I electrodes. Generally, only two electrodes are needed for such application to ignite and then to support such partial oxidation at less than $1 \%$ dissipated electric energy with respect to the enthalpy of the SynGas. New GlidArc-III plasma source [7] solves this problem.

As shown on Fig. 5 we direct $5-$ $20 \%$ of the air (1) to a vortex-like zone (2) that protects one central GlidArc-III electrode (3) while the remaining part of the oxidant is sent through (4), together with the processed fuel, to the plasma zone (5) where the gliding and rotating high-voltage AC discharge strikes between the central electrode (3) and the surrounding metallic nozzle (6) being at the ground potential The fuel and its pyrolysis products cannot now harm the dielectric support (7) of the central electrode. A Diesel fuel conversion into Synthesis Gas was successfully performed this year.

Figures 5 and 6 present our GlidArc-III reformer for various fuels processing.

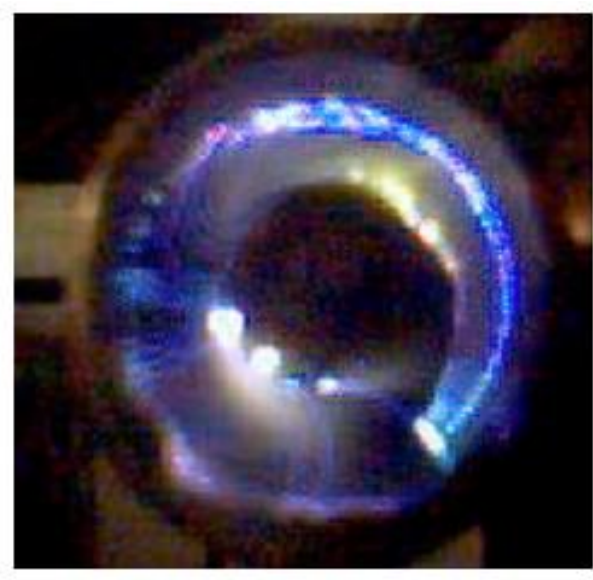

Fig. 5, GlidAre-III discharge.

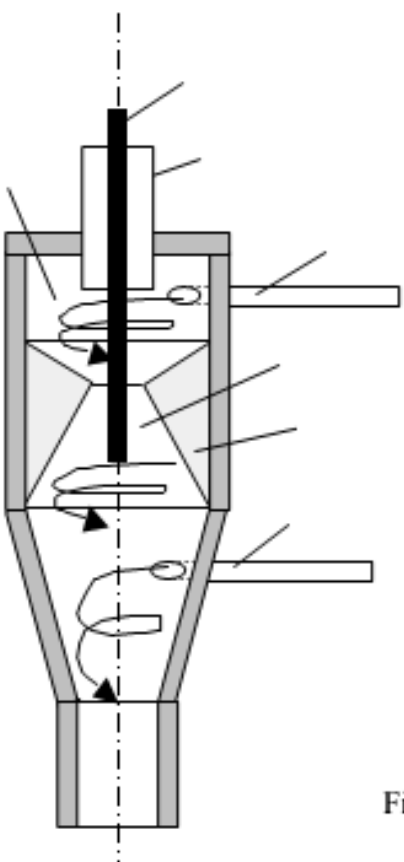

Fig. 4. Principle of the GlidArc-III.

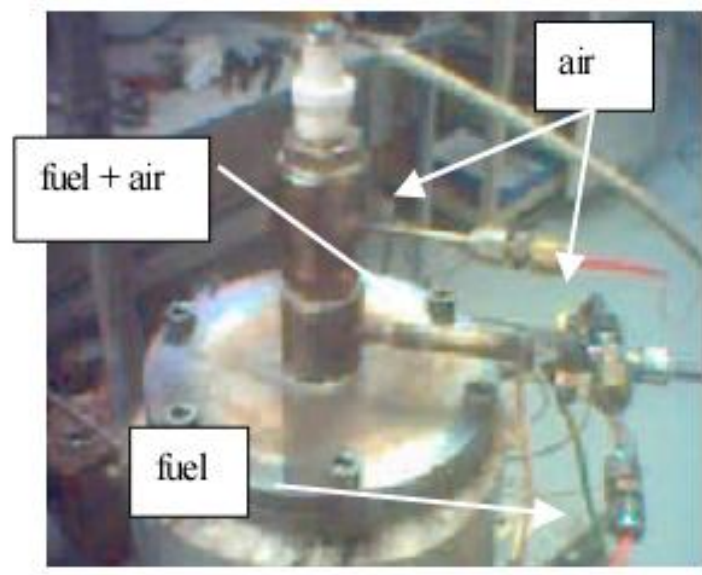

Fig. 6. GlidAre-III at the top of the Fuel Reformer body

\section{Conclusion}

A 45 years in-house story of construction and development of various plasma sources for various applications indicates that GlidArc-type generators are the best solution for plasma-chemical applications. 
They can be as powerful as classical plasma torches while avoiding specific power supplying, water-cooling, electrode erosion, and quite complicated manufacturing. GlidArc instabilities rather help progressing the chemical processes by creating strong fluid turbulences (mixing) and generating very active catalytic species at quite low processed fluid temperature. We are proud to submit already three generations of these low-cost and low-tech devices to the Plasma Chemistry Community.

\section{References}

[1] H. Lesueur, A. Czernichowski, J. Chapelle, Dispositif de Génération de Plasmas Basse Température par Formation de Décharges Electriques Glissantes, French Patent No.2 639172 (1988).

[2] A. Czernichowski, B. Hnatiuc, P. Pastva, A. Ranaivosoloarimanana, Générateurs et circuits électriques pour alimenter des décharges instables de haute tension, French Patent No. 2817444 (2000).

[3] A. Czernichowski, M. Czernichowski, Dispositif modulaire pour générer de multiples décharges électriques glissantes de haute tension, French Patent No. 2842389 (2002).

[4] J. Janca, S. Kuzmin, A. Maximov, J. Titova, A. Czernichowski, Investigation of the Chemical Action of the Gliding and "Point" Arcs Between the Metallic Electrode and Aqueous Solution, Plasma Chemistry and Plasma Processing, vol. 19(1) 53-67 (1999).

[5] A. Czernichowski, J. Sünnen, Procédé et dispositif de production d'un plasma hors d'équilibre, French Patent No. 2763778 (1997)

[6] A. Czernichowski, P. Czernichowski, Partial Oxidation of fossil and renewable fuels into the synthesis gas, this Symposium.

[7] A. Czernichowski, M. Czernichowski, K. Wesolowska, French application (2004). 


\section{Attachment " $F$ "}

(The following report, which pertains solely to emissions measurement testing, was commissioned by McMinnville Electric System as part of this Project and is therefore incorporated and made part of this Final Report as submitted.) 


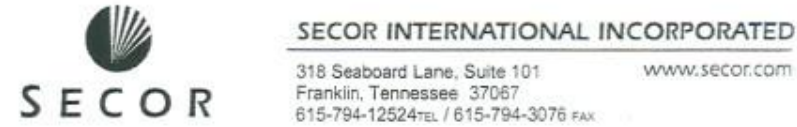

l e $t$ t e r $r$ o f $\quad t \quad r$ a $n$ s $m$ i $t \quad t \quad a$

attention: Mr. Jeryl Stewart date: December 21, 2006

company: $\quad$ Tennessee Department of Environment and Conservation Office of Air Pollution Control

address: $\quad 9^{\text {th }}$ Floor L\&C Annex 401 Church Street Nashville, TN 37243-1531

project: McMinnville Electric System, McMinnville, TN

job no.: $\quad$ 170T.98726.00

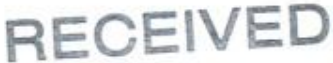

DEC 222006

MICMINNVILLE ELECTRIC SYSTEM

re:

Emissions Measurements for McMinnville Electric System

enclosed:

$\begin{array}{ll}\text { () } & \text { Proposal } \\ \text { () } & \text { Contract } \\ \text { (X) } & \text { Report } \\ \text { () } & \text { Letter } \\ \text { () } & \text { Other: }\end{array}$

$\begin{array}{ll}\text { ( ) } & \text { As Requested } \\ \text { (X) } & \text { Review } \\ \text { () } & \text { Your Information } \\ \text { () } & \text { Approval } \\ \text { () } & \text { Signature } \\ \text { () } & \text { Return } \\ \text { () } & \text { Other: }\end{array}$

comments:

Attached please find the Emissions Measurements Report for McMinnville Electric System in McMinnville, TN for your review.

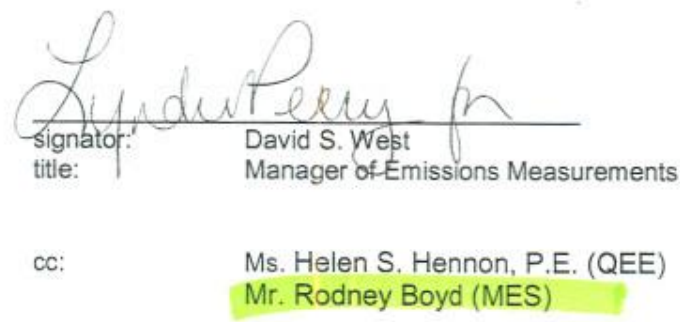

TL 12.21.06.doc

SECOR INTERNATIONAL INCORPORATED 


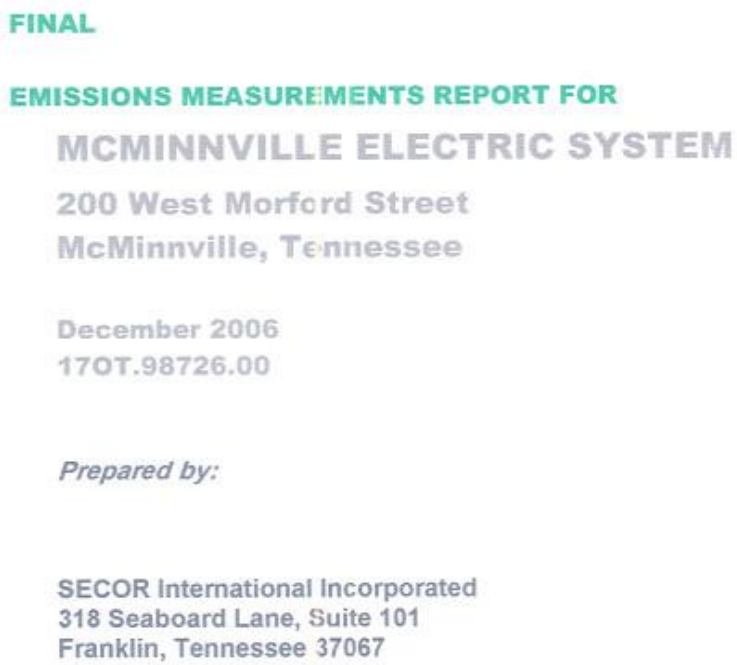




\section{TABLE OF CONTENTS}

1.0 INTRODUCTION......................................................................................................1

2.0 TEST PROGRAM SUMMARY .....................................................................................

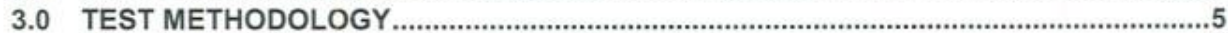

3.1 Support Measurements for Stack Parameters ................................................... 5

3.1.1 Selection of Traverse Points ................................................................

3.1.2 Flow Rate Determination................................................................................

3.1.3 Moisture Content Determination.................................................................... 7

3.2 CEMS Sampling System Description ................................................................. 7

3.2.1 Measurement System Performance .......................................................... 8

3.2.2 $\mathrm{O}_{2}, \mathrm{CO}_{2}$, and $\mathrm{NO}_{x}$ Measurements ..........................................................

3.2.2.1 Calibration Gas Checks ............................................................... 9

3.2.2.2 Calibration Drift and Measurement System Bias Checks ................9

3.2.2.3 Interference Response .............................................................9

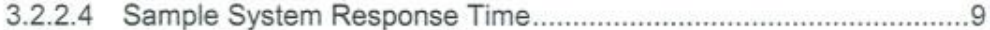

3.2.2.5 $\mathrm{NO}_{2}$ to $\mathrm{NO}$ Conversion Efficiency ....................................................... 10

3.2.2.6 Stratification Test..................................................................... 10

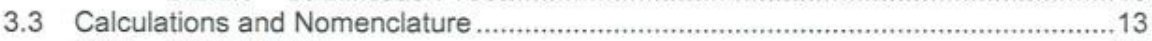

3.3.1 Calculations ...................................................................................... 13

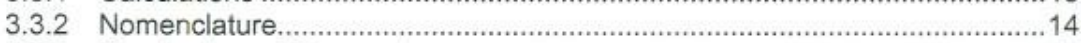

3.3.3 Constants and Conversions ...................................................................... 15

3.3.4 Example Calculations, Engine Exhaust, Run 1 .....................................................15

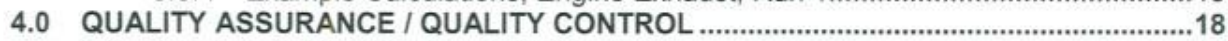

4.1 Presampling Activities and QA Measures .......................................................... 18

4.2 Field Program ................................................................................................ 19

4.3 Sample Documentation ....................................................................................... 19

4.4 Data Reduction and Reporting .................................................................20 


\section{TABLE OF CONTENTS (Continued)}

\section{LIST OF FIGURES}

Figure 3.1 Sample Location Illustration for Engine Exhaust ................................................. 6

Figure 3.2 RM 4 Sampling System Schematic …............................................................... 11

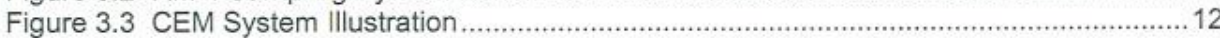

\section{LIST OF TABLES}

E.1 Summary of Emissions Measurements Results.

Table 1.1 Compliance Emissions Measurement Program ............................................................2

Table $2.1 \mathrm{NO}_{x}$ Emissions Measurement Results

\section{LIST OF APPENDICES}

APPENDIX A Field Data and Spreadsheet Calculations APPENDIX B Calibration and Field Notes

APPENDIX C Production Data 


\section{EXECUTIVE SUMMARY}

McMinnville Electric System (MES) operates an electric generating facility located in McMinnville, Tennessee. As detailed in Construction Permit No. 957279F, issued by the Tennessee Department of Environment and Conservation, Division of Air Pollution Control (APC), MES has installed a Caterpillar Model D3516B TA Diesel Engine and Caterpillar SR4B electric generating unit equipped with selective catalytic oxidation (SCO) for the control of the nitrogen oxides $\left(\mathrm{NO}_{x}\right)$ emissions. The unit is identified as emission source reference no. 890104-01 in the construction permit. As prescribed in Condition 15 of the construction permit, MES must conduct an emissions performance test to demonstrate compliance with the $\mathrm{NO}_{x}$ emission limit.

The performance test was conducted while the unit was firing a 99.9 percent biodiesel/0.1 percent ultra low sulfur diesel (ULSD) mixture. The SCO control device was not operational during this compliance program. The construction permit details the $\mathrm{NO}_{x}$ emissions factors at multiple biodiesel/ULSD fuel mixture ratios. Based on the data provided in the construction permit, the potential $\mathrm{NO}_{x}$ emissions increase as the percentage of biodiesel in the fuel mixture increases. This operating scenario provided a worst case condition for $\mathrm{NO}_{x}$ emissions from the unit.

MES retained SECOR International Incorporated (SECOR) to prepare the test plan and protocol (TPP) and complete the emissions measurement program. Mr. Gary Ewing, Senior Project Engineer, was the designated Project Manager for this test program. Mr. Ewing may be reached at SECOR's Tennessee office located at 318 Seaboard Lane, Suite 101, Franklin, Tennessee 37067 , by telephone at (615) 794-1524, by fax at (615) 794-3076, or by email at gewing@secor.com. Mr. Rodney Boyd of MES was responsible for the coordination of the test program. Mr. Boyd may be reached by telephone at (931) 235-7007.

The emissions measurement program was performed November 28, 2006 in accordance with the TPP dated November 8, 2006 and applicable US EPA Reference Methods. No deviations were required. The results of the testing program demonstrate compliance with the limits specified in the permit. Table E.1 provides a summary of the results of the emissions measurements program.

\section{E.1 SUMMARY OF EMISSIONS MEASUREMENTS RESULTS MCMINNVILLE ELECTRIC SYSTEMS \\ NOVEMBER 28, 2006}

\begin{tabular}{|c|c|c|c|c|c|c|}
\hline \multirow[b]{2}{*}{ Run No. } & \multirow{2}{*}{$\begin{array}{c}\text { Generator } \\
\text { Energy } \\
\text { (kWh) }\end{array}$} & \multicolumn{2}{|c|}{$\begin{array}{l}\text { Effluent Stream } \\
\text { Conditions }\end{array}$} & \multicolumn{3}{|c|}{$\mathrm{NO}_{x}$ Emissions } \\
\hline & & $\begin{array}{c}t_{s} \\
\left({ }^{\circ} \mathrm{F}\right)\end{array}$ & $\begin{array}{c}Q_{s} \\
\text { (dscfm) }\end{array}$ & ppm $_{\text {vd }}$ & $\mathrm{lb} / \mathrm{hr}$ & $\frac{\mathrm{lb}}{1 \times 10^{3} \mathrm{kWh}}$ \\
\hline 1 & 1,654 & 633.3 & 5.581 & 740.88 & 29.64 & 17.920 \\
\hline 2 & 1,654 & 632.8 & 5,615 & 744.59 & 29.97 & 18.120 \\
\hline 3 & 1.653 & 639.0 & 5,551 & 746.11 & 29.69 & 17.961 \\
\hline Avg & 1,654 & 635.0 & 5,582 & 743.9 & 29.8 & 18.000 \\
\hline \multicolumn{2}{|c|}{ Emission Limit ${ }^{1}$} & -. & - & - & - & 31.21 \\
\hline
\end{tabular}

${ }^{1}$ Unrestricted Fuel Mix / Uncontrolled 


\subsection{INTRODUCTION}

McMinnville Electric System (MES) operates an electric generating facility located in McMinnville, Tennessee. As detailed in Construction Permit No. 957279F, issued by the Tennessee Department of Environment and Conservation, Division of Air Pollution Control (APC), MES has installed a Caterpillar Model D3516B TA Diesel Engine and Caterpillar SR4B electric generating unit equipped with selective catalytic oxidation (SCO) for the control of the nitrogen oxides $\left(\mathrm{NO}_{x}\right)$ emissions. The unit is identified as emission source reference no. 890104-01 in the construction permit. As prescribed in Condition 15 of the construction permit, MES must conduct an emissions performance test to demonstrate compliance with the $\mathrm{NO}_{x}$ emission limit.

The performance test was conducted while the unit was firing a 99.9 percent biodiesel/0.1 percent ultra low sulfur diesel (ULSD) mixture. The construction permit details the $\mathrm{NO}_{x}$ emissions factors at multiple biodiesel/ULSD fuel mixture ratios. Based on the data provided in the construction permit, the potential $\mathrm{NO}_{x}$ emissions increase as the percentage of biodiesel in the fuel mixture increases. This operating scenario provided a worst case condition for $\mathrm{NO}_{x}$ emissions from the unit.

MES retained SECOR International Incorporated (SECOR) to prepare the test plan and protocol (TPP) and complete the emissions measurement program. Mr. Gary Ewing, Senior Project Engineer, was the designated Project Manager for this test program. Mr. Ewing may be reached at SECOR's Tennessee office located at 318 Seaboard Lane, Suite 101. Franklin, Tennessee 37067 , by telephone at (615) $794-1524$, by fax at (615) $794-3076$, or by email at gewing@secor.com. Mr. Rodney Boyd of MES was responsible for the coordination of the test program. Mr. Boyd may be reached by telephone at (931) 235-7007.

The emissions measurement program was performed November 28, 2006 in accordance with the TPP dated November 8, 2006 and applicable US EPA Reference Methods (RM). No deviations were required. The results of the testing program demonstrate compliance with the limits specified in the permit. SECOR personnel including Mr. David West and Mr. Briggs Evans performed the field measurements program. Mr. Bryan Parker of APC observed the field measurements program. Table 1.1 provides a summary of the methodologies followed for the compliance program.

Section 2.0 of this test report presents a detailed discussion of the results. The test methodologies employed, including instrument calibration, are presented in Section 3.0. A concise description of the quality assurance/quality control (QA/QC) procedures implemented is provided in Section 4.0.

December 2006 170T. .98726 .00 
SECOR

TABLE 1.1 COMPLIANCE EMISSIONS MEASUREMENT PROGRAM MCMINNVILLE ELECTRIC SYSTEM

NOVEMBER 28, 2006

\begin{tabular}{||c|c|c|c|c|c|}
\hline $\begin{array}{l}\text { Sample/ } \\
\text { Measurement } \\
\text { Location }\end{array}$ & $\begin{array}{c}\text { No. of } \\
\text { Runs }\end{array}$ & $\begin{array}{c}\text { Analyte/ } \\
\text { Parameter }\end{array}$ & $\begin{array}{c}\text { Sampling/ } \\
\text { Measurement } \\
\text { Method }\end{array}$ & $\begin{array}{c}\text { Sample Run } \\
\text { Time }\end{array}$ & Analytical Method \\
\hline \multirow{3}{*}{ Engine Exhaust } & 3 & $\begin{array}{c}\text { Volumetric } \\
\text { Flow Rate }\end{array}$ & Methods 1 \& 2 & N/A & N/A \\
\cline { 2 - 6 } & 3 & $\mathrm{O}_{2} / \mathrm{CO}_{2}$ & Method 3A & 60 minutes & $\begin{array}{c}\text { Method 3A } \\
\text { Paramagnetic/lnfrared }\end{array}$ \\
\cline { 2 - 6 } & 3 & Moisture & Method 4 & 60 minutes & $\begin{array}{c}\text { Method 4 } \\
\text { Gravimetric/Volumetric }\end{array}$ \\
\cline { 2 - 6 } & 3 & $\mathrm{NO}_{x}$ & Method 7E & 60 minutes & $\begin{array}{c}\text { Method 7E } \\
\text { Chemiluminescent Analyzer }\end{array}$ \\
\hline
\end{tabular}




\subsection{TEST PROGRAM SUMMARY}

The following section provides a summary of the November 28, 2006 compliance emissions measurements program. The emissions measurements program was performed following the test methods and procedures detailed in 40 CFR 60, Appendix A. The determination of the effluent stream's diluent concentrations was accomplished following 40 CFR 60, Appendix $A$, Reference Method (RM) 3A, "Determination of Oxygen and Carbon Dioxide Concentrations in Emissions from Stationary Sources (Instrumental Analyzer Procedure)." The oxygen $\left(\mathrm{O}_{2}\right)$ concentration was determined using a paramagnetic analyzer and the carbon dioxide $\left(\mathrm{CO}_{2}\right)$ concentration was determined using an infrared (IR) analyzer. The determination of the $\mathrm{NO}_{x}$ emissions was accomplished following the procedures of RM 7E, "Determination of Nitrogen Oxide Emissions from Stationary Sources (Instrumental Analyzer Procedure)." The $\mathrm{NO}_{\mathrm{x}}$ concentration was determined using a chemiluminescent analyzer.

Concurrent with each sample run, RMs 1,2, and 4 were performed at the sample location in order to determine the volumetric flow rate and moisture content of the effluent stream. Upon completion of the sampling program, the $\mathrm{NO}_{x}$ and $\mathrm{CO}$ data measured by the RM $7 \mathrm{E}$ sample system was combined with the measured effluent stream's volumetric flow rate in order to determine the mass emission rate, expressed as pounds per hour $(\mathrm{lb} / \mathrm{hr})$. A total of three 60minute runs were completed for each compliance program.

The field measurements were conducted under normal process operations. SECOR and MES staff maintained close communication to ensure that the collected samples were representative and typical of the process emissions at the time of testing.

The emissions testing program was performed as prescribed in RM 7E. The average measured $\mathrm{NO}_{x}$ concentration was 743.9 parts per million, by volume, dry basis $\left(\mathrm{ppm}_{\mathrm{vd}}\right)$. This equates to an average $\mathrm{NO}_{x}$ mass emission rate of $29.8 \mathrm{lb} / \mathrm{hr}$ at the average measured volumetric flow rate of 5,582 dry standard cubic feet per minute (dscfm). The engine operated at an average of 1,654 kilowatts per hour $(\mathrm{kWh})$ during the test program. This equates to a $\mathrm{NO}_{x}$ mass emission rate of $18.67 \mathrm{lb} / 1,000 \mathrm{kWh}$.

The results of the test program demonstrate compliance with the permitted NOx emission limit of $31.21 \mathrm{lb} / 1,000 \mathrm{kWh}$ for an uncontrolled, unrestricted fuel mix. Table 2.1 provides the results of the emissions measurements program. The supporting data for this sample program is included in the appendices.

FINAL_Compl_Rpt_McMinnville_Electric.doc 170T. 98726.00
December 2006 
SECOR

\section{TABLE $2.1 \mathrm{NO}_{x}$ EMISSIONS MEASUREMENT RESULTS MCMINNVILLE ELECTRIC SYSTEM NOVEMBER 28, 2006}

\begin{tabular}{|c|c|c|c|c|}
\hline & Run 1 & Run 2 & Run 3 & Average \\
\hline Sample Period & $10: 27-11: 27$ & $12: 00-13: 00$ & $13: 24-14: 24$ & - \\
\hline Generator Energy, kWh & 1,654 & 1,654 & 1,653 & 1,654 \\
\hline Sample Time, min & 60 & 60 & 60 & - \\
\hline Barometric Pressure, $\mathrm{P}_{\text {var }}$ (in. $\mathrm{Hg}$ ) & 29.10 & 29.10 & 29.05 & 29.08 \\
\hline Dry Gas Meter I.D. & 1 & 1 & 1 & - \\
\hline Meter Corr. Factor, Y & 0.955 & 0.955 & 0.955 & - \\
\hline Meter $\Delta \mathrm{H}_{\mathrm{g}}$ & 1.994 & 1.994 & 1.994 & - \\
\hline Pitot Coefficient, $C_{p}$ & 0.84 & 0.84 & 0.84 & - \\
\hline Duct Diameter, in. & 15.75 & 15.75 & 15.75 & - \\
\hline Duct Area $\left(A_{s}\right), \mathrm{ft}^{2}$ & 1.35 & 1.35 & 1.35 & - \\
\hline \multicolumn{5}{|l|}{ Effluent Stream Conditions } \\
\hline Temperature, ${ }^{\circ} \mathrm{F}$ & 633.3 & 632.8 & 639.0 & 635.0 \\
\hline $\mathrm{O}_{2}$ Concentration, $\%$ & 11.3 & 11.3 & 11.3 & 11.3 \\
\hline $\mathrm{CO}_{2}$ Concentration, $\%$ & 7.2 & 7.2 & 7.2 & 7.2 \\
\hline Static Pressure, $\mathrm{P}_{\mathrm{g}}$ & 1.90 & 2.20 & 2.70 & 2.27 \\
\hline Stack Pressure, $P_{5}$ & 29.24 & 29.26 & 29.25 & 29.25 \\
\hline \multicolumn{5}{|l|}{ Effluent Steam Moisture Calculations } \\
\hline Meter Volume, $\mathrm{ft}^{3}$ & 34.185 & 30.665 & 34.100 & 32.983 \\
\hline Avg. Dry Gas Meter Temp. $\left({ }^{\circ} \mathrm{F}\right)$ & 77.5 & 84.4 & 84.4 & 82.1 \\
\hline $\mathrm{H}_{2} \mathrm{O}$ Gain, $\mathrm{V}_{\mathrm{ic}}$ & 59.3 & 59.4 & 56.2 & 58.3 \\
\hline Avg. $\Delta \mathrm{H}$ & 1.0 & 1.0 & 1.0 & 1.0 \\
\hline Meter Pressure, in. $\mathrm{Hg}$ & 29.17 & 29.17 & 29.12 & 29.16 \\
\hline Standard Meter Volume, $\mathrm{ft}^{3}\left(\mathrm{Vm}_{\mathrm{std}}\right)$ & 31.300 & 27.720 & 30.773 & 29.931 \\
\hline Standard Water Volume, $\mathrm{ft}^{3}\left(\mathrm{VW}_{\text {sta }}\right)$ & 2.791 & 2.796 & 2.645 & 2.744 \\
\hline Moisture Fraction, Saturation & 1.0000 & 1.0000 & 1.0000 & 1.0000 \\
\hline Moisture Fraction, Measured & 0.0819 & 0.0916 & 0.0792 & 0.0842 \\
\hline Applicable Moisture (lower Sat. vs. Meas.) & 0.0819 & 0.0916 & 0.0792 & 0.0842 \\
\hline \multicolumn{5}{|l|}{ Volumetric Flow Rate } \\
\hline Avg. SQRT $\triangle P$ & 1.9342 & 1.9615 & 1.9238 & 1.9398 \\
\hline Mol. Wt. Stack Gas, $\left(M_{d}\right)$ & 29.60 & 29.60 & 29.60 & 29.60 \\
\hline Mol. Wt. Stack Gas, $\left(\mathrm{M}_{3}\right)$ & 28.65 & 28.54 & 28.68 & 28.62 \\
\hline Velocity, $\left(V_{s}\right)$ & 158.67 & 161.13 & 158.12 & 159.30 \\
\hline At Stack Conditions, acfm $\left(Q_{a}\right)$ & 12,880 & 13,080 & 12,836 & 12,932 \\
\hline At Wet Standard Conditions, wscfm ( $\left.Q_{\text {sw }}\right)$ & 6,081 & 6,183 & 6.030 & 6,098 \\
\hline At Standard Conditions, dscfm $\left(Q_{s}\right)$ & 5,581 & 5,615 & 5,551 & 5,582 \\
\hline \multicolumn{5}{|l|}{$\mathrm{NO}_{\mathrm{x}}$ Emissions Data } \\
\hline ppmid & 740.88 & 744.59 & 746.11 & 743.9 \\
\hline $\mathrm{lb} / \mathrm{hr}$ & 29.64 & 29.97 & 29.69 & 29.8 \\
\hline $\mathrm{lb} / 1,000 \mathrm{kWh}$ & 17.920 & 18.120 & 17.961 & 18.000 \\
\hline Permit Limit, lb/1,000 kWh ${ }^{1}$ & - & - & - & 31.21 \\
\hline
\end{tabular}

Unrestricted fuel mix, uncontrolled. 


\subsection{TEST METHODOLOGY}

The testing program was performed according to the following accepted and approved EPA RMs as contained in the EPA's Quality Assurance Handbook for Air Pollution Measurement Systems, Volume III, Stationary Source Specific Methods, in 40 CFR 60, Appendix A. The general procedures followed to complete this measurement evaluation include:

RM 1 Sample and Velocity Traverses for Stationary Sources

RM 2 Determination of Stack Gas Velocity and Volumetric Flow Rate (Type-S Pitot Tube)

RM 3 A Determination of Oxygen and Carbon Dioxide Concentrations in Emissions from Stationary Sources (Instrumental Analyzer Procedure)

RM 4 Determination of Moisture Content in Stack Gases

RM 7E Determination of Nitrogen Oxides Emissions from Stationary Sources (Instrumental Analyzer Procedure)

\subsection{Support Measurements for Stack Parameters}

EPA Reference Methods 1 through 4 were performed to provide support data for emission rate calculations. Ideally, measurements should be performed at least eight stack diameters downstream and two diameters upstream from any flow disturbance. RM 1, "Sample and Velocity Traverses for Stationary Sources," was conducted using existing test port locations prior to the initiation of the measurements.

\subsubsection{Selection of Traverse Points}

EPA RM 1, "Sample and Velocity Traverses for Stationary Sources," was followed for the selection of measurement points at the test location. The sample location was measured in order to determine the stack diameter and the distance to the nearest upstream and downstream disturbances. This data was used to determine the minimum number of traverse points as detailed in Figure 1-1 of RM 1. For circular stacks, the traverse points were located on two perpendicular diameters according to Table 1-2 of RM 1. Figure 3.1 provides an illustration of the sample location.

\subsubsection{Flow Rate Determination}

The volumetric flow rate at the stack test location was measured using EPA RM 2, "Determination of Stack Gas Velocity and Volumetric Flow Rate (Type-S Pitot Tube)." A stainless steel, Type-S Pitot tube connected to a differential pressure gauge (inclined manometer) was used to measure the pressure differential at each traverse point. The measured velocity head, observed at each traverse point, was recorded on a field data sheet and used for determining the overall volumetric flow rate. 
FIGURE 3.1 SAMPLE LOCATION ILLUSTRATION FOR ENGINE EXHAUST MCMINNVILLE ELECTRIC SYSTEM

NOVEMBER 28, 2006

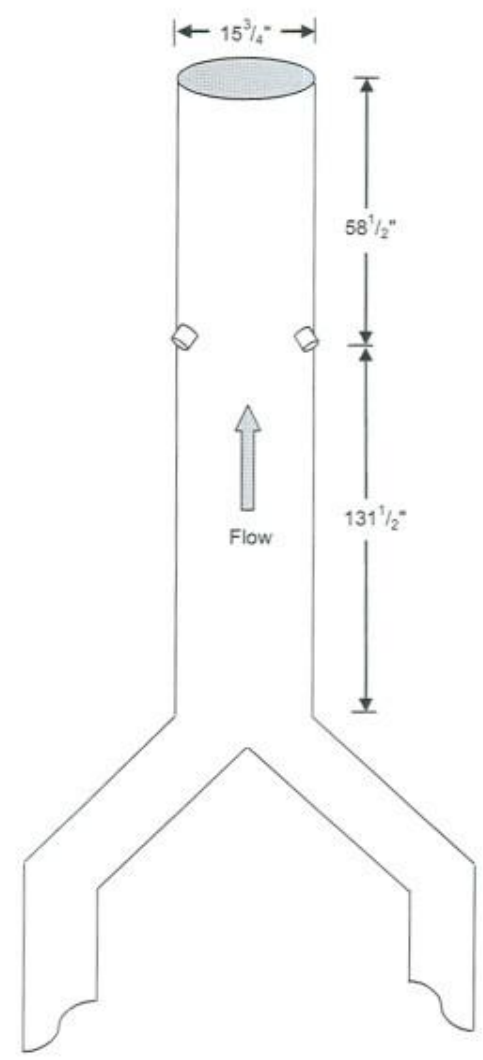

\begin{tabular}{|c|c|c|}
\hline $\begin{array}{c}\text { Traverse } \\
\text { Point }\end{array}$ & $\begin{array}{c}\text { Distance } \\
\text { from Wall }\end{array}$ & $\begin{array}{c}\text { Distance } \\
\text { with Port }\end{array}$ \\
\hline 1 & 1.1 & 2.4 \\
2 & 3.9 & 5.2 \\
3 & 11.8 & 13.1 \\
4 & 14.6 & 15.9 \\
\hline
\end{tabular}

FINAL_Compl_Rpt_McMinnville Electric.doc $170 T .98726 .00$ 
In addition to the velocity head, gas temperatures were measured and recorded concurrently with all the velocity head data. The temperature was measured with a Type-K thermocouple attached to a digital temperature indicator. Temperature readings were recorded from the display of the calibrated digital temperature indicator. The velocity head and temperature data were recorded on field data forms

The average stack gas velocity was calculated using the gas density, the average measured velocity head (differential pressure), and the average measured gas temperature. The flow rate results are presented in terms of acfm (actual cubic feet per minute) and dscfm (dry standard cubic feet per minute).

\subsubsection{Moisture Content Determination}

The effluent moisture content at the test location was determined using EPA RM 4, "Determination of Moisture Content in Stack Gases." The determination of moisture content was accomplished using a condenser and pump assembly connected between a sample probe and metering system.

Throughout each sample run, a known volume of gas (measured by a dry gas meter) passed through the condenser assembly. Upon completion of each sample run, the total amount of condensate collected was volumetrically/gravimetrically measured and the net gain calculated. The total moisture gain, volume of gas extracted, and measured meter temperature data were used to calculate the actual moisture content of the effluent. Figure 3.2 provides a schematic of the RM 4 sample system.

\subsection{CEMS Sampling System Description}

The continuous emissions measurements system (CEMS) consists of an in-stack filter assembly, sample probe, sample gas conditioner, Teflon ${ }^{\otimes}$ sample line, sample pumps and analyzers. A sample of the effluent gas is continuously drawn from the sample location through the in-stack filter assembly, stainless steel probe, gas conditioning system and Teflon ${ }^{\star}$ sample line via a Teflon ${ }^{\odot}$ coated sample pump. The sample gas is then passed through the sample gas manifold prior to delivery to the instrumental analyzers.

The following specific support equipment, instrumentation, and data acquisition systems are incorporated into the gaseous monitoring system to provide reliable and defensible data.

- In-stack Filter Assembly: The in-stack filter assembly is composed of a stainless steel filter holder and 0.1 micron filter.

- Sample Probe: Stainless steel probe inserted through the sample port.

- Moisture Removal System: A stainless steel condenser assembly is used for the sample gas conditioning system. The sample gas conditioning system is located downstream of the sample probe. The gas conditioning system continuously removes condensate from the sample gas without changing the dry concentration of the sample gas. This 
approach is completed with minimal contact between the condensate and the sample gas.

- Sample Line: Teflon ${ }^{\oplus}$ tubing is used to transport the sample gas from the gas conditioning system to the sample pump and gas manifold.

- Data Acquisition: A digital data logger is used for data capture. The electronic output (response) of the analyzers to the calibration standards and the sample gas is continuously directed to the digital data logger and recorded at one-minute intervals. A Campbell Scientific Model $21 \mathrm{X}$ data logger is used as the primary data acquisition system. The data collected by the data logger (one-minute averages) is used for all data reduction and compliance determinations. Additionally, a digital strip chart recorder is used as a secondary data acquisition system. The data from the digital strip chart recorder is maintained electronically in the appropriate project directory. The digital strip chart recorder data is only utilized if the data from the primary data acquisition system is corrupt.

\subsubsection{Measurement System Performance}

The CEM system is composed of several different analyzers. Diluent $\mathrm{O}_{2}$ and $\mathrm{CO}_{2}$ are quantified, on a percent, dry basis, using a California Analytical Instruments Model 300 , or equivalent, Paramagnetic $\mathrm{O}_{2}$ analyzer and non-dispersive infrared (NDIR) $\mathrm{CO}_{2}$ analyzer. A Thermal Environmental Incorporated (TEI) Model $42 \mathrm{H}$, or equivalent, chemiluminescent $\mathrm{NO}_{x}$ analyzer is used to measure the effluent $\mathrm{NO}_{x}$ concentration. The $\mathrm{NO}_{x}$ concentration data is measured on a parts per million, by volume, dry basis (ppm $\left.\mathrm{vg}_{\mathrm{v}}\right)$.

All calibration gases are documented traceable to National Bureau of Standards Reference Materials according to the "EPA Traceability Protocol for Assay and Certification of Gaseous Calibration Standards," September 1997, as amended August 25, 1999, EPA-600/R-97/121. Certification from the gas manufacturer(s) that the protocol was followed is provided in the report appendices.

\subsection{2 $\mathrm{O}_{2}, \mathrm{CO}_{2}$, and $\mathrm{NO}_{x}$ Measurements}

The determinations of the $\mathrm{O}_{2}, \mathrm{CO}_{2}$, and $\mathrm{NO}_{x}$ concentrations of the effluent stream will be accomplished following the sampling methodologies detailed in EPA's Code of Federal Regulations, Title 40, Part 60 (40 CFR 60), Appendix A. Specifically, the $\mathrm{O}_{2}$ and $\mathrm{CO}_{2}$ determinations are accomplished following RM 3A, "Determination of Oxygen and Carbon Dioxide Concentrations in Emissions from Stationary Sources (Instrumental Analyzer Procedure)" and the $\mathrm{NO}_{x}$ following RM 7E, "Determination of Nitrogen Oxide Emissions from Stationary Sources (Instrumental Analyzer Procedure)." 


\section{SECOR}

\subsubsection{Calibration Gas Checks}

Each of the previously mentioned Reference Methods requires the following calibration gas mixtures for calibration:

- High-Level Gas: Calibration gas with a concentration that is equal to the calibration span.

- Mid-Level Gas: Calibration gas with a concentration that is 40 to 60 percent of the calibration span.

- Low-Level Gas: Calibration gas with a concentration less than 20 percent of the calibration span and may be a zero gas.

To calibrate each instrument, the gas standards are introduced directly to each monitor at the sample inlet located on the back of the instrument. The response of each analyzer compared to each certified calibration standard must be within \pm 2 percent of the analyzer span value for each component as required in each method.

\subsubsection{Calibration Drift and Measurement System Bias Checks}

The amount of bias of the sample system is also determined. This is accomplished by introducing the low-level and one (1) up-scale (high-level or mid-level) calibration gas to the CEMS at the point at which the sample probe and sample line are connected. The calibration gas which best approximates the emissions is selected as the up-scale gas. The response of each analyzer to the direct zero and span gases (bias check) must be less than \pm 5 percent of the span value for each component as required by the methods. The bias calibration check is performed prior to and upon completion of each sample run.

The magnitude of calibration drift is also calculated. Calibration drift is the difference in the initial (pre-test) bias calibration response and the final (post-test) bias calibration response for the same gas standard. The calibration drift must be within \pm 3 percent of the span over each sample run for each component gas standard as required by the method.

\subsubsection{Interference Response}

Interference response is based on instrument vendor data, which demonstrates that the interference performance specification is not exceeded. Information will be provided upon request.

\subsubsection{Sample System Response Time}

To determine response time for each component, up-scale gas is introduced into the probe upstream of all sample conditioning components. The time required for the measured concentration to increase to a value that is within 95 percent or $0.5 \mathrm{ppm}$ (whichever is less restrictive) of the certified gas concentration is recorded. This is the up-scale system response time. The low-level gas is then introduced to the system and the time for the concentration response to decrease to a value that is within 5.0 percent or $0.5 \mathrm{ppm}$ (whichever is less

December 2006 
restrictive) of the certified low-range gas concentration is recorded. This is the downscale system response time. The response test is conducted prior to the commencement of the performance test and only repeated if changes are made in the measurement system.

\subsubsection{5 $\mathrm{NO}_{2}$ to $\mathrm{NO}$ Conversion Efficiency}

The $\mathrm{NO}_{x}$ analyzer used during the testing program will undergo the conversion efficiency test detailed in 40 CFR 60, Appendix A, RM 7E, Section 8.2.4. The converter efficiency test is conducted prior to mobilization to the project site. The $\mathrm{NO}_{2}$ to $\mathrm{NO}$ conversion efficiency must be found to meet or exceed the minimum criteria specified in RM 7E ( $\geq 90$ percent of the certified test gas concentration.

\subsubsection{Stratification Test}

Prior to conducting the compliance test program, the stratification test is conducted as prescribed in Section 8.1 of RM 7E. The stratification test must be performed at twelve traverse points located according to Table 1-1 or Table 1-2 of RM 1. Alternatively, measurements may be conducted at three points on a line passing through the centroidal area. The three points must be spaced at $16.7,50.0$, and 83.3 percent of the measurement line. Sampling is conducted at a minimum of twice the system response time at each traverse point. The individual point and mean NOx concentrations are then calculated. The individual point data is compared with the mean concentration in order to determine the minimum number of traverse points to be used for the compliance program as prescribed in Section 8.1.2 of RM 7E. 


\section{FIGURE 3.2 RM 4 SAMPLING SYSTEM SCHEMATIC} MCMINNVILLE ELECTRIC SYSTEM NOVEMBER 28, 2006

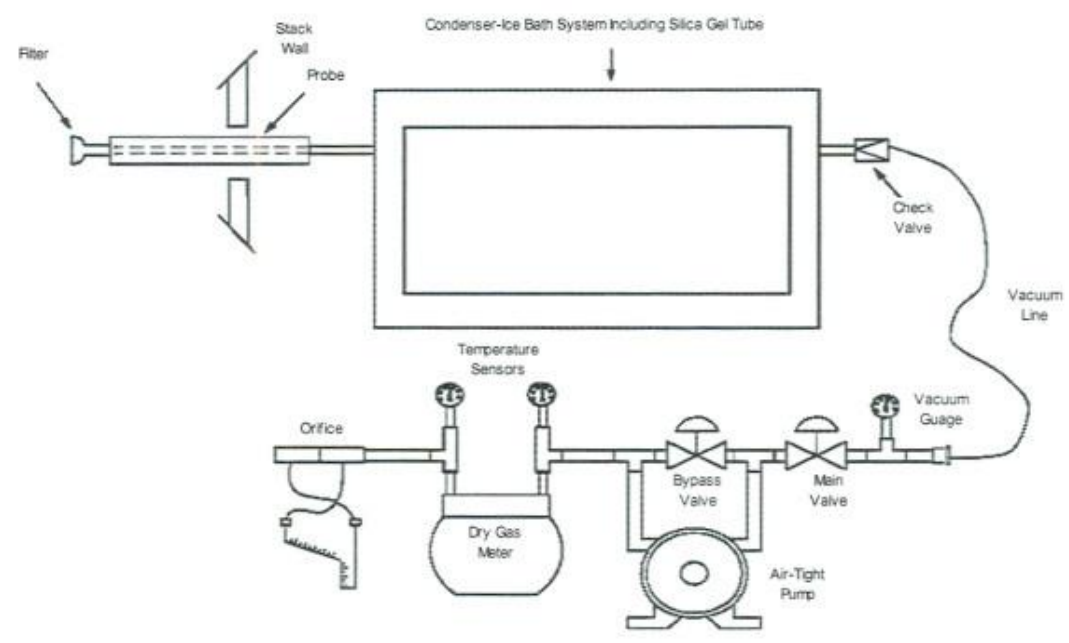




\section{SECOR}

\section{FIGURE 3.3 CEM SYSTEM ILLUSTRATION}

MCMINNVILLE ELECTRIC SYSTEM

NOVEMBER 28, 2006

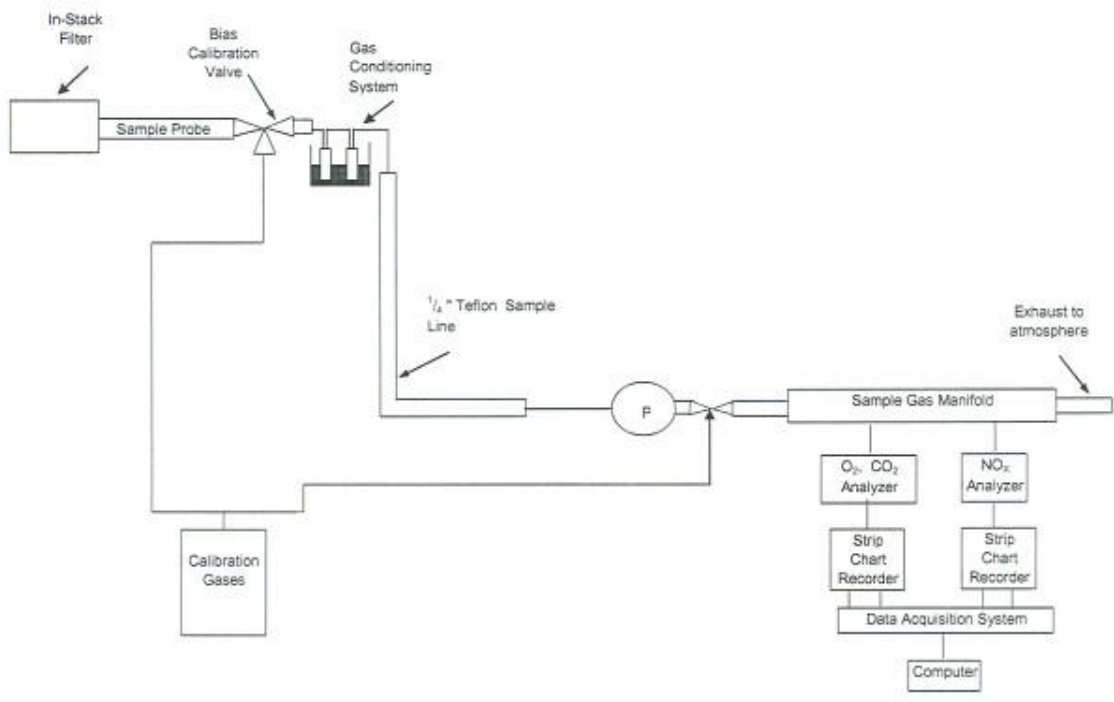

FINAL_Compl_Rpt_McMinnville_Electric.doc 170T. 98726.00 


\subsection{Calculations and Nomenclature}

The following section presents the calculations for determining moisture content, dry sample gas volume, and mass flow rate. In addition, calculations for the determination of $\mathrm{NO}_{x}$ concentrations are provided. The nomenclature for each calculation is also defined.

\subsubsection{Calculations}

Stack Pressure (in. $\mathrm{Hg}$ ):

$$
P_{s}=P_{b a r}+\frac{P_{g}}{13.6}
$$

Meter Pressure (in. $\mathrm{Hg}$ ):

$$
P_{m}=P_{\text {bar }}+\frac{\Delta H}{13.6}
$$

Dry Standard Sample Gas Volume $\left(\mathrm{dsft}^{3}\right)$ :

$$
V_{m(s t d)}=V_{m} \times Y_{d} \times\left(\frac{T_{s t d}}{T_{m}}\right) \times\left(\frac{P_{m}}{P_{s t d}}\right)
$$

Volume of Water Vapor (scf):

$$
V_{w(s t d)}=0.04707 \times V_{i o}
$$

Proportional Moisture Content:

$$
B_{w s}=\frac{V_{w(s t d)}}{V_{w(s t o)}+V_{m(s t d)}}
$$

Percent Moisture (\%):

$$
\% \mathrm{H}_{2} \mathrm{O}=\mathrm{Bws}_{\mathrm{ws}} \times 100
$$

Molecular Weight (dry):

$$
M_{d}=\left(0.44 \times \% \mathrm{CO}_{2}\right)+\left(0.32 \times \% \mathrm{O}_{2}\right)+\left(0.28 \times\left(100-\% \mathrm{CO}_{2}-\% \mathrm{O}_{2}\right)\right)
$$

Molecular Weight (wet):

$$
M_{s}=M_{d} \times\left(1-B_{w s}\right)+\left(18.0 \times B_{w s}\right)
$$


Velocity (fps):

$$
v_{s}=85.49 \times C_{p} \times \sqrt{\Delta p} \times \sqrt{\frac{T_{s}}{P_{s} \times M_{s}}}
$$

Flow Rate (acfm):

$$
Q_{a}=v_{s} \times A_{s} \times 60
$$

Flow Rate (wscfm):

$$
Q_{s w}=Q_{a} \times\left(\frac{T_{s t d}}{T_{s}}\right) \times\left(\frac{P_{s}}{P_{s t d}}\right)
$$

Flow Rate (dscfm):

$$
Q_{s}=Q_{s w} \times\left(1-B_{w s}\right)
$$

Pollutant Mass Emission Rate (lb/hr):

$$
M E R=p p m_{v d} \times \frac{M W}{385.1 \times 10^{6}} \times Q_{s} \times 60
$$

\subsubsection{Nomenclature}

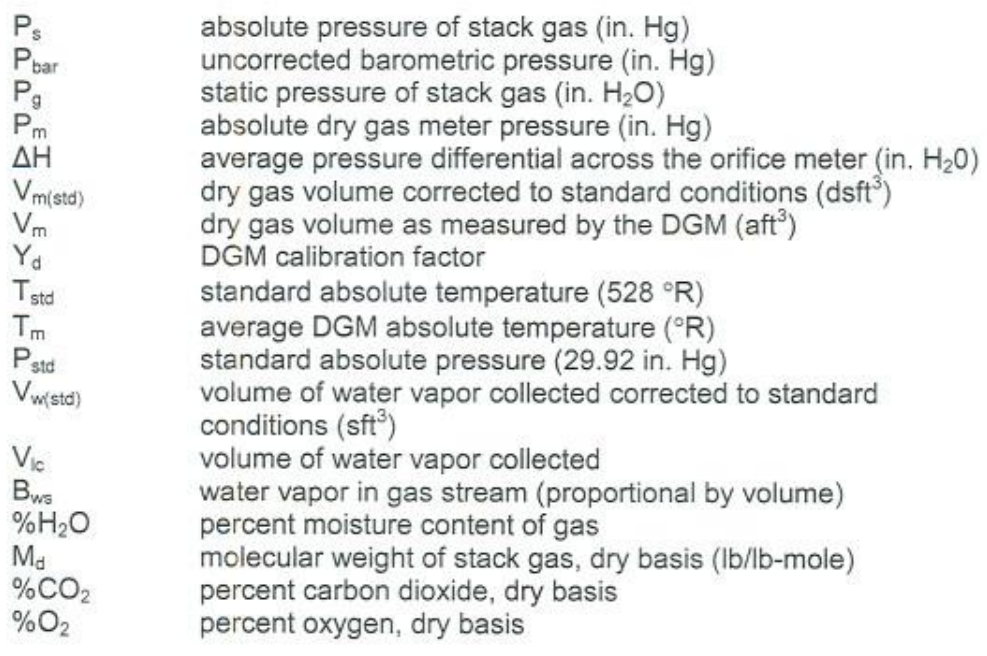




$\begin{array}{ll}M_{s} & \text { molecular weight of stack gas, wet basis (lb/lb-mole) } \\ V_{s} & \text { average gas velocity (feet per second) } \\ C_{p} & \text { pitot tube coefficient, dimensionless ( } 0.84 \text { for Type-S) } \\ \Delta p & \left.\text { velocity head of gas (in. } \mathrm{H}_{2} \mathrm{O}\right) \\ \mathrm{T}_{\mathrm{s}} & \text { stack gas temperature }\left({ }^{\circ} \mathrm{R}\right) \\ \mathrm{Q}_{\mathrm{a}} & \text { volumetric flow rate (actual cubic feet per minute) } \\ \mathrm{A}_{\mathrm{s}} & \text { cross sectional area of the stack (square feet) } \\ \mathrm{Q}_{s w} & \text { volumetric flow rate (wet standard cubic feet per minute) } \\ \mathrm{Q}_{\mathrm{s}} & \text { volumetric flow rate (dry standard cubic feet per minute) } \\ \mathrm{MER} & \text { mass emission rate (lb/hr) } \\ \mathrm{ppm} \text { vd } & \text { part per million, by volume, dry basis } \\ \mathrm{MW} & \text { pollutant molecular weight (lb/lb-mole), }\left(\mathrm{NO}_{x}=46.01\right)\end{array}$

\subsubsection{Constants and Conversions}

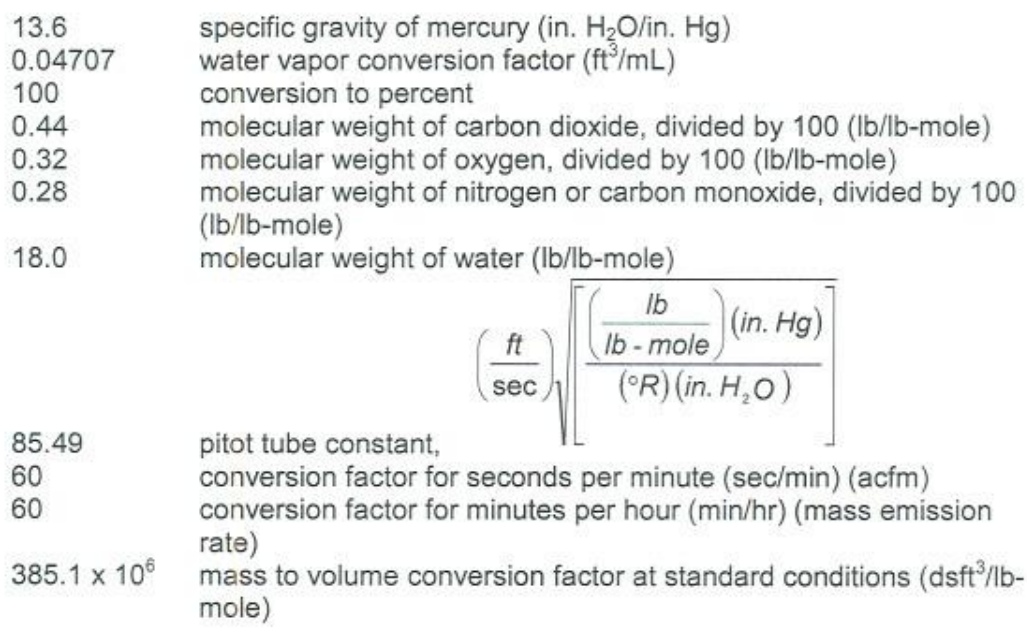

\subsubsection{Example Calculations, Engine Exhaust, Run 1}

Note that the values presented here are rounded numbers and results are those from the spreadsheet calculations. Results calculated using the rounded values may vary slightly.

Stack Pressure (in. $\mathrm{Hg}$ ):

$$
29.24=29.10+\frac{1.90}{13.6}
$$

Meter Pressure (in. $\mathrm{Hg}$ ): 


$$
29.17=29.10+\frac{1.0}{13.6}
$$

Dry Standard Sample Gas Volume $\left(\mathrm{dsft}^{3}\right)$ :

$$
31.300=34.185 \times 0.955 \times\left(\frac{528}{537.5}\right) \times\left(\frac{29.17}{29.92}\right)
$$

Volume of Water Vapor (scf):

$$
2.791=0.04707 \times 59.3
$$

Proportional Moisture Content:

$$
0.0819=\frac{2.791}{2.791+31.300}
$$

Percent Moisture (\%):

$$
8.19=0.0819 \times 100
$$

Molecular Weight (dry):

$$
29.60=(0.44 \times 7.2)+(0.32 \times 11.3)+(0.28 \times(100-7.2-11.3))
$$

Molecular Weight (wet):

$$
28.65=29.60 \times(1-0.0819)+(18.0 \times 0.0819)
$$

Velocity (fps):

$$
158.637=85.49 \times 0.84 \times 1.9342 \times \sqrt{\frac{1,093.3}{29.24 \times 28.65}}
$$

Flow Rate (acfm):

$$
12,880=158.67 \times 1.35 \times 60
$$

Flow Rate (wscfm):

$$
6,081=12,880 \times\left(\frac{528}{1,093.3}\right) \times\left(\frac{29.24}{29.92}\right)
$$


Flow Rate (dscfm):

$$
5,581=6,081 \times(1-0.0819)
$$

Pollutant Mass Emission Rate (lb/hr):

$$
29.64=740.88 \times \frac{46.01}{385.1 \times 10^{6}} \times 5,581 \times 60
$$

December 2006 


\subsection{QUALITY ASSURANCE / QUALITY CONTROL}

The overall objective of SECOR's Quality Assurance/Quality Control (QA/QC) program is to ensure the collection of valid and acceptable data from all environmental measurement projects. Acceptable data is defined in terms of accuracy, precision, completeness, and representativeness.

Quality Control activities are carried out during routine project operations to ensure that the data produced are within established limits of accuracy and precision. Quality Assurance activities are carried out externally and independent of routine project endeavors to document data quality.

Each air measurement program entails numerous activities, during which critical $Q A / Q C$ measures must be incorporated to achieve overall project data quality objectives. Specific QA measures are implemented during each of the following phases of field and laboratory operations:

- Presampling activities

- Sample collection

- Data reduction and reporting

General QA/QC measures and objectives incorporated into all source measurement programs include the following:

- Continually monitor the precision and accuracy of the data being generated for all environmental measurements.

- Implement measures designed to control the precision and accuracy of all data generated for individual sources.

- Maintain permanent records of equipment calibrations that include traceability and certification.

\subsection{Presampling Activities and QA Measures}

Presampling activities include equipment maintenance and calibration. All monitoring equipment is uniquely identified and subjected to continuous preventive maintenance measures at SECOR's Franklin, Tennessee office location. Records of instrument maintenance and calibration are maintained and continually updated. All instrumental analyzers and applicable sampling system components are calibrated prior to and after all field measurements programs according to stringent guidelines set forth in the Quality Assurance Handbook for Air Pollution Measurement Systems, Volume III, Stationary Source Specific Methods and the 40 CFR 60, Appendix $A$ and $F$. 


\subsection{Field Program}

The EPA or applicable local agency, prior to sample initiation, approved field sampling and measurements procedures used in all source measurements programs. All primary emissions testing procedures are referenced in the EPA 40 CFR 60. Appendix A and the EPA Quality Assurance Handbook for Air Pollution Measurement Systems, Volume III, Stationary Source Specific Methods.

All field test personnel involved with this test program are experienced and trained in field sampling methods and procedures. Each field person is assigned key responsibilities in phases of sample collection, sample recovery, chain of custody, and transportation of samples. Basic responsibilities for field personnel include, but are not limited to:

- Record Keeping - Field personnel record all pertinent parameters and relevant observations on the appropriate field data forms.

- Safety Requirements - Field personnel are familiar with company safety regulations and are provided with necessary safety equipment.

- Sample Handling - Field personnel are trained in the proper procedures for handling samples including: use of sample containers, sample preservation, identification, storage of collected samples, and chain-of-custody.

- Instrumentation - Specific field personnel are trained in the proper operation, calibration, trouble shooting, and maintenance of the instrumentation intended for this program. This includes the use of pumps, control console(s), samplers, and instrumentation.

- Quality Control - Field personnel are trained in all aspects of quality control that relate directly to the specific reference method test procedures, sample handling, analysis, and reporting.

A member of the SECOR field team, Mr. David West, was designated as Field Manager and was responsible for coordinating testing activities with the client and answering questions concerning test methodology and quality control. The Field Manager was also responsible for delegating work assignments to the members of the test crew, making sure all QA/QC procedures were carried out, and documenting all field activities in a bound log book.

\subsection{Sample Documentation}

All field data collected for each selected reference method test procedure are documented on field data forms specifically designed for each particular method using recommended formats as described in 40 CFR 60, Appendix A and the EPA Quality Assurance Handbook for Air Pollution Measurement Systems, Volume III, Stationary Source Specific Methods. Each form, specific to each particular sample run, includes information as to the source tested, date and time of sample collection, analyst(s) performing the test and all data necessary for test validation. Each field data sheet is completed by the responsible technician at the time of the test and checked by the Field Manager for accuracy and completeness after each test series. Copies of all raw 


\section{SECOR}

field data sheets are included in this emission test report with the originals maintained in project files at SECOR's Tennessee office.

\subsection{Data Reduction and Reporting}

SECOR has implemented specific measures to ensure that reliable data is generated as a result of the sampling and analytical activities of every field program. The objective of this phase of SECOR's QAVQC program is to follow the proper collection of representative and quality assured field and analytical data with approved data reduction methods and equations.

All calculations are performed using quality assured spreadsheets incorporating standard accepted equations, as required by the applicable pollutant specific sampling methodology. Data reduction is performed by qualified engineers or data analysts familiar with standard engineering practices and approved methods. 
APPENDIX A

FIELD DATA AND SPREADSHEET CALCULATIONS

Emissions Measurements Report

McMinnville Electric System 200 West Morford Street

McMinnville, Tennessee

170T.98726.00

December 2006 
Run 2

CONTINUOUS EMISSION MEASUREMENT RESULTS

Engine Exhaust

\begin{tabular}{|c|c|c|c|c|c|c|c|}
\hline Time & $\begin{array}{c}\mathrm{O}_{2} \\
(\%)\end{array}$ & $\begin{array}{c}\mathrm{O}_{2} \\
(\% \cdot \text { - Bias } \\
\text { Corr. })\end{array}$ & $\begin{array}{l}\mathrm{CO}_{2} \\
\text { (\%) }\end{array}$ & $\begin{array}{c}\mathrm{CO}_{2} \\
(\% \text { - Bias } \\
\text { Corrt })\end{array}$ & $\begin{array}{c}\mathrm{NO}_{2} \\
\left(\mathrm{ppm}_{\mathrm{vd}}\right)\end{array}$ & $\begin{array}{c}\text { NO, } \\
\text { (ppmm } \\
\text { Corr.) }\end{array}$ & $\begin{array}{l}\text { No, } \\
\text { (lb/hr) }\end{array}$ \\
\hline 1200 & 11,28 & 11.34 & 7.19 & 717 & 7388 & 749.6 & 30,17 \\
\hline 1201 & 11.24 & 11.29 & 7.19 & 7.17 & 740.6 & 751.5 & 30.25 \\
\hline 1202 & 11.26 & 11.31 & 7.20 & 7.18 & 7410 & 751.8 & 30.27 \\
\hline 1203 & 11.24 & 11.29 & 7.20 & 7.18 & 740.7 & 751.6 & 30.25 \\
\hline 1204 & 11.24 & 1130 & 7.20 & 7.18 & 740.6 & 751.5 & 30.25 \\
\hline 1205 & 11.25 & 11.30 & 7.19 & 7.17 & 742.9 & 753.8 & 30.34 \\
\hline 1206 & 11.25 & 11.31 & 7.20 & 7.18 & 7445 & 755.5 & 30.41 \\
\hline 1207 & 11.28 & 11.31 & 7.19 & 7.17 & 7449 & 755.9 & 30.43 \\
\hline 1208 & 11,27 & 11.33 & 7.19 & 7.17 & 7432 & 754.2 & 30.36 \\
\hline 1209 & 11.25 & 11,31 & 7.19 & 7.17 & 7430 & 7540 & 30.35 \\
\hline 1210 & 11.28 & 11.33 & 7.19 & 7.17 & 7437 & 754.7 & 30.38 \\
\hline 1211 & 11.26 & 11.32 & 7.19 & 7.17 & 741.3 & 752.3 & 30.28 \\
\hline 1212 & 11,28 & 11.31 & 7.19 & 7.17 & 7419 & 752.8 & 30,30 \\
\hline 1213 & 11.26 & 11.32 & 7.19 & 7.17 & 741.0 & 751.9 & 30.26 \\
\hline 1214 & 11.25 & 11.31 & 7.19 & 7.17 & 739.9 & 750.8 & 30.22 \\
\hline 1215 & 11.26 & 11.31 & 7.18 & 7.16 & 740.5 & 751.4 & 30.25 \\
\hline 1216 & 11.28 & 11.34 & 7.19 & 7.17 & 739.5 & 750.4 & 30.20 \\
\hline 1217 & 11.25 & 11.30 & 7.19 & 7.17 & 738.7 & 749.5 & 30.17 \\
\hline 1218 & 11.26 & 11.31 & 7.20 & 7.17 & 738.0 & 7489 & 30.14 \\
\hline 1219 & 11.25 & 11.31 & 7.20 & 7.18 & 737.4 & 748.2 & 30.12 \\
\hline 1220 & 11.26 & 11.32 & 7.19 & 7.17 & 736.7 & 747.5 & 30.09 \\
\hline 1221 & 11.27 & 11.32 & 7.19 & 7.16 & 736.8 & 747.6 & 30.09 \\
\hline 1222 & 11.26 & 11.32 & 7.19 & 7.17 & 734.8 & 745.5 & 30.01 \\
\hline 1223 & 11.27 & 11.32 & 7.19 & 7.17 & 7336 & 744.4 & 29.96 \\
\hline 1224 & 11.29 & 11.35 & 7.19 & 7.16 & 734.7 & 745.5 & 30.01 \\
\hline 1225 & 11.28 & 11.33 & 7.18 & 7.16 & 734.3 & 745.1 & 29.99 \\
\hline 1226 & 11.26 & 11.31 & 7.18 & 7.16 & 733.5 & 744.3 & 29.96 \\
\hline 1227 & 11.27 & 11.32 & 7.19 & 7.17 & 7320 & 7427 & 29.90 \\
\hline 1228 & 11.27 & 11.32 & 7.19 & 7.17 & 731.0 & 741.7 & 29.86 \\
\hline 1229 & 11.26 & 11.32 & 7.18 & 7.16 & 7302 & 740.9 & 29.82 \\
\hline 1230 & 11.28 & 11.33 & 7.18 & 7. 16 & 731.8 & 742.5 & 29.89 \\
\hline 1231 & 11.28 & 11.33 & 7.18 & 7.16 & 731,1 & 741.8 & 29.86 \\
\hline 1232 & 11.27 & 11.33 & 7.18 & 7.16 & 730.2 & 740.9 & 29.82 \\
\hline 1233 & 11.27 & 11.32 & 7.18 & 7.17 & 728.8 & 739.8 & 29.77 \\
\hline 1234 & 11.26 & 11.31 & 7.19 & 7,17 & 7280 & 738.7 & 29.73 \\
\hline 1235 & 11.27 & 11.32 & 7.19 & 7.16 & 728.7 & 739.3 & 29.76 \\
\hline 1236 & 11.26 & 11.31 & 7.19 & 7.17 & 729.7 & 740.4 & 29.80 \\
\hline 1237 & 11.26 & 11.31 & 7.19 & 7.17 & 729.9 & 740.6 & 29.81 \\
\hline 1238 & 11,26 & 11.31 & 7.20 & 7.17 & 728.6 & 739.3 & 29.76 \\
\hline 1239 & 11.27 & 11.32 & 7.19 & 7.17 & 728.7 & 739.4 & 29.76 \\
\hline 1240 & 11.27 & 11.32 & 7.19 & 7.16 & 728.8 & 739.5 & 29.76 \\
\hline 1241 & 11.27 & 11.33 & 7.18 & 7.17 & 728.4 & 739.0 & 29.75 \\
\hline 1242 & 11.26 & 11.31 & 7.19 & 7.17 & 7279 & 738.6 & 29.73 \\
\hline 1243 & 11.26 & 11.31 & 7.20 & 7.17 & 728.1 & 738.8 & 29.74 \\
\hline 1244 & 11.28 & 11.33 & 7.20 & 7.18 & 7273 & 738,0 & 29.70 \\
\hline 1245 & 11,27 & 11.32 & 7.20 & 7.18 & 727.9 & 738.6 & 29.73 \\
\hline 1246 & 11.27 & 11.32 & 7.20 & 7.18 & 728.0 & 738.7 & 28.73 \\
\hline 1247 & 11.27 & 11.33 & 7.20 & 7.18 & 727.2 & 737.9 & 29.70 \\
\hline 1248 & 11.27 & 11.32 & 7.20 & 7.17 & 727.8 & 738.4 & 29.72 \\
\hline 1249 & 11.28 & 11.33 & 7.20 & 7.18 & 728.3 & 739.0 & 29.75 \\
\hline 1250 & 11.27 & 11.32 & 7.21 & 7.18 & 7289 & 739.6 & 29.77 \\
\hline 1251 & 11.25 & 11.30 & 7.21 & 7.19 & 728.3 & 739.0 & 29.74 \\
\hline 1252 & 11.27 & 11.33 & 7.21 & 719 & 728.8 & 739.5 & 29.76 \\
\hline 1253 & 11,26 & 11.31 & 7.21 & 7.18 & 729.6 & 740.3 & 29.80 \\
\hline 1254 & 11.28 & 11.32 & 7.21 & 719 & 730.1 & 740.8 & 29.82 \\
\hline 1255 & 11.25 & 11,30 & 7.22 & 7.19 & 7290 & 739.6 & 29.77 \\
\hline 1256 & $11: 28$ & 11,31 & 7.22 & 7.19 & 729.4 & 740,1 & 29.79 \\
\hline 1257 & 11,26 & 11.31 & 7.22 & 7.19 & 730.7 & 741.4 & 29.84 \\
\hline 1258 & 11.26 & 11.31 & 7.22 & 719 & 729.8 & 740.4 & 29.80 \\
\hline 1259 & 11.25 & 11.31 & 7.23 & 720 & 729.5 & 740.2 & 29.79 \\
\hline Average & 11.26 & 11.32 & 720 & 7.17 & 733.81 & 74459 & 29.97 \\
\hline
\end{tabular}


Run 3

CONTINUOUS EMISSION MEASUREMENT RESULTS

Engine Exhaust

November 28, 2006

\begin{tabular}{|c|c|c|c|c|c|c|c|c|}
\hline Time & $\begin{array}{l}O_{2} \\
(\%)\end{array}$ & $\begin{array}{c}\mathrm{O}_{2} \\
(\%-\text { - Bias } \\
\text { Corr. })\end{array}$ & $\begin{array}{l}\mathrm{CO}_{2} \\
(\%)\end{array}$ & $\begin{array}{c}\mathrm{CO}_{2} \\
(\% \%-\text { Bias } \\
\text { Corr. })\end{array}$ & $\begin{array}{c}\text { No, } \\
\left(\mathrm{ppm}_{\text {.d }}\right)\end{array}$ & $\begin{array}{c}\mathrm{NO}_{\mathrm{x}} \\
\left(\mathrm{ppm}_{\mathrm{yd}} \text {-Bias }\right. \\
\text { Corr. }\}\end{array}$ & $\begin{array}{l}\text { NO, } \\
\text { (lb/hr) }\end{array}$ & \\
\hline 1324 & 11.24 & 1128 & 7.24 & 7.17 & 7371 & 746.8 & 29.72 & \\
\hline 1325 & 11.25 & 11.30 & 7.25 & 7.17 & 7381 & 7478 & 29.76 & \\
\hline 1326 & 11.22 & 11.27 & 7.25 & 7.17 & 7392 & 748.9 & 29.80 & \\
\hline 1327 & 11.24 & 11.29 & 7.24 & 7.17 & 7391 & 748.8 & 29.80 & \\
\hline 1328 & 11.23 & 11.28 & 7.25 & 7.17 & 740.2 & 749.9 & 29.84 & \\
\hline 1329 & 11.24 & 11.29 & 7.25 & 7.17 & 740.5 & 750.2 & 29.85 & \\
\hline 1330 & 11.25 & 1129 & 7.24 & 7.16 & 7412 & 751.0 & 29.88 & \\
\hline 1331 & 11.24 & 11.29 & 7.24 & 7.16 & 741.5 & 751.2 & 29.89 & \\
\hline 1332 & 11.24 & 11.28 & 724 & 716 & 741.6 & 751.3 & 29.90 & \\
\hline 1333 & 11.23 & 11.28 & 7.25 & 7.17 & 740.9 & 750.7 & 29.87 & \\
\hline 1334 & 11.25 & 11,30 & 7.25 & 7.17 & 740.6 & 750.4 & 29.86 & \\
\hline 1335 & 11.23 & 11.28 & 7.25 & 717 & 7407 & 750.4 & 29.86 & \\
\hline 1336 & 11.24 & 11.28 & 7.25 & 7.17 & 740.5 & 750.2 & 29.85 & \\
\hline 1337 & 11.24 & 11.28 & 725 & 7.17 & 740.6 & 750.3 & 29.86 & \\
\hline 1338 & 11.23 & 11.28 & 7.25 & 7.17 & 739.4 & 749.1 & 29.81 & \\
\hline 1339 & 11.23 & 11.28 & 7.25 & 7.18 & 7403 & 750.0 & 29.84 & \\
\hline 1340 & 11.26 & 11.30 & 7.26 & 7.18 & 7410 & 750.8 & 2988 & \\
\hline 1341 & 11.23 & 11.28 & 7.26 & 7,18 & 740.3 & 750.0 & 2984 & \\
\hline 1342 & 11.24 & 11.29 & 7.26 & 7.18 & 740.0 & 749.7 & 29.83 & \\
\hline 1343 & 11.24 & 11.28 & 7.26 & 7.18 & 740.0 & 749.7 & 29.83 & \\
\hline 1344 & 11.23 & 11.28 & 7.27 & 7.20 & 739.1 & 748.8 & 29.80 & \\
\hline 1345 & 11.24 & 11.29 & 7.28 & 7.19 & 738.9 & 748.6 & 29.79 & \\
\hline 1346 & 11.24 & 11.29 & 7.26 & 7.18 & 7388 & 748.5 & 29.78 & \\
\hline 1347 & 11.24 & 11.29 & 7.26 & 7.19 & 7373 & 747.0 & 29.72 & \\
\hline 1348 & 11.24 & 11.29 & 7.26 & 7,19 & 7370 & 746.6 & 29.71 & \\
\hline 1349 & 11.23 & 11.28 & 7.27 & 7.19 & 737.3 & 747.0 & 29.72 & \\
\hline 1350 & 11.24 & 11.29 & 7.27 & 7.20 & 737.6 & 747.3 & 29.74 & \\
\hline 1351 & 11.24 & 11.28 & 7.27 & 7.20 & 738.2 & 747.9 & 29.76 & \\
\hline 1352 & 11.23 & 11.28 & 7.27 & 720 & 738.2 & 747.9 & 29.76 & \\
\hline 1353 & 11.24 & 11.29 & 7.27 & 7.20 & 7379 & 747.6 & 29.75 & \\
\hline 1354 & 11.23 & 11.28 & 7.28 & 7.20 & 739.4 & 749.1 & 29.81 & \\
\hline 1355 & 11.23 & 11.28 & 7.29 & 7.21 & 7386 & 748.3 & 29.78 & \\
\hline 1356 & 11.22 & 11.27 & 7.29 & 721 & 7377 & 747.4 & 29.74 & \\
\hline 1357 & 11.24 & 11.29 & 7.28 & 7.21 & 7381 & 747.8 & 29.76 & \\
\hline 1358 & 11.24 & 11.29 & 7.28 & 721 & 7385 & 748.2 & 29.77 & \\
\hline 1359 & 11.24 & 11.29 & 7.28 & 7.21 & 737.6 & 747.2 & 29.73 & \\
\hline 1400 & 11.24 & 11.29 & 7.29 & 7.21 & 7379 & 747.6 & 29.75 & \\
\hline 1401 & 11.23 & 11.28 & 7.29 & 7.21 & 7368 & 746.4 & 29.70 & \\
\hline 1402 & 11.25 & 11.30 & 7.29 & 7.21 & 737.9 & 747.6 & 29.75 & \\
\hline 1403 & 11.22 & 11.27 & 7.29 & 7.21 & 7380 & 747.7 & 29.75 & \\
\hline 1404 & 11,24 & 11.29 & 7.29 & 7.21 & 7371 & 746.8 & 29.72 & \\
\hline 1405 & 11.25 & 11.29 & 7.28 & 7.21 & 738.1 & 747.8 & 29.76 & \\
\hline 1406 & 11.25 & 11.30 & 7.29 & 7.21 & 738.2 & 747.9 & 29.76 & \\
\hline 1407 & 11.25 & 11.30 & 7.29 & 7.21 & 7367 & 746.3 & 29.70 & \\
\hline 1408 & 11.25 & 11.30 & 7.29 & 7.21 & 7362 & 7458 & 29.68 & \\
\hline 1409 & 11,25 & 11.30 & 7.29 & 7.21 & 7363 & 7460 & 29.68 & \\
\hline 1410 & 11.26 & 11.30 & 7.29 & 7.21 & 735.1 & 744.7 & 29.64 & \\
\hline 1411 & 11.24 & 11.29 & 7.29 & 7.21 & 733.4 & 743.0 & 29.56 & \\
\hline 1412 & 11.26 & 11.31 & 7.29 & 7.21 & 731.8 & 741.4 & 29.50 & \\
\hline 1413 & 11.25 & 11.30 & 7.29 & 7.21 & 7324 & 7419 & 2952 & \\
\hline 1414 & 11.27 & 11.32 & 7.29 & 7.22 & 7322 & 741.8 & 29.52 & \\
\hline 1415 & 11.24 & 11.29 & 7.29 & 7.21 & 7300 & 739.6 & 29.43 & \\
\hline 1416 & 11.27 & 11.32 & 7.29 & 7.21 & 7270 & 7365 & 29.31 & \\
\hline 1417 & 11.26 & 11.30 & 7.29 & 7.21 & 7272 & 736.7 & 29.31 & \\
\hline 1418 & 11,27 & 11.31 & 7.29 & 721 & 7267 & 736.1 & 29.29 & \\
\hline 1419 & 11.26 & 11.31 & 7.29 & 7.21 & 726.9 & 736.4 & 29.30 & \\
\hline 1420 & 11.25 & 11.30 & 7.29 & 7.22 & 7272 & 736.7 & 29.32 & \\
\hline 1421 & 11.25 & 11.30 & 7.29 & 7.21 & 7239 & 733.4 & 29.18 & \\
\hline 1422 & 11.25 & 11.30 & 7.29 & 7.21 & 7234 & 732.8 & 29.16 & \\
\hline 1423 & 11.26 & 11.31 & 7.29 & 7.21 & 724.1 & 733.5 & 29.19 & \\
\hline Average & 11.24 & 11.29 & 7.27 & 719 & 736.45 & 746.11 & 29.69 & \\
\hline
\end{tabular}


SECOR

ANALYZER CALIBRATION DATA

\begin{tabular}{|c|c|c|c|c|c|c|c|}
\hline \multicolumn{2}{|c|}{$\begin{array}{l}\text { CLIENT: McMinnville Electric } \\
\text { LOCATION: } \\
\text { SOURCE ID: } \\
\text { OPERATOR: } \\
\text { Ongine Exhalle. Tennest } \\
\text { DW. BE }\end{array}$} & \multicolumn{2}{|c|}{$\begin{array}{l}\text { DATE } \\
\text { INITIAL CAL ITIME } \\
\text { FINAL CAL TIME }\end{array}$} & November 28,200 & & & \\
\hline \multicolumn{8}{|c|}{$\mathrm{O}$, Method $3 \mathrm{~A}$} \\
\hline INITIAL SYSTEM CALIBRATION & & $\begin{array}{c}\text { Cal Gas } \\
\text { Range } \\
\text { (\% of Span) }\end{array}$ & $\begin{array}{l}\text { Actual Cylinder } \\
\text { Value }(\%)\end{array}$ & $\begin{array}{c}\text { Instrument } \\
\text { Response (\%) }\end{array}$ & $\begin{array}{c}\text { Absolute } \\
\text { Difference } \\
\text { (\%) }\end{array}$ & $\begin{array}{l}\text { Actual Difference } \\
\text { (Fia) }\end{array}$ & $\begin{array}{c}\text { Allowed } \\
\text { Ditference } \\
(\%)\end{array}$ \\
\hline Span Value: $\quad 25$ & & & & & & & \\
\hline \multicolumn{2}{|l|}{ Model No: $\overline{C A I} 300$} & $\mathrm{~N}_{2}$ or Air & 0.00 & 0.00 & 0.00 & 0.0 & 2 \\
\hline \multirow[t]{2}{*}{ Serial No: R08095 } & MID-RANGE & $40 \cdot 60 \%$ & 12.50 & 12.53 & 0.03 & 0.1 & 2 \\
\hline & HIGH-RANGE & $80-100 \%$ & 20.00 & 20.02 & 0.02 & 0.1 & 2 \\
\hline \multicolumn{8}{|l|}{ FINAL SYSTEM CALIBRATION } \\
\hline \multirow{3}{*}{\multicolumn{2}{|c|}{$\begin{array}{r}\text { ZERO } \\
\text { MID-RANGE } \\
\text { HIGH-RANGE }\end{array}$}} & $\mathrm{N}_{2}$ or Air & 0.00 & $0.03 / /$ & 0.03 & 0.1 & 2 \\
\hline & & $40.60 \%$ & 12.50 & 12.50 & 0.00 & 0.0 & 2 \\
\hline & & $80 \cdot 100 \%$ & 20.00 & 20.00 & 0.00 & 0.0 & 2 \\
\hline \multicolumn{8}{|c|}{$\mathrm{CO}_{2}$ Method $3 \mathrm{~A}$} \\
\hline \multicolumn{2}{|l|}{ INITIAL SYSTEM CALIBRATION } & $\begin{array}{c}\text { Cal Gas } \\
\text { Range } \\
\text { (\% of Span) }\end{array}$ & $\begin{array}{l}\text { Actual Cylinder } \\
\text { Value (\%) }\end{array}$ & $\begin{array}{l}\text { Instrument } \\
\text { Response (\%) }\end{array}$ & $\begin{array}{c}\text { Absolute } \\
\text { Difference } \\
(\%)\end{array}$ & $\begin{array}{l}\text { Actual Difference } \\
\text { (\$) }\end{array}$ & $\begin{array}{c}\text { Allowed } \\
\text { Ditference } \\
(\%)\end{array}$ \\
\hline \multicolumn{8}{|l|}{ Span Value: $\quad 25$} \\
\hline \multicolumn{2}{|l|}{ Model No: CAI 300} & $\mathrm{~N}_{2}$ or Air & 0.00 & 0.00 & 0.00 & 0.0 & 2 \\
\hline \multirow[t]{2}{*}{ Serial No: R08095 } & MID-RANGE & $40-60 \%$ & 12.40 & 12.40 & 0.00 & 0.0 & 2 \\
\hline & HIGH-RANGE & $80 \cdot 100 \%$ & 19.70 & 19.70 & 0.00 & 0.0 & 2 \\
\hline \multicolumn{8}{|l|}{ FINAL SYSTEM CALIBRATION } \\
\hline \multirow{3}{*}{\multicolumn{2}{|c|}{$\begin{array}{r}\text { ZERO } \\
\text { MID-RANGE } \\
\text { HIGH-RANGE }\end{array}$}} & $\mathrm{N}_{2}$ or Air & 0.00 & 0.12 & 0.12 & 0.5 & 2 \\
\hline & & $40.60 \%$ & 12.40 & $12.51>$ & 0.11 & 0.4 & 2 \\
\hline & & $80 \cdot 100 \%$ & 19.70 & 19.83 & 0.13 & 0.5 & $\frac{2}{2}$ \\
\hline \multicolumn{8}{|c|}{ NO, Method 7E } \\
\hline \multicolumn{2}{|l|}{ INITIAL SYSTEM CALIBRATION } & $\begin{array}{c}\text { Cal Gas } \\
\text { Range } \\
\text { (\%) of Span) }\end{array}$ & $\begin{array}{l}\text { Actual Cylinder } \\
\text { Value (ppm) }\end{array}$ & $\begin{array}{c}\text { Instrument } \\
\text { Response (ppm) }\end{array}$ & $\begin{array}{l}\text { Absolute } \\
\text { Difference } \\
\text { (pom) }\end{array}$ & $\begin{array}{c}\text { Actual Difference } \\
\text { (\$S) }\end{array}$ & $\begin{array}{c}\text { Allowed } \\
\text { Difference } \\
(\%)\end{array}$ \\
\hline \multicolumn{8}{|l|}{ Span Vaiue: $\quad 1000$} \\
\hline \multicolumn{2}{|l|}{ Model No: $\overline{T E I} 42 \mathrm{H}$} & $\mathrm{N}_{2}$ or Air & 0.00 & 1.18 & 1.18 & 0.1 & 2 \\
\hline \multirow[t]{2}{*}{ Serial No: $\overline{42 \mathrm{H}-50850-286}$} & MID-RANGE & $40.60 \%$ & 500.80 & 504.90 & 4.10 & 0.4 & 2 \\
\hline & HIGH-RANGE & $80-100 \%$ & 988.60 & 991.50 & 2.90 & 0.3 & $\frac{2}{2}$ \\
\hline \multicolumn{8}{|l|}{ FINAL SYSTEM CALIBRATION } \\
\hline & ZERO & $\mathrm{N}_{2}$ or Air & 0.00 & 0.54 & 0.54 & 0.1 & 2 \\
\hline & MID-RANGE & $40.50 \%$ & 500.80 & 503.50 & 2.70 & 0.3 & 2 \\
\hline & HIGH-RANGE & $80 \cdot 100 \%$ & 988.60 & 986.70 & 1.90 & 0.2 & 2 \\
\hline
\end{tabular}

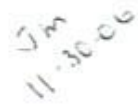

NOx,CEM_Daras Cals 
SECOR

CEMS BIAS DATA

CLIENT: MCMinnville Electric LOCATION: McMinnville. Tennessee SOURCE 1.D. Engine Exhaus!

DATE: November 28. 2006 OPERATOR: DW, BE

\begin{tabular}{|c|c|c|c|c|c|c|c|c|c|c|}
\hline \multicolumn{11}{|c|}{$\mathrm{O}_{2}$ Method 3A } \\
\hline \multirow{10}{*}{ Span Value: } & \multirow[b]{2}{*}{25} & & $\begin{array}{c}\text { Instrument } \\
\text { Response } \\
(\%)\end{array}$ & $\begin{array}{l}\text { CEMS } \\
\text { CEMS } \\
\text { Response }\end{array}$ & $\begin{array}{c}\text { Pre Test } \\
\text { Calibration } \\
\text { Bias (\%) }\end{array}$ & $\begin{array}{l}\text { CEMS } \\
\text { Response } \\
\text { Con }\end{array}$ & $\begin{array}{c}\text { Post Test } \\
\text { Calibration } \\
\text { Bias (\%) }\end{array}$ & $\begin{array}{c}\text { Allowed } \\
\text { Bias } \\
(\%)\end{array}$ & $\begin{array}{c}\text { Calibration } \\
\text { Drift }(\%)\end{array}$ & $\begin{array}{c}\text { Allowed } \\
\text { Drift } \\
(\%)\end{array}$ \\
\hline & & & \multicolumn{8}{|c|}{ Run 1} \\
\hline & \multirow{3}{*}{\multicolumn{2}{|c|}{$\begin{array}{r}\text { ZERO } \\
\text { BIAS GAS }\end{array}$}} & 0.00 & 0.04 & 0.2 & 0.03 & 0.1 & 5 & 0.0 & 3 \\
\hline & & & 20.02 & $19.94 \cdot$ & 0.3 & 19.89 & 0.5 & 5 & 0.2 & 3 \\
\hline & & & \multicolumn{8}{|c|}{ Run 2} \\
\hline & \multirow{3}{*}{\multicolumn{2}{|c|}{$\begin{array}{r}\text { ZERO } \\
\text { BIAS GAS }\end{array}$}} & 0.00 & 0.03 & 0.1 & 0.05 & 0.2 & 5 & 0.1 & 3 \\
\hline & & & 20.02 & 19.89 & 0.5 & $19.86 /$ & 0.6 & 5 & 0.1 & 3 \\
\hline & & & \multicolumn{8}{|c|}{ Run 3} \\
\hline & \multirow{2}{*}{\multicolumn{2}{|c|}{$\begin{array}{r}\text { ZERO } \\
\text { BIAS GAS }\end{array}$}} & 0.00 & 0.05 & 0.2 & $0.05>$ & 0.2 & 5 & 0.0 & 3 \\
\hline & & & 20.02 & 19.86 & 0.6 & 19.89 & 0.5 & 5 & 0.1 & 3 \\
\hline \multicolumn{11}{|c|}{$\mathrm{CO}_{2}$ Method $3 \mathrm{~A}$} \\
\hline \multirow{10}{*}{ Span Value: } & \multirow{2}{*}{\multicolumn{2}{|c|}{25}} & $\begin{array}{c}\text { Instrument } \\
\text { Response } \\
(\%)\end{array}$ & $\begin{array}{l}\text { TE TEST } \\
\text { CEMS } \\
\text { Response } \\
\text { Lo }\end{array}$ & $\begin{array}{c}\text { Pre Test } \\
\text { Calibration } \\
\text { Bias (\%) }\end{array}$ & $\begin{array}{l}\text { CEMT } \\
\text { CEMS } \\
\text { Response }\end{array}$ & $\begin{array}{c}\text { Post Test } \\
\text { Calibration } \\
\text { Bias (\%) }\end{array}$ & $\begin{array}{c}\text { Allowed } \\
\text { Bias } \\
(\%)\end{array}$ & $\begin{array}{c}\text { Calibration } \\
\text { Drift }(\%)\end{array}$ & $\begin{array}{c}\text { Allowed } \\
\text { Drift } \\
(\%)\end{array}$ \\
\hline & & & \multicolumn{8}{|c|}{ Run 1} \\
\hline & \multirow{3}{*}{\multicolumn{2}{|c|}{$\begin{array}{r}\text { ZERO } \\
\text { BIAS GAS }\end{array}$}} & 0.00 & 0.00 & 0.0 & 0.02 & 0.1 & 5 & 0.1 & 3 \\
\hline & & & 19.70 & 19.66 & 0.2 & 19.65 & 0.2 & 5 & 0.0 & 3 \\
\hline & & & \multicolumn{8}{|c|}{ Run 2} \\
\hline & \multirow{3}{*}{\multicolumn{2}{|c|}{$\begin{array}{r}\text { ZERO } \\
\text { BIAS GAS }\end{array}$}} & 0.00 & 0.02 & 0.1 & 0.12 & 0.5 & 5 & 0.4 & 3 \\
\hline & & & 19.70 & 19.65 & 0.2 & 19.64 & 0.2 & 5 & 0.0 & 3 \\
\hline & & & \multicolumn{8}{|c|}{ Run 3} \\
\hline & & ZERO & 0.00 & 0.12 & 0.5 & 0.14 & 0.6 & 5 & 0.1 & 3 \\
\hline & & BIAS GAS & 19.70 & 19.64 & 0.2 & 19.73 & 0.1 & 5 & 0.4 & 3 \\
\hline & & & & & $\mathrm{NO}_{x}$ Method 7 & & & & & \\
\hline \multirow{10}{*}{ Span Value: } & & & $\begin{array}{l}\text { Instrument } \\
\text { Response } \\
\text { (ppm) }\end{array}$ & $\begin{array}{l}\text { CEMS } \\
\text { Response }\end{array}$ & $\begin{array}{c}\text { Pre Test } \\
\text { Calibration } \\
\text { Bias }(\%)\end{array}$ & $\begin{array}{l}\text { CEMS } \\
\text { Response }\end{array}$ & $\begin{array}{c}\text { Post Test } \\
\text { Calibration } \\
\text { Bias (\%) }\end{array}$ & $\begin{array}{c}\text { Allowed } \\
\text { Bias } \\
(\%)\end{array}$ & $\begin{array}{c}\text { Calibration } \\
\text { Drift }(\%)\end{array}$ & $\begin{array}{c}\text { Allowed } \\
\text { Drift } \\
(\%)\end{array}$ \\
\hline & 1000 & & \multicolumn{8}{|c|}{ Run 1} \\
\hline & \multirow{3}{*}{\multicolumn{2}{|c|}{$\begin{array}{r}\text { ZERO } \\
\text { BIAS GAS }\end{array}$}} & 1.18 & $6.31 \quad$ & 0.5 & 5.85 & 0.5 & 5 & 0.0 & 3 \\
\hline & & & 991.50 & 978.20 & 1.3 & 974.60 & 1.7 & 5 & 0.4 & 3 \\
\hline & & & \multicolumn{8}{|c|}{ Run 2} \\
\hline & \multirow{3}{*}{\multicolumn{2}{|c|}{$\begin{array}{r}\text { ZERO } \\
\text { BIAS GAS }\end{array}$}} & 1.18 & 5.85 & 0.5 & 2.00 & 0.1 & 5 & 0.4 & 3 \\
\hline & & & 991.50 & 974.60 & 1.7 & $971.40 /$ & 2.0 & 5 & 0.3 & 3 \\
\hline & & & \multicolumn{8}{|c|}{ Run 3} \\
\hline & & ZERO & 1.18 & 2.00 & 0.1 & 5.70 & 0.5 & 5 & 0.4 & 3 \\
\hline & & BIAS GAS & 991.50 & 971.40 & 2.0 & 977.70 & 1.4 & 5 & 0.6 & 3 \\
\hline
\end{tabular}

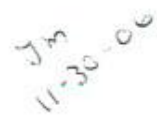




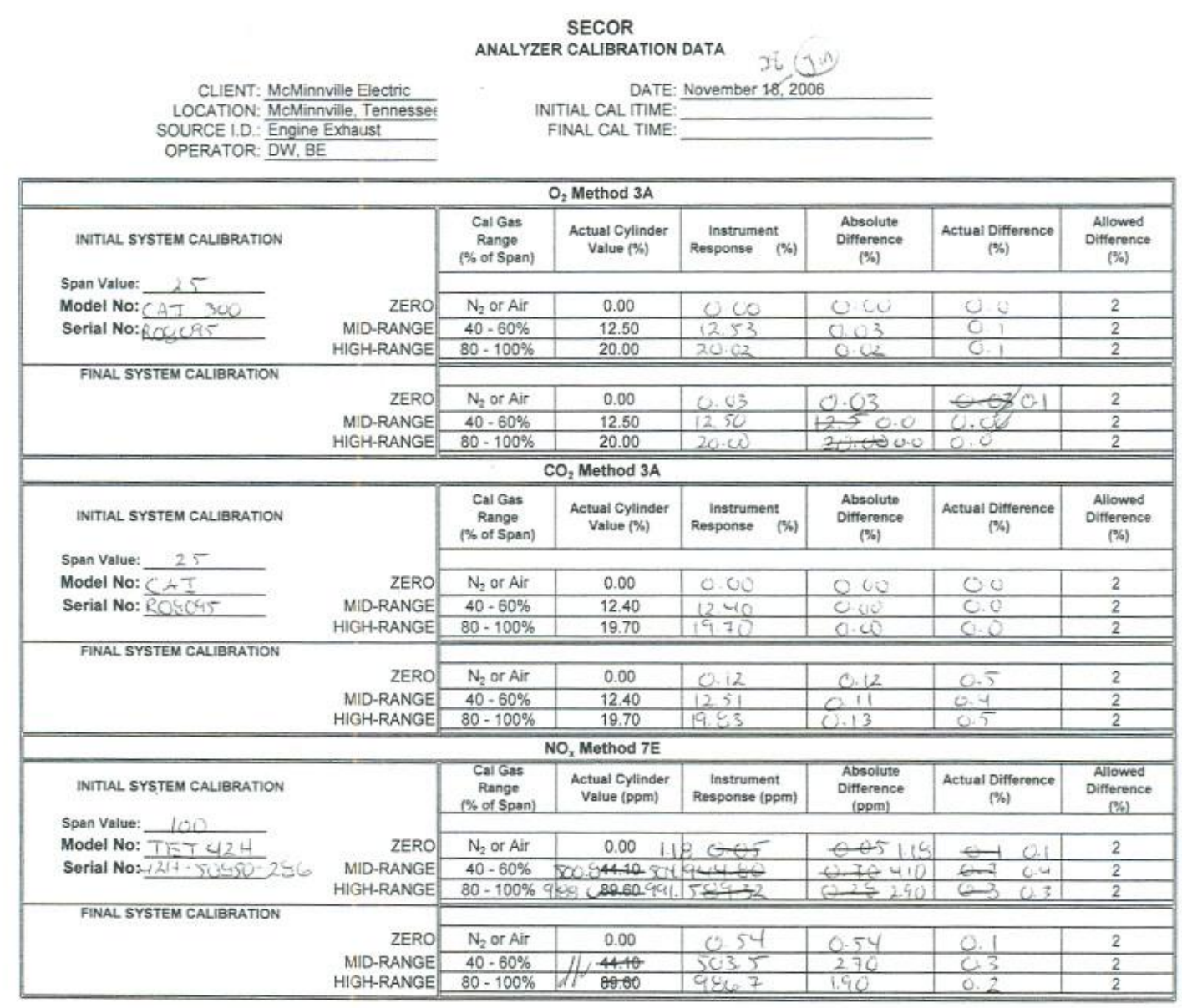




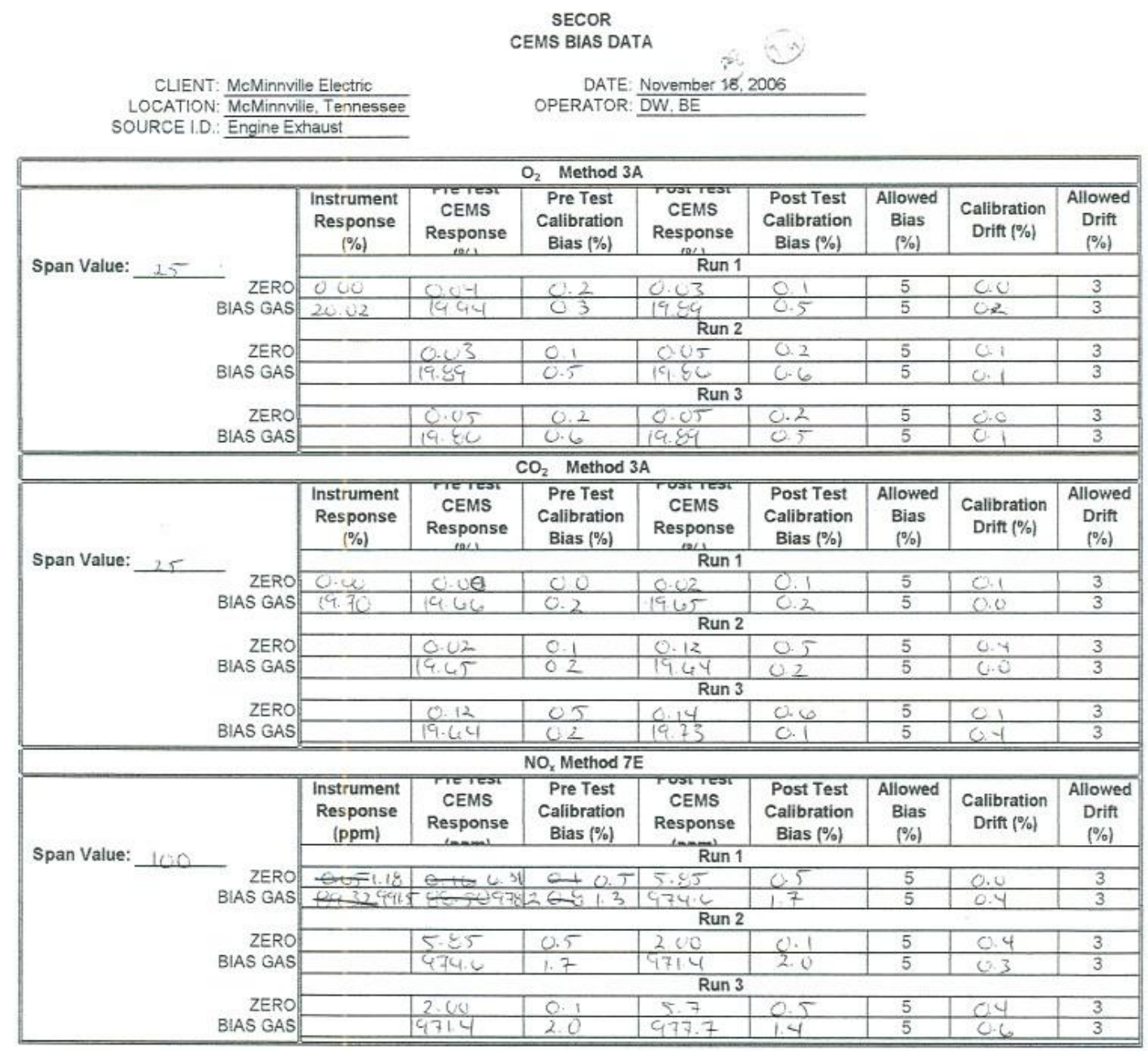




\begin{tabular}{|c|c|c|c|c|c|}
\hline DAY & Time & $\mathrm{CO} 2$ & $\mathrm{O} 2$ & $\mathrm{NOx}$ & \\
\hline 332 & 728 & 0.18865 & 20.854 & -0.1372 & \\
\hline 332 & 729 & 0.19477 & 20.83 & -0.1372 & \\
\hline 332 & 730 & 0.19093 & 20.832 & -0.14063 & \\
\hline 332 & 731 & 0.19122 & 20.83 & -0.1029 & \\
\hline 332 & 732 & 0.19265 & 20.755 & -0.1372 & \\
\hline 332 & 733 & 0.1392 & 0.44274 & -0.15549 & \\
\hline 332 & 734 & 0.00171 & 0.02887 & -0.24696 & \\
\hline 332 & 735 & -0.00229 & 0.00286 & 0.04802 & \\
\hline 332 & 736 & 12.044 & 13.338 & 0.06517 & \\
\hline 332 & 737 & 19.13 & 19.983 & 0.05945 & \\
\hline 332 & 738 & 19.704 & 20.022 & 0.05831 & \\
\hline 332 & 739 & 15.754 & 16.104 & 0.04459 & \\
\hline 332 & 740 & 12.396 & 12.53 & 0.06059 & \\
\hline 332 & 741 & 12.262 & 12.631 & 0.05373 & \\
\hline 332 & 742 & 0.07117 & 0.45275 & 57.678 & \\
\hline 332 & 743 & 0.01429 & 0.04659 & 100.11 & \\
\hline 332 & 744 & 0.006 & 0.03173 & 100.11 & \\
\hline 332 & 745 & 0.00543 & -0.00715 & 100.14 & \\
\hline 332 & 746 & 0.00029 & 0.01229 & 100.12 & \\
\hline 332 & 747 & 0 & 0.02258 & 100.11 & \\
\hline 332 & 748 & 0.00171 & 0.01515 & 99.709 & \\
\hline 332 & 749 & -0.00314 & 0.00114 & 94.167 & \\
\hline 332 & 750 & -0.00286 & 0.01286 & 93.126 & \\
\hline 332 & 751 & -0.00086 & -0.00029 & 89.953 & \\
\hline 332 & 752 & 0 & -0.01772 & 89.323 & \\
\hline 332 & 753 & 0.00857 & 0.29755 & 80.883 & \\
\hline 332 & 754 & -0.00286 & 0.01458 & 44.796 & \\
\hline 332 & 755 & -0.00257 & 0.01858 & 43.517 & \\
\hline 332 & 756 & 0 & -0.00114 & 47.515 & \\
\hline 332 & 757 & 0.002 & -0.00029 & 48.559 & 52.29 NO2 NOx Conv Eff. Ck \\
\hline 332 & 758 & -0.00114 & 0.20951 & 48.399 & $92.86 \%$ \\
\hline 332 & 759 & 0.00286 & 0.11004 & 41.928 & \\
\hline 332 & 800 & -0.004 & 0.1129 & 44.181 & \\
\hline 332 & 801 & -0.00257 & 0.10347 & 44.513 & \\
\hline 332 & 802 & 0.00086 & 0.12062 & 44.7 & \\
\hline 332 & 803 & -0.00486 & 0.1089 & 44.804 & \\
\hline 332 & 804 & -0.00114 & 0.12548 & 44.925 & \\
\hline 332 & 805 & 0.03144 & 16.356 & 36.746 & \\
\hline 332 & 806 & 0.01572 & 7.4148 & 1.8579 & \\
\hline 332 & 807 & -0.00171 & 0.0383 & 0.27441 & \\
\hline 332 & 808 & -0.00114 & 0.03602 & 0.16351 & \\
\hline
\end{tabular}




$\begin{array}{lcrrr}\text { DAY } & \text { Time } & \text { CO2 } & \text { O2 } & \text { NOx } \\ 332 & 809 & 14.689 & 14.992 & 0.15664 \\ 332 & 810 & 19.631 & 19.899 & 0.0686 \\ 332 & 811 & 19.661 & 19.94 & 0.05031 \\ 332 & 812 & 16.336 & 16.565 & 0.53284 \\ 332 & 813 & 0.91354 & 0.82525 & 48.199 \\ 332 & 814 & 0.03087 & 0.0646 & 87.638 \\ 332 & 815 & 0.01458 & 0.01915 & 88.496 \\ 332 & 816 & 0.01115 & 4.1147 & 88.076 \\ 332 & 817 & 0.04859 & 20.721 & 33.964 \\ 332 & 818 & 0.04774 & 20.891 & 0.25042 \\ 332 & 819 & 0.04545 & 20.872 & 0.12464 \\ 332 & 911 & 7.1685 & 11.336 & 756.65 \\ 332 & 912 & 7.1569 & 11.341 & 757.07 \\ 332 & 913 & 7.16 & 11.338 & 757.96 \\ 332 & 914 & 3.9712 & 6.5768 & 742.94 \\ 332 & 915 & 0.00286 & 0.0243 & 160.24 \\ 332 & 916 & -0.00772 & 0.0203 & 1.1778 \\ 332 & 917 & -0.01344 & 0.12007 & 14.842 \\ 332 & 918 & -0.0203 & 0.07147 & 782.93 \\ 332 & 919 & -0.01601 & 0.04745 & 996.67 \\ 332 & 920 & -0.01858 & 0.07089 & 997.67 \\ 332 & 921 & -0.01744 & 0.04088 & 983.05 \\ 332 & 922 & -0.01829 & 0.05403 & 982.33 \\ 332 & 923 & -0.02287 & 0.05574 & 991.52 \\ 332 & 924 & -0.01858 & 0.05574 & 897.52 \\ 332 & 925 & -0.01972 & 0.04002 & 510.15 \\ 332 & 926 & -0.02344 & 0.04402 & 504.92 \\ 332 & 927 & 5.0012 & 8.0619 & 548.44 \\ 332 & 928 & 1.8242 & 2.9123 & 608.69 \\ 332 & 929 & 0.00086 & 0.05945 & 52.457 \\ 332 & 930 & -0.00229 & 0.0363 & 6.3112 \\ 332 & 931 & -0.00286 & 0.07889 & 10.462 \\ 332 & 932 & -0.00143 & 0.12605 & 602.84 \\ 332 & 933 & -0.00171 & 0.12176 & 977.67 \\ 332 & 934 & -0.00457 & 0.13005 & 978.17 \\ 332 & 935 & 4.5906 & 7.3062 & 945.84 \\ 332 & 936 & 7.1354 & 11.306 & 765.94 \\ 332 & 937 & 7.1419 & 11.275 & 752.3 \\ 332 & 938 & 7.1494 & 11.299 & 753.87 \\ 332 & 939 & 7.1529 & 11.269 & 752.7 \\ 332 & 940 & 7.1549 & 11.294 & 751.97\end{array}$




\begin{tabular}{|c|c|c|c|c|c|c|}
\hline DAY & Time & $\mathrm{CO}_{2}$ & $\mathrm{O} 2$ & NOx & & \\
\hline 332 & 941 & 7.1536 & 11.276 & 751.42 & & \\
\hline 332 & 942 & 5.9955 & 12.811 & 681.06 & & \\
\hline 332 & 943 & 2.8809 & 16.919 & 80.627 & & \\
\hline 332 & 944 & 0.24696 & 20.492 & 14.131 & & \\
\hline 332 & 945 & 0.2058 & 20.628 & 15.012 & & \\
\hline 332 & 946 & 0.04802 & 20.805 & 2.8583 & & \\
\hline 332 & 947 & 0.39615 & 11.596 & 1.7721 & & \\
\hline 332 & 948 & 6.8559 & 10.804 & 319.65 & & \\
\hline 332 & 949 & 7.1557 & 11.291 & 738.84 & & Difference \\
\hline 332 & 950 & 7.1634 & 11.257 & 748.3 & & 0.08 \\
\hline 332 & 951 & 7.1676 & 11.276 & 749.28 & & \\
\hline 332 & 952 & 7.1691 & 11.287 & 750.83 & & \\
\hline 332 & 953 & 7.172 & 11.278 & 751.63 & & 0.53 \\
\hline 332 & 954 & 7.1674 & 11.277 & 749.58 & & \\
\hline 332 & 955 & 7.1617 & 11.293 & 744.98 & & -0.36 \\
\hline 332 & 956 & 7.1503 & 11.332 & 739.5 & & \\
\hline 332 & 957 & 7.1517 & 11.335 & 737.37 & & -1.38 \\
\hline 332 & 958 & 3.5836 & 16.14 & 679.13 & & \\
\hline 332 & 959 & 6.2726 & 12.554 & 355.01 & & \\
\hline 332 & 1000 & 7.1748 & 11.305 & 736.33 & & \\
\hline 332 & 1001 & 7.1701 & 11.309 & 751.58 & & \\
\hline 332 & 1002 & 7.1796 & 11.297 & 752.59 & & 0.66 \\
\hline 332 & 1003 & 7.1801 & 11.294 & 753.18 & & \\
\hline 332 & 1004 & 7.183 & 11.297 & 752.58 & & 0.66 \\
\hline 332 & 1005 & 7.1775 & 11.299 & 752.04 & & \\
\hline 332 & 1006 & 7.1692 & 11.306 & 748.93 & & 0.17 \\
\hline 332 & 1007 & 7.1743 & 11.316 & 745.45 & & \\
\hline 332 & 1008 & 6.9457 & 11.599 & $744.94 \mathrm{Avg}=$ & 747.665 & -0.36 \\
\hline 332 & 1009 & 1.0238 & 19.62 & 501.21 & & \\
\hline 332 & 1010 & 0.05602 & 20.832 & 27.781 & & \\
\hline 332 & 1011 & 0.05373 & 20.874 & 7.0995 & & \\
\hline 332 & 1012 & 0.04944 & 20.831 & 5.9792 & & \\
\hline 332 & 1013 & 0.04973 & 20.851 & 4.7673 & & \\
\hline 332 & 1014 & 0.04802 & 20.833 & 3.6241 & & \\
\hline 332 & 1015 & 0.04601 & 20.849 & 3.4411 & & \\
\hline 332 & 1016 & 0.04173 & 20.851 & 2.7552 & & \\
\hline 332 & 1017 & 0.0463 & 20.848 & 2.7209 & & \\
\hline 332 & 1018 & 0.03973 & 20.855 & 2.7324 & & \\
\hline 332 & 1019 & 0.03515 & 20.854 & 2.1493 & & \\
\hline 332 & 1020 & 0.0383 & 20.85 & 1.692 & & \\
\hline 332 & 1021 & 0.03773 & 20.854 & 1.7149 & & \\
\hline
\end{tabular}




\begin{tabular}{|c|c|c|c|c|}
\hline DAY & Time & $\mathrm{CO} 2$ & $\mathrm{O} 2$ & NOx \\
\hline 332 & 1022 & 0.7388 & 19.949 & 1.9206 \\
\hline 332 & 1023 & 6.7058 & 11.906 & 303.45 \\
\hline 332 & 1024 & 7.1566 & 11.293 & 728.61 \\
\hline 332 & 1025 & 7.1586 & 11.3 & 739.95 \\
\hline 332 & 1026 & 7.1603 & 11.308 & 740.91 \\
\hline 332 & 1027 & 7.1612 & 11.323 & 740.16 \\
\hline 332 & 1028 & 7.1599 & 11.3 & 736.71 Run 1 \\
\hline 332 & 1029 & 7.1553 & 11.346 & 735.22 \\
\hline 332 & 1030 & 7.1564 & 11.323 & 731.74 \\
\hline 332 & 1031 & 7.1573 & 11.331 & 732.61 \\
\hline 332 & 1032 & 7.1564 & 11.334 & 732.49 \\
\hline 332 & 1033 & 7.1571 & 11.32 & 731 \\
\hline 332 & 1034 & 7.1541 & 11.318 & 730.18 \\
\hline 332 & 1035 & 7.1557 & 11.326 & 728.31 \\
\hline 332 & 1036 & 7.1559 & 11.334 & 726.6 \\
\hline 332 & 1037 & 7.156 & 11.333 & 726.82 \\
\hline 332 & 1038 & 7.1575 & 11.328 & 725.04 \\
\hline 332 & 1039 & 7.1551 & 11.336 & 725.25 \\
\hline 332 & 1040 & 7.1643 & 11.324 & 725.57 \\
\hline 332 & 1041 & 7.1658 & 11.338 & 724.64 \\
\hline 332 & 1042 & 7.1611 & 11.311 & 726.17 \\
\hline 332 & 1043 & 7.1551 & 11.303 & 726.5 \\
\hline 332 & 1044 & 7.1577 & 11.298 & 726.43 \\
\hline 332 & 1045 & 7.1685 & 11.328 & 725.72 \\
\hline 332 & 1046 & 7.1657 & 11.354 & 724.85 \\
\hline 332 & 1047 & 7.1606 & 11.329 & 725 \\
\hline 332 & 1048 & 7.161 & 11.325 & 727.54 \\
\hline 332 & 1049 & 7.1592 & 11.318 & 726.73 \\
\hline 332 & 1050 & 7.1567 & 11.339 & 728.25 \\
\hline 332 & 1051 & 7.1669 & 11.332 & 727.66 \\
\hline 332 & 1052 & 7.1673 & 11.319 & 727.12 \\
\hline 332 & 1053 & 7.1697 & 11.323 & 727.33 \\
\hline 332 & 1054 & 7.1668 & 11.321 & 727.94 \\
\hline 332 & 1055 & 7.1699 & 11.327 & 728.41 \\
\hline 332 & 1056 & 7.1762 & 11.296 & 729.37 \\
\hline 332 & 1057 & 7.1745 & 11.28 & 729.46 \\
\hline 332 & 1058 & 7.1745 & 11.316 & 730.61 \\
\hline 332 & 1059 & 7.1775 & 11.309 & 732.88 \\
\hline 332 & 1100 & 7.1756 & 11.324 & 732.46 \\
\hline 332 & 1101 & 7.1817 & 11.309 & 731.64 \\
\hline 332 & 1102 & 7.1807 & 11.302 & 731.69 \\
\hline
\end{tabular}




\begin{tabular}{llrrr} 
DAY & Time & CO2 & O2 & NOx \\
332 & 1103 & 7.1802 & 11.298 & 735.52 \\
332 & 1104 & 7.1825 & 11.297 & 735.9 \\
332 & 1105 & 7.1891 & 11.304 & 735.42 \\
332 & 1106 & 7.1897 & 11.283 & 735.13 \\
332 & 1107 & 7.1932 & 11.278 & 736.47 \\
332 & 1108 & 7.2038 & 11.27 & 735.7 \\
332 & 1109 & 7.1945 & 11.289 & 736.3 \\
332 & 1110 & 7.2007 & 11.279 & 738.27 \\
332 & 1111 & 7.1955 & 11.279 & 739.41 \\
332 & 1112 & 7.1954 & 11.3 & 737.28 \\
332 & 1113 & 7.1988 & 11.28 & 737.28 \\
332 & 1114 & 7.2004 & 11.271 & 739.06 \\
332 & 1115 & 7.2053 & 11.268 & 739.01 \\
332 & 1116 & 7.2064 & 11.263 & 742.54 \\
332 & 1117 & 7.2018 & 11.29 & 742.35 \\
332 & 1118 & 7.2068 & 11.293 & 740.94 \\
332 & 1119 & 7.2105 & 11.242 & 740.08 \\
332 & 1120 & 7.2008 & 11.293 & 742.85 \\
332 & 1121 & 7.2087 & 11.253 & 744.1 \\
332 & 1122 & 7.2092 & 11.267 & 743.49 \\
332 & 1123 & 7.2108 & 11.263 & 742.16 \\
332 & 1124 & 7.2088 & 11.264 & 742.5 \\
332 & 1125 & 7.2031 & 11.273 & 745.18 \\
332 & 1126 & 7.1994 & 11.284 & 742.1 \\
332 & 1127 & 7.2031 & 11.271 & 740.67 \\
332 & 1128 & 6.391 & 10.031 & 739.58 \\
332 & 1129 & 0.37973 & 0.49945 & 389.98 \\
332 & 1130 & 0.02886 & 0.04086 & 14.001 \\
332 & 1131 & 0.01914 & 0.02914 & 7.2804 \\
332 & 1132 & 1.8267 & 1.9533 & 5.8517 \\
332 & 1133 & 19.171 & 19.482 & 4.8802 \\
332 & 1134 & 19.654 & 19.893 & 3.7487 \\
332 & 1135 & 16.746 & 16.97 & 7.0974 \\
332 & 1136 & 0.82918 & 0.78432 & 504.68 \\
332 & 1137 & 0.05886 & 0.07058 & 962.31 \\
332 & 1138 & 0.038 & 0.06886 & 974.6 \\
332 & 1139 & 1.0466 & 1.6238 & 978.32 \\
332 & 1140 & 7.0969 & 11.108 & 855.52 \\
\hline 32 & 1141 & 7.1955 & 11.257 & 747.93 \\
\hline 32 & 1143 & 7.1975 & 11.276 & 742.2
\end{tabular}




$\begin{array}{rrrrr}\text { DAY } & \text { Time } & \text { CO2 } & \text { O2 } & \text { NOx } \\ 332 & 1144 & 7.1987 & 11.268 & 741.4 \\ 332 & 1145 & 7.206 & 11.271 & 740.55 \\ 332 & 1146 & 7.1994 & 11.262 & 739.32 \\ 332 & 1147 & 7.2029 & 11.262 & 739.45 \\ 332 & 1148 & 7.2058 & 11.266 & 739.93 \\ 332 & 1149 & 7.2057 & 11.257 & 739.34 \\ 332 & 1150 & 7.2057 & 11.243 & 739.18 \\ 332 & 1151 & 7.2034 & 11.266 & 739.4 \\ 332 & 1152 & 7.1948 & 11.255 & 739.28 \\ 332 & 1153 & 5.3953 & 13.714 & 732.91 \\ 332 & 1154 & 0.12886 & 20.803 & 249.11 \\ 332 & 1155 & 0.07858 & 20.842 & 8.309 \\ 332 & 1156 & 0.06972 & 20.834 & 6.046 \\ 332 & 1157 & 0.67802 & 20.055 & 4.9716 \\ 332 & 1158 & 7.0165 & 11.467 & 339.49 \\ 332 & 1159 & 7.1993 & 11.237 & 726.58 \\ 332 & 1200 & 7.1914 & 11.284 & 738.76 \quad \text { Run } 2 \\ 332 & 1201 & 7.1913 & 11.241 & 740.6 \\ 332 & 1202 & 7.1996 & 11.257 & 740.98 \\ 332 & 1203 & 7.2034 & 11.241 & 740.7 \\ 332 & 1204 & 7.2023 & 11.243 & 740.56 \\ 332 & 1205 & 7.1932 & 11.25 & 742.86 \\ 332 & 1206 & 7.2001 & 11.254 & 744.51 \\ 332 & 1207 & 7.1927 & 11.255 & 744.93 \\ 332 & 1208 & 7.192 & 11.273 & 743.24 \\ 332 & 1209 & 7.1907 & 11.254 & 742.99 \\ 332 & 1210 & 7.1909 & 11.276 & 743.71 \\ 332 & 1211 & 7.1921 & 11.263 & 741.33 \\ 332 & 1212 & 7.192 & 11.257 & 741.9 \\ 332 & 1213 & 7.191 & 11.263 & 740.96 \\ 332 & 1214 & 7.1911 & 11.252 & 739.9 \\ 332 & 1215 & 7.1843 & 11.261 & 740.5 \\ 332 & 1216 & 7.1906 & 11.284 & 739.46 \\ 332 & 1217 & 7.1929 & 11.248 & 738.66 \\ 332 & 1218 & 7.1951 & 11.255 & 738.01 \\ 332 & 1219 & 7.2002 & 11.253 & 737.36 \\ 332 & 1220 & 7.1945 & 11.262 & 736.65 \\ 332 & 1221 & 7.1892 & 11.266 & 736.77 \\ 332 & 1222 & 7.1916 & 11.264 & 734.75 \\ 332 & 1223 & 7.1917 & 11.268 & 733.64 \\ & 1224 & 7.1868 & 11.292 & 734.69 \\ 332 & & & \end{array}$




$\begin{array}{ccrrr}\text { DAY } & \text { Time } & \text { CO2 } & \text { O2 } & \text { NOx } \\ 332 & 1225 & 7.1839 & 11.276 & 734.3 \\ 332 & 1226 & 7.1842 & 11.26 & 733.49 \\ 332 & 1227 & 7.1907 & 11.269 & 731.99 \\ 332 & 1228 & 7.1899 & 11.267 & 731.01 \\ 332 & 1229 & 7.1843 & 11.264 & 730.24 \\ 332 & 1230 & 7.1817 & 11.28 & 731.77 \\ 332 & 1231 & 7.1815 & 11.276 & 731.14 \\ 332 & 1232 & 7.1809 & 11.272 & 730.18 \\ 332 & 1233 & 7.1902 & 11.266 & 728.87 \\ 332 & 1234 & 7.1911 & 11.258 & 727.99 \\ 332 & 1235 & 7.1886 & 11.265 & 728.66 \\ 332 & 1236 & 7.1917 & 11.26 & 729.7 \\ 332 & 1237 & 7.1929 & 11.257 & 729.93 \\ 332 & 1238 & 7.1983 & 11.258 & 728.63 \\ 332 & 1239 & 7.19 & 11.27 & 728.73 \\ 332 & 1240 & 7.1885 & 11.27 & 728.78 \\ 332 & 1241 & 7.1916 & 11.272 & 728.36 \\ 332 & 1242 & 7.1904 & 11.257 & 727.93 \\ 332 & 1243 & 7.1959 & 11.261 & 728.09 \\ 332 & 1244 & 7.2007 & 11.277 & 727.33 \\ 332 & 1245 & 7.2004 & 11.267 & 727.9 \\ 332 & 1246 & 7.2 & 11.268 & 728.01 \\ 332 & 1247 & 7.2014 & 11.273 & 727.21 \\ 332 & 1248 & 7.1985 & 11.265 & 727.77 \\ 332 & 1249 & 7.2003 & 11.28 & 728.32 \\ 332 & 1250 & 7.208 & 11.268 & 728.88 \\ 332 & 1251 & 7.2105 & 11.248 & 728.31 \\ 332 & 1252 & 7.2135 & 11.272 & 728.78 \\ 332 & 1253 & 7.2087 & 11.261 & 729.62 \\ 332 & 1254 & 7.212 & 11.262 & 730.1 \\ 332 & 1255 & 7.2158 & 11.247 & 728.95 \\ 332 & 1256 & 7.2163 & 11.257 & 729.42 \\ 332 & 1257 & 7.2189 & 11.256 & 730.73 \\ 332 & 1258 & 7.2189 & 11.259 & 729.75 \\ 332 & 1259 & 7.2251 & 11.254 & 729.48 \\ 332 & 1300 & 6.8212 & 10.641 & 728.82 \\ 332 & 1301 & 0.73222 & 1.0176 & 801.45 \\ 332 & 1302 & 0.10485 & 0.06114 & 960.07 \\ 332 & 1303 & 0.09772 & 0.06715 & 969.29 \\ & 1304 & 2.2152 & 2.2576 & 971.4 \\ & 1305 & 19.2 & 19.468 & 490.11\end{array}$




\begin{tabular}{|c|c|c|c|c|}
\hline DAY & Time & $\mathrm{CO} 2$ & $\mathrm{O} 2$ & NOx \\
\hline 332 & 1306 & 19.635 & 19.864 & 7.166 \\
\hline 332 & 1307 & 16.953 & 17.12 & 2.743 \\
\hline 332 & 1308 & 1.0889 & 0.89604 & 2.743 \\
\hline 332 & 1309 & 0.12258 & 0.04857 & 2.6973 \\
\hline 332 & 1310 & 0.20601 & 0.16973 & 2.0002 \\
\hline 332 & 1311 & 6.6273 & 10.285 & 284.8 \\
\hline 332 & 1312 & 7.2295 & 11.234 & 728.85 \\
\hline 332 & 1313 & 7.238 & 11.241 & 736.56 \\
\hline 332 & 1314 & 7.2507 & 11.233 & 736.06 \\
\hline 332 & 1315 & 7.2484 & 11.235 & 736.97 \\
\hline 332 & 1316 & 7.253 & 11.225 & 737.51 \\
\hline 332 & 1317 & 7.2478 & 11.238 & 737 \\
\hline 332 & 1318 & 1.7342 & 18.722 & 565.53 \\
\hline 332 & 1319 & 0.14891 & 20.841 & 31.85 \\
\hline 332 & 1320 & 0.14234 & 20.818 & 5.8308 \\
\hline 332 & 1321 & 3.335 & 16.56 & 32.184 \\
\hline 332 & 1322 & 7.2295 & 11.236 & 588.33 \\
\hline 332 & 1323 & 7.2466 & 11.242 & 731.1 \\
\hline 332 & 1324 & 7.2442 & 11.236 & 737.11 \\
\hline 332 & 1325 & 7.2491 & 11.253 & 738.09 \\
\hline 332 & 1326 & 7.2467 & 11.217 & 739.16 \\
\hline 332 & 1327 & 7.2424 & 11.242 & 739.13 \\
\hline 332 & 1328 & 7.2484 & 11.23 & 740.19 \\
\hline 332 & 1329 & 7.2451 & 11.238 & 740.49 \\
\hline 332 & 1330 & 7.2357 & 11.245 & 741.22 \\
\hline 332 & 1331 & 7.2407 & 11.238 & 741.46 \\
\hline 332 & 1332 & 7.2406 & 11.236 & 741.55 \\
\hline 332 & 1333 & 7.246 & 11.228 & 740.93 \\
\hline 332 & 1334 & 7.2473 & 11.248 & 740.64 \\
\hline 332 & 1335 & 7.2469 & 11.23 & 740.69 \\
\hline 332 & 1336 & 7.249 & 11.236 & 740.51 \\
\hline 332 & 1337 & 7.2469 & 11.236 & 740.56 \\
\hline 332 & 1338 & 7.2514 & 11.228 & 739.35 \\
\hline 332 & 1339 & 7.2548 & 11.233 & 740.28 \\
\hline 332 & 1340 & 7.2586 & 11.256 & 741.04 \\
\hline 332 & 1341 & 7.2581 & 11.231 & 740.28 \\
\hline 332 & 1342 & 7.2594 & 11.237 & 739.98 \\
\hline 332 & 1343 & 7.2617 & 11.235 & 739.96 \\
\hline 332 & 1344 & 7.2725 & 11.231 & 739.09 \\
\hline 332 & 1345 & 7.2637 & 11.241 & 738.89 \\
\hline 332 & 1346 & 7.2619 & 11.238 & 738.79 \\
\hline
\end{tabular}




$\begin{array}{llrrr}\text { DAY } & \text { Time } & \text { CO2 } & \text { O2 } & \text { NOx } \\ 332 & 1347 & 7.2624 & 11.243 & 737.3 \\ 332 & 1348 & 7.2628 & 11.24 & 736.96 \\ 332 & 1349 & 7.2677 & 11.233 & 737.29 \\ 332 & 1350 & 7.2729 & 11.239 & 737.62 \\ 332 & 1351 & 7.2745 & 11.235 & 738.23 \\ 332 & 1352 & 7.2749 & 11.231 & 738.22 \\ 332 & 1353 & 7.2732 & 11.241 & 737.94 \\ 332 & 1354 & 7.2804 & 11.231 & 739.41 \\ 332 & 1355 & 7.2857 & 11.231 & 738.64 \\ 332 & 1356 & 7.2883 & 11.221 & 737.68 \\ 332 & 1357 & 7.2824 & 11.244 & 738.08 \\ 332 & 1358 & 7.2846 & 11.238 & 738.49 \\ 332 & 1359 & 7.2849 & 11.24 & 737.56 \\ 332 & 1400 & 7.2862 & 11.238 & 737.92 \\ 332 & 1401 & 7.289 & 11.234 & 736.77 \\ 332 & 1402 & 7.2856 & 11.249 & 737.91 \\ 332 & 1403 & 7.289 & 11.221 & 737.97 \\ 332 & 1404 & 7.2875 & 11.243 & 737.1 \\ 332 & 1405 & 7.2841 & 11.245 & 738.12 \\ 332 & 1406 & 7.2892 & 11.247 & 738.23 \\ 332 & 1407 & 7.2914 & 11.25 & 736.68 \\ 332 & 1408 & 7.2868 & 11.25 & 736.16 \\ 332 & 1409 & 7.2872 & 11.25 & 736.33 \\ 332 & 1410 & 7.2892 & 11.256 & 735.11 \\ 332 & 1411 & 7.2903 & 11.24 & 733.37 \\ 332 & 1412 & 7.2903 & 11.259 & 731.8 \\ 332 & 1413 & 7.2863 & 11.249 & 732.36 \\ 332 & 1414 & 7.2921 & 11.267 & 732.19 \\ 332 & 1415 & 7.2906 & 11.241 & 730.02 \\ 332 & 1416 & 7.2877 & 11.269 & 727.04 \\ 332 & 1417 & 7.29 & 11.256 & 727.19 \\ 332 & 1418 & 7.289 & 11.265 & 726.65 \\ 332 & 1419 & 7.2908 & 11.262 & 726.91 \\ 332 & 1420 & 7.2923 & 11.247 & 727.21 \\ 332 & 1421 & 7.2873 & 11.253 & 723.93 \\ 332 & 1422 & 7.2883 & 11.251 & 723.39 \\ 332 & 1423 & 7.2857 & 11.26 & 724.11 \\ 332 & 1424 & 7.2879 & 11.252 & 724.62 \\ 332 & 1425 & 3.2395 & 4.883 & 648.51 \\ 332 & 1426 & 0.14783 & 0.04604 & 89.853 \\ & 1427 & 0.12867 & 0.01515 & 7.6175\end{array}$




$\begin{array}{rrrrr}\text { DAY } & \text { Time } & \text { CO2 } & \text { O2 } & \text { NOx } \\ 332 & 1428 & 0.13782 & 0.05433 & 5.6957 \\ 332 & 1429 & 16.509 & 16.674 & 4.8607 \\ 332 & 1430 & 19.734 & 19.894 & 3.9686 \\ 332 & 1431 & 16.311 & 16.427 & 7.3997 \\ 332 & 1432 & 0.9324 & 0.79944 & 515.16 \\ 332 & 1433 & 0.16641 & 0.09864 & 960.06 \\ 332 & 1434 & 0.14238 & 0.06891 & 973.38 \\ 332 & 1435 & 0.6976 & 1.0516 & 977.7 \\ 332 & 1436 & 0.75446 & 14.166 & 602.82 \\ 332 & 1437 & 0.12693 & 0.05947 & 735.16 \\ 332 & 1438 & 0.12493 & 0.05975 & 983.05 \\ 332 & 1439 & 0.12664 & 0.0566 & 986.65 \\ 332 & 1440 & 0.12693 & 0.08233 & 887.44 \\ 332 & 1441 & 0.12407 & 0.05603 & 510.6 \\ 332 & 1442 & 0.11864 & 0.03802 & 503.48 \\ 332 & 1443 & 15.567 & 15.733 & 417.27 \\ 332 & 1444 & 19.83 & 20.001 & 12.601 \\ 332 & 1445 & 16.136 & 16.316 & 0.67466 \\ 332 & 1446 & 12.512 & 12.5 & 0.66322 \\ 332 & 1447 & 12.507 & 12.509 & 0.68607 \\ 332 & 1448 & 2.4627 & 2.4376 & 0.54886 \\ 332 & 1449 & 0.12263 & 0.02944 & 0.53741\end{array}$




\begin{tabular}{|c|c|c|c|c|c|}
\hline \multicolumn{6}{|c|}{ Moisture and Volumetric Flow Rate Calculations } \\
\hline \multirow{3}{*}{ Client: McMinnville Electric } & \multirow{2}{*}{\multicolumn{5}{|c|}{$\begin{aligned} & \text { Location: } \text { McMinnville, TN } \\
& \text { Date: } \text { November 28, } 2006 \\
&\end{aligned}$}} \\
\hline & & & & & \\
\hline & Run 1 & Run 2 & Run 3 & Run 4 & Average \\
\hline Time Began & $10: 27$ & $12: 00$ & $13: 24$ & & $\ldots$ \\
\hline Time Ended & $11: 27$ & $13: 00$ & $14: 24$ & & $\ldots$ \\
\hline Sample Time, min & 60 & 60 & 60 & & 60 \\
\hline Barometric Pressure, $P_{b a r}($ in. $\mathrm{Hg}$ ) & 29.10 & 29.10 & 29.05 & & 29.08 \\
\hline Dry Gas Meter I.D. & 1 & 1 & 1 & & 1 \\
\hline Meter Corr. Factor, Y & 0.955 & 0.955 & 0.955 & & 0.955 \\
\hline Meter $\mathrm{DH}_{\oplus}$ & 1.994 & 1.994 & 1.994 & & 1.994 \\
\hline Pitot Coefficient, $C_{p}$ & 0.84 & 0.84 & 0.84 & & 0.84 \\
\hline Duct Diameter, in. & 15.75 & 15.75 & 15.75 & & 15.75 \\
\hline Duct Area $\left(A_{\mathrm{s}}\right), \mathrm{ft}^{2}$ & 1.35 & 1.35 & 1.35 & & 1.35 \\
\hline \multicolumn{6}{|l|}{ Stack Gas } \\
\hline Temperature, ${ }^{\circ} \mathrm{F}$ & 633.3 & 632.8 & 639.0 & & 635.0 \\
\hline $\mathrm{O}_{2}$ Concentration, $\%$ & 11.3 & 11.3 & 11.3 & & 11.3 \\
\hline $\mathrm{CO}_{2}$ Concentration, $\%$ & 7.2 & 7.2 & 7.2 & & 7.2 \\
\hline Static Pressure, $P_{\theta}$ & 1.90 & 2.20 & 2.70 & & 2.27 \\
\hline Stack Pressure, $P_{s}$ & 29.24 & 29.26 & 29.25 & & 29.25 \\
\hline \multicolumn{6}{|l|}{ Moisture Caiculations } \\
\hline Meter Volume, $\mathrm{ft}^{3}$ & 34.185 & 30.665 & 34.100 & & 32.983 \\
\hline Avg. Dry Gas Meter Temp. ( $\left.{ }^{\circ} \mathrm{F}\right)$ & 77.5 & 84.4 & 84.4 & & 82.1 \\
\hline $\mathrm{H}_{2} \mathrm{O}$ Gain, $V_{k}$ & 59.3 & 59.4 & 56.2 & & 58.3 \\
\hline Avg. DH & 1.0 & 1.0 & 1.0 & & 1.0 \\
\hline Meter Pressure, in. $\mathrm{Hg}$ & $29.17 /$ & 29.17 & 29.12 & & 29.16 \\
\hline Standard Meter Volume, $\mathrm{ft}^{3}\left(\mathrm{Vm}_{\mathrm{std}}\right)$ & $31.300^{\prime}$ & 27.720 & 30.773 & & 29.931 \\
\hline Standard Water Volume, $\mathrm{ft}^{3}\left(\mathrm{VW}_{\mathrm{std}}\right)$ & $2.791 /$ & 2.796 & 2.645 & & 2.744 \\
\hline Moisture Fraction, Saturation & 1.0000 & 1.0000 & 1.0000 & & 1.0000 \\
\hline Moisture Fraction, Measured & 0.0819 & 0.0916 & 0.0792 & & 0.0842 \\
\hline Applicable Moisture (lower Sat. vs. Me & 0.0819 & 0.0916 & 0.0792 & & 0.0842 \\
\hline \multicolumn{6}{|l|}{ Volumetric Flow Rate } \\
\hline Avg. SQRT DP & 1.9342 & 1.9615 & 1.9238 & & 1.9398 \\
\hline Mol. Wt. Stack Gas, (Md) & $29.60^{\prime}$ & 29.60 & 29.60 & & 29.60 \\
\hline Mol, Wt. Stack Gas, $\left(M_{s}\right)$ & 28.65 & 28.54 & 28.68 & & 28.62 \\
\hline Velocity, $\left(\mathrm{V}_{\mathrm{s}}\right)$ & 158.67 & 161.13 & 158.12 & & 159.30 \\
\hline At Stack Conditions, acfm $\left(Q_{2}\right)$ & 12,880 & 13.080 & 12,836 & & 12,932 \\
\hline At Wet Standard Conditions ${ }^{a}$, wscfm (C & $6,081 /$ & 6,183 & 6,030 & & 6,098 \\
\hline At Standard Conditions ${ }^{3}, \operatorname{dscfm}\left(Q_{3}\right)$ & $5.581 /$ & 5,615 & 5.551 & & 5.582 \\
\hline
\end{tabular}

${ }^{2} 68^{\circ} \mathrm{F} .29 .92 \mathrm{in} . \mathrm{Hg}$.

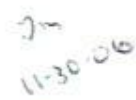

Eng_Exh_RM4 xis: PMTAL. 

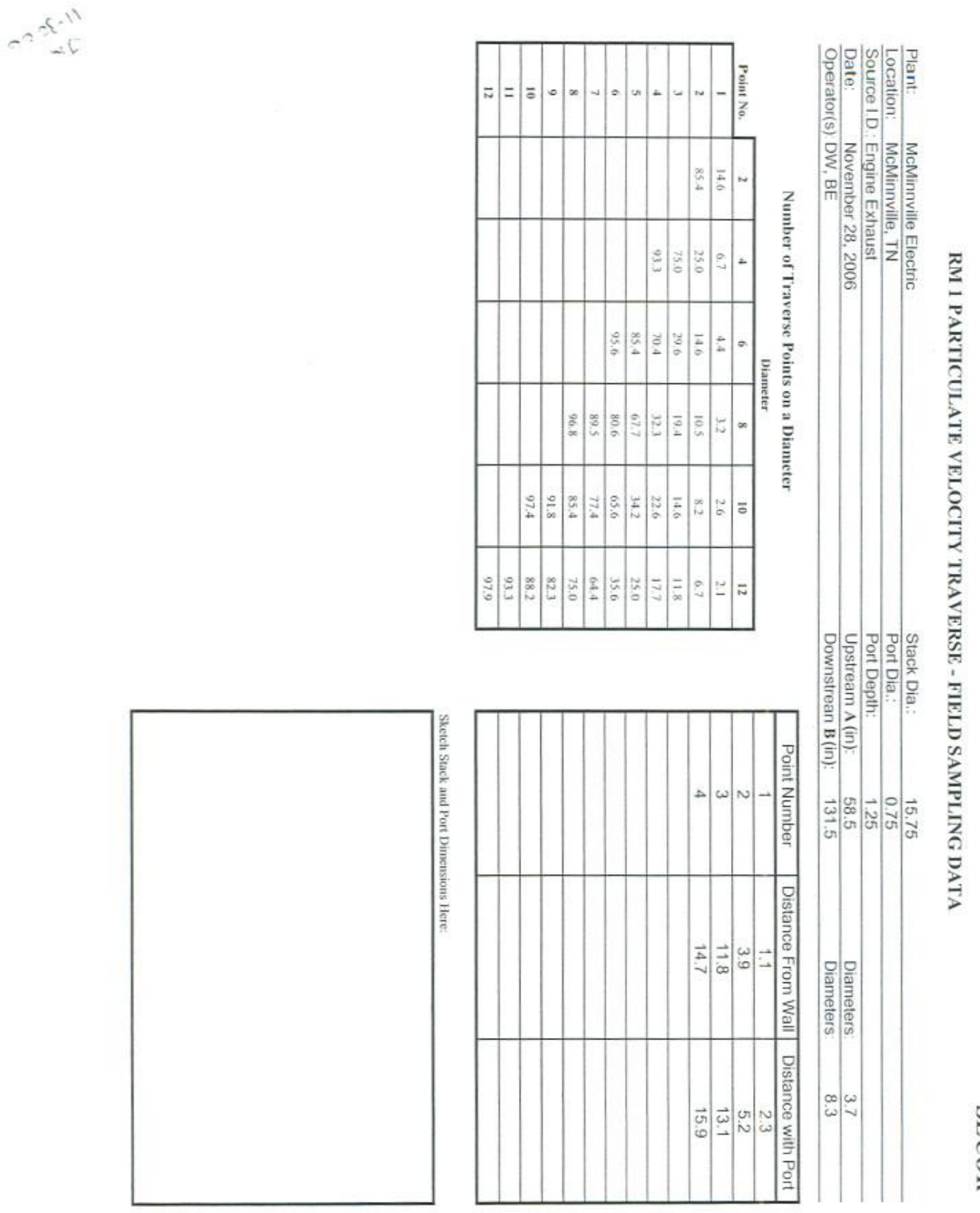

$\frac{2}{2}$ 


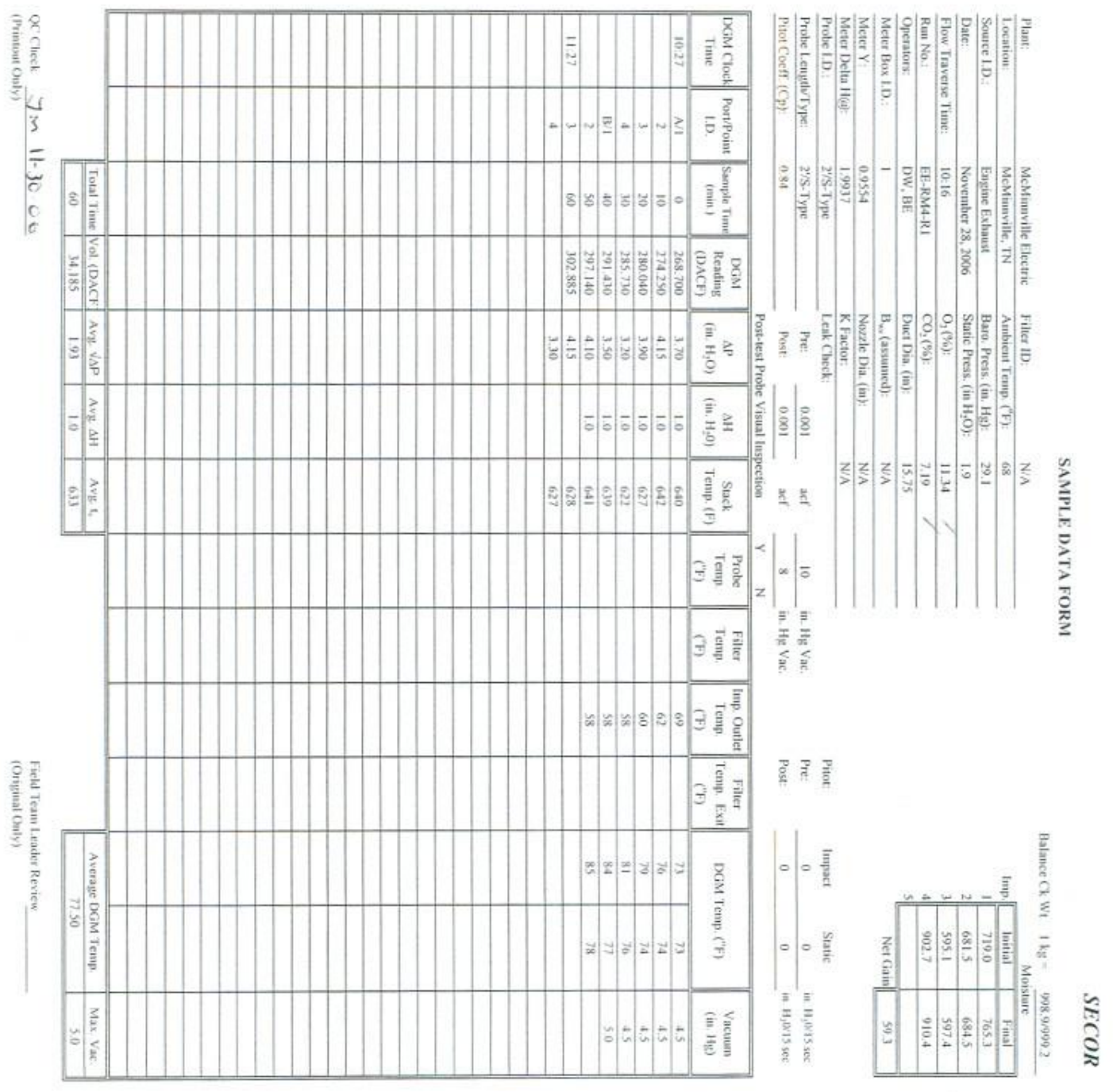




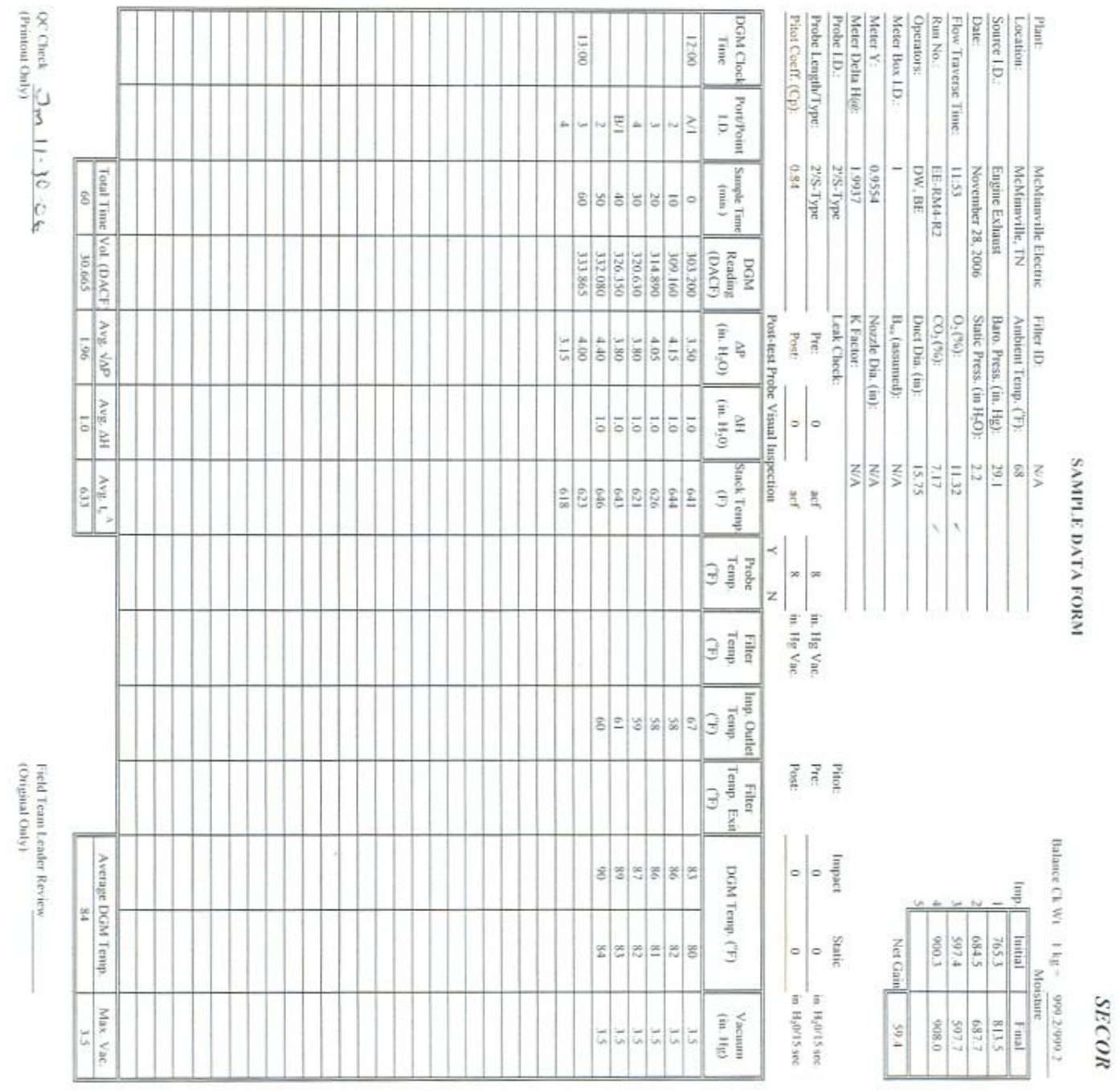




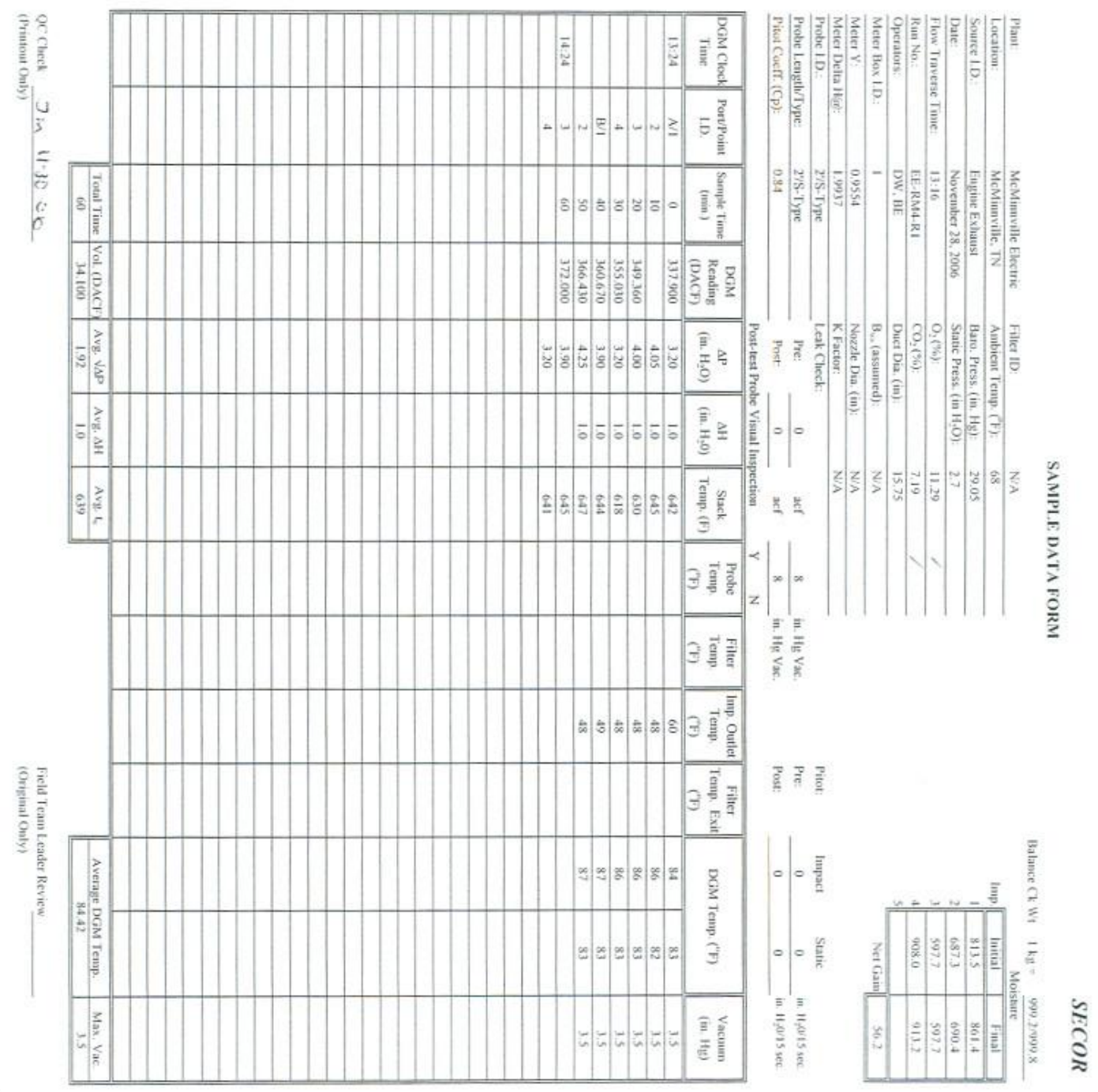



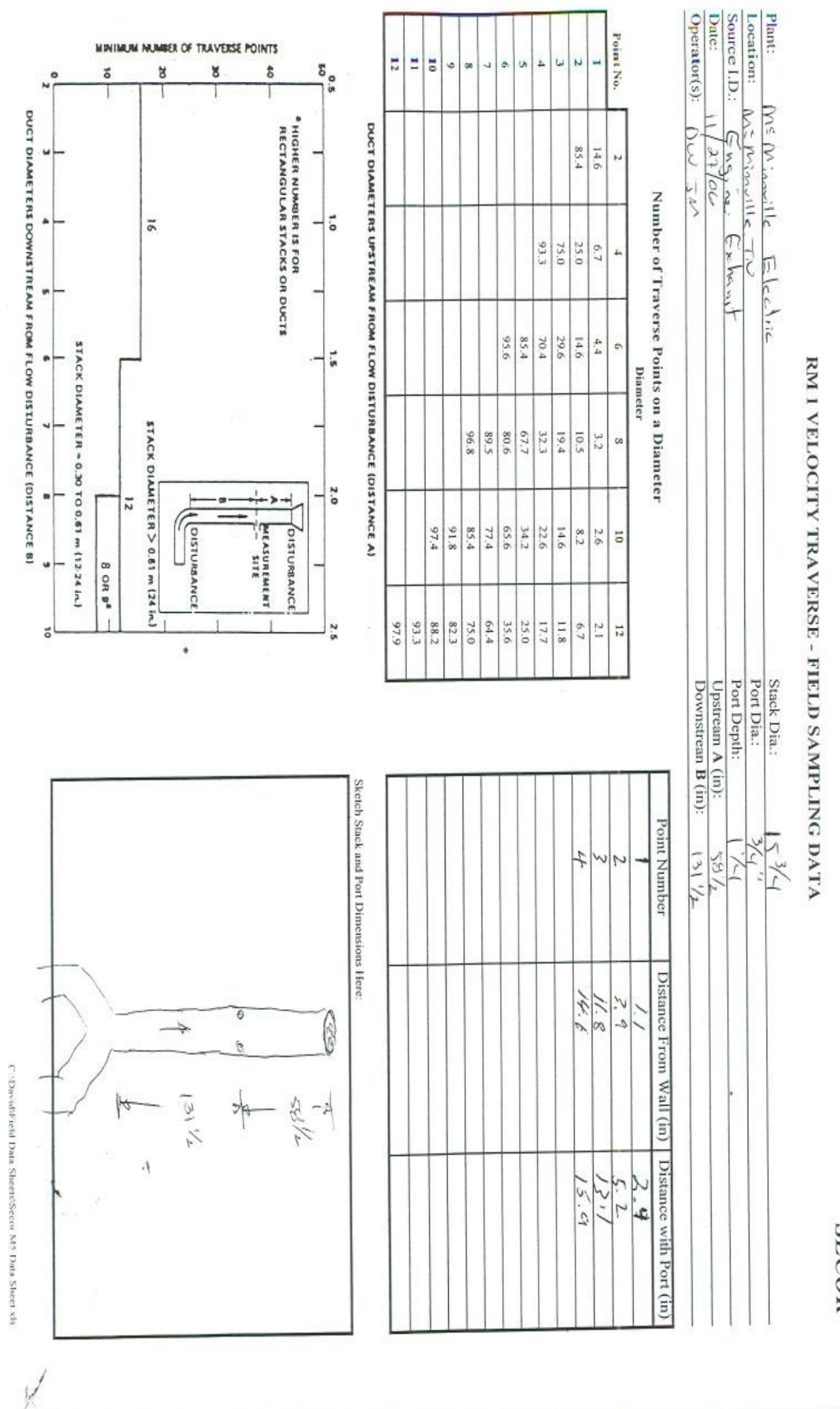

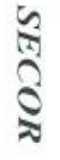


SECOR

CYCLONIC FLOW FIELD CALCULATION SHEET

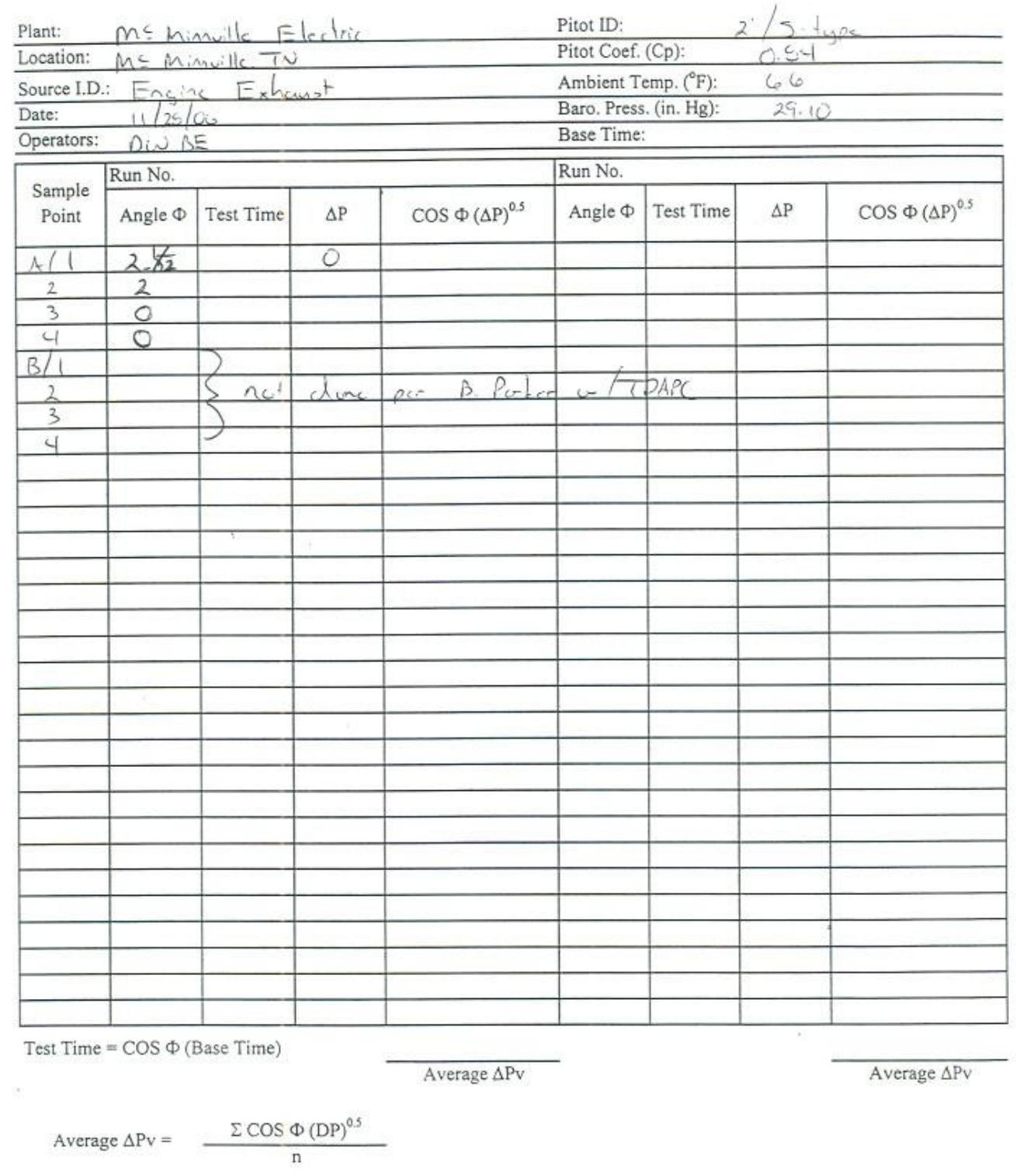




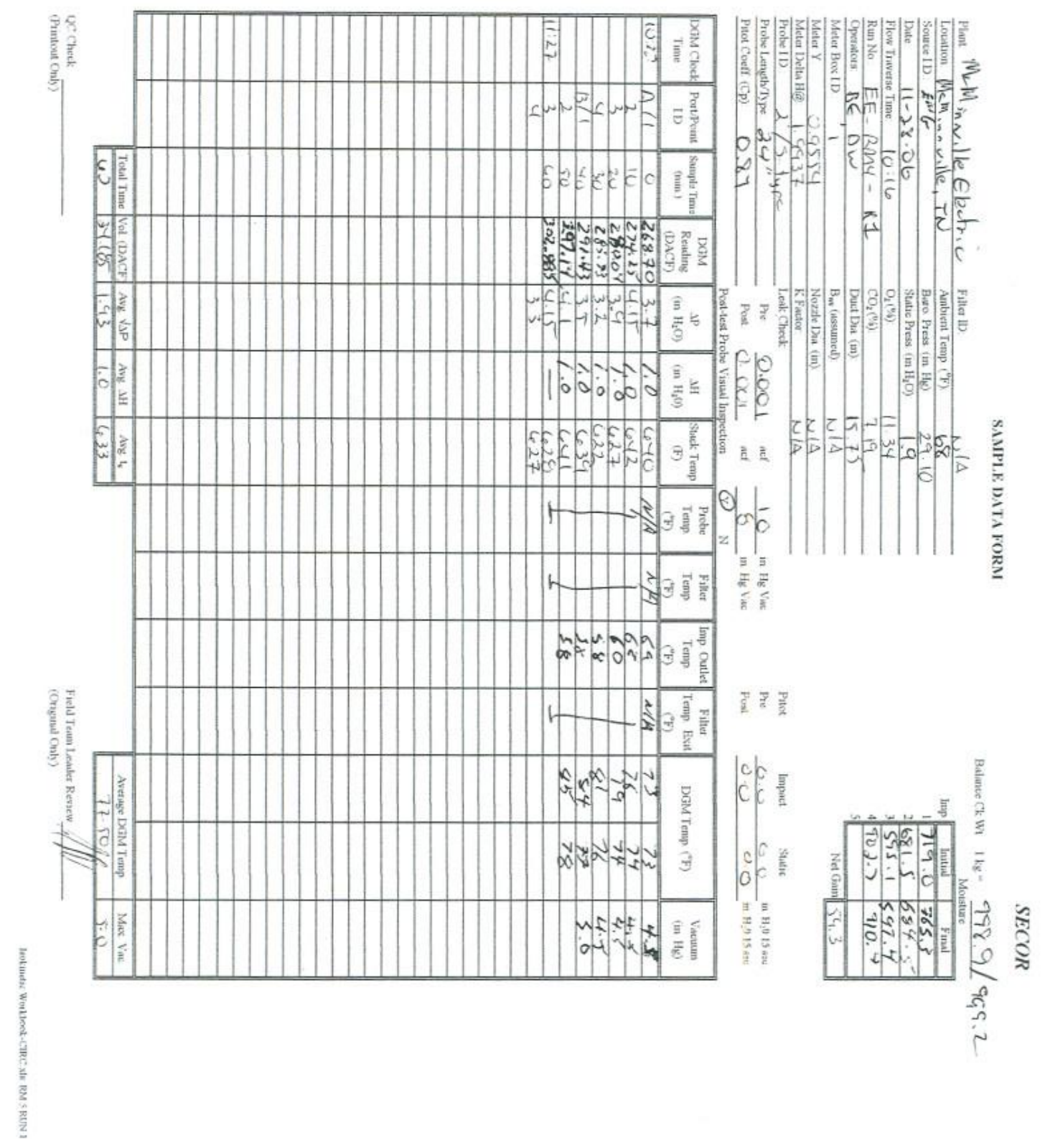




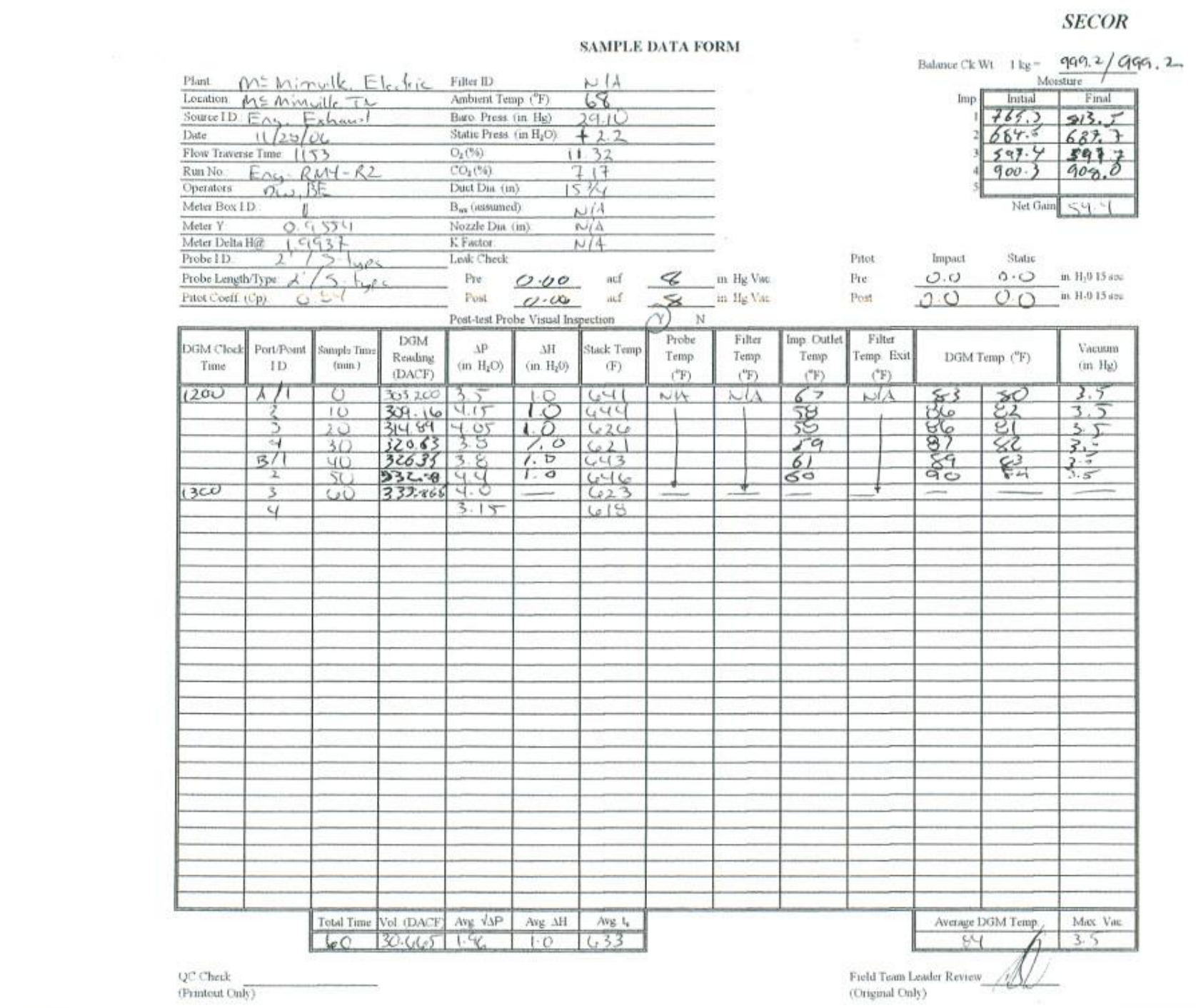


SANPLE DATA FORM

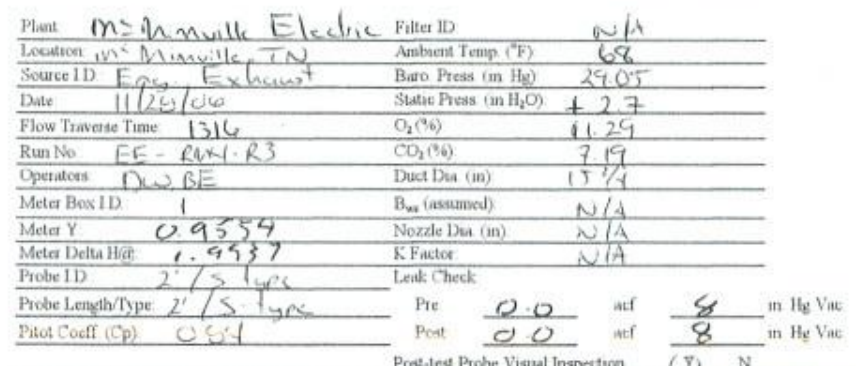

SECOR

Ballence C2 Wh $1 \mathrm{~kg}=999.2 / 999.5$

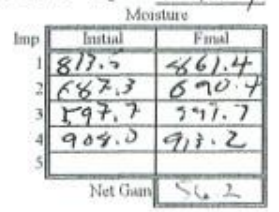

Pitol Impuct static

Pre $0 \mathrm{OC} \quad \mathrm{O} 0$ in $\mathrm{H}_{3} \mathrm{O} 15 \mathrm{~kat}$

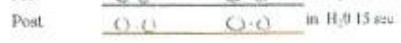

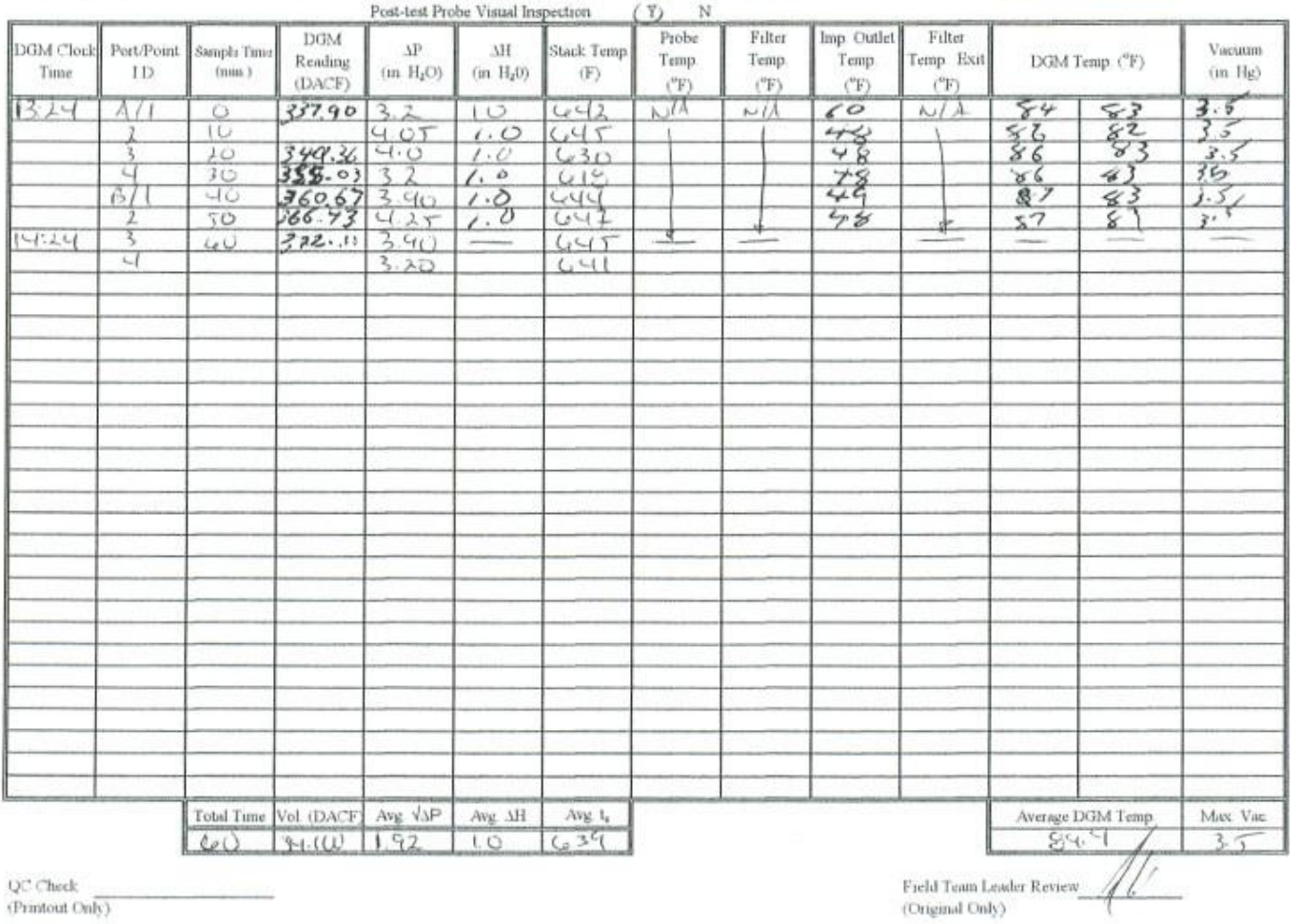

1018 104 
APPENDIX B

CALIBRATION AND FIELD NOTES

Emissions Measurements Report McMinnville Electric System 200 West Morford Street McMinnville, Tennessee 170T. 98726.00

December 2006 


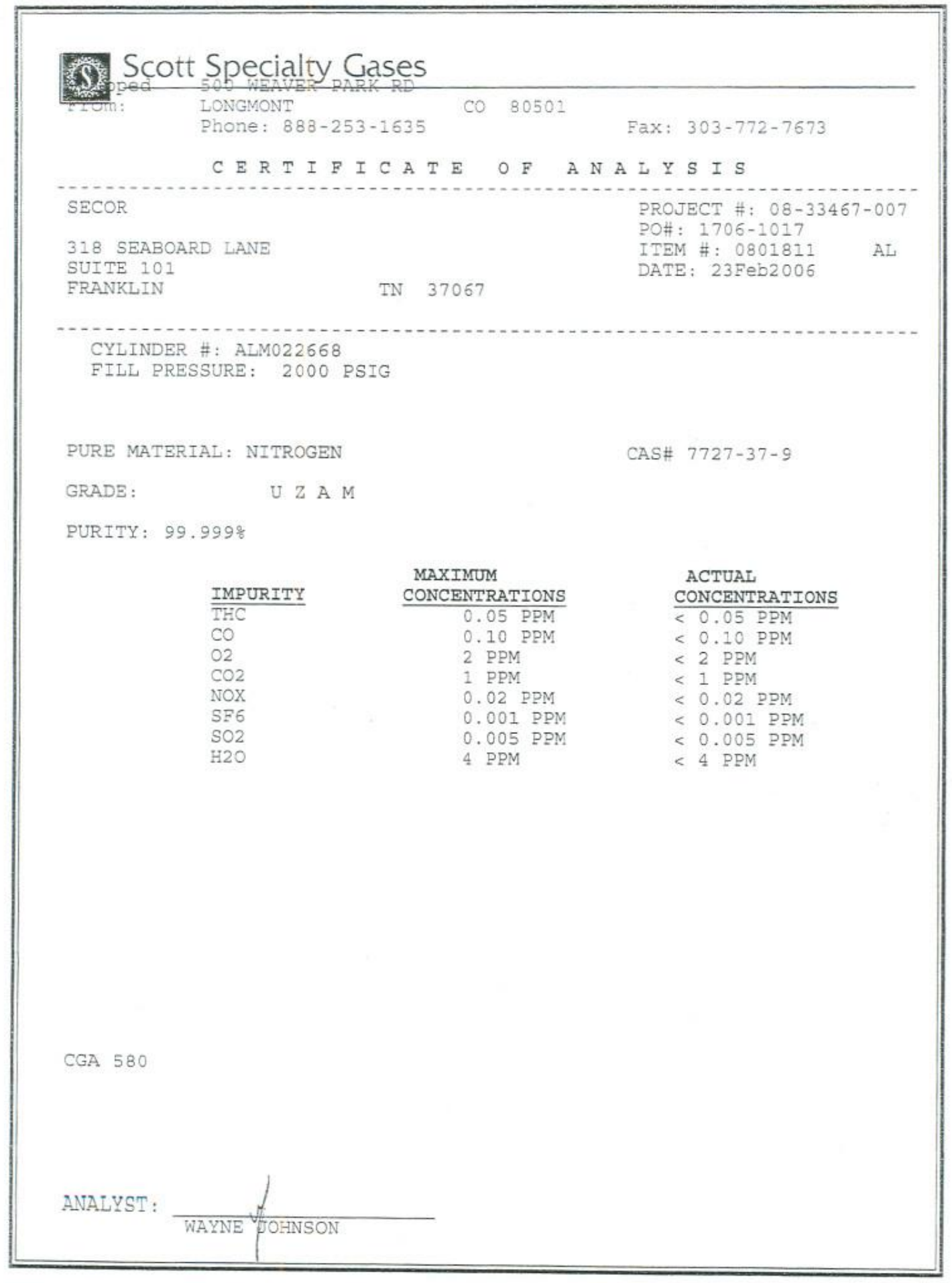


(ब) Scott Specialty Gases

Close Window | Save As | Print

500 WEAVER PARK RD,LONGMONT, CO 80501 Phone 888-253-1635 Fax 303-772-7673

Dual-Analyzed Calibration Standard

\section{CERTIFICATE OF ACCURACY: Interference Free ${ }^{\mathrm{TM}}$ Multi-Component EPA Protocol Gas}

$\begin{array}{lll}\text { Assay Laboratory } & & \text { Customer } \\ \text { SCOTT SPECIALTYGASES } & \text { P.O. No: } 1705-1017 & \text { SECOR } \\ \text { SO0 WEAVER PARK RD } & \text { Project No: } 08-33467-008 & \text { 318 SEABOARD LANE } \\ \text { LONGMONT.CO } 80501 & & \text { SUITE } 101 \\ & & \text { FRANKLIN TN } 37067\end{array}$

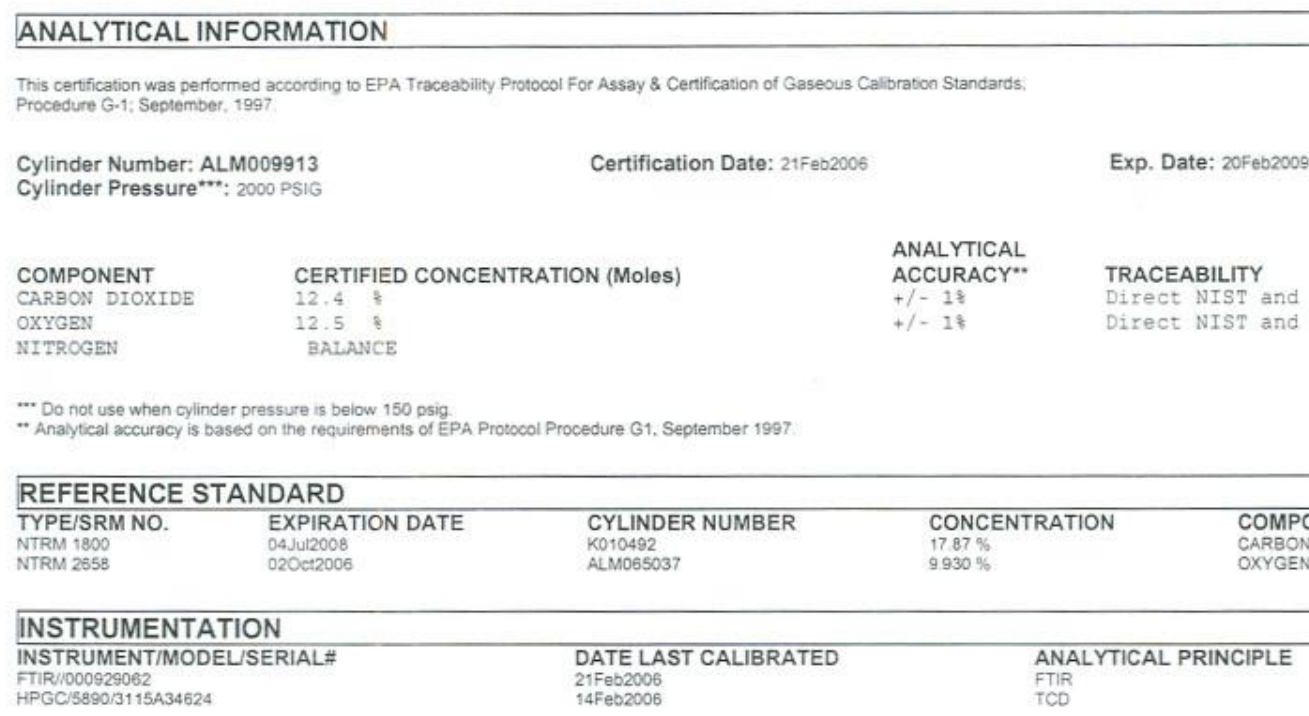

ANALYZER READINGS

( $Z=$ Zero Gas R=Reference Gas T=Test Gas r=Correlation Coefficient)

First Triad Analysis

CARBON DIOXIDE

Date: 21 Feb2006 Response Unit \%

$21=0.00025 \quad R 1=17.85852 T 1=12.42262$

$R 2=17.87372 Z 2=0.00743 T 2=12.42652$

. $3=0.00855$ T3=12.42953 R3 $=17,8788$

Avg. Concentration: 12.42 \%

OXYGEN

Date 17 Feb2006 Response Unit \%

$21=0.00000 \quad R 1=210161.0 \quad T 1=264469$
$R^{2}=211578$

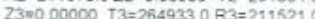

Avg Concentration: $1254 \%$

(Z=Zero Gas R=Reierence Gas T-Test Gas r=Correlaton Coeficient)

Special Notes:

RANGE 12-13\% O2\& CO2

Second Triad Analysis

Calibration Curve

Concentration $=A+B \times+C \times 2+D \times 3+E \times 4$

$r=9.99981 \mathrm{E}-1$

Constants: $A=0.00000 E+0$

B=9.12314E-1 C=1.22200E-2

$D=0.00000 E+0 \quad E=0.00000 E+$

Concentration $=\mathrm{A}+\mathrm{B} \times \mathrm{C}+\mathrm{C} \times 2+\mathrm{D} \times 3+\mathrm{E} \times 4$

T=0 999999

Constants. $A=.000289913$

$D=E=-05$ C-2BeE-12

http://www.scottecatalog.com/eScott2.nsf/(Cert)?OpenAgent\&UNID=677C207C7D80E...

$12 / 20 / 2006$ 
(2) Scott Specialty Gases

Close Window | Save As | Print

500 WEAVER PARK RD.LONGMONT.CO 80501 Phone 888-253-1635 Fax-303-772-7673

Dual-Analyzed Calibration Standard

\section{CERTIFICATE OF ACCURACY: Interference Free ${ }^{\mathrm{TM}}$ Multi-Component EPA Protocol Gas}

\begin{tabular}{|c|c|c|}
\hline $\begin{array}{l}\text { Assay Laboratory } \\
\text { SCOTT SPECIALTY GASES }\end{array}$ & PO. No: $1705-1017$ & $\begin{array}{l}\text { Customer } \\
\text { SECOR }\end{array}$ \\
\hline \multirow{3}{*}{ LONGMONT.CO 80501} & Project No: $08-33467-009$ & 318 SEABOARD LANE \\
\hline & & SUITE 101 \\
\hline & & FRANKLIN TN 37067 ? \\
\hline
\end{tabular}

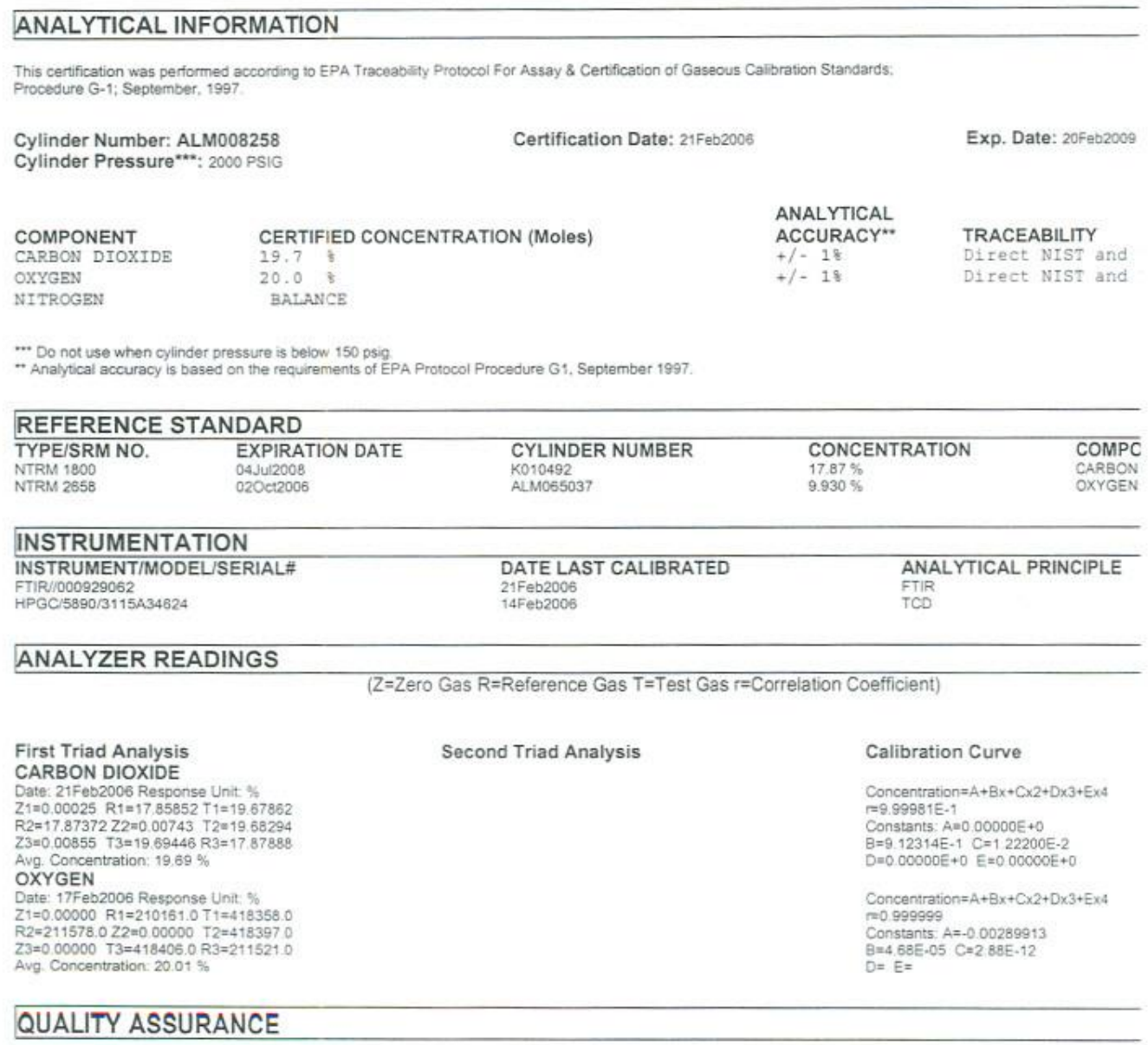




\section{Airgas}

Airgas Specialty Gases

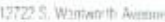

Certificate of Analysis

sincomo, it Bos

$1-733.785-3000$

Fas : $1733-796-1928$

\begin{tabular}{|c|c|c|c|}
\hline Date of Analysis: & $6 / 26 / 2006$ & Reference Number: & $54-124068484-3$ \\
\hline Customer Name: & & Part Number: & X03NI99C15A4554 \\
\hline Grade of Product: & $\begin{array}{l}\text { CERTIFIED } \\
\text { STANDARD-SPEC }\end{array}$ & & \\
\hline Cylinder Number & Component & $\begin{array}{l}\text { Requested } \\
\text { Concentration }\end{array}$ & Actual Concentration \\
\hline \multirow[t]{3}{*}{ CC111673 } & NITROGEN DIOXIDE & 50 PPM & 52.29 PPM \\
\hline & OXYGEN & $1000 \mathrm{PPN}$ & 860 PPM \\
\hline & NITROGEN & Balance & Balance \\
\hline
\end{tabular}

Notes:

Relative Uncertainty of Analytical Value: $+1-2 \%$ of component or $+/-5 \%$ of component, if less than 50 PPM

Product composition verified by direct comparison to calibration standards traceable to NIST weights and/or NIST gas mixture reference materials

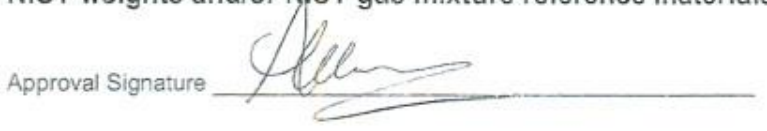

Page 1 


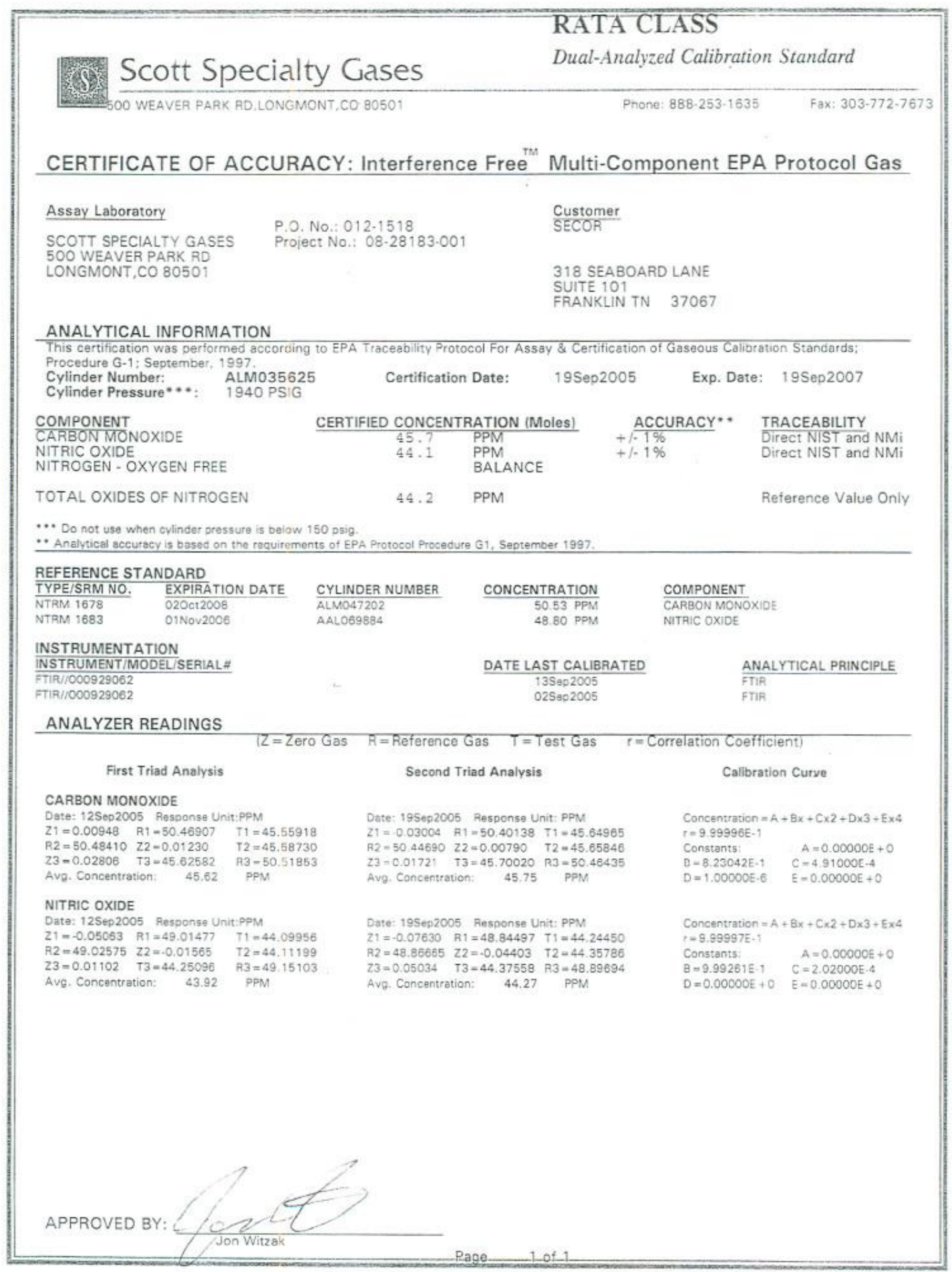




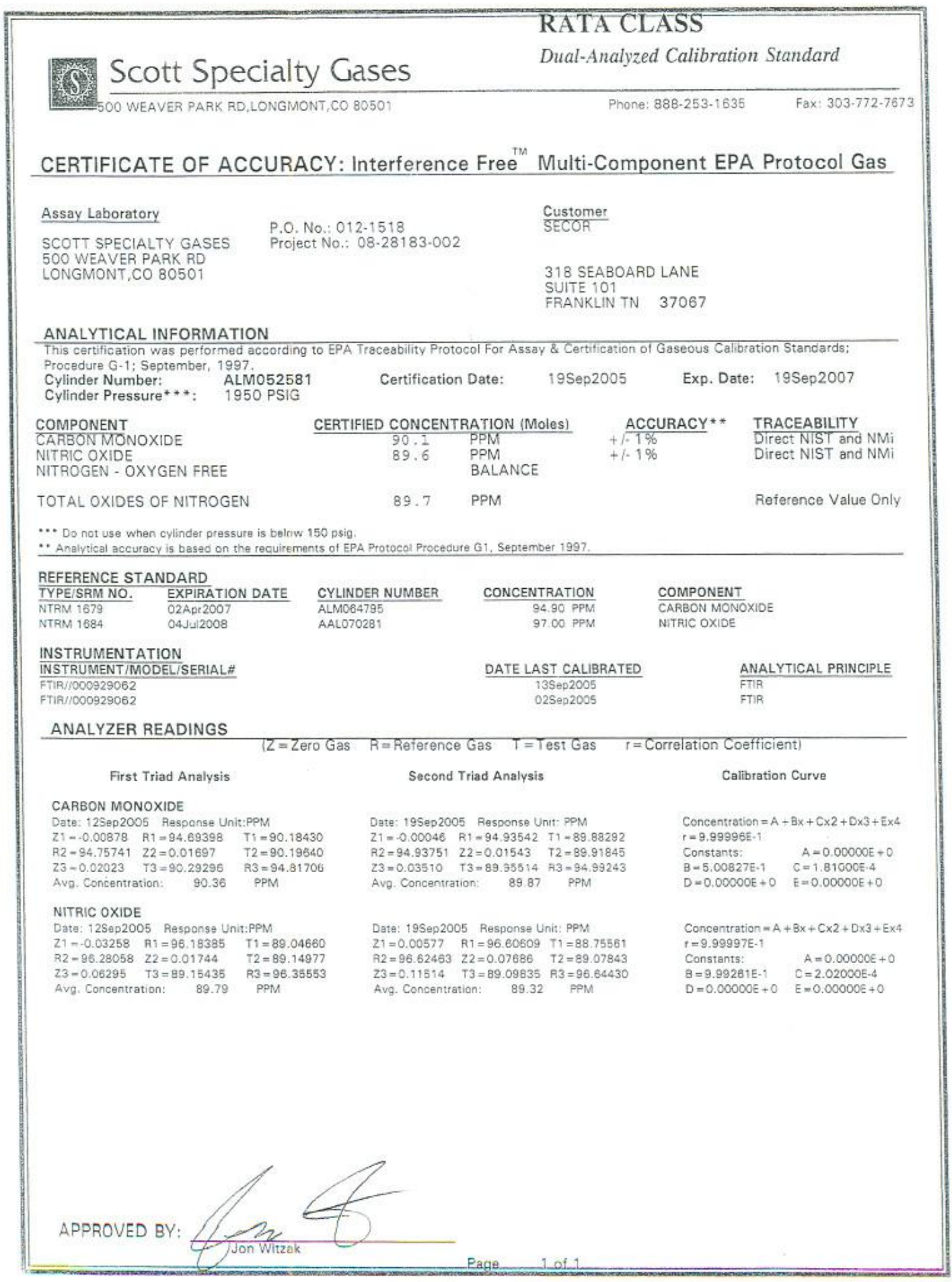




\section{Airgas}

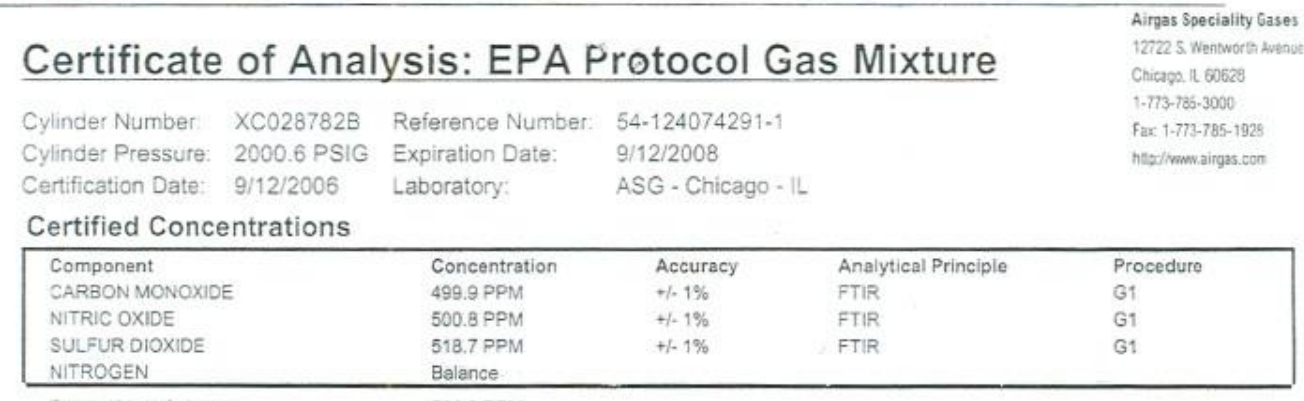

Total oxides of nitrogen

501.2 PPM

Certification performed in accordance with "EPA Traceability Protocol (Sept. 1997)" using the assay procedures listed. Analytical Methodology does not require correction for analytical interferences

Notes:

Do not use cylinder below 150 psig.

Approval Signature

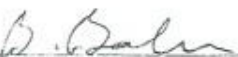

Reference Standard Information

\begin{tabular}{|c|c|c|c|c|}
\hline Type & Balance Gas & Component & Cyl.Number & Concentratior \\
\hline NTRM 1051108 & & SULFUR DIOXIDE & SG9149767BAL & $125 t$ PPM \\
\hline NTRM 111203 & & NITRIC OXIDE & SG9134620BAL & 990.6 PPM \\
\hline NTRM 52403 & & CARBON MONOXIDE & SG9162928BAL & 973.6 PPM \\
\hline
\end{tabular}

Analytical Results

CARBON MONOXIDE

09/05/2006

1st Analysis Date:

R 9852 S 5062

S $507.3 \quad Z 1.085$

$Z 1.073 \quad R 985.7$

2nd Analysis Date

R 980.9 S 506 .

S $505.2 \quad Z 107$

Z $1.09 \quad$ R 986.8

3rd Component

1st Analysis Date:

R 1262 S 523.2

S $522.5 \quad$ Z. 0.262

Z 0.081

R 1261

2no Analysis Date

R $1269 \quad \$ 521.7$

S $520.8 \quad$ Z .0 .04

$\begin{array}{ll}7.029 & R \\ & 1257\end{array}$
$\mathrm{Z} 1.090$ Conc $499.7 \mathrm{PPM}$

R 988.3 Conc 499.3 PPM

S 506.9 Conc 500.1 PPM

AVG: 499.7 PPM

$09 / 12 / 2006$

Z 1.09 Conc 501.8 PPM

$R 983.5$ Conc 499.5 PPM

S 506.7 Conc 499.4 PPM AVG: 500.2 PPM

SULFUR DIOXIDE

$09 / 05 / 2006$

$\mathrm{Z}-0.180 \quad$ Cone $518.6 \mathrm{PPH}$

R 1261 Conc 518.6 PPM

S523.4 Conc 519.4 PPi

AVG: 518.8 PPI

$09 / 12 / 2005$

Z - $0.41 \quad$ Conc 518.8 PPM

R 1257 Conc 518 3 PPM

S521.1 Conc 518.9 PPM 2nd Component NITRIC OXIDE

1st Analysis Date: $\quad$ 09/05/2006

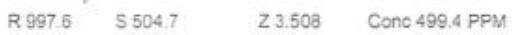

$\begin{array}{llll}5506.1 & Z 3637 & R 996.1 & \text { Conc 501.5 PPM }\end{array}$

23.629 R995.1 $\quad \$ 505.6$ Conc 501.5 PPM

AVG: 500.B PPM

2nd Analysis Date: $\quad 09 / 12 / 2006$

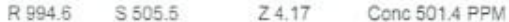

$\begin{array}{llll}55061 & Z 399 & R 997.1 & \text { Cone 500.8 PPM }\end{array}$

$\begin{array}{llll}23.87 & R 996.8 & S 505.7 & \text { Conc } 500.6 \text { PPM }\end{array}$ 


\begin{tabular}{|c|c|c|c|c|}
\hline \multirow{2}{*}{\multicolumn{4}{|c|}{ Certificate of Analysis: EPA Protocol Gas Mixture }} & \multirow{2}{*}{$\begin{array}{l}\text { Airgas Spotiality Gases } \\
127225 \text { Watworth Avenue }\end{array}$} \\
\hline & & & & \\
\hline Culinder Number & SG913385C & Reference Numh & & $1-773-785.3000$ \\
\hline Culinder Pressure: & 2000.6 PSIG & Expiration Date: & $\begin{array}{l}54-1240 / 4 \\
9 / 21 / 2008\end{array}$ & $f a x+1-773 \cdot 765-1228$ \\
\hline Certification Date: & $9 / 21 / 2006$ & Laboratory. & ASG - Chicago - IL & 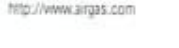 \\
\hline
\end{tabular}

Certified Concentrations

\begin{tabular}{|c|c|c|c|c|}
\hline Component & Concentration & Accuracy & Analytical Principle & Procedure \\
\hline NITRIC OXIDE & 988.64 PPM & $+1.1 \%$ & FTIR & G1 \\
\hline CARBON MONOXIDE & 999.57 PPM & $+1.1 \%$ & $F T R$ & G: \\
\hline SULFUR DIOXIDE & $1039.00 \mathrm{PPM}$ & $+1-1 \%$ & FTIR & Q1 \\
\hline NITROGEN & Balance & & & \\
\hline
\end{tabular}

Total oxides of nitrogen

994.0 PPM

Certification performed in accordance with "EPA Traceability Protocol (Sept. 1997)" using the assay procedures listed. Analytical Methodology does not require correction for analytical interferences.

Notes:

Do not use cylinder below 150 psig.

Reference Standard Information

TVRe
NTRM 1051108
NTRM 100703
NTRM 20503

Balance Gas

NTRM 20503

Analytical Results

$\begin{array}{ll}\text { 1st Component } & \text { NITRIC OXID } \\ \text { 1st Analysis Date: } & 09 / 13 / 2006 \\ \text { R } 1507 \quad \text { S } 1006 & 2-1.17\end{array}$

5999.6 Conc $\$ 84.0$ PPM

AVG: 986.4 PPM

2nd Analysis Date:

R 14985 S 51003.7

$09 / 21 / 2006$

$\begin{array}{llll}S 1004.4 & Z \cdot 690 & \text { Z } .716 & \text { Conc } 989.51 \text { PPM } \\ \text { Z.995 } & \text { R } 1491.5 & \$ 992.9 & \text { Conc } 993.86 \text { PPM } \\ & & & \end{array}$

Approval Signature

3rd Component

S 998.47 Conc 989.09 PPM
AVG 990.82 PPM

Cyl. Number

SULFUR DIOXIDE SOY149767BAL

NITRIC OXIDE SG9169554BAL

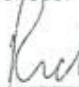

1st Analysis Date:

R $1262 \quad$ S 1048

SULFUR DIOXIDE

SG9153846BAL

Concentration

1251 PPM

1477 PPM

$\begin{array}{llll}S 1050 & Z & 0.12 & R \\ Z & 1263 & \text { Conc } 1041 \text { PPM }\end{array}$

Z 0.22 R 1262 S 1050 Conc 1040 PPM

Ins Anatysis Date: $\quad 09 / 21 / 2003$

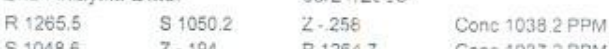

$\begin{array}{llll}S & 1048.6 & Z=194 & R \\ Z & 1264.7 & \text { Conc } 1037.2 \mathrm{PPM}\end{array}$

$\begin{array}{llll}Z & \text { R } 31264.0 & 51048.5 & \text { Conc } 1037.6 \mathrm{PPM}\end{array}$

AVG. 1037.6PPM 


\begin{abstract}
EMISSION MEASUREMENT CENTER
APPROVED ALTERNATIVE METHOD (ALT-011)

ALTERNATIVE METHOD 2

THERMOCOUPLE CALIBRATION PROCEDURE

\section{INTRODUCTION}

In EPA Method 2, EPA recommended the use of an extrapolation technique for a simplified, post-test, thermocouple calibration procedure using a two point calibration: (1) ice bath and (2) boiling water. Because of the inherent accuracy and precision of the thermocouple within $\pm 1.3^{\circ} \mathrm{F}$ in the range of $-32^{\circ} \mathrm{F}$ to $2500^{\circ} \mathrm{F}$, the two-point post-test calibration procedure may be replaced with a single-point check.

A single-point calibration procedure that checks the operation of a thermocouple system within \pm 1.0 percent of the absolute measured temperature is all that is necessary to check the system for the presence of disconnected wire junctions, other loose connections, or a potential miscalibrated emf readout. A system that performs accurately at one temperature is expected to behave similarly at other temperatures.

Therefore, an alternative to the Method 2, two-point, thermocouple calibration can be used and the procedure is as follows:
\end{abstract}

\title{
ALTERNATIVE POST-TEST AND RECOMMENDED PRETEST CALIBRATION PROCEDURE
}

After each test run series, check the accuracy (and, hence, the calibration) of each thermocouple system at ambient temperature, or any other temperature, within the range specified by the manufacture, using a reference thermometer (either ASTM reference thermometer or a thermometer that has been calibrated against an ASTM reference thermometer). The temperatures of the thermocouple and reference thermometers shall agree to within $\pm 2{ }^{\circ} \mathrm{F}$.

A crimp in the connecting wires or crossed lines that change the location of the reference junction will affect readings. Check the continuity of the thermocouple by subjecting it to a change in the temperature (e.g..., removing it from the stack or touching an ice cube). This step will also check for loose connections and reversed connections (noted by a wrong change in the temperature).

To ensure linearity of the measurements, it is recommended that the emf meter be originally calibrated against a NIST traceable or a comparable voltage source at several points covering the range of intended use, e.g., $0,500,1000$, and $2000^{\circ} \mathrm{F}$.

\section{REFERENCE}

1. Shigehara, R.T., E.W. Stewart, Kenneth Alexander, "Simplified Thermocouple Calibration Procedure", Entropy, Incorporated, contained in the EMTIC TSAR Library.

Prepared by Michael K. Ciolek, EMC EMC ALT-011

EMAD, OAQPS, EPA $\quad$ June 21, 1994 


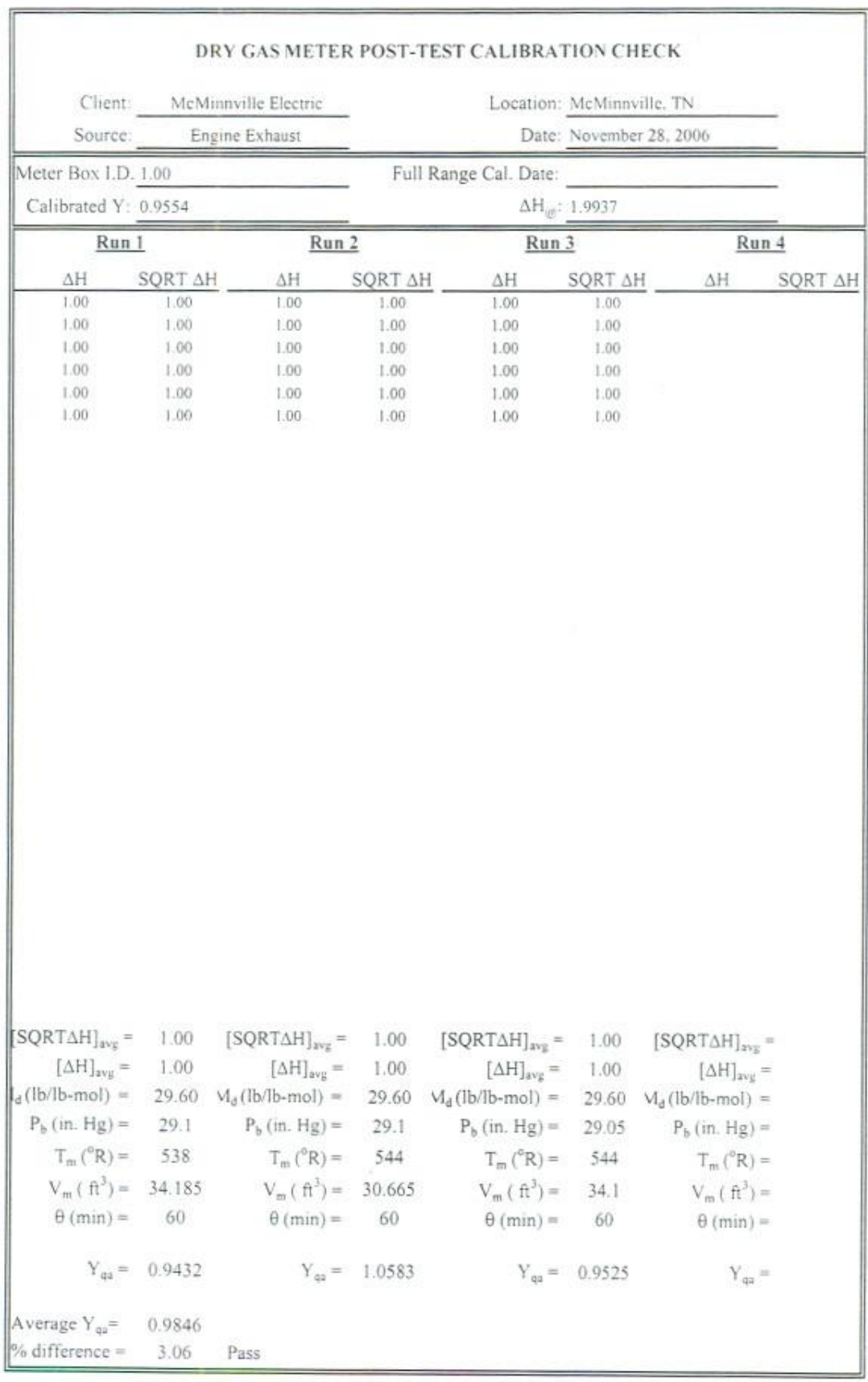

Eng_Exh RM4 xis: Postcal 

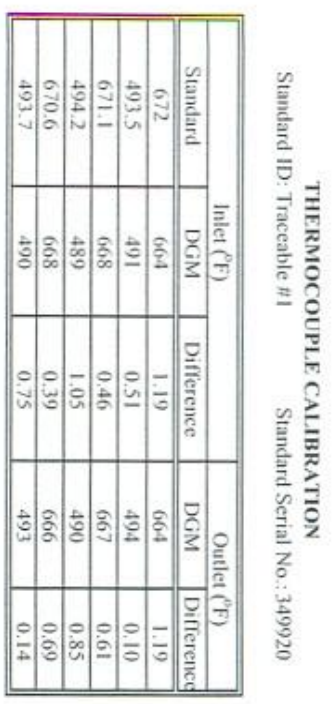

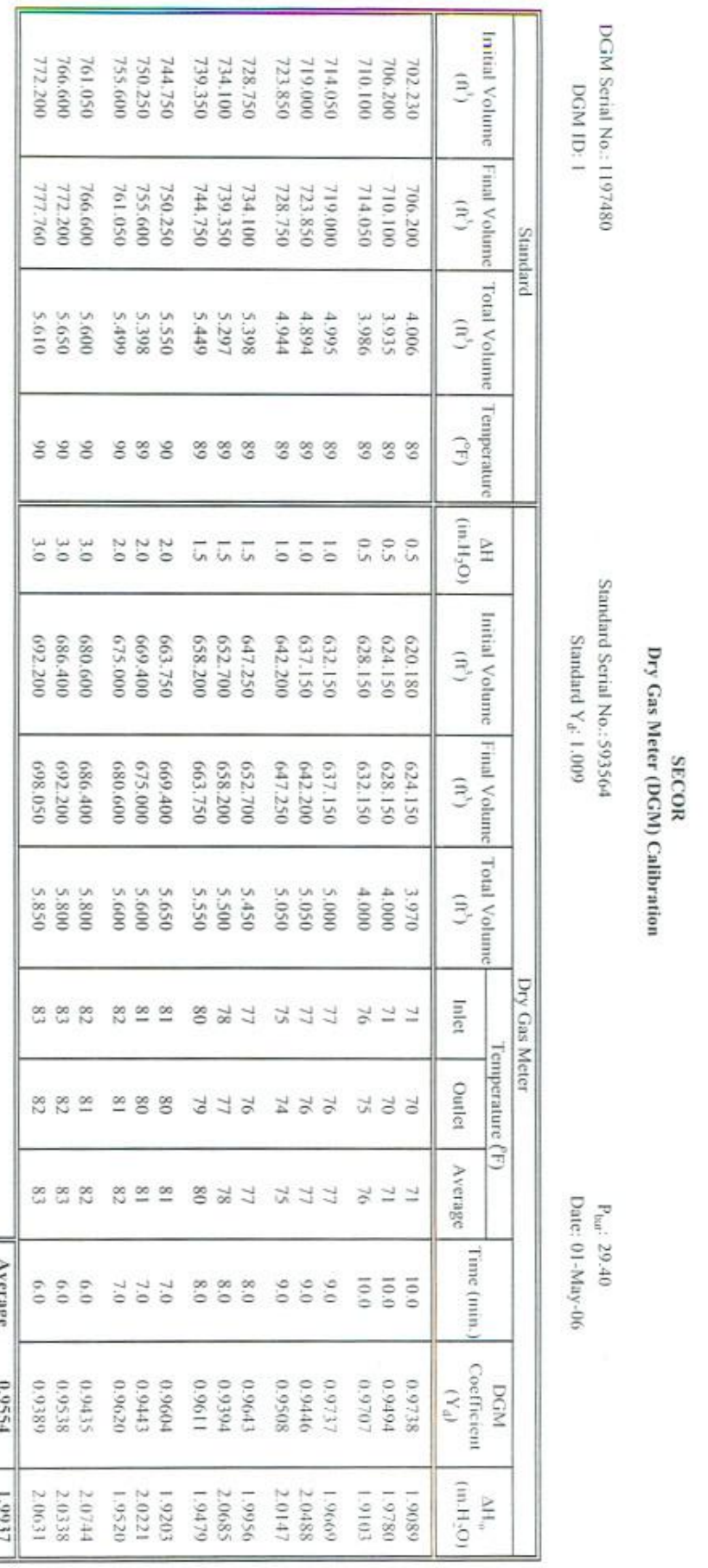




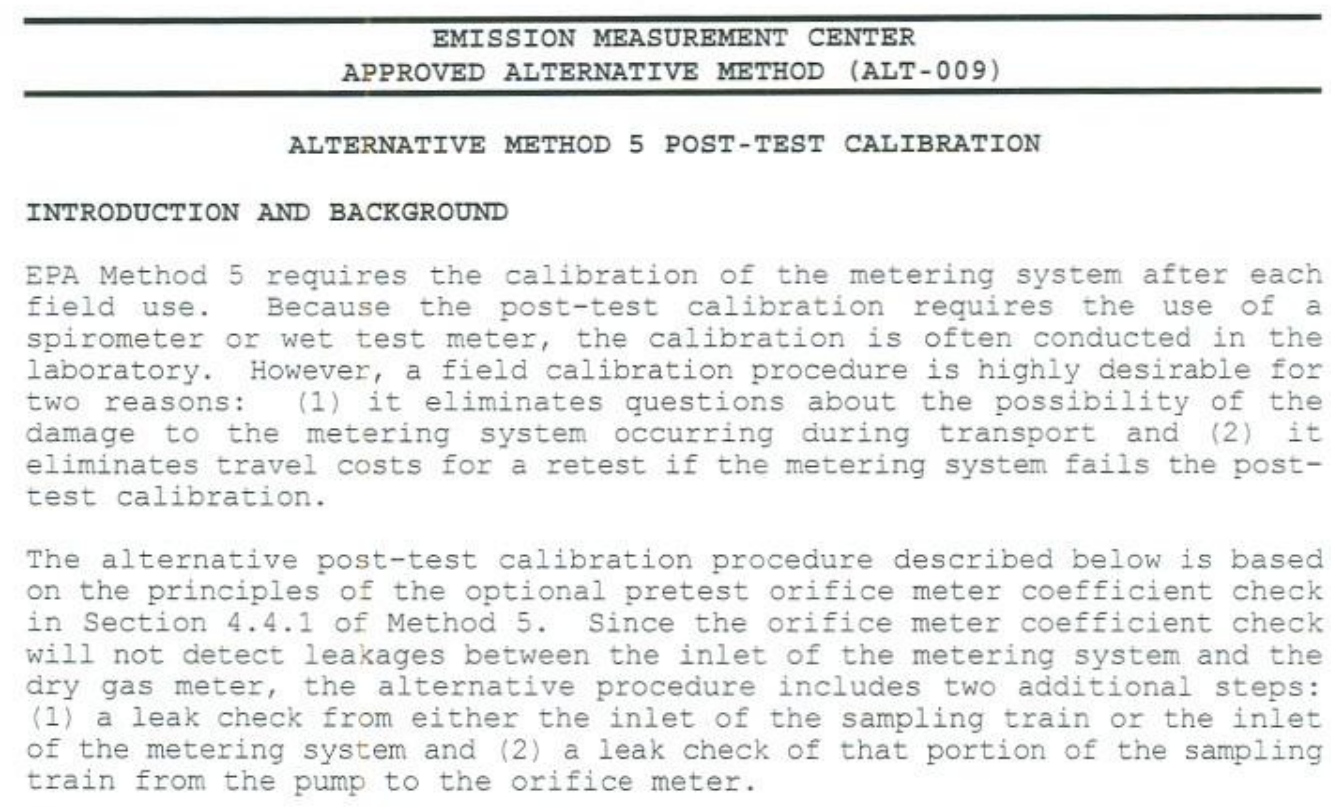

PROCEDURE

The alternative to the post-test calibration in Section 5.3 .2 of Method 5 is as follows:

After each test run, do the following:

1. Ensure that the metering system has passed the post-test leakcheck. If not, conduct a leak-check of the metering system from its inlet.

2. Conduct the leak-check of that portion of the train from the pump to the orifice meter as described in Section 5.6 of Method 5.

3. Calculate $Y_{q a}$ for each test run using the following equation:

$$
Y_{q a}=\frac{\dot{V}}{V_{m}} \sqrt{\frac{0.0319 T_{m}}{H_{\theta}\left(P_{b}+\cdot \frac{H_{a v g}}{13.6}\right)} \frac{29}{M_{d}}}(\sqrt{\cdot H}) \mathrm{avg}
$$

where:

Prepared by Michael K. Ciolek, EMC EMC ALT-009

EMAD, OAQPS, EPA $\quad$ June 21, 1994 


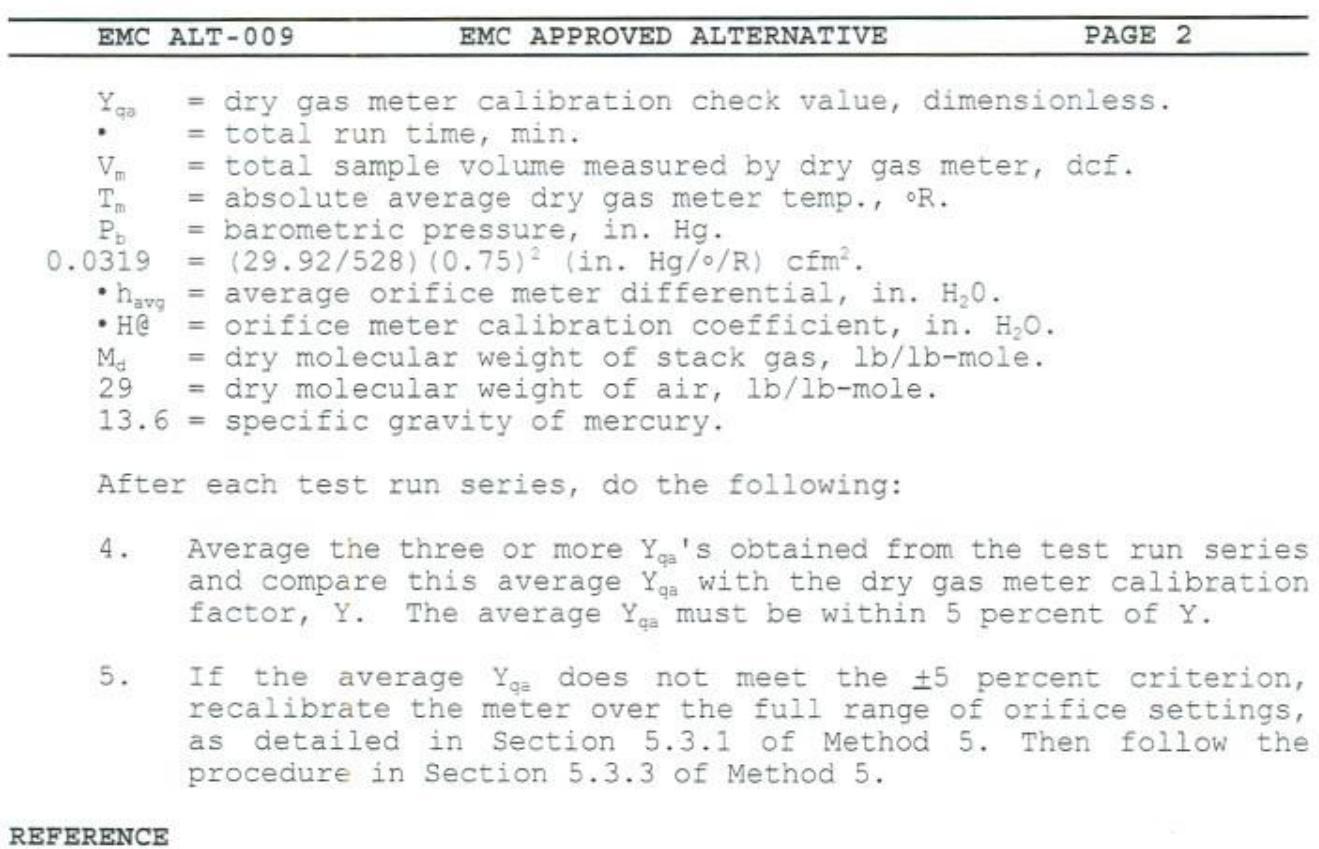

1. Roger T. Shigehara, P.G. Royals, and E.W. Steward, "Alternative Method 5 Post-Test Calibration", Entropy, Inc, contained in the EMTIC TSAR Library. 


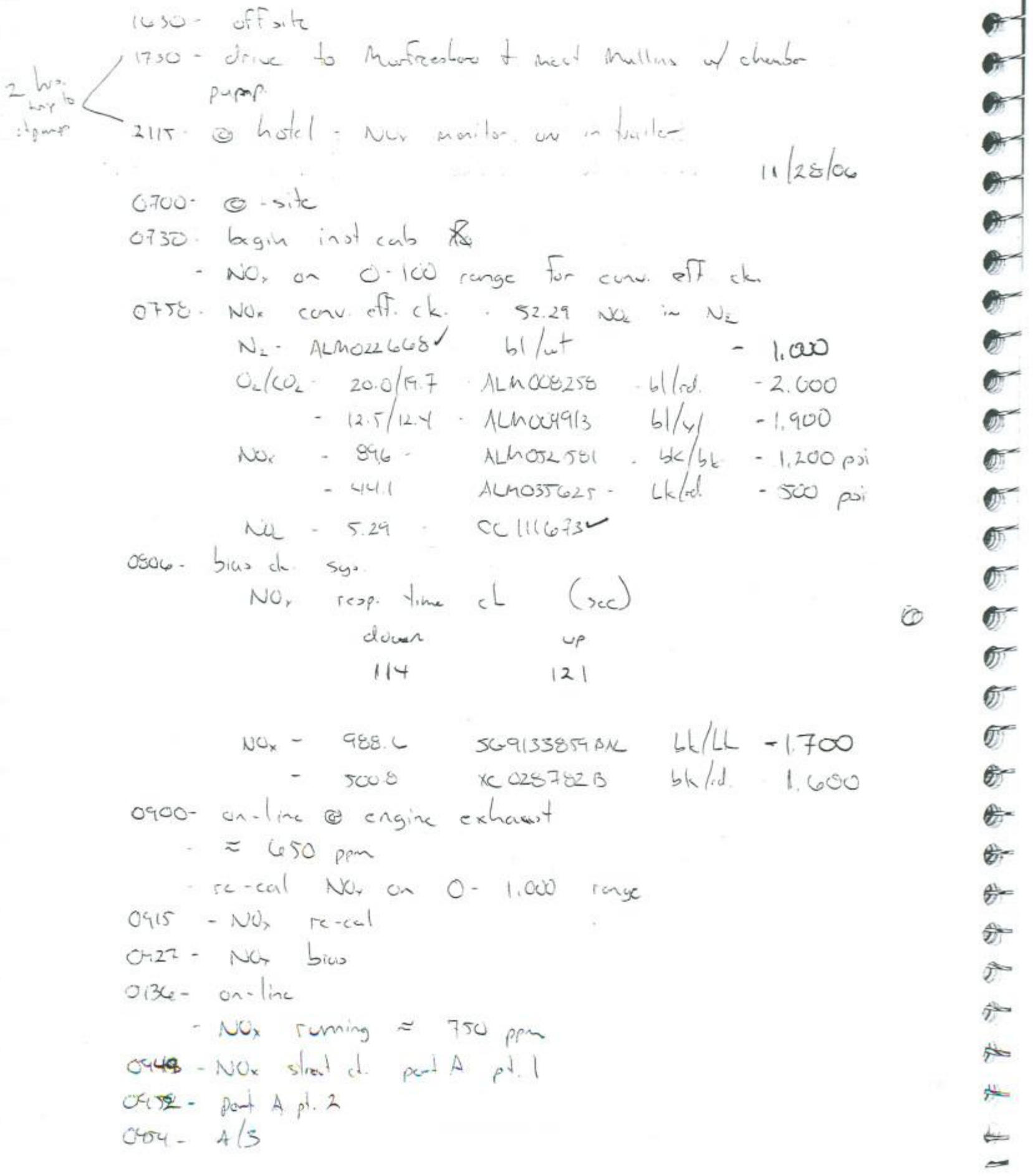




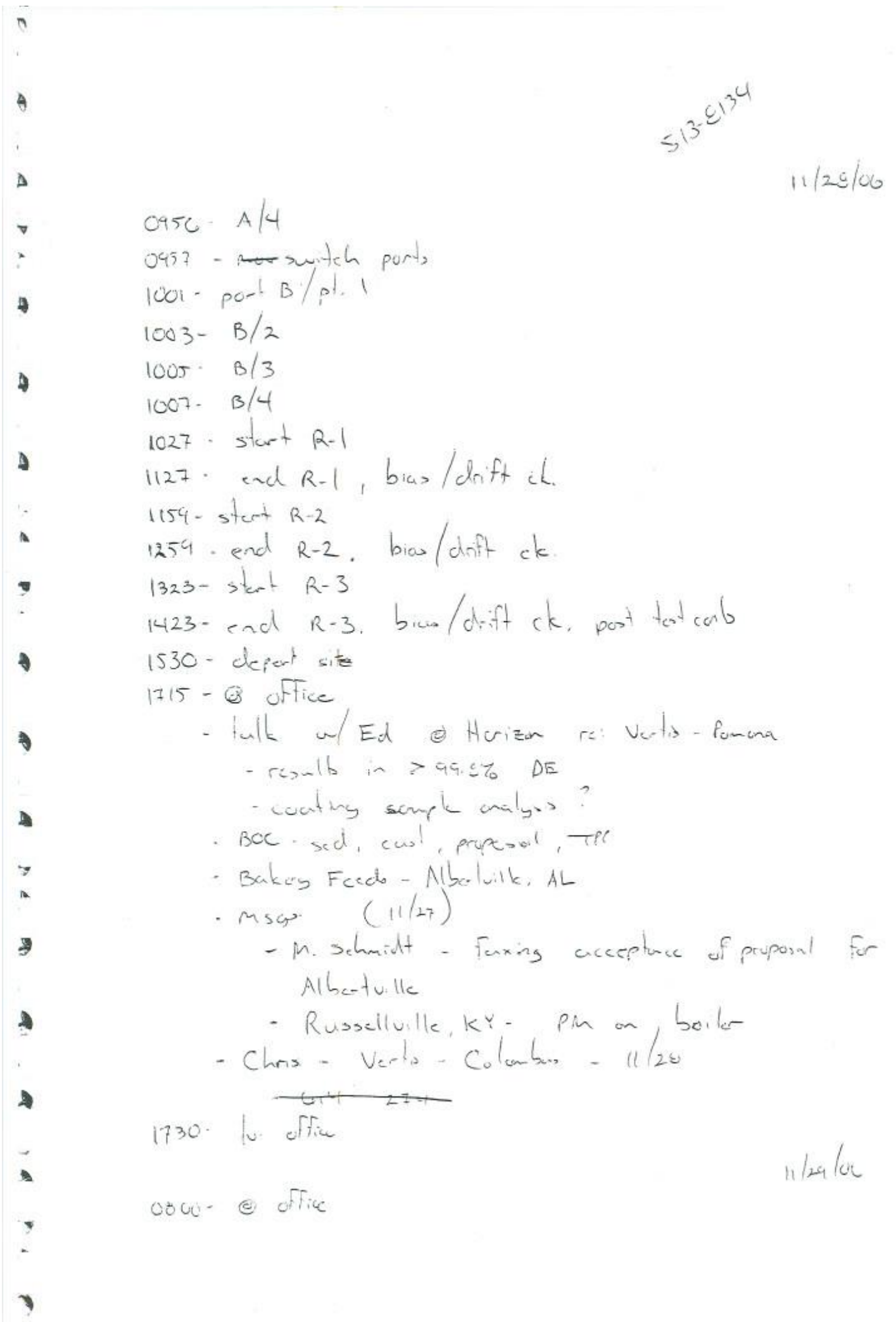

1 


\section{APPENDIX C PRODUCTION DATA \\ Emissions Measurements Report \\ McMinnville Electric System 200 West Morford Street McMinnville, Tennessee \\ 170T. 98726.00 \\ December 2006}


Device ID: $\quad 89498523$

Serial Number: $\quad 89498523$

Kh: 1.8

Interval Length: $30 \mathrm{~min}$

Values are in units

Date Time

$11 / 28 / 2006 \quad 9: 30: 00$

$11 / 28 / 2006 \quad 10: 00: 00$

$11 / 28 / 2006 \quad 10: 30: 00$

$11 / 28 / 2006 \quad 11: 00: 00$

$11 / 28 / 2006 \quad 11: 30: 00$

$11 / 28 / 2006 \quad 12: 00: 00$

$11 / 28 / 2006 \quad 12: 30: 00$

$11 / 28 / 2006 \quad 13: 00: 00$

$11 / 28 / 2006 \quad 13: 30: 00$

$11 / 28 / 2006 \quad 14: 00: 00$

$11 / 28 / 2006 \quad 14: 30: 00$

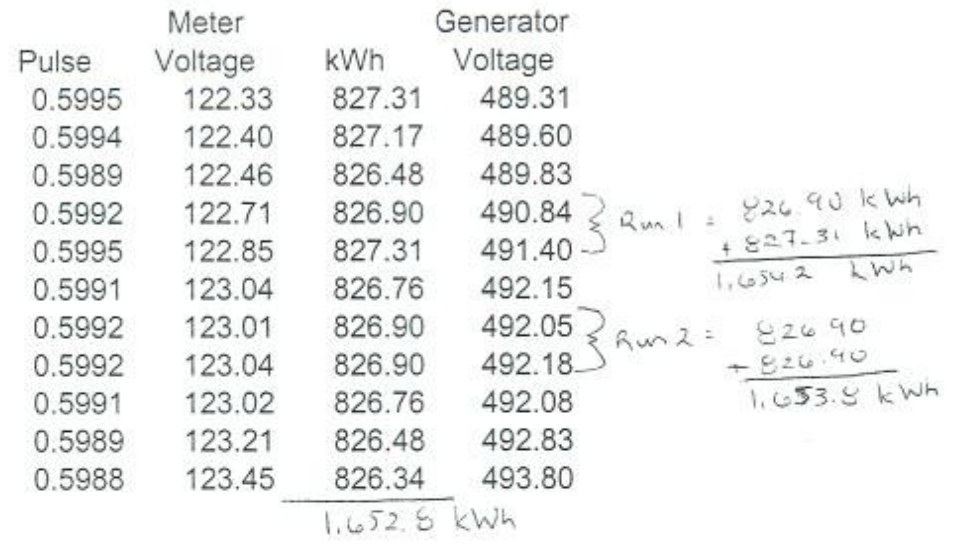




\section{Attachment "G"}

(The following report, which pertains solely to emissions measurement testing and fuel quality was submitted by Ralph Boroughs on behalf of the Tennessee Valley Authority as part of this Project and is therefore incorporated and made part of this Final Report as submitted.) 


\section{TVA Activities in Support of the McMinnville BioDiesel / SCONOX Project}

\section{Introduction}

TVA's interest in this project stemmed from a desire to develop clean, renewable generation, and to be responsive to customer proposals; in this case, a proposal from McMinnville Electric System (MES) to install a new generator, dedicated to biodiesel fuel, and equipped with an advanced NOx removal system.

As a 'power production' project, TVA was not interested in any new diesel generation, primarily because of the high NOx emissions of diesels. Biodiesel, while cleaner burning in many respects, has not been shown to reduce NOx, and in some cases even increase NOx emissions. (TVA's policy "not to pursue or consider new contracts for use or installation of additional diesel generation", was established February 22, 2001, and was re-affirmed in July 2002 after reviewing the MES proposal.) Nevertheless, TVA did approve our participation in a 'research and development' project to test advanced emissions controls, using biodiesel in a diesel-generator set.

The TVA role in the overall project was focused on primarily on emission monitoring, to verify that the NOx removal system could meet TVA emissions targets. A target NOx limit was set at 0.16 pounds per million BTU, 1.57 pounds per MWh, or 0.5 grams per brake horsepower-hour, based on TVA's internal environmental review in 2002. This limit corresponds to emissions achievable by a well-controlled coalfired plant, but is much stricter than any then-existing emissions standards for diesels. TVA's NOx target has no direct linkage to EPA or Tennessee regulations for diesels, but is instead a goal, which, if met, might motivate and inform a reconsideration of TVA's policy on diesel generation.

[TVA did not participate in emissions testing for compliance with state air permits, because stateapproved testing of diesels requires specialized equipment as well as detailed knowledge of state regulations and how they are applied.]

Although TVA was primarily focused on emissions monitoring, TVA also contributed to the project planning process and fuel testing.

\section{Test Plan}

The actual testing schedule did not follow the planned schedule. Phases 1 through 3 were compressed to compensate for time and cost overruns earlier in the project. Phase 4 was compressed further, because problems with the plasma reformer (which we had hoped to resolve in phase 1) kept recurring, and attempts to resolve these problems added additional costs. The table below compares an early test plan to the actual implementation. 


\begin{tabular}{|l|l|l|l|}
\hline Test Phase & Description & Planned Duration & Actual Duration \\
\hline 1 & $\begin{array}{l}\text { Commissioning, Start up, \& } \\
\text { Regeneration System Tests }\end{array}$ & 10 days & $\sim 4.5$ days \\
$6 / 29-7 / 3$
\end{tabular}

Note that optimization of the EMx reactor (phase 2) continued into the blend testing (phase 3).

\section{Emissions Test Equipment}

TVA used a PACE 400 electrochemical analyzer, by Ametek, which simultaneously measures $\mathrm{NO}, \mathrm{NO}_{2}$, $\mathrm{SO}_{x}, \mathrm{O}_{2}, \mathrm{CO}, \mathrm{CO}_{2}$ and hydrocarbons. The PACE 400 determines the contents of a flue gas stream by continually extracting samples that are routed into a peltier-effect (thermo-electric) cooling system, which removes water vapor from the sample before the sample is passed over electrochemical gas sensors for analysis. The probe and hose assembly contain an integrated thermocouple and water trap, to measure the stack temperature and pressure. A laptop computer was used to capture data from the data analyzer.

Before use of the analyzer, TVA Environmental Technologies Group ${ }^{3}$ performed characterization tests with synthetic stack gas to determine the linearity, precision, stability, and response time for $\mathrm{NO}, \mathrm{NO}_{2}$, $\mathrm{CO}, \mathrm{SO}_{2}$ and $\mathrm{O}_{2}$. The study found that at a 15 -second sample scan the linearity and precision were very good with values of less than 1 percent of the test concentration levels. This was better than the factory specifications. As for response time, 90 percent of a step change was registered for $\mathrm{NO}, \mathrm{NO}_{2}, \mathrm{CO}, \mathrm{SO}_{2}$ and $\mathrm{O}_{2}$ within 15 to 30 seconds.

\footnotetext{
3 "Report on laboratory testing of THERMOX PACE 400 analyzer with synthetic stack gas mixtures", Ralph J. Valente and Vince Van Pelt, TVA, Environmental Technologies, April 6, 2005
} 
The system was calibrated by utilizing standardized calibration gases. The accuracy of the sensor readings are displayed below:

\begin{tabular}{|c|c|}
\hline $\mathrm{O}_{2}$ & $\pm 0.3 \%$ of gas concentration \\
\hline $\mathrm{CO}_{2}$ & $\begin{array}{l} \pm 5 \% \text { of reading, } 0-2000 \mathrm{ppm} \\
\pm 10 \% \text { of reading, } 2001-40,000 \mathrm{ppm}\end{array}$ \\
\hline NO & $\begin{array}{l} \pm 5 \% \text { or } \\
\pm 5 \text { ppm of reading, } 0-2000 \mathrm{ppm}\end{array}$ \\
\hline $\mathrm{NO}_{2}$ & $\begin{array}{l} \pm 5 \% \text { or } \\
\pm 5 \mathrm{ppm} \text { of reading, } 0-500 \mathrm{ppm}\end{array}$ \\
\hline $\mathrm{SO}_{2}$ & $\begin{array}{l} \pm 5 \% \text { or } \\
\pm 10 \mathrm{ppm} \text { of reading, } 0-2000 \mathrm{ppm}\end{array}$ \\
\hline Combustibles & $\pm 5 \%$ of full scale \\
\hline Pressure & $\begin{array}{l}. \pm 2 \% \text { of reading of or } \\
\pm 0.05 \text { millibar whichever is greater }\end{array}$ \\
\hline Stack Temperature & $\begin{array}{l} \pm 4^{\circ} \mathrm{F} \text { between } 32 \text { and } 255^{\circ} \mathrm{F} \\
\pm 6^{\circ} \mathrm{F} \text { between } 256 \text { and } 480^{\circ} \mathrm{F} \\
\pm 8{ }^{\circ} \mathrm{F} \text { between } 481 \text { and } 752^{\circ} \mathrm{F}\end{array}$ \\
\hline
\end{tabular}

Calibrations were also done regularly during field tests.

Emissions were monitored before and after the EmeraChem EMx Catalyst system. Two ports, at right angles were available for use at each test plane. In early runs, traverses were conducted to look for signs of flow stratification.

Baseline emissions tests were conducted on Ultra-Low Sulfur Fuel Oil (ULSFO) and then emissions tests were conducted with nominal blends of $2 \%, 5 \%, 20 \%$ and $50 \%$ biodiesel, or B2, B5, B20 and B50.

Finally, emissions tests were done with $100 \%$ biodiesel or B100.

In presenting test results, the raw measurements (here, in ppm or parts per million) may be thought to be the most reliable, because these can be tied directly to the instrument calibration. However, any air in-leakage into the sampling train can dilute the concentration, and engine controls may change the air 
to fuel ratio. Furthermore, the concentration has no direct relevance to the environmental impact, which is more a function of the pollutant mass flow.

The best compromise between usefulness and accuracy is usually found by expressing the emissions results as mass per unit of fuel-energy-input. Thus, power plant measurements are usually expressed as pounds per million BTU.

The pollution load can also be expressed as mass per unit power output. This has the virtue of encouraging efficient use of fuel, but introduces some additional uncertainty, due to the need to accurately measure efficiency, which depends on both fuel input flows and energy output. To ensure these additional measurements are accurate, one must usually operate at a fixed condition over a long period of time, which proved impractical for our tests. Units for these measurements are typically expressed as pounds per MWh for large plants, and grams per brake horsepower hour for engine manufacturers.

The information is presented below in both pounds per million BTU and grams per brake-horsepowerhour, but is always calculated from the fuel-input. When showing output-based numbers, a fixed efficiency is assumed for convenience, although we recognize that actual efficiency will vary, depending primarily on ambient air temperature and pressure.

\section{Results}

\section{Baseline Tests}

Testing began on July 6, 2005, with baseline tests, using ultra-low sulfur ( $<15 \mathrm{ppm}$ ) petroleum diesel. (This was before the $<15$ ppm Sulfur fuel was widely available, starting in September of 2006.)

Untreated engine emissions were about $3.1 \mathrm{~g} / \mathrm{hp}$-h, well within the manufacturer's specification for NOx emissions of $<4.45 \mathrm{~g} / \mathrm{hp}-\mathrm{h}$.

As discussed by EmeraChem (see Attachment "B", pages 47 and 53) the NOx removal in this test was lower than expected, due to significant leakage of untreated exhaust around the catalyst. This leakage was subsequently discovered and corrected prior to the B20 tests. Despite these leaks, the time averaged NOx emissions ( $0.131 \mathrm{lbs} /$ million BTU) met TVA's goal ( $<0.16 \mathrm{lbs} /$ million BTU), although peak concentration ( $0.266 \mathrm{lbs} /$ million BTU) did not. Results are shown on the next page.

The saw-toothed pattern reflects the regeneration cycle, while the overall upward trend reflects incomplete regeneration, especially in chamber $\mathrm{Rx} 200$. Causes for this incomplete regeneration include the bypass leakage flow and the lower than expected hydrogen output from the reformer (for more details see Attachment " $\mathrm{B}$ ", page 53). The alternating pattern of high and low NOx peaks reflects the greater bypass flow in chamber Rx200, compared to Rx100. 


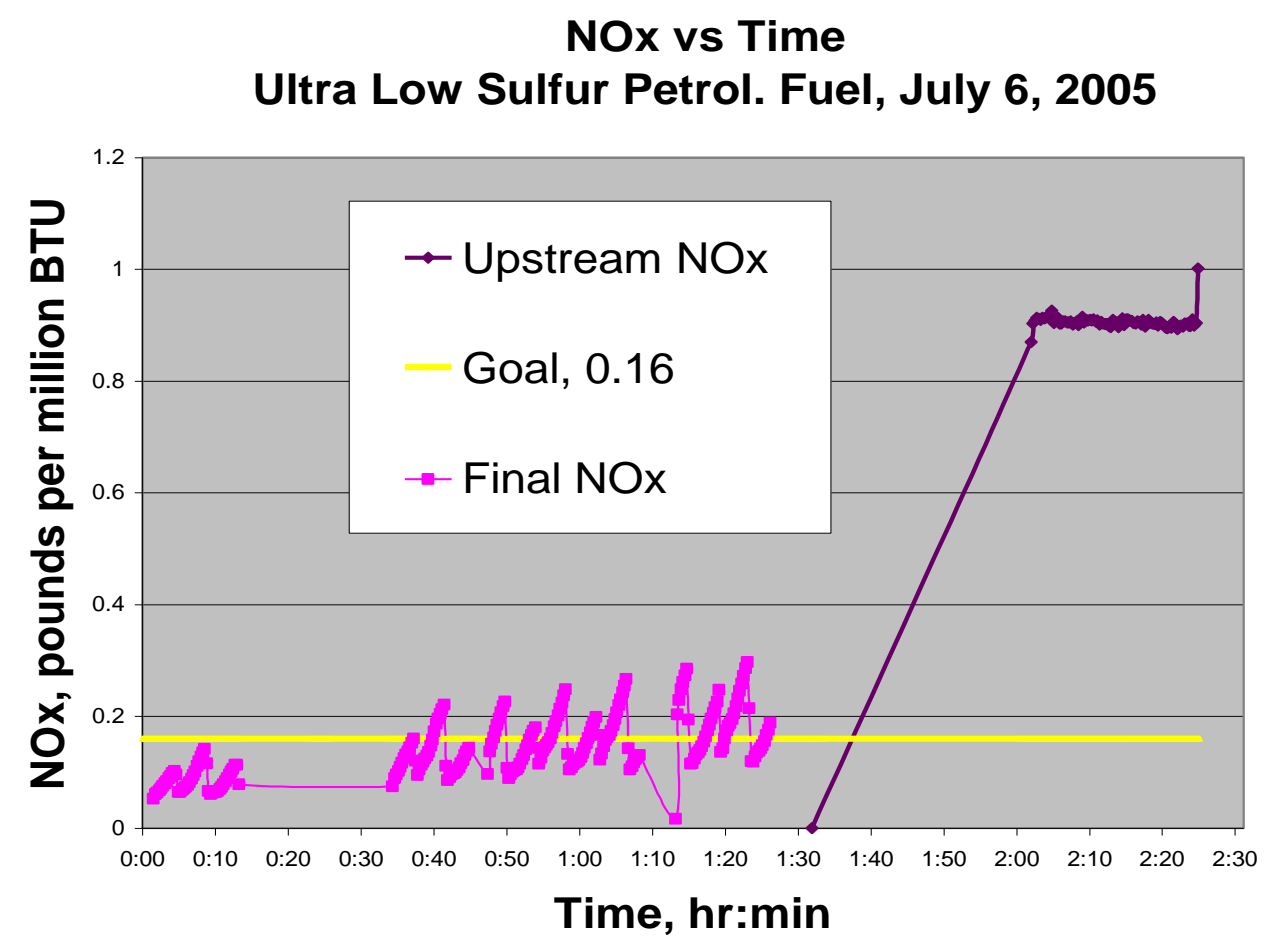

Again as grams per brake horsepower-hour:

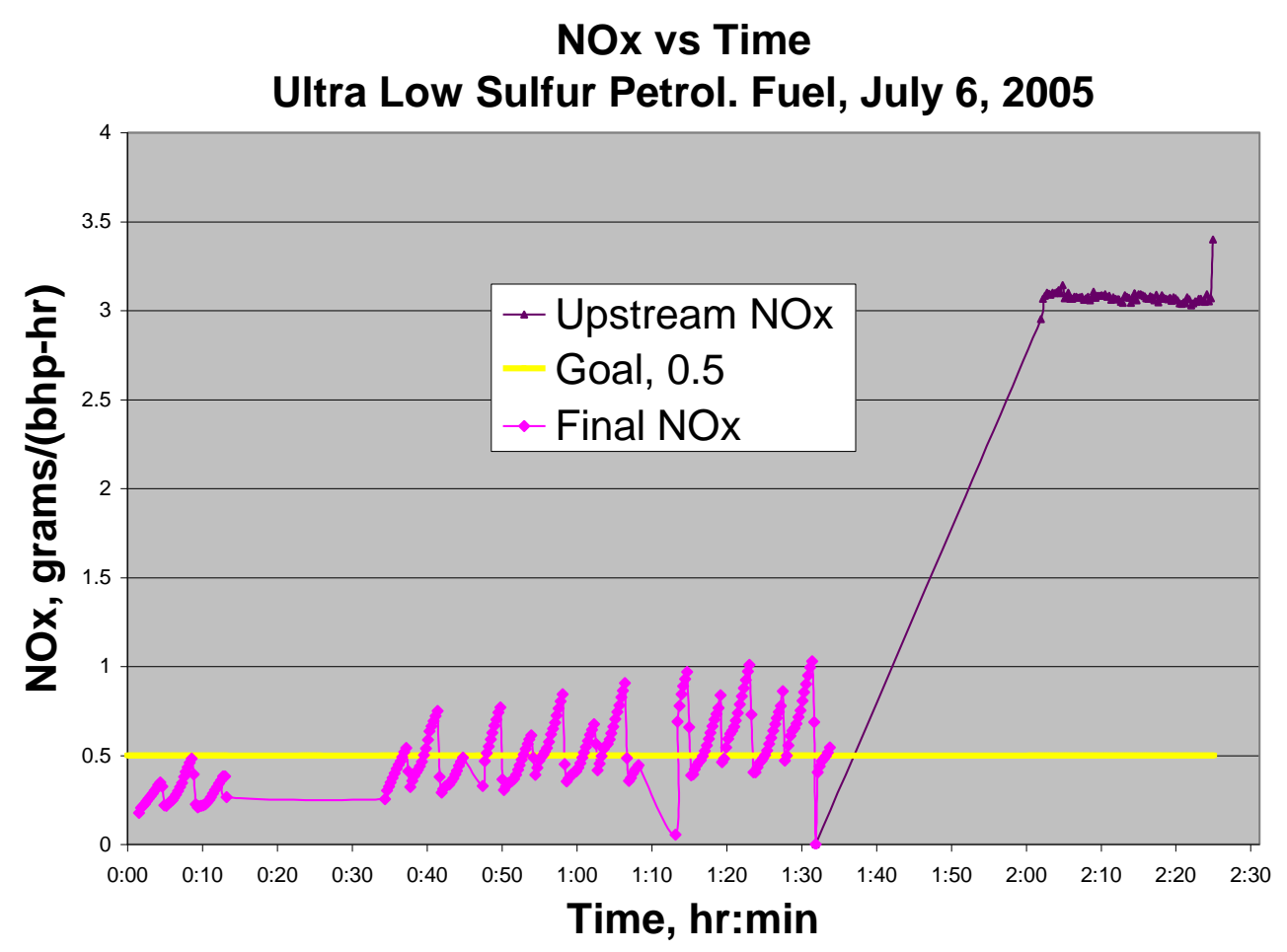




\section{B2 BioDiesel Blend}

Testing continued on July 6, with a nominal $2 \%$ blend of BioDiesel in Ultra-Low Sulfur Petroleum Diesel. The final NOx averages about 0.24 pounds per million BTU, well above the TVA target. Reasons for this poor performance include lower than expected hydrogen output from the reformer, leakage flow bypassing the catalyst, and incomplete washing of the catalyst. More details are given in EmeraChem's report (see Attachment

NOx vs Time

B2 Tests, July 7, 2005

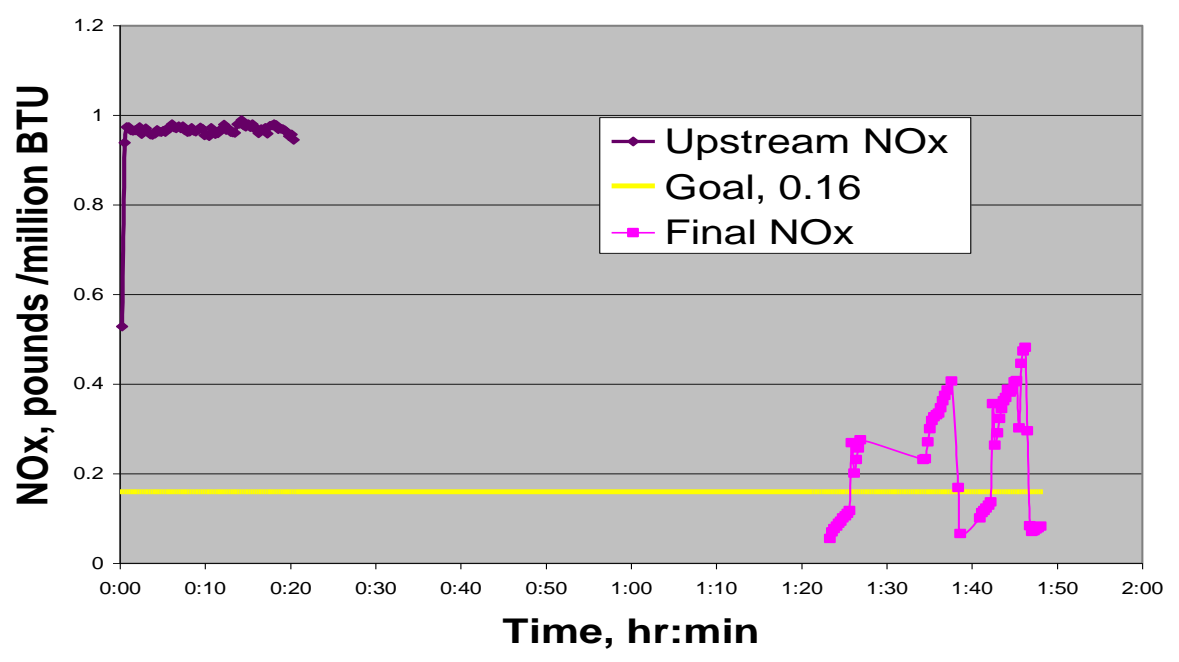

"B", page 53).

Based on a 2002 study by EPA (EPA420-P02-001), we had expected the untreated NOx emissions to increase by about $10 \%$ for B100, and a proportionately smaller increase $(<1 \%)$ for B2. In contrast, our B2 test showed a $6.87 \%$ increase. While still well below the manufacturer's

specification, untreated NOx emissions increased from $3.07 \mathrm{~g} / \mathrm{hp}$-hr for petroleum diesel to $3.28 \mathrm{~g} / \mathrm{hp}$ hr. for B2.

NOx vs Time

B2 Tests, July 7, 2005

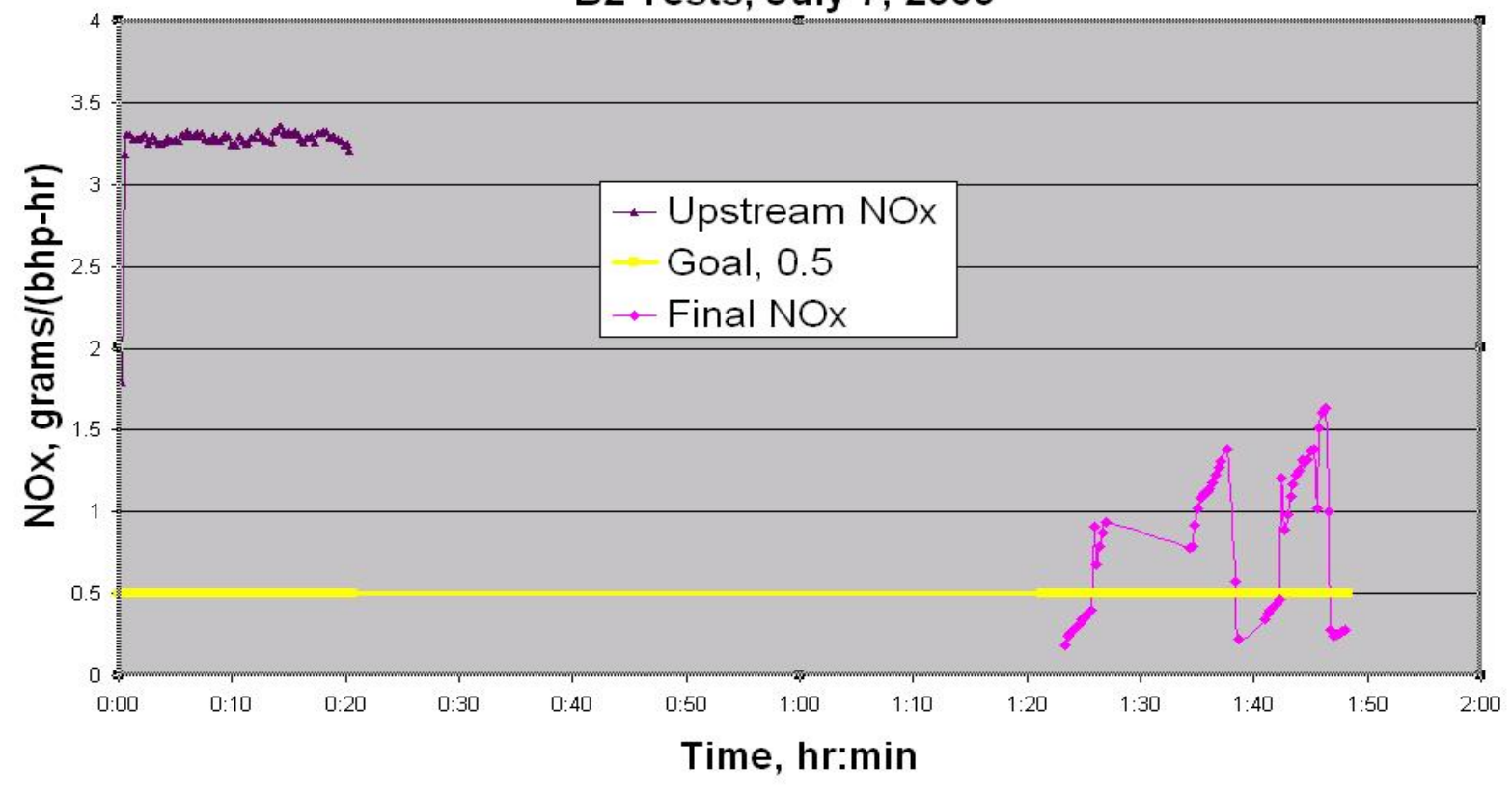




\section{B5 BioDiesel Blend}

Later the same day, July 6, testing began on a nominal $5 \%$ BioDiesel blend. Results are shown below. Again, it is clear that performance is deteriorating, and the same causes are suspected, namely: lower than expected hydrogen output from the reformer, leakage flow bypassing the catalyst, and incomplete washing of the catalyst. Obviously, the NOx removal goal was generally not met, although it was met periodically for a few minutes.

\section{NOx vs Time B5 Tests, July 7, 2005}

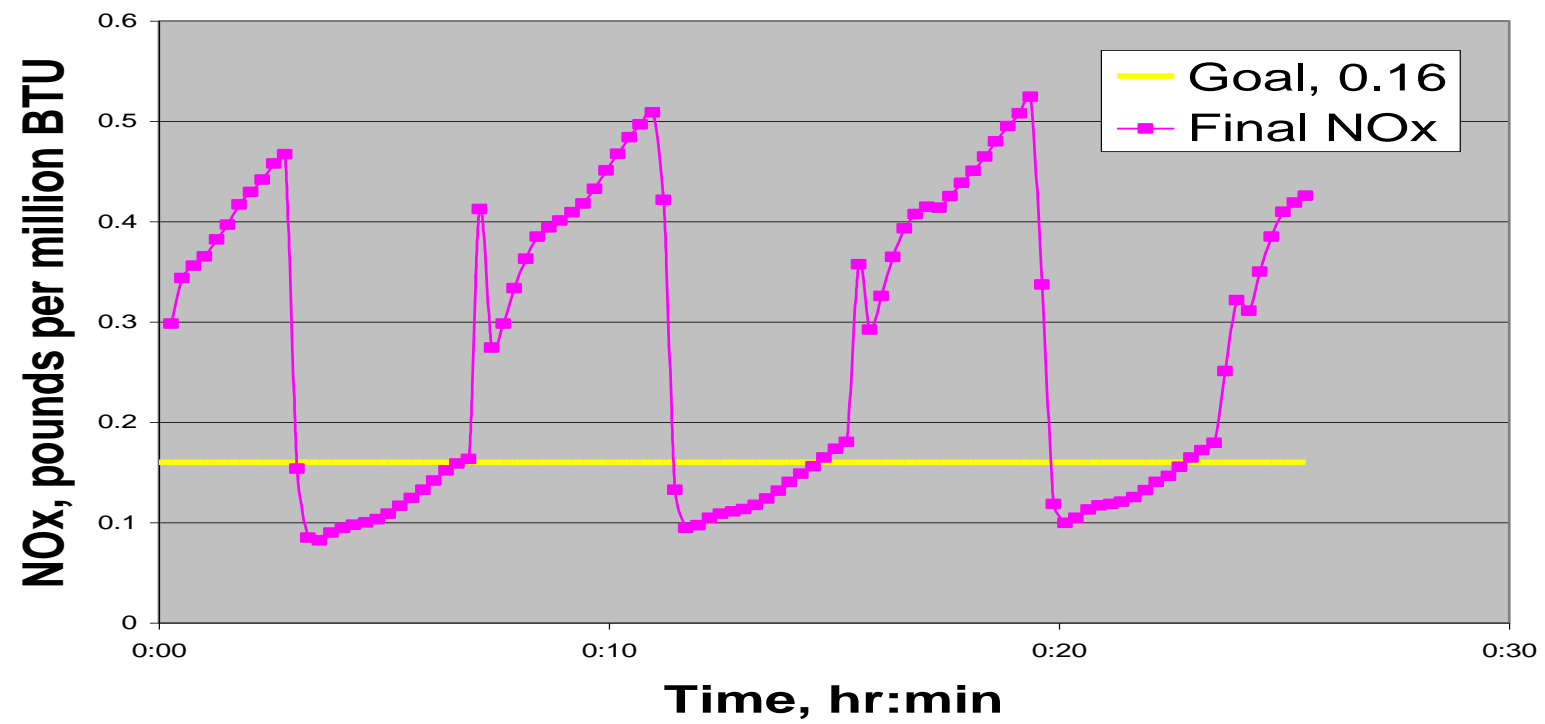

After completion of the B5 test, EmeraChem re-washed the catalyst and reworked the catalyst chamber. Bypass flow was restricted by the use of bars to straighten and stiffen the back wall of the catalyst chamber and act as a labyrinth seal. Gaskets were added to the door to improve sealing on the front side. The reformer was also modified and refurbished. Details are given in Attachment " $\mathrm{B}$ ", page 54. 


\section{B20 BioDiesel Blend Testing}

Testing resumed on July 9, using a nominal $20 \%$ BioDiesel blend. NOx removal results were excellent, and far exceeded our goal

\section{NOx vs Time \\ B20 Tests, July 9, 2005}

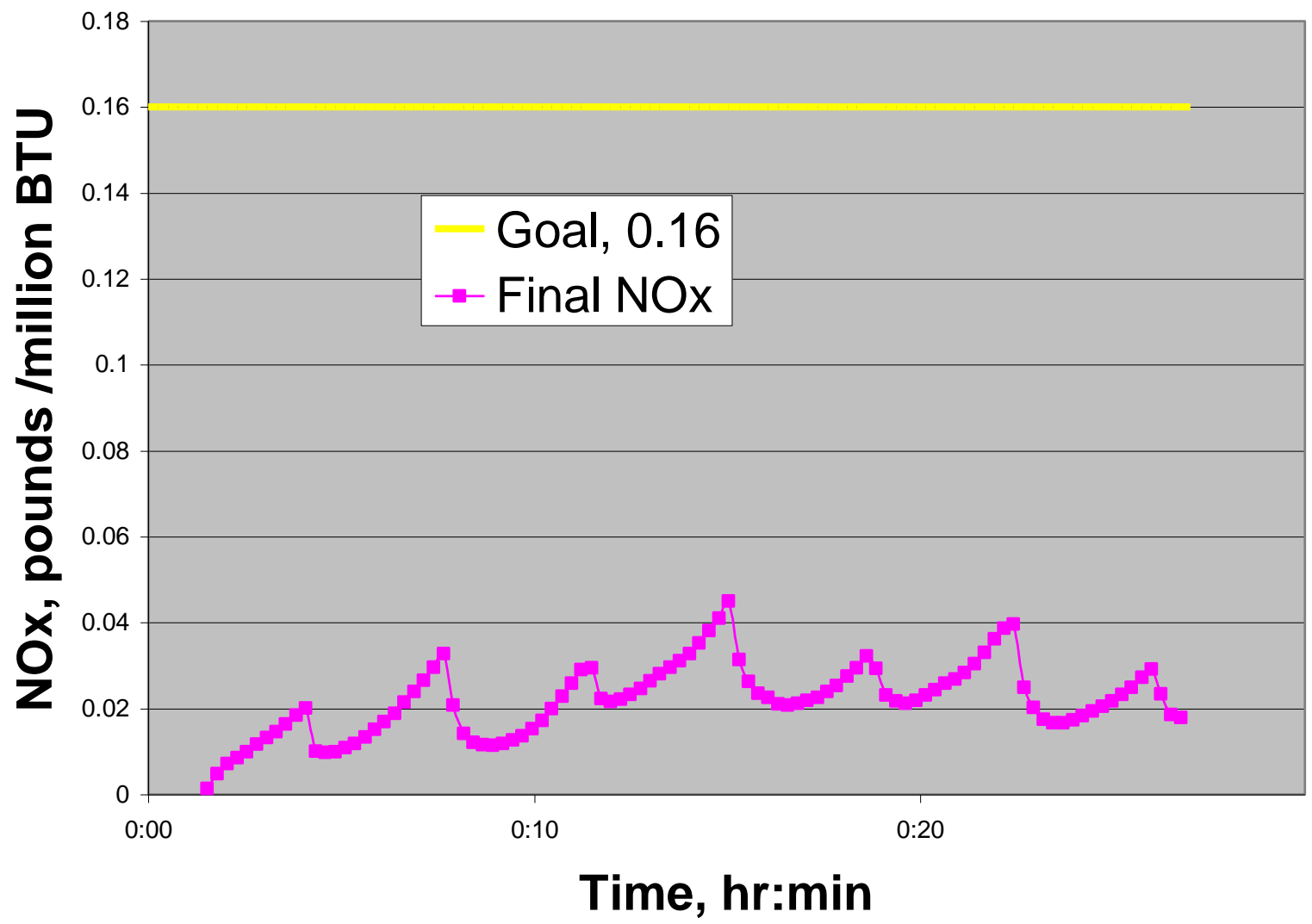




\section{B50 BioDiesel Blend Testing}

Testing continued on July 9, using a nominal $50 \%$ BioDiesel blend. Again, NOx removal results were excellent, and far exceeded our goals.

\section{NOx vs Time B50 Tests, July 9, 2005}

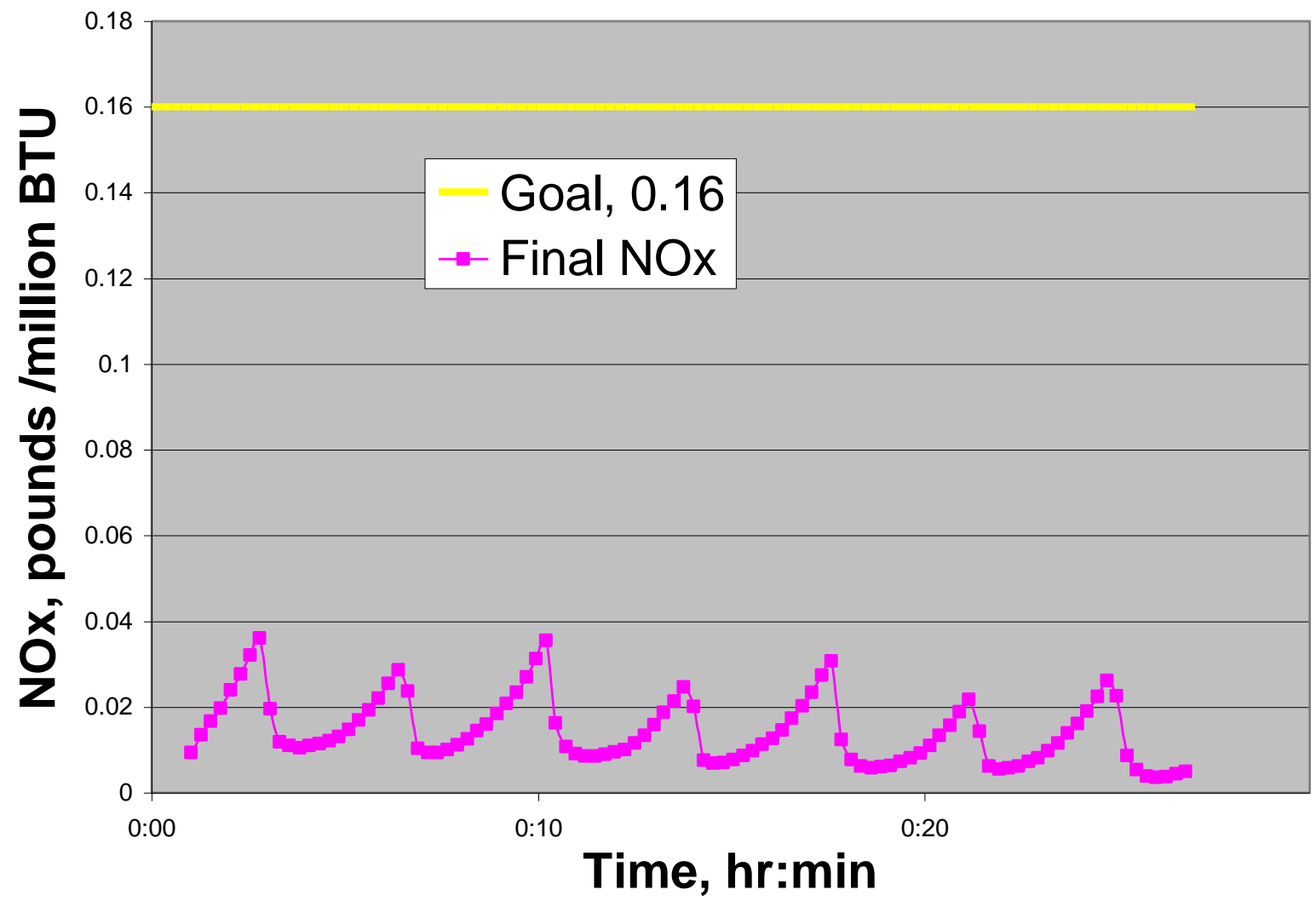




\section{B100 BioDiesel Testing}

Testing continued on July 9, using $100 \%$ BioDiesel. Again, results were excellent, and the TVA target was met. The results are displayed on the in two forms: pounds/million BTU, and grams per brakehorsepower-hour.

The untreated NOx emissions average $4.23 \mathrm{~g} / \mathrm{hp}$-hr, using B100. This compares to $3.075 \mathrm{~g} / \mathrm{hp}$-hr using Ultra-Low Sulfur Petroleum Diesel, and $3.07 \mathrm{~g} / \mathrm{hp}$-hr using B2. NOx emissions are apparently a nonlinear function of the percentage biodiesel, and using B100 increases the NOx emissions by about 38\% compared to petroleum diesel. (Recent studies have shown that biodiesel does not increase NOx emissions in some engines, and this may depend on the engine's timing adjustment.)

\section{NOx vs Time B100 Tests, July 10, 2005}

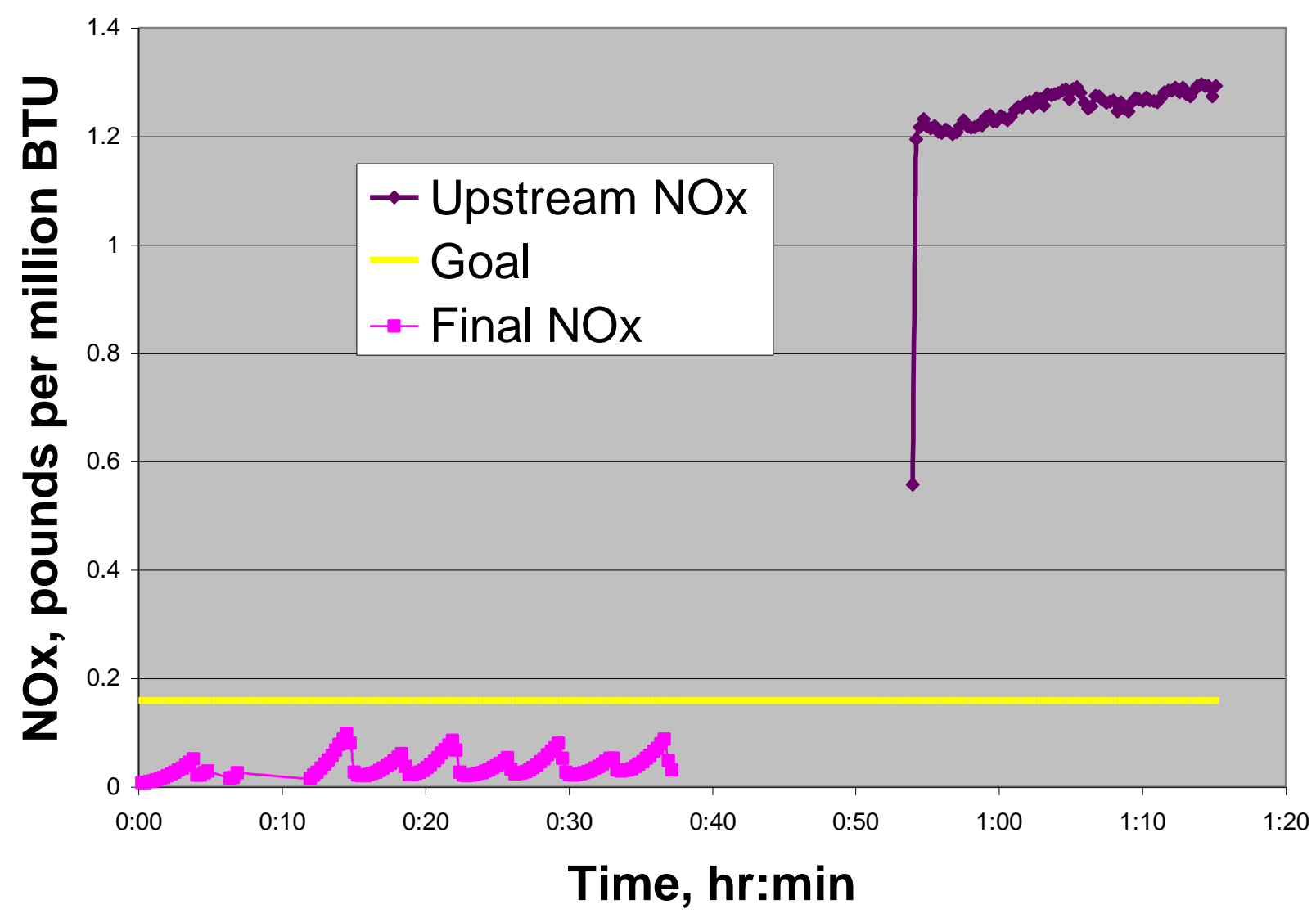




\section{NOx vs Time \\ B100 Tests, July 10, 2005}

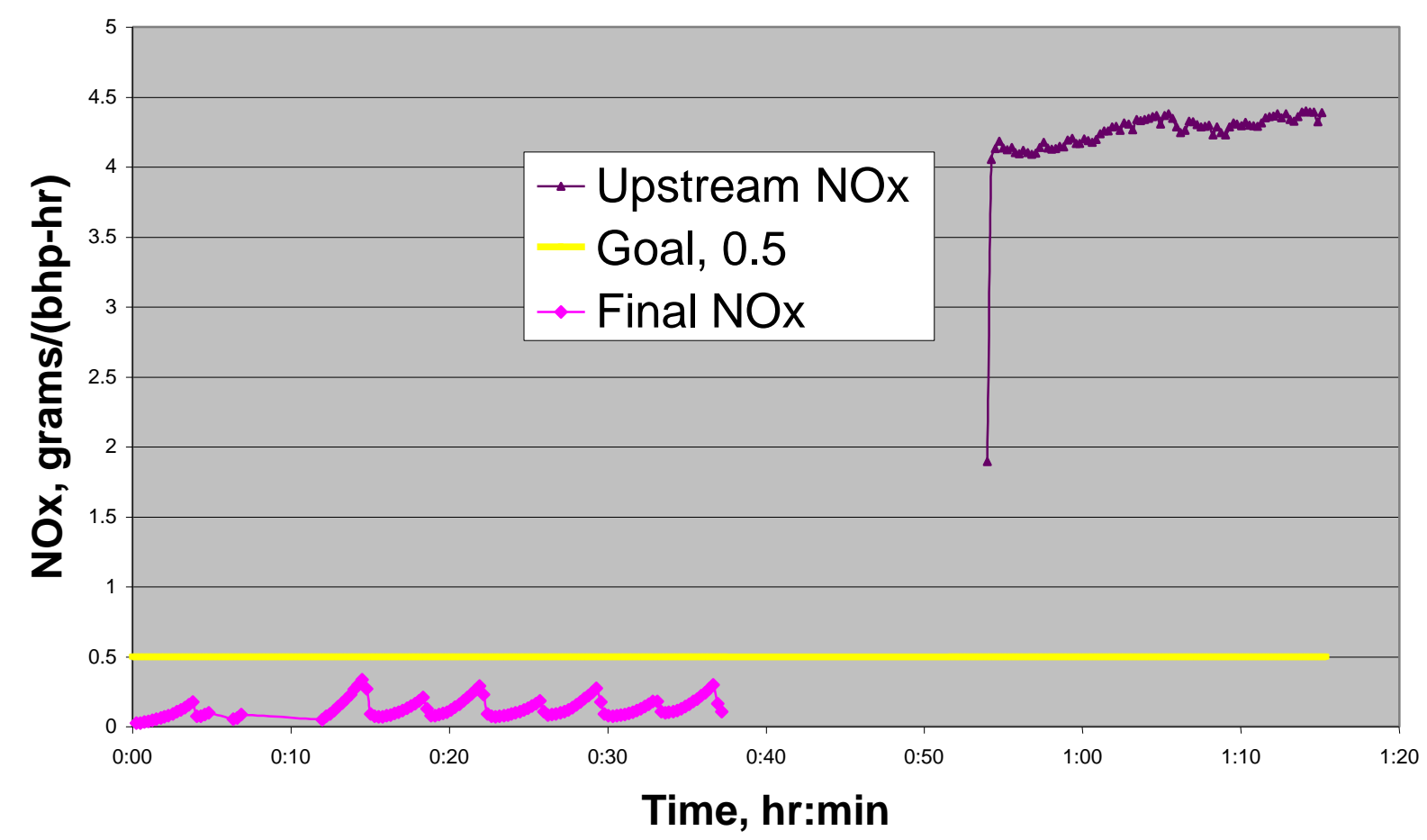

TVA had planned to follow-up with two additional emissions test campaigns during the B100 endurance runs, but these tests were postponed, and then cancelled because of the reformer failure.

Nevertheless, we conclude that if a reliable reformer or other source of hydrogen can be developed, a system similar to that demonstrated here should be capable of meeting TVA goals for NOx emissions control, when fueled with any blend of biodiesel and low sulfur petroleum diesel. 


\section{Fuel Characterization Tests}

In order to make the stoichiometric calculations required for emissions analysis, one must first analyze the fuel to determine an empirical formula. For the fuels used in this work, the major constituents are carbon, hydrogen and oxygen. This analysis was done by TVA's central laboratory, using standard methods. The results are tabulated below:

\begin{tabular}{|l|l|l|l|l|l|l|}
\hline $\begin{array}{l}\text { Sample } \\
\text { Description }\end{array}$ & ULSFO & B02 & B05 & B20 & B50 & B100 \\
\hline Carbon wt.\% & 85.2 & 85.06 & 84.57 & 83.08 & 82.65 & 76.23 \\
\hline $\begin{array}{l}\text { Hydrogen } \\
\text { wt.\% }\end{array}$ & 13.83 & 13.75 & 13.55 & 13.26 & 13.1 & 11.85 \\
\hline $\begin{array}{l}\text { Nitrogen } \\
\text { wt.\% }\end{array}$ & $<0.01$ & $<0.01$ & $<0.01$ & $<0.01$ & $<0.01$ & $<0.01$ \\
\hline BTU/lb & 19801 & 19674 & 19649 & 19212 & 18679 & 16725 \\
\hline Ash & $<0.001$ & $<0.001$ & $<0.001$ & 0.001 & 0.003 & -- \\
\hline $\begin{array}{l}\text { Density g/ml } \\
\text { Oxygen } \\
\text { by dif, wt \% }\end{array}$ & 0.8195 & 0.8205 & 0.8219 & 0.8305 & 0.8398 & 0.8785 \\
\hline
\end{tabular}

Oxygen content is plotted below vs. the nominal percentage BioDiesel. It appears that the B5 and B20 blends were higher than nominal BioDiesel, while the B50 was lower. 


\section{Oxygen vs BioDiesel \%}

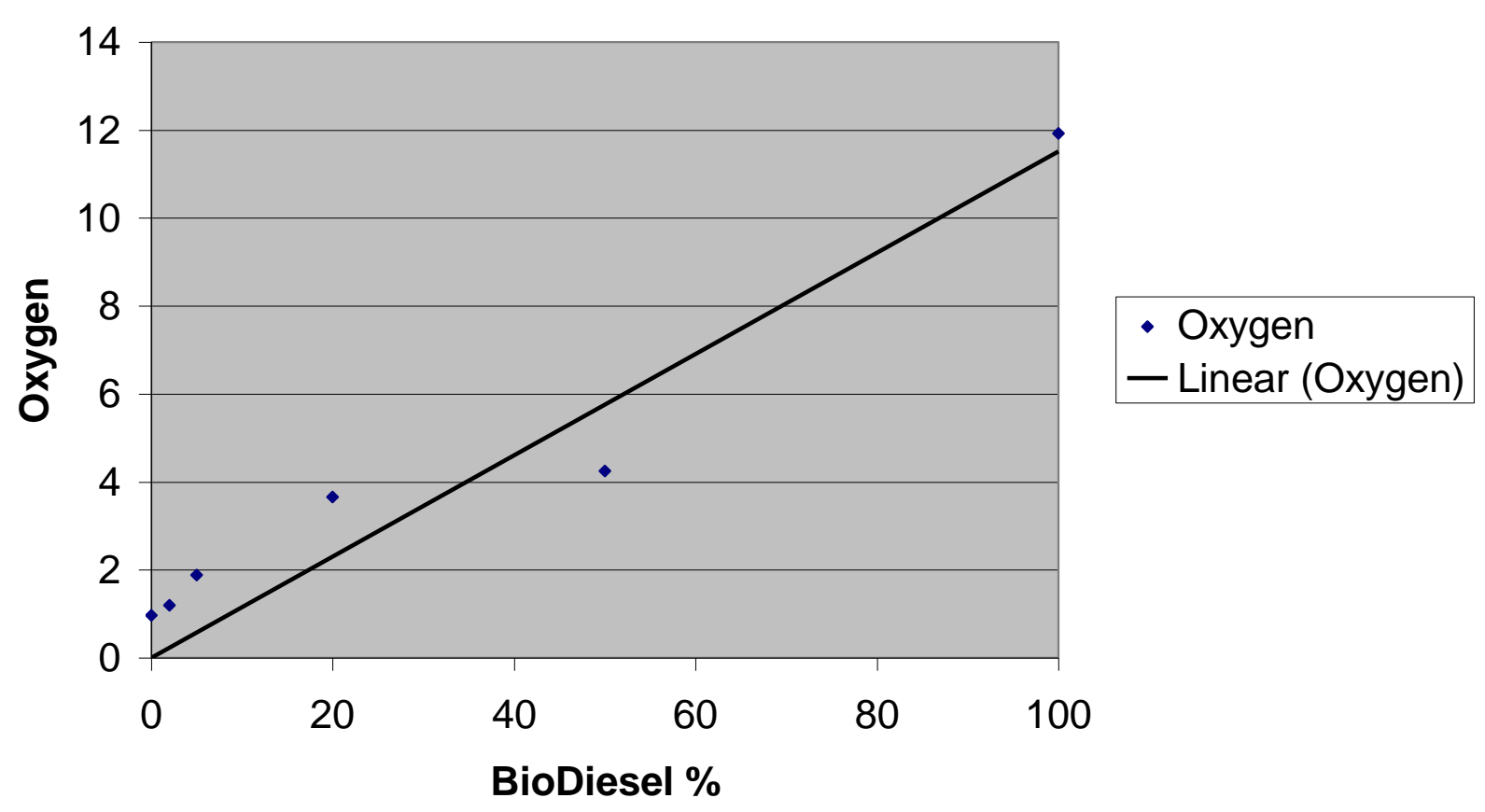

Samples were sent to two labs to help understand this situation. Findings are tabulated below:

\begin{tabular}{|l|l|l|l|l|}
\hline $\begin{array}{l}\text { Sample } \\
\text { Name }\end{array}$ & $\begin{array}{l}\text { Nominal } \\
\text { Blend }\end{array}$ & Magellan & Minnesota & \% Methanol \\
\hline MG-B & $2 \%$ & $1.40 \%$ & $1.87 \%$ & \\
\hline MG-D & $5 \%$ & $11.00 \%$ & $4.85 \%$ & \\
\hline MG-C & $20 \%$ & $25.10 \%$ & $20.76 \%$ & \\
\hline MG-A & $50 \%$ & $32.60 \%$ & $36.96 \%$ & \\
\hline MG-E & $100 \%$ & $93.20 \%$ & $96.95 \%$ & $\sim 3 \%$ \\
\hline
\end{tabular}

Jim Hedman of the State of Minnesota's Department of Commerce, Weights and Measures Division, was able to identify a problem with the B100 blend; it contained about 3\% Methanol! (His analysis is detailed in Attachment " $A$ ") With levels this high, the samples would not have passed the flash point 
test. Taking into account for the methanol effect, the blend ratios appear to have been reasonably accurate, except for the B50, which was clearly an outlier.

Because the methanol issue heightened our sensitivity to the issue, we began routinely gathering biodiesel samples and having them analyzed for conformity to a subset ASTM standard D-6751. As discussed earlier (Report, page 8), samples were frequently found to have excess glycerin. Excess methanol was not a problem in later samples. 


\section{This Page Left Intentionally Blank}

